\title{
Development and regulation of body weight: A genetic, behavioral and neuro-endocrinological approach
}

Citation for published version (APA):

Rutters, F. (2009). Development and regulation of body weight: A genetic, behavioral and neuroendocrinological approach. [Doctoral Thesis, Maastricht University]. Maastricht University. https://doi.org/10.26481/dis.20090904fr

Document status and date:

Published: 01/01/2009

DOI:

10.26481/dis.20090904fr

Document Version:

Publisher's PDF, also known as Version of record

\section{Please check the document version of this publication:}

- A submitted manuscript is the version of the article upon submission and before peer-review. There can be important differences between the submitted version and the official published version of record. People interested in the research are advised to contact the author for the final version of the publication, or visit the DOI to the publisher's website.

- The final author version and the galley proof are versions of the publication after peer review.

- The final published version features the final layout of the paper including the volume, issue and page numbers.

Link to publication

\footnotetext{
General rights rights.

- You may freely distribute the URL identifying the publication in the public portal. please follow below link for the End User Agreement:

www.umlib.nl/taverne-license

Take down policy

If you believe that this document breaches copyright please contact us at:

repository@maastrichtuniversity.nl

providing details and we will investigate your claim.
}

Copyright and moral rights for the publications made accessible in the public portal are retained by the authors and/or other copyright owners and it is a condition of accessing publications that users recognise and abide by the legal requirements associated with these

- Users may download and print one copy of any publication from the public portal for the purpose of private study or research.

- You may not further distribute the material or use it for any profit-making activity or commercial gain

If the publication is distributed under the terms of Article $25 \mathrm{fa}$ of the Dutch Copyright Act, indicated by the "Taverne" license above, 


\section{Development and regulation of body weight}

A genetic, behavioral and neuro-endocrinological approach 
The studies presented in this thesis were performed at the Nutrition and Toxicology Research Institute Maastricht (NUTRIM), which participates in the graduate school VLAG (Food Technology, Agro biotechnology, Nutrition and Health Sciences), accredited by the Royal Netherlands Academy of Arts and Sciences.

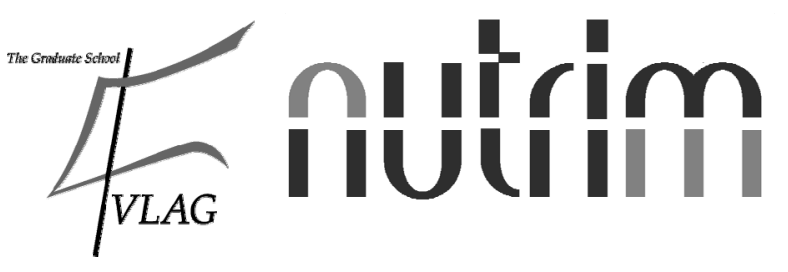

Printing of this thesis was financially supported by the J.E. Jurriaanse stichting.

Cover design: Femke Rutters and Jurriaan Born

Cover: Jurriaan Born

Layout: Femke Rutters and Datawyse

Printed by: Datawyse, Universitaire Pers Maastricht

(C) F. Rutters, Maastricht 2009

ISBN: 9789052788524 


\section{Development and regulation of body weight}

A genetic, behavioral and neuro-endocrinological approach

\section{Proefschrift}

Ter verkrijging van de graad van doctor aan de universiteit Maastricht, op gezag van de Rector Magnificus, Prof. mr. G.P.M.F. Mols, volgens het besluit van het College van Decanen, in het openbaar te verdedigen op vrijdag 4 september 2009 om 14.00 uur

door

\section{Femke Rutters}

Geboren te Waalwijk op 1 september 1982

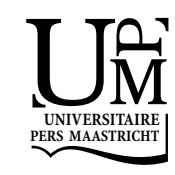




\section{Promotor}

Prof. dr. M.S. Westerterp-Plantenga

\section{Copromotor}

Dr. A.G. Nieuwenhuizen

\section{Beoordelingscommissie}

Prof. dr. K.R. Westerterp (voorzitter)

Dr. W.J. Gerver

Dr. S.E. La Fleur (Universiteit Amsterdam)

Prof. dr. N. Schaper

Prof. dr. J. Wardle (University College London) 


\section{Content}

\section{Chapter 1}

General introduction

\section{Chapter 2}

Associations between the FTO gene (rs9939609) and development of obesity related characteristics over time in a Dutch children cohort

\section{Chapter 3}

Leptin-adiposity relationship changes, plus behavioral and parental factors, are involved in the development of body weight in a Dutch children cohort

\section{Chapter 4}

Sleep duration and body-weight development during puberty in a Dutch children cohort

\section{Chapter 5}

The relationship between leptin concentrations, gonadotrophic hormones, and body composition during puberty in a Dutch children cohort

\section{Chapter 6}

The hypothalamic-pituitary-adrenal-axis in the regulation of energy balance

\section{Chapter 7}

Sex specific associations between the BclI polymorphism in the glucocorticoid receptor gene and HPA axis exposure as well as feedback sensitivity

\section{Chapter 8}

Hypothalamus/Pituitary/Adrenal (HPA) axis functioning in relation to body fat distribution

\section{Chapter 9}

Acute stress-related changes in eating in the absence of hunger

\section{Chapter 10}

Hyperactivity of the HPA axis is related to dietary restraint in normal weight women

\section{Chapter 11}

General discussion

\section{Summary}

Samenvatting

\section{Curriculum Vitae}



Chapter 1

\section{Introduction}




\section{General}

In healthy adults, body weight normally fluctuates around a relatively constant value, and therefore appears to be regulated with remarkable precision [1]. A stable body weight is a reflection of a balance between energy intake and energy expenditure. A chronic deregulation of energy balance, with energy intake exceeding energy expenditure, leads to the storage of the excessive energy as fat, a characteristic feature of overweight and obesity [2]. Overweight and obesity are classified by the body mass index (BMI) and body composition. According to the World Health Organization, adults with a BMI between 20 and $24.9 \mathrm{~kg} / \mathrm{m}^{2}$ and body fat percentage of $10-15 \%$ in men and 20 $25 \%$ in women are defined as normal weight, with a BMI between 25.0 and 29.9 $\mathrm{kg} / \mathrm{m}^{2}$ and body fat percentage of $>15 \%$ in men and $>25 \%$ in women as overweight, and with a BMI between 30.0 and $34.9 \mathrm{~kg} / \mathrm{m}^{2}$ as obese [3]. In children BMI changes substantially with age, therefore Cole et al. (2000) [4] recently developed age and sex specific cut off points for BMI to be able to define overweight and obesity during childhood. Chronic deregulation of body weight, as seen in obesity, reflects a multi-factorial disorder [4]. Development and regulation of body weight are determined by a number of factors namely genetic, parental, behavioral, endocrine, and the interaction between these factors.

The first part of this thesis elaborates on the factors involved in body-weight development during childhood and puberty. Thereafter, the second part of this thesis elaborates on the role of the neuro-endocrine system of the hypothalamus/pituitary/adrenal (HPA) axis in body-weight regulation in adults.

\section{Body-weight development during childhood and puberty}

First, relevant genetic factors involved in development of body weight during childhood and puberty will be dealt with. The interaction between genetic factors and body-weight development is typically studied by means of twin studies, adoption studies and/or single nucleotide polymorphism (SNP) association studies [5].

In this thesis, we focus on polymorphisms that previously have been related to variation in body weight, body composition and/or energy intake such as the ciliary neurotrophic factor (CNTF) gene $[6,7]$, the peroxisome proliferatedactivated receptor $\mathrm{Y} 2$ (PPARY2) gene [8], and the fat mass and obesity-associated gene (FTO) [9-11].

CNTF is a neurocytokine that is involved in control of energy balance, as administration of CNTF leads to weight loss in humans [12]. The null mutation $\mathrm{G}$ $>\mathrm{A}$ of the CNTF gene leads to an inactive CNTF protein, and is related to a higher BMI [7], lower leptin concentrations, and a smaller decrease in leptin concentrations during weight loss in adults [6]. In children, the CNTF $\mathrm{G}>\mathrm{A}$ null mutation has not been related to obesity yet. PPARY is nuclear receptor protein that functions as a transcription factor in the regulation of adipocyte differentiation [13]. The PPARy polymorphism Pro12Ala represents a substitution of proline to alanine in exon B, and leads to decreased transcriptional activity [14]. In children, the PPARy polymorphism Pro12Ala is related to deficiency in energy storage and utilization, which leads to reduced growth $[13,15]$, increased obesity risk [16], increased adiposity [17], and insulin resistance $[18,19]$.

The FTO gene is involved in the control of energy balance, as FTO expression is decreased in the hypothalamus in fasted mice, when compared to fed mice [20]. In children, the A allele of the FTO gene (rs9939609) is related to a number of obesity related characteristics, such as an increased BMI [11, 21], increased hip circumference [22], increased adiposity [9], increased leptin levels [23, 24], increased energy intake $[25,26]$, and reduced satiety responsiveness [27]. The influence of these SNP's may change over time as gene expression changes over time [28]. The effects of the SNP's during body-weight development therefore need to be assessed over time. 


\section{Parental factors}

Parental factors are also important in body-weight development during childhood. Parental factors are a combination of genetic and behavioral factors, and for instance, parental obesity is an important parental factor [29], as the BMI of the child is positively related to the BMI of the parent $[29,30]$. Also parents' restrained eating behavior affects children's body-weight development, since the child's body weight at age $12 y$ has been shown to be positively related to the restraint score of the mother [30]. The parental association is due to genetic and environmental factors, such as shared lifestyles (i.e. diets, feeding practices and food choices) and patterns of activity [29].

\section{Behavioral factors}

Behavioral factors, such as eating behavior and sleep duration are involved in body-weight development during childhood as well. Eating behavior in general can be analyzed using the Three Factor Eating Questionnaire (TFEQ) [31]. The TFEQ assesses three factors involved in eating behavior: dietary restraint, disinhibition and feeling of hunger. Dietary restraint refers to conscious restriction of food intake to achieve or maintain a preferred body weight. Disinhibition reflects individual differences in the extent to which release from the cognitive suppression of eating occurs in response to the presence of palatable food or other disinhibiting stimuli, such as emotional distress. The third factor refers to the general feeling of hunger [31]. In 11-12 y old children dietary restraint only occurs in the overweight children [30], while in adults dietary restraint also occurs in lean people who are called 'successfully dietary restrained eaters' [32]. The development of dietary restraint in lean people may start during puberty.

In children an inverse relationship between the behavioral factor sleep duration and BMI has been observed [3638], which suggests that short sleep has an effect on body-weight development. Sleep duration could affect body-weight development $[33,34]$, as short sleep duration is already present from a very young age onwards [35]. Some studies even observed a curvilinear relationship between sleep duration and BMI $[39,40]$, which suggests that sleeping too short and too long have a negative effect on body-weight development. Also, negative relationships have been observed between sleep duration and body fat percentage $[41,42]$, waist circumference [36], leptin levels [42], as well as insulin resistance $[42,43]$.

Sleep duration during childhood is however subjected to developmental changes, in particular during puberty when a significant decrease in sleep duration has been observed $[35,44]$. Previous longitudinal studies on sleep duration and BMI in children have observed a consistent negative linear association between habitual sleep duration and later obesity [44-47]. However they have not investigated whether changes in sleep duration are associated with changes in BMI.

\section{Endocrine factors}

Furthermore, the endocrine factor leptin appears to play a remarkable role in bodyweight development during childhood, especially during puberty $[48,49]$, as leptin is thought to affect development of body weight as well as body composition during puberty [50]. In children and adults, concentrations of the hormone leptin are directly related to the amount of adiposity, since leptin is derived from the adipocytes [51,52]. Leptin is thought to be a permissive factor for the start of puberty, since puberty is suggested to start when a critical amount of body weight or fat mass is achieved [51-53]. Until children reach puberty, body composition in boys and girls are similar, however, during puberty the percentage of fat mass in girls increases when compared to boys [50]. During puberty and adulthood, a 'healthy' body composition beholds a body fat percentage of $10-15 \%$ in boys/men and $20-25 \%$ in girls/women [50]. The proposed mechanism behind leptin as a permissive factor for the start of puberty, beholds that leptin independently of fat 
mass acts on the hypothalamic luteinizing hormone-releasing hormone (LHRH) pulse generator, which stimulates the release of luteinizing hormone (LH) and folliclestimulating hormone (FSH) from the pituitary [54-56]. LH and FSH in turn stimulate the gonads to release testosterone and estradiol that will form a negative feedback loop, which will inhibit the secretion of LH and FSH $[55,56]$. Moreover, testosterone alone will form a negative feedback loop that will inhibit leptin secretion from the adipocytes, and estradiol will form a positive feedback loop, which stimulates leptin secretion from the adipocytes [56-58]. This suggests that leptin, gonadotrophic hormones, and gonadal hormones are temporarily related during puberty and this may alter the relationship between leptin concentrations and body fat during puberty. The role of leptin during puberty is an interesting issue, which deserves more research.

During adulthood genetic, parental, behavioral, physiological i.e. mainly endocrine factors are also involved in body-weight regulation, however it is suggested that the magnitude of involvement of the factors is different. Body-weight regulation during adulthood is for example affected by behavioral and endocrine factors, such as stress and cortisol concentrations [59]. The hypothalamus/pituitary/adrenal (HPA) axis is involved in the stress-response and secretion of cortisol. The second part of this thesis elaborates on the role of the neuro-endocrine system of the HPA axis in the regulation of body weight in adults.

\section{Hypothalamus/pituitary/adrenal (HPA) axis and body-weight regulation}

The second part of this thesis elaborates on the role of the neuro-endocrine system of the HPA axis in body-weight regulation in adults. The HPA axis is involved in the stress-response through regulating the physical and behavioral adaptations to stressors [60]. The cascade of the HPA axis beholds that the hypothalamus produces corticotropin-releasing hormone $(\mathrm{CRH})$, which subsequently stimulates the production of adrenocortiocotropin (ATCH) from the anterior pituitary, which in turn will stimulate the synthesis and release of cortisol by the adrenal cortex. Cortisol exerts its actions through binding to and activation of two types of intracellular receptors, the low affinity glucocorticoid receptor (GR) and the high affinity mineralocorticoid receptor. The GR induces negative feedback of the HPA axis through GRs on the hypothalamus and pituitary. The mineralocorticoid receptor is supposed to regulate basal activity of the HPA axis [60]. Support for the involvement of the HPA axis in bodyweight regulation is found in two extremes of plasma cortisol levels in humans; Addison's disease (hypocortisolism) that has been related to weight loss, and Cushing's syndrome (hypercortisolism) that has been related to rapid weight gain, particularly of the trunk and face with sparing of the limbs [61].

\section{Genetic factors}

Support for the involvement of the HPA axis in body-weight regulation is also derived from genetic studies. In this thesis we focus on the BclI (rs41423247) polymorphism of the GR gene, which has been related to disturbed body-weight regulation and obesity-related characteristics [62]. The BclI G/G genotype has been related to an increased BMI $[63,64]$, more visceral fat deposition [63], insulin resistance [65], increased blood pressure and cholesterol levels [66, 67], and larger weight loss during a very low calorie diet $[6,67]$. With respect to HPA axis functioning, the BclI polymorphism results in decreased GR density, possibly resulting in altered cortisol sensitivity [62]. Consequently, the BclI G/G genotype is related to variation in HPA axis functioning, such as increased salivary cortisol concentrations $[68,69]$ and increased cortisol concentrations after a dexamethasone suppression test [6971]. Remarkably, sex differences were shown in the cortisol response to stress, as men with the BclI G/G genotype show a diminished cortisol response to 
psychosocial stress [72], while women show an increased cortisol response. This inconsistency may either be explained by different research protocols, or may suggest a sex specific association between the BclI genotype and HPA axis functioning, which has not been investigated before.

\section{Endocrine factors}

Additional support for the involvement of the HPA axis in body-weight regulation is found in humans with visceral fat accumulation. Visceral fat accumulation in obese subjects is related to altered HPA axis functioning, such as decreased salivary and serum cortisol levels [73-78], increased urinary secretion of cortisol [76, 79], decreased cortisol variability [73, 74, 80-82], and enhanced cortisol awakening response [83]. In both lean and obese subjects, visceral fat distribution has been associated with increased cortisol secretion after physical and psychological stressors [73-76, 79, 84]. However studies on the relationship between negative feedback of the HPA axis and body fat distribution have yielded inconclusive results. Some studies find an increased capacity of dexamethasone (a GR agonist) to suppress plasma cortisol concentrations $[74,85]$, while some studies find no differences in the capacity of dexamethasone to suppress plasma cortisol concentrations $[73,75,76,80]$, or some find even a decreased capacity [86]. This inconclusiveness possibly results from differences in techniques to test HPA feedback functioning. Previously, Petrides et al. (1997)[87] developed a technique to test HPA axis feedback functioning under a physical stressor. Using this technique they observed, even in a relatively homogenous population of young men, a large inter-individual variance in HPA axis feedback functioning [87]. It however remains unknown whether intra-individual variation in HPA axis functioning can be related to fat distribution in a normal-weight to obese population, and whether HPA axis feedback functioning tested under a physical stressor is related to fat distribution.

\section{Behavioral factors}

Final support for the involvement of the HPA axis in body-weight regulation is found in the involvement of the HPA axis in energy intake. Most of the data directly indicating a crucial role of the HPA axis in the regulation in food intake are derived from animal studies, showing that the anorectic effects of adrenalectomy can be reversed by corticosterone replacement $[88,89]$. Human studies support the orexigenic effect of cortisol, as cortisol administration stimulates food intake [90]. The orexigenic effect of cortisol may underlie the reported increase of energy intake after stress, as psychological stress seems to increase the intake frequency, increase the amount of food taken in [9193], and alter food preference towards intake of sweet and fat foods [94]. The alterations in energy intake during psychological stress have been suggested to relate to non-homeostatic regulatory mechanisms involved in eating behavior, such as reward [95]. Dallman and colleagues [96] even introduced the term 'comfort foods' to emphasize the fact that the drive behind stress-induced eating is not necessarily a homeostatic need for calories, translated into feelings of hunger.

Reward is defined by two distinct processes namely 'liking' and 'wanting' [97], and involves the neural networks of the opioid and dopamineric system [97, 98]. Disturbance of these neural networks is thought to underlie stress-induced eating, as HPA axis activation leads to a decrease in opioid sensitivity in rats [99], and increased dopamine levels in rats [100]. Altered levels through administration of antagonists of opioid and dopamine lead to a reduction of food intake and reduced pleasantness of food in humans $[101,102]$. The involvement of non-homeostatic regulatory mechanisms, such as reward, in stress-induced eating has however never been directly demonstrated in humans. Moreover, previous studies in humans could not exclude a role for hunger [103].

In humans, stress affects eating in a bidirectional way; in a subgroup of about 
$30 \%$ stress decreases food intake, indicating that large inter-individual differences are present. These individual differences in response to stress may relate to eating behavior characteristics [92-94, 104], as these are determined using the Three Factor Eating

Questionnaire (TFEQ) [31]. An increase in energy intake during stress has been found in individuals with high scores on dietary restraint and/or disinhibition [92$94,104]$. Moreover, subjects that have a high cortisol response to a laboratory stressor have a larger energy intake after the stressor when compared to subjects with a low cortisol response [92]. These data suggest that there may be a link between cortisol response and eating behavior characteristics. For instance weight loss and/or weight maintenance are experienced as demanding tests, and can therefore be perceived as stressors, even in normal weight women [105-107]. Several studies have shown increased cortisol concentrations (86-88), in normal weight women who attempt to cognitively control their food intake (high dietary restraint score) when compared to those who do not (low dietary restraint score). When dietary restraint is considered as a chronic physiological stressor, it may lead to alterations in HPA axis functioning, such as a decreased sensitivity of the GR to cortisol, which results in decreased negative feedback of the HPA axis [59]. It remains unknown however, whether dietary restraint affects cortisol feedback functioning.

\section{Outline of this thesis}

A stable body weight reflects a balance between energy intake and energy expenditure. This thesis encompasses genetic, parental, behavioral, physiological i.e. mainly endocrine factors involved in body-weight development and regulation during childhood, puberty and adulthood.

From a large cohort of Dutch children born between 1990 and 1993 valuable anthropometrical data from birth till age 7y are available. To study body-weight development during puberty, follow-up studies were performed yearly between 2004 and 2008, when the children had a mean age of 12 to $16 \mathrm{y}$. The roles of relevant genetic factors, such as the FTO gene, in body-weight development are described in chapter 2. Subsequently, the assessment of the roles of parental, behavioral, and physiological i.e. mainly endocrine factors in body-weight

development during puberty are dealt with in chapter 3 and 4.

The amount of adiposity is directly related to leptin concentrations, which is thought to be a permissive factor for the start of puberty, since puberty starts when a critical amount of body weight or fat mass is achieved. The changing relationship between leptin and gonadotropic hormones during puberty is described in

\section{chapter 5.}

During adulthood it is suggested that the magnitude of effect of the factors involved in body-weight regulation is different. Body-weight regulation is for example affected by behavioral and endocrine factors, such as stress and cortisol concentrations. Through the secretion of cortisol, the HPA axis plays an important role in the regulation of the stress response. The present knowledge of the role of the HPA axis in the body-weight regulation in adults is described in

chapter 6. Subsequently, the role of genetic factors, such as the BclI polymorphism, and physiological factors, such as body composition, in HPA axis functioning are dealt with in chapter 7 and 8.

Stress has been related to alterations in eating behavior, such as an increase or decrease in energy intake. Assessment of food intake in the absence of hunger after psychological stress exposure is given in chapter 9. The intra-individual differences in the effect of stress on food intake may relate to eating behavior characteristics, such as dietary restraint, which in turn is related to alterations in HPA axis functioning. Weight loss and/or weight maintenance can be perceived as a stressor, even in normal weight women, and therefore dietary restraint may lead to alterations in HPA axis functioning as dealt with in chapter $\mathbf{1 0 .}$ 
Finally in chapter 11, the results and

interpretations of the previous described

studies are discussed and put into a

broader perspective. 


\section{References}

1. Sullivan, P.W., E.H. Morrato, V. Ghushchyan, H.R. Wyatt, and J.O. Hill, Obesity, inactivity, and the prevalence of diabetes and diabetes-related cardiovascular comorbidities in the U.S., 2000-2002. Diabetes Care, 2005. 28(7): p. 1599-603.

2. Tremblay, A., L. Perusse, and C. Bouchard, Energy balance and body-weight stability: impact of gene-environment interactions. Br J Nutr, 2004. 92 Suppl 1: p. S63-6.

3. Obesity: preventing and managing the global epidemic. Report of a WHO consultation. World Health Organ Tech Rep Ser, 2000. 894: p. i-xii, 1-253.

4. Cole, T.J., M.C. Bellizzi, K.M. Flegal, and W.H. Dietz, Establishing a standard definition for child overweight and obesity worldwide: international survey. Bmj, 2000. 320(7244): p. 1240-3.

5. Dina, C., New insights into the genetics of body weight. Curr Opin Clin Nutr Metab Care, 2008. 11(4): p. 378-84.

6. Vogels, N., E.C. Mariman, F.G. Bouwman, A.D. Kester, K. Diepvens, and M.S. Westerterp-Plantenga, Relation of weight maintenance and dietary restraint to peroxisome proliferator-activated receptor gamma2, glucocorticoid receptor, and ciliary neurotrophic factor polymorphisms. Am J Clin Nutr, 2005. 82(4): p. 740-6.

7. O'Dell, S.D., H.E. Syddall, A.A. Sayer, C. Cooper, C.H. Fall, E.M. Dennison, et al., Null mutation in human ciliary neurotrophic factor gene confers higher body mass index in males. Eur J Hum Genet, 2002. 10(11): p. 749-52.

8. Rosmond, R., M. Chagnon, and C. Bouchard, The Pro12Ala PPARgamma2 gene missense mutation is associated with obesity and insulin resistance in Swedish middle-aged men. Diabetes Metab Res Rev, 2003. 19(2): p. 159-63.

9. Andreasen, C.H., K.L. Stender-Petersen, M.S. Mogensen, S.S. Torekov, L. Wegner, G. Andersen, et al., Low physical activity accentuates the effect of the FTO rs9939609 polymorphism on body fat accumulation. Diabetes, 2008. 57(1): p. 95-101.

10. Kring, S.I., C. Holst, E. Zimmermann, T. Jess, T. Berentzen, S. Toubro, et al., FTO gene associated fatness in relation to body fat distribution and metabolic traits throughout a broad range of fatness. PLoS ONE, 2008. 3(8): p. e2958.

11. Frayling, T.M., N.J. Timpson, M.N. Weedon, E. Zeggini, R.M. Freathy, C.M. Lindgren, et al., A common variant in the FTO gene is associated with body mass index and predisposes to childhood and adult obesity. Science, 2007. 316(5826): p. 889-94.

12. Ettinger, M.P., T.W. Littlejohn, S.L. Schwartz, S.R. Weiss, H.H. McIlwain, S.B. Heymsfield, et al., Recombinant variant of ciliary neurotrophic factor for weight loss in obese adults: a randomized, dose-ranging study. Jama, 2003. 289(14): p. 1826-32.

13. Cecil, J.E., B. Fischer, A.S. Doney, M. Hetherington, P. Watt, W. Wrieden, et al., The Pro12Ala and C-681G variants of the PPARG locus are associated with opposing growth phenotypes in young schoolchildren. Diabetologia, 2005. 48(8): p. 1496-502.

14. Kuliczkowska, J., A. Filus, A. Trzmiel, U. Tworowska, M. Demissie, D. Jedrzejuk, et al., PPAR-gamma2 Pro12Ala polymorphism in the population of obese and non-obese men of the city of Wroclaw. Endokrynol Pol, 2008. 59(4): p. 312-5.

15. Cecil, J.E., C.N. Palmer, B. Fischer, P. Watt, D.J. Wallis, I. Murrie, et al., Variants of the peroxisome proliferatoractivated receptor gamma- and beta-adrenergic receptor genes are associated with measures of compensatory eating behaviors in young children. Am J Clin Nutr, 2007. 86(1): p. 167-73.

16. Ochoa, M.C., A. Marti, C. Azcona, M. Chueca, M. Oyarzabal, R. Pelach, et al., Gene-gene interaction between PPAR gamma 2 and ADR beta 3 increases obesity risk in children and adolescents. Int J Obes Relat Metab Disord, 2004. 28 Suppl 3: p. S37-41.

17. Lagou, V., R.A. Scott, Y. Manios, T.L. Chen, G. Wang, E. Grammatikaki, et al., Impact of peroxisome proliferatoractivated receptors gamma and delta on adiposity in toddlers and preschoolers in the GENESIS Study. Obesity (Silver Spring), 2008. 16(4): p. 913-8.

18. Chen, T.J., C.Y. Ji, X.Y. Zheng, and Y.H. Hu, Association of beta3 adrenergic receptor and peroxisome proliferatoractivated receptor gamma 2 polymorphisms with insulin sensitivity: a twin study. Biomed Environ Sci, 2007. 20(2): p. 99-105.

19. Ghoussaini, M., D. Meyre, S. Lobbens, G. Charpentier, K. Clement, M.A. Charles, et al., Implication of the Pro12Ala polymorphism of the PPAR-gamma 2 gene in type 2 diabetes and obesity in the French population. BMC Med Genet, 2005. 6: p. 11.

20. Stratigopoulos, G., S.L. Padilla, C.A. LeDuc, E. Watson, A.T. Hattersley, M.I. McCarthy, et al., Regulation of Fto/Ftm gene expression in mice and humans. Am J Physiol Regul Integr Comp Physiol, 2008. 294(4): p. R118596.

21. Jess, T., E. Zimmermann, S.I. Kring, T. Berentzen, C. Holst, S. Toubro, et al., Impact on weight dynamics and general growth of the common FTO rs9939609: a longitudinal Danish cohort study. Int J Obes (Lond), 2008. 32(9): p. 1388-94.

22. Scuteri, A., S. Sanna, W.M. Chen, M. Uda, G. Albai, J. Strait, et al., Genome-wide association scan shows genetic variants in the FTO gene are associated with obesity-related traits. PLoS Genet, 2007. 3(7): p. e115.

23. Qi, L., K. Kang, C. Zhang, R.M. van Dam, P. Kraft, D. Hunter, et al., FTO Gene Variant Is Associated with Obesity: Longitudinal Analyses in Two Cohort Studies and Functional Test. Diabetes, 2008.

24. Do, R., S.D. Bailey, K. Desbiens, A. Belisle, A. Montpetit, C. Bouchard, et al., Genetic variants of FTO influence adiposity, insulin sensitivity, leptin levels, and resting metabolic rate in the Quebec Family Study. Diabetes, 2008. 57(4): p. 1147-50.

25. Wardle, J., C. Llewellyn, S. Sanderson, and R. Plomin, The FTO gene and measured food intake in children. Int J Obes (Lond), 2008.

26. Cecil, J.E., R. Tavendale, P. Watt, M.M. Hetherington, and C.N. Palmer, An obesity-associated FTO gene variant and increased energy intake in children. N Engl J Med, 2008. 359(24): p. 2558-66.

27. Wardle, J., S. Carnell, C.M. Haworth, I.S. Farooqi, S. O'Rahilly, and R. Plomin, Obesity associated genetic variation in FTO is associated with diminished satiety. J Clin Endocrinol Metab, 2008. 93(9): p. 3640-3.

28. Bergen, S.E., C.O. Gardner, and K.S. Kendler, Age-related changes in heritability of behavioral phenotypes over adolescence and young adulthood: a meta-analysis. Twin Res Hum Genet, 2007. 10(3): p. 423-33.

29. Maffeis, C., Aetiology of overweight and obesity in children and adolescents. Eur J Pediatr, 2000. 159 Suppl 1: p. S35-44.

30. Vogels, N., D.L. Posthumus, E.C. Mariman, F. Bouwman, A.D. Kester, P. Rump, et al., Determinants of overweight in a cohort of Dutch children. Am J Clin Nutr, 2006. 84(4): p. 717-24. 
31. Stunkard, A.J. and S. Messick, The three-factor eating questionnaire to measure dietary restraint, disinhibition and hunger. J Psychosom Res, 1985. 29(1): p. 71-83.

32. Westerterp-Plantenga, M.S., L. Wouters, and F. ten Hoor, Restrained eating, obesity, and cumulative food intake curves during four-course meals. Appetite, 1991. 16(2): p. 149-58.

33. Patel, S.R. and F.B. Hu, Short sleep duration and weight gain: a systematic review. Obesity (Silver Spring), 2008. 16(3): p. 643-53.

34. Marshall, N.S., N. Glozier, and R.R. Grunstein, Is sleep duration related to obesity? A critical review of the epidemiological evidence. Sleep Med Rev, 2008. 12(4): p. 289-98.

35. Thorleifsdottir, B., J.K. Bjornsson, B. Benediktsdottir, T. Gislason, and H. Kristbjarnarson, Sleep and sleep habits from childhood to young adulthood over a 10-year period. J Psychosom Res, 2002. 53(1): p. 529-37.

36. Chaput, J.P. and A. Tremblay, Does short sleep duration favor abdominal adiposity in children? Int J Pediatr Obes, 2007. 2(3): p. 188-91.

37. Nixon, G.M., J.M. Thompson, D.Y. Han, D.M. Becroft, P.M. Clark, E. Robinson, et al., Short sleep duration in middle childhood: risk factors and consequences. Sleep, 2008. 31(1): p. 71-8.

38. Knutson, K.L., The association between pubertal status and sleep duration and quality among a nationally representative sample of U. S. adolescents. Am J Hum Biol, 2005. 17(4): p. 418-24.

39. Eisenmann, J.C., P. Ekkekakis, and M. Holmes, Sleep duration and overweight among Australian children and adolescents. Acta Paediatr, 2006. 95(8): p. 956-63.

40. Gillman, M.W., S.L. Rifas-Shiman, K. Kleinman, E. Oken, J.W. Rich-Edwards, and E.M. Taveras, Developmental Origins of Childhood Overweight: Potential Public Health Impact. Obesity (Silver Spring), 2008.

41. Yu, Y., B.S. Lu, B. Wang, H. Wang, J. Yang, Z. Li, et al., Short sleep duration and adiposity in Chinese adolescents. Sleep, 2007. 30(12): p. 1688-97.

42. Hitze, B., A. Bosy-Westphal, F. Bielfeldt, U. Settler, S. Plachta-Danielzik, M. Pfeuffer, et al., Determinants and impact of sleep duration in children and adolescents: data of the Kiel Obesity Prevention Study. Eur J Clin Nutr, 2008.

43. Zhou, F., J.F. Fu, C.L. Wang, L. Liang, and Z.Y. Zhao, [Study on the relationships of childhood obesity and the duration of sleep as well as insulin resistance]. Zhonghua Liu Xing Bing Xue Za Zhi, 2007. 28(9): p. 910-3.

44. Snell, E.K., E.K. Adam, and G.J. Duncan, Sleep and the body mass index and overweight status of children and adolescents. Child Dev, 2007. 78(1): p. 309-23.

45. Reilly, J.J., Obesity in childhood and adolescence: evidence based clinical and public health perspectives. Postgrad Med J, 2006. 82(969): p. 429-37.

46. Dieu, H.T., M.J. Dibley, D. Sibbritt, and T.T. Hanh, Prevalence of overweight and obesity in preschool children and associated socio-demographic factors in Ho Chi Minh City, Vietnam. Int J Pediatr Obes, 2007. 2(1): p. 40-50.

47. Agras, W.S., L.D. Hammer, F. McNicholas, and H.C. Kraemer, Risk factors for childhood overweight: a prospective study from birth to 9.5 years. J Pediatr, 2004. 145(1): p. 20-5.

48. Lewis, K. and P.A. Lee, Endocrinology of male puberty. Curr Opin Endocrinol Diabetes Obes, 2009. 16(1): p. 5-9.

49. DiVall, S.A. and S. Radovick, Endocrinology of female puberty. Curr Opin Endocrinol Diabetes Obes, 2009. 16(1): p. 1-4.

50. Loomba-Albrecht, L.A. and D.M. Styne, Effect of puberty on body composition. Curr Opin Endocrinol Diabetes Obes, 2009. 16(1): p. 10-5.

51. Friedman, J.M., Leptin at 14 y of age: an ongoing story. Am J Clin Nutr, 2009. 89(3): p. 973S-979S.

52. Farooqi, I.S. and S. O'Rahilly, Leptin: a pivotal regulator of human energy homeostasis. Am J Clin Nutr, 2009. 89(3): p. 980S-984S.

53. Frisch, R.E., Pubertal adipose tissue: is it necessary for normal sexual maturation? Evidence from the rat and human female. Fed Proc, 1980. 39(7): p. 2395-400.

54. Dunkel, L., H. Alfthan, U.H. Stenman, G. Selstam, S. Rosberg, and K. Albertsson-Wikland, Developmental changes in 24-hour profiles of luteinizing hormone and follicle-stimulating hormone from prepuberty to midstages of puberty in boys. J Clin Endocrinol Metab, 1992. 74(4): p. 890-7.

55. Grumbach, M.M., The neuroendocrinology of human puberty revisited. Horm Res, 2002. 57 Suppl 2: p. 2-14.

56. Roemmich, J.N. and A.D. Rogol, Hormonal changes during puberty and their relationship to fat distribution. Am J Human Biol, 1999. 11(2): p. 209-224.

57. Kristensen, K., S.B. Pedersen, and B. Richelsen, Regulation of leptin by steroid hormones in rat adipose tissue. Biochem Biophys Res Commun, 1999. 259(3): p. 624-30.

58. Machinal-Quelin, F., M.N. Dieudonne, R. Pecquery, M.C. Leneveu, and Y. Giudicelli, Direct in vitro effects of androgens and estrogens on ob gene expression and leptin secretion in human adipose tissue. Endocrine, 2002. 18(2): p. 179-84.

59. Bjorntorp, P. and R. Rosmond, Obesity and cortisol. Nutrition, 2000. 16(10): p. 924-36.

60. Tsigos, C. and G.P. Chrousos, Hypothalamic-pituitary-adrenal axis, neuroendocrine factors and stress. J Psychosom Res, 2002. 53(4): p. 865-71.

61. Hankin, M.E., H.M. Theile, and A.W. Steinbeck, An evaluation of laboratory tests for the detection and differential diagnosis of Cushing's syndrome. Clin Endocrinol (Oxf), 1977. 6(3): p. 185-96.

62. Derijk, R.H. and E.R. de Kloet, Corticosteroid receptor polymorphisms: determinants of vulnerability and resilience. Eur J Pharmacol, 2008. 583(2-3): p. 303-11.

63. Rosmond, R., Y.C. Chagnon, G. Holm, M. Chagnon, L. Perusse, K. Lindell, et al., A glucocorticoid receptor gene marker is associated with abdominal obesity, leptin, and dysregulation of the hypothalamic-pituitary-adrenal axis. Obes Res, 2000. 8(3): p. 211-8.

64. Buemann, B., M.C. Vohl, M. Chagnon, Y.C. Chagnon, J. Gagnon, L. Perusse, et al., Abdominal visceral fat is associated with a BclI restriction fragment length polymorphism at the glucocorticoid receptor gene locus. Obes Res, 1997. 5(3): p. 186-92.

65. Weaver, J.U., G.A. Hitman, and P.G. Kopelman, An association between a Bc1I restriction fragment length polymorphism of the glucocorticoid receptor locus and hyperinsulinaemia in obese women. J Mol Endocrinol, 1992. 9(3): p. 295-300.

66. Watt, G.C., S.B. Harrap, C.J. Foy, D.W. Holton, H.V. Edwards, H.R. Davidson, et al., Abnormalities of glucocorticoid metabolism and the renin-angiotensin system: a four-corners approach to the identification of genetic determinants of blood pressure. J Hypertens, 1992. 10(5): p. 473-82.

67. Ukkola, O., R. Rosmond, A. Tremblay, and C. Bouchard, Glucocorticoid receptor Bcl I variant is associated with an increased atherogenic profile in response to long-term overfeeding. Atherosclerosis, 2001. 157(1): p. 221-4. 
68. Rautanen, A., J.G. Eriksson, J. Kere, S. Andersson, C. Osmond, P. Tienari, et al., Associations of body size at birth with late-life cortisol concentrations and glucose tolerance are modified by haplotypes of the glucocorticoid receptor gene. J Clin Endocrinol Metab, 2006. 91(11): p. 4544-51.

69. Rosmond, R., Y.C. Chagnon, M. Chagnon, L. Perusse, C. Bouchard, and P. Bjorntorp, A polymorphism of the 5'flanking region of the glucocorticoid receptor gene locus is associated with basal cortisol secretion in men. Metabolism, 2000. 49(9): p. 1197-9.

70. Stevens, A., D.W. Ray, E. Zeggini, S. John, H.L. Richards, C.E. Griffiths, et al., Glucocorticoid sensitivity is determined by a specific glucocorticoid receptor haplotype. J Clin Endocrinol Metab, 2004. 89(2): p. 892-7.

71. Panarelli, M., C.D. Holloway, R. Fraser, J.M. Connell, M.C. Ingram, N.H. Anderson, et al., Glucocorticoid receptor polymorphism, skin vasoconstriction, and other metabolic intermediate phenotypes in normal human subjects. J Clin Endocrinol Metab, 1998. 83(6): p. 1846-52

72. Wust, S., E.F. Van Rossum, I.S. Federenko, J.W. Koper, R. Kumsta, and D.H. Hellhammer, Common polymorphisms in the glucocorticoid receptor gene are associated with adrenocortical responses to psychosocial stress. J Clin Endocrinol Metab, 2004. 89(2): p. 565-73.

73. Ljung, T., G. Holm, P. Friberg, B. Andersson, B.A. Bengtsson, J. Svensson, et al., The activity of the hypothalamicpituitary-adrenal axis and the sympathetic nervous system in relation to waist/hip circumference ratio in men. Obes Res, 2000. 8(7): p. 487-95

74. Duclos, M., B. Gatta, J.B. Corcuff, M. Rashedi, F. Pehourcq, and P. Roger, Fat distribution in obese women is associated with subtle alterations of the hypothalamic-pituitary-adrenal axis activity and sensitivity to glucocorticoids. Clin Endocrinol (Oxf), 2001. 55(4): p. 447-54.

75. Duclos, M., P. Marquez Pereira, P. Barat, B. Gatta, and P. Roger, Increased cortisol bioavailability, abdominal obesity, and the metabolic syndrome in obese women. Obes Res, 2005. 13(7): p. 1157-66.

76. Marin, P., N. Darin, T. Amemiya, B. Andersson, S. Jern, and P. Bjorntorp, Cortisol secretion in relation to body fat distribution in obese premenopausal women. Metabolism, 1992. 41(8): p. 882-6.

77. Travison, T.G., A.B. O'Donnell, A.B. Araujo, A.M. Matsumoto, and J.B. McKinlay, Cortisol levels and measures of body composition in middle-aged and older men. Clin Endocrinol (Oxf), 2007. 67(1): p. 71-7.

78. Misra, M., M.A. Bredella, P. Tsai, N. Mendes, K.K. Miller, and A. Klibanski, Lower growth hormone and higher cortisol are associated with greater visceral adiposity, intramyocellular lipids, and insulin resistance in overweight girls. Am J Physiol Endocrinol Metab, 2008. 295(2): p. E385-92.

79. Pasquali, R., S. Cantobelli, F. Casimirri, M. Capelli, L. Bortoluzzi, R. Flamia, et al., The hypothalamic-pituitaryadrenal axis in obese women with different patterns of body fat distribution. J Clin Endocrinol Metab, 1993. 77(2): p. 341-6.

80. Garcia-Prieto, M.D., F.J. Tebar, F. Nicolas, E. Larque, S. Zamora, and M. Garaulet, Cortisol secretary pattern and glucocorticoid feedback sensitivity in women from a Mediterranean area: relationship with anthropometric characteristics, dietary intake and plasma fatty acid profile. Clin Endocrinol (Oxf), 2007. 66(2): p. 185-91.

81. Farag, N.H., W.E. Moore, W.R. Lovallo, P.J. Mills, S. Khandrika, and J.E. Eichner, Hypothalamic-pituitary-adrenal axis function: relative contributions of perceived stress and obesity in women. J Womens Health (Larchmt), 2008. 17(10): p. 1647-55.

82. Putignano, P., A. Dubini, P. Toja, C. Invitti, S. Bonfanti, G. Redaelli, et al., Salivary cortisol measurement in normal-weight, obese and anorexic women: comparison with plasma cortisol. Eur J Endocrinol, 2001. 145(2): p. 165-71.

83. Therrien, F., V. Drapeau, J. Lalonde, S.J. Lupien, S. Beaulieu, A. Tremblay, et al., Awakening cortisol response in lean, obese, and reduced obese individuals: effect of gender and fat distribution. Obesity (Silver Spring), 2007. 15(2): p. 377-85.

84. Epel, E.S., B. McEwen, T. Seeman, K. Matthews, G. Castellazzo, K.D. Brownell, et al., Stress and body shape: stress-induced cortisol secretion is consistently greater among women with central fat. Psychosom Med, 2000. 62(5): p. 623-32.

85. Pasquali, R., B. Ambrosi, D. Armanini, F. Cavagnini, E.D. Uberti, G. Del Rio, et al., Cortisol and ACTH response to oral dexamethasone in obesity and effects of sex, body fat distribution, and dexamethasone concentrations: a dose-response study. J Clin Endocrinol Metab, 2002. 87(1): p. 166-75.

86. Ljung, T., B. Andersson, B.A. Bengtsson, P. Bjorntorp, and P. Marin, Inhibition of cortisol secretion by dexamethasone in relation to body fat distribution: a dose-response study. Obes Res, 1996. 4(3): p. $277-82$.

87. Petrides, J.S., P.W. Gold, G.P. Mueller, A. Singh, C. Stratakis, G.P. Chrousos, et al., Marked differences in functioning of the hypothalamic-pituitary-adrenal axis between groups of men. J Appl Physiol, 1997. 82(6): p. 1979-88.

88. Ia Fleur, S.E., The effects of glucocorticoids on feeding behavior in rats. Physiol Behav, 2006. 89(1): p. 110-4.

89. la Fleur, S.E., S.F. Akana, S.L. Manalo, and M.F. Dallman, Interaction between corticosterone and insulin in obesity: regulation of lard intake and fat stores. Endocrinology, 2004. 145(5): p. 2174-85.

90. Tataranni, P.A., D.E. Larson, S. Snitker, J.B. Young, J.P. Flatt, and E. Ravussin, Effects of glucocorticoids on energy metabolism and food intake in humans. Am J Physiol, 1996. 271(2 Pt 1): p. E317-25.

91. Heatherton, T.F., C.P. Herman, and J. Polivy, Effects of physical threat and ego threat on eating behavior. J Pers Soc Psychol, 1991. 60(1): p. 138-43.

92. Epel, E., R. Lapidus, B. McEwen, and K. Brownell, Stress may add bite to appetite in women: a laboratory study of stress-induced cortisol and eating behavior. Psychoneuroendocrinology, 2001. 26(1): p. 37-49.

93. Mitchell, S.L. and L.H. Epstein, Changes in taste and satiety in dietary-restrained women following stress. Physiol Behav, 1996. 60(2): p. 495-9.

94. Oliver, G., J. Wardle, and E.L. Gibson, Stress and food choice: a laboratory study. Psychosom Med, 2000. 62(6): p. 853-65.

95. Adam, T.C. and E.S. Epel, Stress, eating and the reward system. Physiol Behav, 2007. 91(4): p. 449-58.

96. Dallman, M.F., A.M. Strack, S.F. Akana, M.J. Bradbury, E.S. Hanson, K.A. Scribner, et al., Feast and famine: critical role of glucocorticoids with insulin in daily energy flow. Front Neuroendocrinol, 1993. 14(4): p. 303-47.

97. Berridge, K.C. and T.E. Robinson, What is the role of dopamine in reward: hedonic impact, reward learning, or incentive salience? Brain Res Brain Res Rev, 1998. 28(3): p. 309-69.

98. Pecina, S. and K.C. Berridge, Opioid site in nucleus accumbens shell mediates eating and hedonic 'liking' for food: map based on microinjection Fos plumes. Brain Res, 2000. 863(1-2): p. 71-86.

99. Yoshida, M., S. Koyanagi, A. Matsuo, T. Fujioka, H. To, S. Higuchi, et al., Glucocorticoid hormone regulates the circadian coordination of micro-opioid receptor expression in mouse brainstem. J Pharmacol Exp Ther, 2005. 315(3): p. 1119-24. 
100. Barrot, M., D.N. Abrous, M. Marinelli, F. Rouge-Pont, M. Le Moal, and P.V. Piazza, Influence of glucocorticoids on dopaminergic transmission in the rat dorsolateral striatum. Eur J Neurosci, 2001. 13(4): p. 812-8.

101. Yeomans, M.R. and R.W. Gray, Effects of naltrexone on food intake and changes in subjective appetite during eating: evidence for opioid involvement in the appetizer effect. Physiol Behav, 1997. 62(1): p. 15-21.

102. Leddy, J.J., L.H. Epstein, J.L. Jaroni, J.N. Roemmich, R.A. Paluch, G.S. Goldfield, et al., Influence of methylphenidate on eating in obese men. Obes Res, 2004. 12(2): p. 224-32.

103. Greeno, C.G. and R.R. Wing, Stress-induced eating. Psychol Bull, 1994. 115(3): p. 444-64.

104. Zellner, D.A., S. Loaiza, Z. Gonzalez, J. Pita, J. Morales, D. Pecora, et al., Food selection changes under stress. Physiol Behav, 2006. 87(4): p. 789-93.

105. Anderson, D.A., J.R. Shapiro, J.D. Lundgren, L.E. Spataro, and C.A. Frye, Self-reported dietary restraint is associated with elevated levels of salivary cortisol. Appetite, 2002. 38(1): p. 13-7.

106. McLean, J.A., S.I. Barr, and J.C. Prior, Cognitive dietary restraint is associated with higher urinary cortisol excretion in healthy premenopausal women. Am J Clin Nutr, 2001. 73(1): p. 7-12.

107. Newman, E., D.B. O'Connor, and M. Conner, Daily hassles and eating behaviour: the role of cortisol reactivity status. Psychoneuroendocrinology, 2007. 32(2): p. 125-32. 



\section{Chapter 2}

Associations between the FTO gene (rs9939609) and development of obesity related characteristics over time in a Dutch children cohort

F. Rutters, A.G. Nieuwenhuizen, F. Bouwman, E. Mariman, M.S. WesterterpPlantenga

Submitted 


\begin{abstract}
Objective: to replicate earlier findings on the relationship between FTO and obesity related characteristics, as well as investigate the effect of FTO on BMI, body composition, leptin concentrations, and physical activity longitudinally.
\end{abstract}

Subjects and measurements: FTO (rs9939609) was genotyped in 101 children, from whom we have collected anthropometric measurements from birth to age $15 \mathrm{y}$, as well as body composition, leptin concentrations, and physical activity (Baecke questionnaire) yearly from age 12 to $15 y$.

Results: children with the A/A and A/T genotype had a higher BMI at age 12, 13, 14, 15y (19.5 \pm 2.9 vs. $18.3 \pm 1.9,20.2 \pm 3.3$ vs. $18.6 \pm 2.0,21.0 \pm 3.2$ vs. $20.0 \pm 2.1,21.9 \pm 3.6$ vs. $\left.20.8 \pm 2.2 \mathrm{~kg} / \mathrm{m}^{2}, \mathrm{p}<0.05\right)$, and a larger increase in BMI from age $7-15 \mathrm{y}(6.3 \pm 2.9 \mathrm{vs}$. $\left.5.4 \pm 1.6 \mathrm{~kg} / \mathrm{m}^{2}, \mathrm{p}<0.05\right)$, when compared to children with the T/T genotype. Additionally, children with the $A / A$ and $A / T$ genotype had a higher fat mass index (FMI) at age 12 and $13 y\left(4.2 \pm 2.1\right.$ vs. $3.4 \pm 1.5 \mathrm{~kg} / \mathrm{m}^{2}$ and $4.3 \pm 2.3$ vs. $\left.3.4 \pm 1.5 \mathrm{~kg} / \mathrm{m}^{2}, \mathrm{p}<0.03\right)$, a lower Baecke score at age $13 y(7.8 \pm 0.8$ vs. $8.2 \pm 0.8, p<0.03)$, higher leptin concentrations at age 12 and $13 y(8.7 \pm 7.3$ vs. $5.9 \pm 4.5 \mathrm{ng} / \mathrm{ml}, \mathrm{p}<0.02$ and $6.8 \pm 6.1$ vs. $4.5 \pm 3.8 \mathrm{ng} / \mathrm{ml}$, $\mathrm{p}<0.05)$, as well as a larger leptin peak at age $12 \mathrm{y}$, when compared to children with the $\mathrm{T} / \mathrm{T}$ genotype. At age 13y, an association was observed between BMI and leptin concentrations $(\mathrm{ng} / \mathrm{ml})$, Baecke scores, and the FTO A allele $\left(R^{2}=0.523, p<0.001\right)$.

Conclusion: the FTO A allele (rs9939609) is associated with higher BMI, FMI, leptin concentrations, and lower activity scores from childhood to puberty; these associations are independent and change in strength over time. 


\section{Introduction}

The prevalence of obesity is emerging as a major health problem [1] and is associated with several risk factors, such as an increased risk on cardiovascular disease and type 2 diabetes [2, 3]. Individual susceptibility to obesity is determined by interactions between genetic, behavioral, and environmental factors [4]. To study the interaction between genetics and obesity often single nucleotide polymorphism (SNP) association studies are used [5]. Recent SNP association studies identified a relationship between the FTO (fat mass and obesity associated) gene (rs9939609) and the control of energy balance, since FTO expression is decreased in the hypothalamus in fasted mice, when compared to fed mice [6].

SNP association studies have linked the $A$ allele of the FTO gene (rs9939609) to a number of obesity related characteristics, such as an increased BMI [7-10], increased hip circumference [11], increased adiposity $[5,7,8]$, increased leptin levels $[12,13]$, increased C-reactive protein levels [14], elevated dietary fat intake $[15,16]$, increased energy intake $[17,18]$, and reduced satiety responsiveness [19]. Additionally, Andreasen et al. observed an interaction between the FTO genotype and physical activity, where physically inactive subjects with the AA genotype had a higher BMI when compared to T/T genotype [7]. Previous studies, however, only assessed the effect of FTO polymorphisms in one single population at one time point $[7,8$, 14-17, 19], or assessed only BMI longitudinally $[9,12,20,21]$. Gene expression however changes developmentally [22], and so the influence of FTO may change over time. It therefore remains unknown whether the effect of FTO is stable during life on other obesity related characteristics, such as body composition, leptin concentrations, as well as physical activity, and whether FTO influences the obesity related characteristics independently.
Consequently, the objective of our study was to replicate earlier findings on the relationship between FTO and obesity related characteristics, as well as investigate the effect of FTO (rs9939609) on BMI, body composition, leptin concentrations, and physical activity longitudinally. Therefore, we determined in 101 children anthropometric measurements yearly from birth to age $15 y$, as well as body composition, leptin concentrations, and physical activity yearly from age 12 to $15 y$.

\section{Subjects and methods Subjects}

Subjects were recruited from a Dutch Caucasian cohort of children born between 1990 and 1993 [23, 24]. Anthropometric data were available from these children, no interventions were executed, and follow-up studies were performed with 58 boys and 43 girls. Each child and their parents gave written informed consent to participate in the study, which was approved by the Central Committee Human Research and by the Medical Ethical Committee of Maastricht University.

\section{Study design}

Children's body weight (BW), height, body mass index (BMI), waist circumference, body composition [24, 25], leptin concentrations, as well as physical activity were determined in the afternoon after a 3-hour fast.

\section{Measurements}

Anthropometry

The children's BW was determined using a digital balance accurate to $0.1 \mathrm{~kg}$ (Sauter D7470, Ebingen, Germany) and their height was determined using a wallmounted stadiometer (Seca, model 220, Hamburg, Germany). Measurements were executed in underwear, after a 3-hour fast, and after voiding the bladder. BMI was calculated by BW/height ${ }^{2}\left(\mathrm{~kg} / \mathrm{m}^{2}\right)$ and BMI changed substantially with age in childhood. To define normal weight, overweight and obesity in children, we 
used the specific cut off points described by Cole et al. 2000 [2]. The waist circumference was measured at the site of the smallest circumference between the rib cage and the ileac crest, with the subjects in standing position. The pubertal stage (development of breast, genitalia, and pubic hair) was determined in all children, according to the classification by Tanner [26]. Anthropometric measurements were determined at age 7 , $12,13,14$ and $15 y$.

\section{Body composition}

Body composition was measured using the deuterium dilution technique $\left(\mathrm{D}_{2} \mathrm{O}\right) . \mathrm{D}_{2} \mathrm{O}$ dilution was used to measure total body water (TBW). Subjects were asked to collect a urine sample in the evening just before drinking the deuterium-enriched water solution. After ingestion of this solution, no further consumption was allowed. Ten hours after drinking the water solution, another urine sample was collected. The dilution of the deuterium isotope is a measure of the TBW of the subject. Deuterium was measured in the urine samples with an isotope ratio mass spectrometer (VG-Isogas Aqua Sira, VG Isogas, Middlewich, Cheshire, England). TBW was obtained by dividing the measured deuterium dilution space by 1.04. Fat free mass (FFM) was calculated by dividing TBW by the hydration factor 0.73 [27-29]. Fat mass (FM) was determined as BW-FFM. Fat mass index (FMI) was calculated by fat mass/height ${ }^{2}$ $\left(\mathrm{kg} / \mathrm{m}^{2}\right)$ and fat free mass index (FFMI) was calculated by fat free mass $/$ height $^{2}$ $\left(\mathrm{kg} / \mathrm{m}^{2}\right)$. Body composition was measured at age $12,13,14$ and $15 y$.

\section{Leptin}

Plasma leptin concentrations were measured with a double-antibody, sandwich-type enzyme-linked immunosorbent assay that used a monoclonal antibody specific for human leptin. The lower and upper limits of detection were $0.5 \mu \mathrm{g} / \mathrm{L}$ and $50 \mu \mathrm{g} / \mathrm{L}$ respectively. The intra- and inter assay CVs were $9 \%$ and $12 \%$, respectively. The leptin concentrations of normal-weight subject's range from 2 to $12 \mu \mathrm{g} / \mathrm{L}$. Plasma leptin concentrations were measured at age $7,12,13,14$ and $15 y$.

\section{Physical activity}

Physical activity was measured with the Baecke questionnaire. The Baecke questionnaire consists of three components: work activity, sports activity and leisure activity, and has been validated using doubly labeled water [30]. For the children, the work index was replaced by a school index with similar questions (e.g. 'When I am at school, I walk: never/seldom/sometimes/often/all the time?'). The Baecke questionnaire for children was validated by Vogels et al. 2007 [31]. Physical activity was determined at age $12,13,14$ and $15 y$.

\section{Determination of FTO genotypes}

The genomic DNAs of 101 participants were isolated from peripheral blood leukocytes using a QIAamp kit (QIAgen, Germany). FTO (rs9939609) genotypes were determined using Taqman allelic discrimination ( $A B$, Applied Biosystems).

\section{Statistical analysis}

Student t-tests (for continuous variables) and chi-square tests (for the nominal variables) were executed to determine differences in single variables between groups. Differences over time and between conditions were determined using two-factor ANOVA with repeated measures. Relationships between dependent and independent variables were determined using simple linear regression and multiple regression models.

The genotypic and allelic distributions of the FTO polymorphism are provided in

\section{table 1.}

Table 1: FTO genotype frequencies and the frequency of the $A$ allele in the study sample $(n=101)$

\begin{tabular}{lllllll}
\hline Poly-morphism & Genotype & $\mathrm{F}(\mathrm{n})$ & $\mathrm{F}(\%)$ & Allele & $\mathrm{F}(\%)$ & HWE $^{\mathrm{a}}$ \\
\hline Rs9939609 & T & 45 & 44.6 & $\mathrm{~T}$ & 67.8 & 0.93 \\
$\mathrm{~T}>\mathrm{A}$ & TA & 47 & 45.5 & A & 32.1 & \\
& AA & 9 & 8.9 & & & \\
\hline
\end{tabular}

F, Frequency, either absolute ( $n$ ) or relative (\%); a P-values obtained from the Chi-square test of Hardy Weinberg Equilibrium (HWE) 
The genotype frequencies were in Hardy Weinberg Equilibrium. Because of the small study population and since the data of the homozygotes for the minor allele (A/A) did not differ significantly from the heterozygotes $(A / T)$, they were taken together in the analysis and compared to the homozygotes for the major allele $(T / T)$.

All tests were two-sided and differences were considered significant at $\mathrm{P}<0.05$. Values are expressed as mean \pm standard deviation (s.d.).

\section{Results}

Data on height, BW, BMI, waist circumference, body composition, leptin concentrations, and Baecke scores were collected at age 7 to $15 y$ from 58 boys and 43 girls. The subject characteristics at age $15 y$ are presented in table $\mathbf{2}$. At age $15 y$ most children were at Tanner stage 3 of the pubertal development, and $11 \%$ of the children were overweight. Overweight status measured as BMI and body fat percentage, was defined on the basis of age- and sex-appropriate international standards [2]. With respect to genotypic distribution of the FTO polymorphism more overweight and obese children had the $A / A$ and $T / A$ genotype when compared to the T/T genotype at age 12 (14.3 and 31.4 vs. $4.9 \%)$ and $15 y$ (28.6 and 31.3 vs. $5.1 \%)$.

Table 2: Characteristics of the boys $(n=58)$ and girls $(n=43)$ at the mean age of $15 y$

\begin{tabular}{llll}
\hline & Boys & Girls & P-value \\
\hline Body weight $(\mathrm{kg})$ & $65.4 \pm 10.8$ & $60.5 \pm 10.8$ & 0.02 \\
Height $(\mathrm{cm})$ & $176.1 \pm 7.2$ & $165.8 \pm 6.8$ & 0.01 \\
Body mass index $\left(\mathrm{kg} / \mathrm{m}^{2}\right)$ & $20.9 \pm 2.7$ & $21.9 \pm 3.5$ & 0.18 \\
Waist $(\mathrm{cm})$ & $73.4 \pm 6.1$ & $70.4 \pm 7.4$ & 0.01 \\
Body fat $(\%)$ & $15.9 \pm 6.0$ & $27.5 \pm 5.7$ & 0.01 \\
Leptin $(\mu \mathrm{g} / \mathrm{L})$ & $2.2 \pm 1.9$ & $9.8 \pm 6.5$ & 0.01 \\
Baecke score & $8.3 \pm 0.9$ & $8.1 \pm 1.0$ & 0.25 \\
\hline
\end{tabular}

\section{$B M I$}

Figure 1 depicts the development of the BMI $\left(\mathrm{kg} / \mathrm{m}^{2}\right)$ of children with the A/A and $A / T$ genotype versus the $T / T$ genotype over time. BMI was not different between birth and age 7, however BMI was significantly higher at age $12,13,14$, and $15 y$ in children with the $A / A$ and $A / T$ genotype, when compared to children with the $T / T$ genotype. Over time, a significant increase in BMI was seen in all groups from age 7 to $15 y$, and in children with the $A / A$ and $A / T$ genotype a stronger increase was observed, when compared to children with the $T / T$ genotype $(6.3 \pm 2.9$ vs. $\left.5.4 \pm 1.6 \mathrm{~kg} / \mathrm{m}^{2}, \mathrm{p}<0.05\right)$.

Figure 1: Development of body mass index $\left(\mathrm{kg} / \mathrm{m}^{2}\right)$ in children with the A/A and A/T genotype $(n=56)$ versus the T/T genotype $(n=45)$. Values are means.

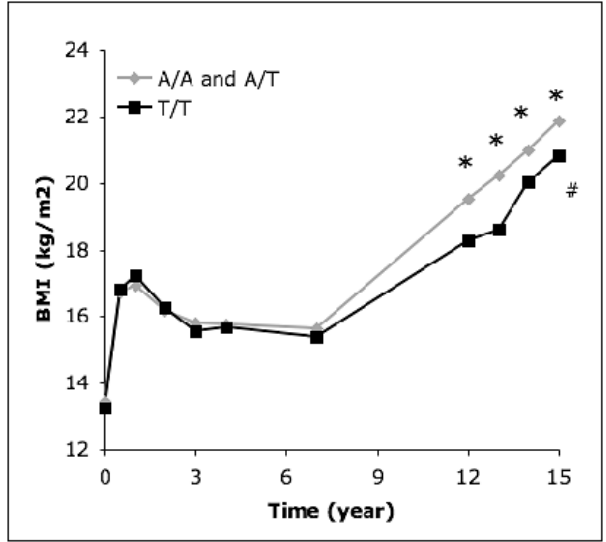

\# $\mathrm{P}<0.05$ overall group $x$ time interaction between $\mathrm{A} / \mathrm{A}$ and $A / T$ genotype vs. T/T genoype (2- factor ANOVA repeated measures)

* $\mathrm{P}<0.05$ for differences in children with the A/A and $A / T$ genotype vs. T/T genoype (2- factor ANOVA repeated measures)

Figure 2: Development of fat mass index $(F M I)\left(\mathrm{kg} / \mathrm{m}^{2}\right)$ in children with the A/A and A/T genotype $(n=56)$ versus the T/T genotype $(n=45)$. Values are means.

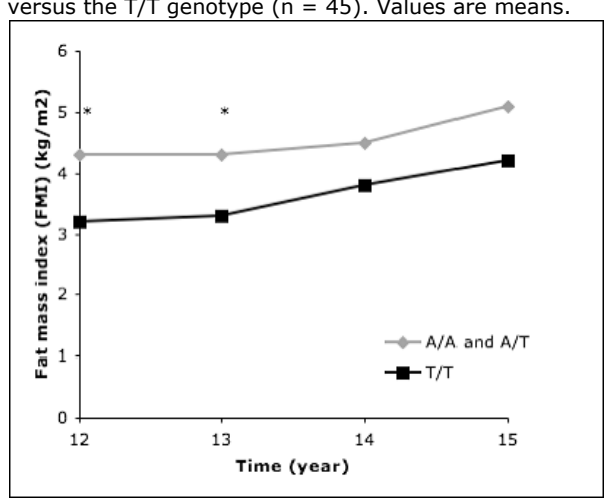

$* \mathrm{P}<0.05$ for differences in children with the A/A and $A / T$ genotype vs. T/T genoype (2- factor ANOVA repeated measures)

\section{Fat Mass Index (FMI)}

Fat mass index (FMI) was calculated by fat mass $/$ height $^{2}\left(\mathrm{~kg} / \mathrm{m}^{2}\right)$. Figure 2 depicts the development of the FMI $\left(\mathrm{kg} / \mathrm{m}^{2}\right)$ of children with the $\mathrm{A} / \mathrm{A}$ and $\mathrm{A} / \mathrm{T}$ genotype versus the $T / T$ genotype over time. FMI was significantly higher at age 
12 and $13 y$ in children with the $A / A$ and $A / T$ genotype, when compared to children with the T/T genotype. Over time no significant changes in FMI were present. Surprisingly, no differences over time were found in FFMI $\left(\mathrm{kg} / \mathrm{m}^{2}\right)$ between the $A / A$ and $A / T$ genotype versus the $T / T$ genotype.

\section{Leptin concentrations}

Figure 3 depicts the development of the leptin concentrations $(\mathrm{ng} / \mathrm{ml})$ of children with the $A / A$ and $A / T$ genotype versus the $T / T$ genotype over time. Leptin concentrations were significantly higher at age 12 and $13 y$ in children with the A/A and $A / T$ genotype, when compared to children with the $T / T$ genotype. A significant group $x$ time effect was found in leptin concentration measurements $(p<0.03$, two-factor ANOVA repeated measures). A significant higher peak value was observed in children with the $A / A$ and $A / T$ genotype, when compared to children with the T/T genotype, as a stronger increase between 7 and $12 y(5.7 \pm 8.3$ vs. $1.0 \pm 5.3 \mathrm{ng} / \mathrm{ml}, \mathrm{p}<0.01$ ) and a stronger decrease between 12 and $14 y(-2.2 \pm 3.2$ vs. $-1.2 \pm 5.3 \mathrm{ng} / \mathrm{ml}, \mathrm{p}<0.10)$ was observed in children with the $A / A$ and $A / T$ genotype.

Figure 3: Development of leptin concentrations ( $\mathrm{ng} / \mathrm{ml}$ ) in children with the $A / A$ and $A / T$ genotype $(n=56)$ versus the $T / T$ genotype $(n=45)$. Values are means.

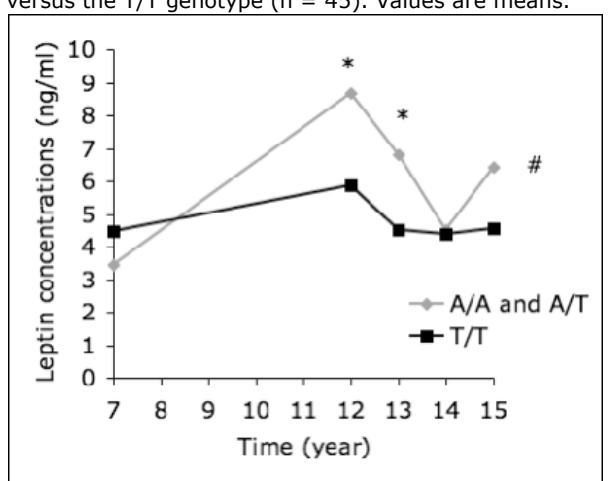

\# $P<0.05$ overall group $x$ time interaction between $A / A$ and $A / T$ genotype vs. T/T genoype (2-factor ANOVA repeated measures)

$* P<0.05$ for differences in children with the A/A and $A / T$ genotype vs. T/T genoype (2- factor ANOVA repeated measures)

\section{Activity scores}

Figure 4 depicts the development of the Baecke scores of children with the $A / A$ and $A / T$ genotype versus the $T / T$ genotype over time. Baecke scores were significantly higher at age $13 y$ in children with the T/T genotype, when compared to children with the $A / A$ and $A / T$ genotype. When adjusted for BMI, the association between FTO and Baecke scores remained. Over time Baecke scores in children with the T/T genotype were significantly higher, when compared to children with the A/A and $A / T$ genotype $(p<0.05)$. No alterations over time in Baecke scores were observed in both groups.

Figure 4: Development of Baecke scores in children with the $A / A$ and $A / T$ genotype $(n=56)$ versus the $T / T$ genotype $(n=45)$. Values are means.

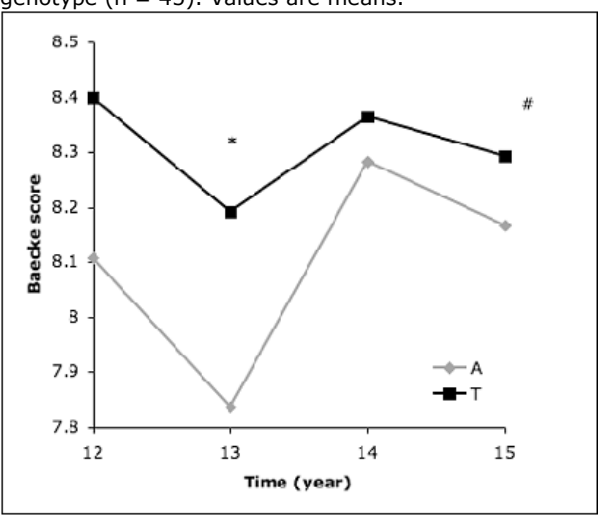

$\# P<0.05$ overall group $x$ time interaction between $A / A$ and $A / T$ genotype vs. T/T genoype (2- factor ANOVA repeated measures)

$* P<0.05$ for differences in children with the $A / A$ and A/T genotype vs. $T / T$ genoype (2- factor ANOVA repeated measures)

Table 3A depicts linear regression analyses with FTO allele genotypes $(A=1 / T=0)$ at a certain age as the dependent variable and BMI $\left(\mathrm{kg} / \mathrm{m}^{2}\right)$ at that age as the independent variable. The association between FTO allele genotype and BMI were not significant until age $12 y$ and became weaker again from age $13 y$. Per year, multiple regression analyses were performed with BMI $\left(\mathrm{kg} / \mathrm{m}^{2}\right)$ as the dependent variable and leptin concentrations $(\mathrm{ng} / \mathrm{ml})$, Baecke scores, and FTO allele as the independent variables. Multiple regression analyses with BMI $\left(\mathrm{kg} / \mathrm{m}^{2}\right)$ at a certain age as the 
dependent variable showed that only the leptin concentrations contributed significantly to the model at age $12 y\left(R^{2}=\right.$ $0.45, p<0.01)$, at age $14 y\left(R^{2}=0.17\right.$, $p<0.05)$, and at age 15y $\left(R^{2}=0.44\right.$, $\mathrm{p}<0.01$ ).

Only at age $13 y$ a significant association was observed between all 3 independent variables, and therefore table 3B depicts the multiple regression analysis with BMI $\left(\mathrm{kg} / \mathrm{m}^{2}\right)$ at age $13 \mathrm{y}$ as the dependent variable and leptin concentrations $(\mathrm{ng} / \mathrm{ml})$, Baecke scores, and FTO allele genotypes at age $13 y$ as the independent variables $\left(R^{2}=0.523, p<0.001\right)$.

Table 3A: linear regression analysis with FTO allele genotypes $(A=1 / T=0)$ at a certain age as the dependent variable and BMI $\left(\mathrm{kg} / \mathrm{m}^{2}\right)$ at that age as the independent variable

\begin{tabular}{llll}
\hline Age (year) & Correlation coefficient $(r)$ & $\mathrm{R}^{2}$ & P-value \\
\hline 0 & 0.09 & 0.008 & 0.38 \\
1 & 0.10 & 0.01 & 0.34 \\
2 & 0.02 & 0.001 & 0.81 \\
3 & 0.10 & 0.01 & 0.37 \\
4 & 0.04 & 0.002 & 0.71 \\
7 & 0.08 & 0.007 & 0.42 \\
12 & 0.24 & 0.058 & 0.02 \\
13 & 0.28 & 0.078 & 0.001 \\
14 & 0.17 & 0.029 & 0.09 \\
15 & 0.17 & 0.030 & 0.09 \\
\hline
\end{tabular}

Table 3B: multiple regression with BMI $\left(\mathrm{kg} / \mathrm{m}^{2}\right)$ at age $13 y$ as the dependent variable and leptin concentrations ( $\mathrm{ng} / \mathrm{ml})$, Baecke scores, and FTO allele genotypes at age $13 y$ as the independent variables

\begin{tabular}{llll}
\hline & Partial $\beta$ & Std. Error & $P$ value \\
\hline Intercept & 10.32 & 2.5 & 0.001 \\
$\begin{array}{l}\text { Leptin concentrations } \\
\text { (ng/ml) }\end{array}$ & 0.36 & 0.047 & 0.001 \\
Baecke scores & & & \\
FTO allele genotype & 0.82 & 0.30 & 0.007 \\
$(\mathrm{~A}=1 / \mathrm{T}=0)$ & 1.30 & 0.52 & 0.01 \\
\hline
\end{tabular}

$\mathrm{R}^{2}=0.523, \mathrm{p}<0.001$

\section{Discussion}

The objective of our study was to replicate earlier findings on the relationship between FTO and obesity related characteristics, as well as investigate the effect of FTO (rs9939609) on BMI, body composition, leptin concentrations, and physical activity longitudinally. We observed that children with the A/A and $\mathrm{A} / \mathrm{T}$ genotype had a higher BMI at age 12 to $15 y$, and a larger increase in BMI from age 7-15y, when compared to children with the $T / T$ genotype. Children with the $A / A$ and $A / T$ genotype also had a higher
FMI at age 12 and 13y, lower Baecke score at age $13 y$, higher leptin concentrations at age $12 y$, as well as a larger leptin peak at age $12 \mathrm{y}$ when compared to children with the T/T genotype. Additionally, the association between the FTO gene and BMI increased with age, and only at age $13 y$ BMI was associated with leptin concentrations, Baecke scores and the FTO A allele.

The strengths of our study is the fact that we have longitudinal data from a cohort of solely Caucasian children, thereby eliminating population stratification, as well as determination of body fat percentage using a high-quality method, such as the deuterium dilution technique [29]. Although the sample seems rather small, the genotype frequency distribution of our cohort was consistent with the frequency distributions in other Caucasian populations $[7,17]$, and because the minor allele frequency is over $30 \%$, sufficient power will be present to study differences in physiological parameters. This reassured us that the use of the FTO genotype in this smaller cohort was a valid approach. In concordance with previous studies $[9,10,20,21]$, we observed a significant association between FTO and BMI during childhood, and no association at birth. Furthermore, we observed a higher BMI from 7y onwards in subjects with the $A / A$ and $A / T$ genotype, which is supported by two other longitudinal studies $[20,21]$, but is in contrast to the longitudinal study by Jess et al. 2008 [9]. Differences may be explained by time of measurement, while we measured the children yearly, Jess et al. 2008 [9] only measured the children at birth, 7, 10, and $13 y$, thereby they possibly did not observe changes in BMI during puberty. We however observed that the association between the FTO gene and BMI increased with age, and became significant at age $12 y$, which has been reported by Haworth et al [20]. Overall, these results imply that the FTO A allele is associated with a higher BMI during early childhood, and that the association becomes stronger during puberty [20]. 
To determine if the FTO polymorphism was associated with differences in development of body composition and physical activity, we measured body composition and Baecke scores from age 12 to $15 y$. Children with the $A / A$ and $A / T$ genotype had a significantly higher FMI at age 12 and 13y, as well as lower Baecke scores over time, when compared to children with the T/T genotype. These results confirm several cross-sectional studies on FTO and body composition [5, $7,8]$. Previous studies observed inconsistent results on the relationship between FTO genotypes and physical activity; Andreasen et al [7] in concordance to our results observed an association, while others have observed no associations [21, 32]. Differences between the studies may be explained different study populations and different measurement techniques.

Additionally, we measured leptin concentrations from age 7 to $15 y$ and observed that children with the $A / A$ and $A / T$ genotype showed higher leptin concentrations at age $12 y$, which confirms several cross-sectional studies [12, 13]. Furthermore, we observed that children with the $A / A$ and $A / T$ genotype had a larger leptin peak at age $12 \mathrm{y}$. The leptin peak has been observed to be the onset of sexual maturation $[33,34]$, and a larger leptin peak may result in increased gonadal hormones concentrations that in turn alter the relationship between leptin concentrations and body fat [35]. Together, these results suggest that the associations between the FTO A allele and decreased physical activity, increased FMI along with increased leptin concentrations are stable during puberty.

Multiple linear regression analysis showed that at age $13 y$ a larger BMI was associated to the FTO A allele, larger leptin concentrations, and decreased physical activity. These results implicate that at age $13 y$ genetic, physiological and psychological factors are independent predictors for BMI. At age 12, 14, and 15y BMI was only associated to leptin concentrations, which implicates that during puberty BMI is only temporarily predicted by FTO. This has previously been suggested by Haworth et al. [20], which implicates that during puberty BMI is predominately predicted by physiological factors. The strong point of the present study is the fact that we found associations that change in strength over time, between FTO and a number of obesity related characteristics in this relatively small cohort. Our study can however not elucidate causality concerning the development of the obesity related characteristics. We conclude that the FTO A allele (rs9939609) is associated with higher BMI, FMI, leptin concentrations, and lower activity scores from childhood to puberty; these associations are independent and change in strength over time.

\section{Acknowledgements}

We want to thank our subjects for their participation in our cohort study. We gratefully thank Loek Wouters and Wendy Sluijsmans for their assistance. FR carried out the study, collected and analyzed the data, and wrote the largest part of the manuscript. FB (supervised by EM) contributed to the practical work. AN and MW supervised FR. Planning, processing the results and writing the manuscript were done under general supervision by AN and MW. The authors had no conflict of interest. 


\section{Literature}

1. Reilly, J.J., Obesity in childhood and adolescence: evidence based clinical and public health perspectives. Postgrad Med J, 2006. 82(969): p. 429-37.

2. Cole, T.J., M.C. Bellizzi, K.M. Flegal, and W.H. Dietz, Establishing a standard definition for child overweight and obesity worldwide: international survey. Bmj, 2000. 320(7244): p. 1240-3.

3. Mossberg, H.O., 40-year follow-up of overweight children. Lancet, 1989. 2(8661): p. 491-3.

4. Hotta, K., Y. Nakata, T. Matsuo, S. Kamohara, K. Kotani, R. Komatsu, et al., Variations in the FTO gene are associated with severe obesity in the Japanese. J Hum Genet, 2008. 53(6): p. 546-53.

5. Dina, C., New insights into the genetics of body weight. Curr Opin Clin Nutr Metab Care, 2008. 11(4): p. 378-84.

6. Stratigopoulos, G., S.L. Padilla, C.A. LeDuc, E. Watson, A.T. Hattersley, M.I. McCarthy, et al., Regulation of Fto/Ftm gene expression in mice and humans. Am J Physiol Regul Integr Comp Physiol, 2008. 294(4): p. R118596.

7. Andreasen, C.H., K.L. Stender-Petersen, M.S. Mogensen, S.S. Torekov, L. Wegner, G. Andersen, et al., Low physical activity accentuates the effect of the FTO rs9939609 polymorphism on body fat accumulation. Diabetes, 2008. 57(1): p. 95-101.

8. Kring, S.I., C. Holst, E. Zimmermann, T. Jess, T. Berentzen, S. Toubro, et al., FTO gene associated fatness in relation to body fat distribution and metabolic traits throughout a broad range of fatness. PLoS ONE, 2008. 3(8): p. e2958.

9. Jess, T., E. Zimmermann, S.I. Kring, T. Berentzen, C. Holst, S. Toubro, et al., Impact on weight dynamics and general growth of the common FTO rs9939609: a longitudinal Danish cohort study. Int J Obes (Lond), 2008. 32(9): p. 1388-94.

10. Frayling, T.M., N.J. Timpson, M.N. Weedon, E. Zeggini, R.M. Freathy, C.M. Lindgren, et al., A common variant in the FTO gene is associated with body mass index and predisposes to childhood and adult obesity. Science, 2007. 316(5826): p. 889-94.

11. Scuteri, A., S. Sanna, W.M. Chen, M. Uda, G. Albai, J. Strait, et al., Genome-wide association scan shows genetic variants in the FTO gene are associated with obesity-related traits. PLoS Genet, 2007. 3(7): p. e115.

12. Qi, L., K. Kang, C. Zhang, R.M. van Dam, P. Kraft, D. Hunter, et al., FTO Gene Variant Is Associated with Obesity: Longitudinal Analyses in Two Cohort Studies and Functional Test. Diabetes, 2008.

13. Do, R., S.D. Bailey, K. Desbiens, A. Belisle, A. Montpetit, C. Bouchard, et al., Genetic variants of FTo influence adiposity, insulin sensitivity, leptin levels, and resting metabolic rate in the Quebec Family Study. Diabetes, 2008. 57(4): p. 1147-50.

14. Fisher, E., M.B. Schulze, N. Stefan, H.U. Haring, F. Doring, H.G. Joost, et al., Association of the FTO rs9939609 Single Nucleotide Polymorphism With C-reactive Protein Levels. Obesity (Silver Spring), 2008.

15. Timpson, N.J., P.M. Emmett, T.M. Frayling, I. Rogers, A.T. Hattersley, M.I. McCarthy, et al., The fat mass- and obesity-associated locus and dietary intake in children. Am J Clin Nutr, 2008. 88(4): p. 971-8.

16. Speakman, J.R., K.A. Rance, and A.M. Johnstone, Polymorphisms of the FTO gene are associated with variation in energy intake, but not energy expenditure. Obesity (Silver Spring), 2008. 16(8): p. 1961-5.

17. Wardle, J., C. Llewellyn, S. Sanderson, and R. Plomin, The FTO gene and measured food intake in children. Int J Obes (Lond), 2008.

18. Cecil, J.E., R. Tavendale, P. Watt, M.M. Hetherington, and C.N. Palmer, An obesity-associated FTO gene variant and increased energy intake in children. N Engl J Med, 2008. 359(24): p. 2558-66.

19. Wardle, J., S. Carnell, C.M. Haworth, I.S. Farooqi, S. O'Rahilly, and R. Plomin, Obesity associated genetic variation in FTO is associated with diminished satiety. J Clin Endocrinol Metab, 2008. 93(9): p. 3640-3.

20. Haworth, C.M., S. Carnell, E.L. Meaburn, O.S. Davis, R. Plomin, and J. Wardle, Increasing Heritability of BMI and Stronger Associations With the FTO Gene Over Childhood. Obesity (Silver Spring), 2008.

21. Hakanen, M., O.T. Raitakari, T. Lehtimaki, N. Peltonen, K. Pahkala, L. Sillanmaki, et al., FTO Genotype Is Associated with Body Mass Index after the Age of 7 Years but Not with Energy Intake or Leisure-time Physical Activity. J Clin Endocrinol Metab, 2009.

22. Bergen, S.E., C.O. Gardner, and K.S. Kendler, Age-related changes in heritability of behavioral phenotypes over adolescence and young adulthood: a meta-analysis. Twin Res Hum Genet, 2007. 10(3): p. 423-33.

23. Rump, P., R.P. Mensink, A.D. Kester, and G. Hornstra, Essential fatty acid composition of plasma phospholipids and birth weight: a study in term neonates. Am J Clin Nutr, 2001. 73(4): p. 797-806.

24. Vogels, N., D.L. Posthumus, E.C. Mariman, F. Bouwman, A.D. Kester, P. Rump, et al., Determinants of overweight in a cohort of Dutch children. Am J Clin Nutr, 2006. 84(4): p. 717-24.

25. Rutters, F., A.G. Nieuwenhuizen, N. Vogels, F. Bouwman, E. Mariman, and M.S. Westerterp-Plantenga, Leptinadiposity relationship changes, plus behavioral and parental factors, are involved in the development of body weight in a Dutch children cohort. Physiol Behav, 2008. 93(4-5): p. 967-74.

26. Rico, H., M. Revilla, L.F. Villa, E.R. Hernandez, M. Alvarez de Buergo, and M. Villa, Body composition in children and Tanner's stages: a study with dual-energy x-ray absorptiometry. Metabolism, 1993. 42(8): p. 967-70.

27. van Marken Lichtenbelt, W.D., K.R. Westerterp, and L. Wouters, Deuterium dilution as a method for determining total body water: effect of test protocol and sampling time. Br J Nutr, 1994. 72(4): p. 491-7.

28. Schoeller, D.A., E. van Santen, D.W. Peterson, W. Dietz, J. Jaspan, and P.D. Klein, Total body water measurement in humans with 180 and $2 \mathrm{H}$ labeled water. Am J Clin Nutr, 1980. 33(12): p. 2686-93.

29. Westerterp, K.R., L. Wouters, and W.D. van Marken Lichtenbelt, The Maastricht protocol for the measurement of body composition and energy expenditure with labeled water. Obes Res, 1995. 3 Suppl 1: p. 49-57.

30. Philippaerts, R.M., K.R. Westerterp, and J. Lefevre, Doubly labelled water validation of three physical activity questionnaires. Int J Sports Med, 1999. 20(5): p. 284-9.

31. Vogels, N., K.R. Westerterp, D.L. Posthumus, F. Rutters, and M.S. Westerterp-Plantenga, Daily physical activity counts vs structured activity counts in lean and overweight Dutch children. Physiol Behav, 2007. 92(4): p. 611-6.

32. Berentzen, T., S.I. Kring, C. Holst, E. Zimmermann, T. Jess, T. Hansen, et al., Lack of association of fatnessrelated FTO gene variants with energy expenditure or physical activity. J Clin Endocrinol Metab, 2008. 93(7): p. 2904-8.

33. Garcia-Mayor, R.V., M.A. Andrade, M. Rios, M. Lage, C. Dieguez, and F.F. Casanueva, Serum leptin levels in normal children: relationship to age, gender, body mass index, pituitary-gonadal hormones, and pubertal stage. J Clin Endocrinol Metab, 1997. 82(9): p. 2849-55. 
34. Blum, W.F., P. Englaro, S. Hanitsch, A. Juul, N.T. Hertel, J. Muller, et al., Plasma leptin levels in healthy children and adolescents: dependence on body mass index, body fat mass, gender, pubertal stage, and testosterone. J Clin Endocrinol Metab, 1997. 82(9): p. 2904-10.

35. Rutters, F., A.G. Nieuwenhuizen, S.P. Verhoef, S.G. Lemmens, N. Vogels, and M.S. Westerterp-Plantenga, The relationship between leptin, gonadotropic hormones, and body composition during puberty in a Dutch children cohort. Eur J Endocrinol, 2009. 160(6): p. 973-8. 


\section{Chapter 3}

Leptin-adiposity relationship changes, plus behavioral and parental factors, are involved in the development of body weight in a Dutch children cohort

F. Rutters, A.G. Nieuwenhuizen, N. Vogels, F. Bouwman, E. Mariman and M.S. Westerterp-Plantenga

Physiology and behavior 2008 March 18; 93 (4-5); 967-74 


\begin{abstract}
Background: the development of body weight is determined by different factors, namely genetic, behavioral, parental and physiological.

Objective: to investigate whether genetic, behavioral, parental and physiological factors are involved and the extent of involvement in the development of body weight at age 12 and $13 y$ in a Dutch children cohort.
\end{abstract}

Methods: In a Dutch cohort of 94 children at age 12 and 13y, we determined anthropometric measurements, body composition, leptin concentrations, TFEQ scores, physical activity, as well as 3 polymorphisms, and determined anthropometric measurements and TFEQ scores in the parents.

Results: $11 \%$ of the children in the cohort were classified as overweight. The genotype frequency distributions of the PPARy2, BCLI and CNTF genes) at age 12 and $13 y$ were not significantly different for the overweight children compared to the lean children.

Overweight children showed higher dietary restraint and disinhibition scores. Overweight children's parents had a higher BMI, dietary restraint and disinhibition scores, compared to lean children's parents. A peak in leptin concentrations between 7 to $13 y$ was shown at $12 y$. In lean boys, the decrease in leptin concentrations between 12 and $13 y$ was related to an increase in fat free mass. At the age of $12 y$ predominantly the physiological factors were predictors for body weight, and at the age of $13 y$ both the physiological and behavioral factors were predictors for body weight.

Conclusion: we conclude from this longitudinal study, that leptin appeared to play an important role in the development of body weight during puberty, in addition to behavioral and parental factors. 


\section{Introduction}

The prevalence of childhood overweight is emerging as a major health problem [1] and is associated with several risk factors, such as the increased risk on overweight during adulthood $[2,3]$. The development of body weight is determined by different factors, namely genetic, behavioral, parental and physiological factors [3-6]. Several genetic factors have been linked to the development of body weight, three of them being the polymorphisms of the peroxisome proliferators-activated receptor (PPAR), the glucocorticoid receptor (GR) and the neurocytokine ciliary neurotrophic factor (CNTF). PPARy is a nuclear fatty acid receptor that is involved in adipocyte differentiation and represents a direct link between adiposity, food response and control of appetite in adults [7-9]. In children a link was found between the PPARy2 polymorphism Pro12Ala and obesity, as Cecil et al. found that the Proala12 mutation is related to deficiency in energy storage and utilization, leading to reduced growth [10]. The GR has an important role in the metabolism of adipose tissue and in the regulation of abdominal fat distribution. Mutations in the GR gene may result in perturbation of the glucocorticoid receptor, leading to diminished sensitivity to cortisol, which could lead to stressinduced obesity. Adults with the GR polymorphism IVS2-BclI have been associated with increased BMI, waist-tohip circumference and leptin concentrations $[11,12]$. In children the BclI polymorphism has been related to a larger increase in adiposity during puberty [13]. CNTF is a neurocytokine that works via the signaling pathway normally activated by leptin. The null mutation $\mathrm{G}>$ A leads to an inactive CNTF protein, resulting in diminished initiation of anorectic pathways, which leads to an increase in body mass. In adults with the $\mathrm{G}>\mathrm{A}$ null mutation, a higher BMI and a smaller decrease in leptin concentrations during weight loss, have been found [8, 14]. In children, no associations between the CNTF G > A null mutation and obesity have been found yet.

Several behavioral factors such as eating behavior and physical activity have been related to the development of body weight. Eating behavior can be analyzed using the Three Factor Eating Questionnaire (TFEQ) and assesses 3 factors involved in eating behavior: dietary restraint, disinhibition and feeling of hunger. Dietary restraint refers to conscious restriction of food intake to achieve or maintain a preferred bodyweight. Disinhibition reflects individual differences in the extent to which release from the cognitive suppression of eating occurs in response to the presence of palatable food or other disinhibiting stimuli, such as emotional distress $[15,16]$. Before, we have shown that dietary restraint only occurred in the 11-12 y old overweight children, thus it appeared to be an effect rather than a cause of overweight [6]. Additionally, physical activity can be analyzed using the BAECKE questionnaire, as several studies have shown that increased physical activity levels are protection against overweight development $[17,18]$.

Furthermore, several parental factors have been related to the development of body weight, like the fact that children with obese parents are more likely to become obese themselves [19]. It is likely that the family association is due to genetic factors and partly to shared lifestyles (i.e. diets and patterns of activity). Early experiences with food, feeding practices and family food choices affect children's nutritional habits. Additionally, parents' restrained eating behavior may affect children's bodyweight development as dietary restraint of mothers, and their perception about their daughters' risk of overweight, predicted maternal child feeding practices. This in turn predicted the daughters' eating and relative weight [20].

In addition several physiological, especially endocrine factors have been 
related to the development of body weight. The start of puberty around the age is of $12 y$ is a period of pronounced changes in the endocrine milieu. For the start of puberty, the achievement of a critical body weight or fat mass is thought to play a prominent role. In children and adults, leptin concentrations are directly related to the amount of adiposity, consequently the hormone leptin has been proposed as a physiological link between adiposity status and the start of sexual maturation [21, 22]. However, most studies investigating this physiological link were done in transversal cohorts, and not yet in a longitudinal cohort.

Overall, the objective of our study was to investigate whether genetic, behavioral, parental and physiological factors are involved and the extent of involvement in the development of body weight at age 12 and $13 y$ in a Dutch children cohort.

Therefore, we determined in a Dutch cohort of 94 children at age 12 and $13 y$ anthropometric measurements, body composition, leptin concentrations, TFEQ scores, physical activity, as well as 3 polymorphisms, and determined anthropometric measurements and TFEQ scores in the parents. We hypothesized that at the age of 12 and $13 y$ body weight may be influenced by predominantly physiological factors, in addition to the genetic, behavioral, and parental factors that we previously described before in Vogels et al. 2006 [6].

\section{Subjects and methods Subjects}

Subjects were recruited from a Dutch Caucasian cohort of children born between 1990 and 1993 [6, 23]. As infants, these children and their mothers participated in i) a study of essential fatty acids during pregnancy and pregnancy outcome [23], and ii) a study, performed between 1997 and 2000, about the long-term effects of fetal essential fatty acid availability [24]. Anthropometric data were available from these children and no interventions were provided. To evaluate the development of obesity and related parameters, follow-up studies were performed in 2004 and 2005 with 94 children [6]. Each child and one of his or her parents gave written informed consent to participate in the study, which was approved by the CCMO (Central Committee Human Research) and by the MEC (Medical Ethical Committee) of the University Maastricht.

\section{Study design}

Children's body weight (BW), height, body mass index (BMI), waist circumference, body composition, leptin concentrations, Three Factor Eating Questionnaire (TFEQ) scores and physical activity were determined in 2004 [6] and 2005, when the mean age was 12.4 and 13.4 years (range 11-15 years), respectively. Moreover, the polymorphisms of three relevant genes (PPARy2, BclI and CTNF) were determined [23, 24]. BW, height, BMI and TFEQ scores of both parents were determined in 2005.

\section{Measurements}

\section{Anthropometry}

At the mean age of 12 and 13 year, the children's BW was measured using a digital balance accurate to $0.1 \mathrm{~kg}$ (Sauter D7470, Ebingen, Germany) and height was measured using a wall-mounted stadiometer (Seca, model 220, Hamburg, Germany). Measurements were executed in underwear, after an overnight fast and after voiding the bladder. BMI was calculated by $\mathrm{BW} / \mathrm{height}^{2}\left(\mathrm{~kg} / \mathrm{m}^{2}\right)$ and BMI in childhood changes substantially with age. To define normal, overweight and obesity in children, we used the specific cut of points described by Cole et al. 2000 [2]. The waist circumference was measured at the site of the smallest circumference between the rib cage and the ileac crest, with the subjects in standing position. The pubertal stage (development of breast, genitalia, and pubic hair) was documented in all children, according to the classification by Tanner.

\section{Body composition}

Body composition was measured using the deuterium dilution technique $\left(\mathrm{D}_{2} \mathrm{O}\right) . \mathrm{D}_{2} \mathrm{O}$ dilution was used to measure total body 
water (TBW). Subjects were asked to collect a urine sample in the evening just before drinking the deuterium-enriched water solution. After ingestion of this solution, no further consumption was allowed. Ten hours after drinking the water solution, another urine sample was collected. The dilution of the deuterium isotope is a measure of the TBW of the subject. Deuterium was measured in the urine samples with an isotope ratio mass spectrometer (VG-Isogas Aqua Sira, VG Isogas, Middlewich, Cheshire, England). TBW was obtained by dividing the measured deuterium dilution space by 1.04. Fat free mass (FFM) was calculated by dividing TBW by the hydration factor 0.73 [25-27]. Fat mass (FM) was determined as BW-FFM.

\section{Leptin}

Serum leptin concentrations were measured with a double-antibody, sandwich-type enzyme-linked immunosorbent assay that used a monoclonal antibody specific for human leptin. The lower limit of detection is $\mathbf{0 . 5}$ $\mu \mathrm{g} / \mathrm{L}$ and the upper limit is $50 \mu \mathrm{g} / \mathrm{L}$. The intra- and inter assay CVs were $9 \%$ and $12 \%$, respectively. The leptin concentrations of normal-weight subjects range from 2 to $12 \mu \mathrm{g} / \mathrm{L}$. Serum leptin concentrations were also measured at age 7,12 and $13 y$.

\section{Attitude towards eating}

Eating behavior was analyzed using a validated Dutch translation of the TFEQ [15], which was translated at some questions into an easier, understandable Dutch language for children. The TFEQ consists of 3 factors measuring a person's attitude towards eating. Dietary restraint reflects the extent to which individuals attempt to cognitively control their food intake [15]. Inhibition of restraint reflects individual differences in the extent to which release from the cognitive suppression of eating occurs in response to the presence of palatable food or other disinhibiting stimuli, such as emotional distress [15]. The third factor refers to the subjective feeling of hunger [15].

\section{Physical activity}

Physical activity was estimated with the Baecke Questionnaire. This questionnaire consists of three components: work activity, sports activity and leisure activity [28] and has been validated using doubly labelled water $[18,29]$. For the children the work index was replaced by a school index with exactly the same questions.

\section{Determination of the genotypes}

The genomic DNAs of the 94 subjects were isolated from peripheral blood leukocytes using a QIAamp kit (Qiagen, Hilden, Germany). Followed by genotyping of the PPARY2, BCLI and CNTF polymorphisms, which has been previously described by Vogels 2006 et al [6].

\section{Parental characteristics}

Both the parents reported actual BW measured at home according to our standard instructions (as previously described). Height was copied from their passports, originally measured using a wall-mounted stadiometer. BMI was calculated by BW/height ${ }^{2}\left(\mathrm{~kg} / \mathrm{m}^{2}\right)$. In addition, attitude towards eating was measured with the TFEQ.

\section{Statistical analysis}

Student $t$-tests and ANOVA-tests (for the continuous variables), and chi-square tests (for the nominal variables) were executed to determine differences in single variables between groups (i.e. lean vs. overweight) and between polymorphisms. The ANOVA tests were followed by Scheffe's test or a Fishers PLSD test. All tests were two-sided and differences were considered significant at $\mathrm{P}<0.05$. Relationships between dependent and independent variables were tested using simple linear regression and multiple linear regression models. Values are expressed as mean \pm standard deviation (s.d.).

\section{Results}

In our cohort $11 \%$ of the children were overweight, which was determined using two measures, BMI and body fat 
percentage. BMI strongly related to body fat percentage $\left(R^{2}=0.60, p<0.001\right)$, and also leptin concentrations were related to body fat percentage $(\mathrm{R} 2=$ $0.825, \mathrm{p}<0.001)$, which has been shown previously $[6,30]$.

The characteristics of the boys $(n=55)$ and girls $(n=39)$, divided by overweight status at age 12 and $13 y$ are presented in table 1. At age 12 and $13 y$ overweight boys and girls showed significantly higher BW, BMI, waist circumference, body fat percentage, fat mass and leptin levels when compared to lean children. At age 12 and $13 y$ no significant differences were shown in height. At age 12y no significant difference was shown in fat free mass, however, at age 13y overweight boys showed a significant higher fat free mass compared to lean girls.

With respect to the genetic parameters i.e. analysis of the PPARy2, BclI and CNTF genotypes of the subjects, the overall genotype frequencies were in HardyWeinberg equilibrium. The genotype frequency distributions of the PPARy2, BclI and CNTF genes (table 2) at age 12 and $13 y$ were not significantly different for the overweight children compared to the lean children.

The behavioral characteristics (TFEQ and Baecke scores) of the boys and girls, divided by overweight status at age 12 and $13 y$ are presented in table 3. At age $12 y$ no differences were found in restraint score between the four groups, however, at age 13 lean boys showed significant lower restraint scores in comparison to other three groups. At age 12 and $13 y$ the disinhibition scores were significantly higher in overweight boys compared to the other three groups. Overall, no differences between groups were found for feeling of hunger scores and Baecke scores.

The characteristics of the parents of the lean and overweight children are presented in table 4. The fathers of overweight children have a higher BW, BMI and restraint score compared to the fathers of lean children. The mothers of the overweight children have a higher disinhibition score compared to the mothers of lean children.

A simple linear regression was used to test the association between BMI and restraint or disinhibition scores of the children, fathers or mothers. A significant correlation was found between the restraint score and the BMI of the children $\left(R^{2}=0.131, p<0.0001\right)$. Also, significant associations were found in the fathers and mothers between the disinhibition score and their BMI $\left(R^{2}=0.252, p<0.001\right)\left(R^{2}\right.$ $=0.168, p<0.001)$. No correlations were found between the TFEQ scores of the parents and the BMI of the children.

Table 1: characteristics of the boys $(n=55)$ and girls $(n=39)$, divided by overweight status at age 12 and $13 y$

\begin{tabular}{|c|c|c|c|c|c|c|}
\hline 12 year & Total $(n=94)$ & Lean girls $(n=33)$ & Overweight girls $(n=6)$ & Lean boys $(n=51)$ & Overweight boys $(n=4)$ & P-value ${ }^{2}$ \\
\hline$\overline{\mathrm{BW}}(\mathrm{kg})^{3}$ & $48.4 \pm 10.3$ & $47.3 \pm 8.2^{\mathrm{ab}}$ & $61.4 \pm 11.2^{\mathrm{ac}}$ & $46.6 \pm 10.1^{\text {cd }}$ & $60.7 \pm 6.4^{\text {bd }}$ & 0.01 \\
\hline Height $(\mathrm{cm})$ & $159.2 \pm 10.2$ & $158.7 \pm 9.7$ & $160.7 \pm 10.3$ & $159.2 \pm 10.6$ & $161.6 \pm 12.5$ & 0.94 \\
\hline $\operatorname{BMI}\left(\mathrm{kg} / \mathrm{m}^{2}\right)^{3}$ & $18.9 \pm 2.6$ & $18.6 \pm 1.8^{a}$ & $23.7 \pm 2.7^{a b}$ & $18.3 \pm 2.2^{b}$ & $23.3 \pm 2.1^{b}$ & 0.01 \\
\hline Body fat $(\%)$ & $19.6 \pm 7.6$ & $21.7 \pm 5.2^{\mathrm{ab}}$ & $29.7 \pm 6.1^{\text {ac }}$ & $16.6 \pm 6.6^{\mathrm{cd}}$ & $29.1 \pm 10.5^{\text {bd }}$ & 0.01 \\
\hline Fat mass $(\mathrm{kg})$ & $9.69 \pm 4.9$ & $10.5 \pm 3.4^{\mathrm{ab}}$ & $18.1 \pm 5.3^{\mathrm{ab}}$ & $7.8 \pm 3.9^{a}$ & $17.4 \pm 5.8^{b}$ & 0.01 \\
\hline Fat free mass $(\mathrm{kg})$ & $38.4 \pm 7.7$ & $37.4 \pm 6.3$ & $43.1 \pm 8.1$ & $38.5 \pm 8.0$ & $43.3 \pm 9.4$ & 0.26 \\
\hline$\overline{B W}(\mathrm{~kg})^{3}$ & $53.1 \pm 10.6$ & $50.9 \pm 8.3^{\mathrm{ab}}$ & $66.1 \pm 9.8^{\text {ac }}$ & $51.8 \pm 10^{\text {cd }}$ & $69.0 \pm 8.7^{a b}$ & 0.01 \\
\hline Height $(\mathrm{cm})$ & $164.9 \pm 10.1$ & $163.1 \pm 8.6$ & $163.7 \pm 8.4$ & $165.8 \pm 10.9$ & $168.9 \pm 14.4$ & 0.54 \\
\hline BMI $\left(\mathrm{kg} / \mathrm{m}^{2}\right)^{3}$ & $19.5 \pm 2.9$ & $19.0 \pm 1.9^{a}$ & $26.2 \pm 2.8^{a b}$ & $18.7 \pm 2.1^{b}$ & $24.1 \pm 0.9^{b}$ & 0.01 \\
\hline Waist $(\mathrm{cm})$ & $68.0 \pm 6.2$ & $65.6 \pm 5^{a b}$ & $76.2 \pm 5.8^{a c}$ & $67.6 \pm 5.2^{\mathrm{cd}}$ & $80.7 \pm 2.9^{\text {bd }}$ & 0.01 \\
\hline Body fat (\%) & $19.8 \pm 7.5$ & $21.8 \pm 4.4^{\mathrm{ab}}$ & $31.3 \pm 6.9$ ac & $15.9 \pm 5.9^{\mathrm{cd}}$ & $27.9 \pm 10^{\text {bd }}$ & 0.01 \\
\hline
\end{tabular}

${ }_{1}$ Overweight as defined by age and sex specific cut off points described by Cole et al.

2 Differences between lean vs. overweight boys and girls using ANOVA

${ }^{3}$ BW, body weight; BMI, body mass index

a $p<0.05$ (2-factor ANOVA with group $x$ group interaction); ${ }^{b} p<0.05$ (2-factor ANOVA with group $x$ group interaction)

${ }^{c} \mathrm{p}<0.05$ (2-factor ANOVA with group $x$ group interaction); ${ }^{d} p<0.05$ (2-factor ANOVA with group $x$ group interaction) 
Table 2: genotype frequency distributions of the PPARy2, GRL and CNTF genes in lean and overweight ${ }^{1}$ children at age 12 and $13 y$

\begin{tabular}{lllll}
\hline 12 and 13 year & Total $(n=92)$ & Lean $(n=84)$ & Overweight $(n=10)$ & P-value $^{2}$ \\
\hline PPARy2 $^{3}(\mathrm{PP} / \mathrm{PA} / \mathrm{AA})$ & $75 / 24 / 1 \%$ & $77 / 22 / 1 \%$ & $60 / 40 / 0 \%$ & 0.43 \\
GRL $^{3}(\mathrm{CC} / \mathrm{CG} / \mathrm{GG})$ & $49 / 36 / 15 \%$ & $47 / 37 / 16 \%$ & $10 / 30 / 60 \%$ & 0.74 \\
CNTF $^{3}$ (GG/GA/AA) & $78 / 19 / 2 \%$ & $79 / 18 / 2 \%$ & $70 / 30 / 0 \%$ & 0.96 \\
\hline
\end{tabular}

${ }^{1}$ Overweight as defined by age and sex specific cut off points described by Cole et al.

2 Differences between lean vs. overweight children using chi-square test

${ }_{3}$ PPAR 2 , peroxisome proliferator-activated receptor $\gamma 2$; GRL, glucocorticoid receptor; CNTF, ciliary neurotrophic factor

Table 3: behavioral characteristics of the boys and girls, divided overweight status ${ }^{1}$ at age 12 and $13 y$

\begin{tabular}{|c|c|c|c|c|c|c|}
\hline 12 year & $\begin{array}{l}\text { Total } \\
(\mathrm{n}=94)\end{array}$ & $\begin{array}{l}\text { Lean girls } \\
(n=33)\end{array}$ & $\begin{array}{l}\text { Overweight girls } \\
(n=6)\end{array}$ & $\begin{array}{l}\text { Lean boys } \\
(n=51)\end{array}$ & $\begin{array}{l}\text { Overweight boys } \\
(n=4)\end{array}$ & P-value ${ }^{2}$ \\
\hline Factor 1 (TFEQ) ${ }^{3}$ & $5.1 \pm 3.5$ & $4.8 \pm 3.5$ & $7.2 \pm 3.1$ & $4.9 \pm 3.2$ & $7.5 \pm 5.9$ & 0.22 \\
\hline Factor 2 (TFEQ) ${ }^{3}$ & $2.7 \pm 1.3$ & $2.6 \pm 1.4^{\mathrm{a}}$ & $3.3 \pm 1.5$ & $2.6 \pm 1.1^{b}$ & $4.3 \pm 0.9^{\mathrm{ab}}$ & 0.04 \\
\hline Factor 3 (TFEQ) ${ }^{3}$ & $3.0 \pm 2.4$ & $2.7 \pm 2.5$ & $3.0 \pm 3.3$ & $5.3 \pm 3.8$ & $5.3 \pm 3.8$ & 0.23 \\
\hline Physical activity (Baecke) & $8.2 \pm 1.0$ & $8.3 \pm 0.8$ & $7.6 \pm 1.1$ & $8.3 \pm 0.9$ & $8.2 \pm 2.2$ & 0.38 \\
\hline \multicolumn{7}{|l|}{13 Year } \\
\hline Factor 1 (TFEQ) ${ }^{3}$ & $5.7 \pm 3.2$ & $6.7 \pm 3.1^{\mathrm{a}}$ & $8.3 \pm 4.1^{b}$ & $4.7 \pm 2.6^{\mathrm{bcd}}$ & $9.5 \pm 4.2^{c}$ & 0.01 \\
\hline Factor 2 (TFEQ) $^{3}$ & $2.4 \pm 1.4$ & $2.5 \pm 1.5^{\mathrm{a}}$ & $2.7 \pm 1.3^{b}$ & $2.2 \pm 1.0^{c}$ & $5.0 \pm 2.7^{\mathrm{abc}}$ & 0.01 \\
\hline Factor 3 (TFEQ) ${ }^{3}$ & $3.1 \pm 2.3$ & $2.8 \pm 2.1$ & $2.5 \pm 0.8$ & $3.5 \pm 2.2$ & $4.5 \pm 5.8$ & 0.35 \\
\hline Physical activity (Baecke) & $7.9 \pm 0.8$ & $8.1 \pm 0.9$ & $7.9 \pm 0.5$ & $7.9 \pm 0.8$ & $8.1 \pm 0.9$ & 0.96 \\
\hline
\end{tabular}

${ }_{1}^{1}$ Overweight as defined by age and sex specific cut off points described by Cole et al.

2 Differences between lean vs. overweight children using ANOVA

${ }^{3}$ TFEQ, three-factor eating questionnaire; Factor 1, dietary restraint eating behavior; Factor 2, inhibition of restraint;

Factor 3 , general feelings of hunger

a $\mathrm{p}<0.05$ (2-factor ANOVA with group $\times$ group interaction); ${ }^{\mathrm{b}} \mathrm{p}<0.05$ (2-factor ANOVA with group $\times$ group interaction)

${ }^{c} p<0.05$ (2-factor ANOVA with group $\times$ group interaction); ${ }^{d} p<0.05$ (2-factor ANOVA with group $x$ group interaction)

Table 4: Parental characteristics of lean and overweight children

\begin{tabular}{|c|c|c|c|c|c|c|}
\hline & \multicolumn{2}{|l|}{ All children } & \multicolumn{2}{|c|}{ Lean children } & \multicolumn{2}{|c|}{ Overweight children } \\
\hline & Father & Mother & Father & Mother & Father & Mother \\
\hline$\overline{\mathrm{BW}(\mathrm{kg})^{2}}$ & $84.9 \pm 15.8$ & $69.3 \pm 13.8$ & $83.7 \pm 13.5$ & $69.2 \pm 14.2$ & $94.5 \pm 27.7^{1}$ & $69.9 \pm 10.7$ \\
\hline Height $(\mathrm{cm})$ & $179.9 \pm 6.8$ & $166.9 \pm 5.9$ & $180.0 \pm 6.9$ & $166.9 \pm 5.9$ & $179.9 \pm 6.3$ & $167.3 \pm 5.9$ \\
\hline BMI $\left(\mathrm{kg} / \mathrm{m}^{2}\right)^{2}$ & $26.1 \pm 4.4$ & $24.4 \pm 3.9$ & $25.7 \pm 3.6$ & $24.4 \pm 4.0$ & $29.1 \pm 8.3^{1}$ & $25.0 \pm 3.7$ \\
\hline Factor 1 (TFEQ) $)^{2}$ & $4.8 \pm 3.2$ & $7.3 \pm 3.7$ & $4.6 \pm 3.1$ & $7.4 \pm 3.8$ & $5.8 \pm 3.7^{1}$ & $6.4 \pm 2.9$ \\
\hline Factor 2 (TFEQ) ${ }^{2}$ & $2.7 \pm 1.5$ & $3.4 \pm 2.2$ & $2.8 \pm 1.6$ & $3.4 \pm 2.1$ & $2.3 \pm 0.8$ & $3.5 \pm 2.8^{1}$ \\
\hline Factor 3 (TFEQ) ${ }^{2}$ & $2.5 \pm 2.4$ & $2.6 \pm 2.2$ & $2.6 \pm 2.5$ & $2.6 \pm 2.0$ & $2.3 \pm 1.8$ & $2.4 \pm 3.5$ \\
\hline
\end{tabular}

${ }^{1}$ Significant differences in characteristic between the father/mother of overweight children, compared to the father/mother of lean children $(p<0.05)$

2 BW, body weight; BMI, body mass index; TFEQ, three-factor eating questionnaire; Factor 1, dietary restraint eating

behavior; Factor 2, inhibition of restraint; Factor 3, general feelings of hunger

Table 5: Multiple linear regression analyses with body weight $(\mathrm{kg})$ as the dependent variable at age 12 and $13 y(n=94)$

\begin{tabular}{|c|c|c|c|}
\hline 12 year & Partial $\beta$ & Std. Error & P-value \\
\hline$\overline{\text { (Constant) }}$ & 39.534 & 6.376 & 0.0001 \\
\hline Leptin concentrations $(\mu \mathrm{l} / \mathrm{L})$ & 0.450 & 0.170 & 0.0098 \\
\hline Factor 1 child (TFEQ) ${ }^{1}$ & 0.282 & 0.325 & 0.3883 \\
\hline Factor 2 child (TFEQ) ${ }^{1}$ & 1.142 & 0.800 & 0.1574 \\
\hline BMI father $\left(\mathrm{kg} / \mathrm{m}^{2}\right)^{1}$ & -0.036 & 0.239 & 0.8790 \\
\hline Factor 2 mother (TFEQ) ${ }^{1}$ & 0.692 & 0.460 & 0.1363 \\
\hline \multicolumn{4}{|l|}{13 Year } \\
\hline (Constant) & 43.559 & 6.687 & 0.0001 \\
\hline Leptin concentrations $(\mu \mathrm{l} / \mathrm{L})$ & 0.514 & 0.226 & 0.0253 \\
\hline Factor 1 child (TFEQ) ${ }^{1}$ & -0.132 & 0.381 & 0.7305 \\
\hline Factor 2 child (TFEQ) ${ }^{1}$ & 1.811 & 0.767 & 0.0206 \\
\hline BMI father $\left(\mathrm{kg} / \mathrm{m}^{2}\right)^{1}$ & 0.027 & 0.249 & 0.9147 \\
\hline Factor 2 mother (TFEQ) ${ }^{1}$ & 0.748 & 0.472 & 0.1165 \\
\hline
\end{tabular}

${ }_{1}^{1}$ TFEQ, three-factor eating questionnaire; Factor 1, dietary restraint eating behavior; Factor 2, inhibition of restraint; $\mathrm{BMI}$, body mass index. Model 12 year, $\mathrm{R}^{2}=0.187$; Model 13 year, $\mathrm{R}^{2}=0.181$ 
The mean leptin concentrations $(\mu \mathrm{l} / \mathrm{L})$ of the boys and girls, divided by overweight status at age 7,12 and $13 y$ are presented in figure 1.

Figure 1: Mean of plasma leptin concentrations of the boys $(n=55)$ and girls $(n=39)$, divided by overweight stage at age 7,12 and $13 y$.

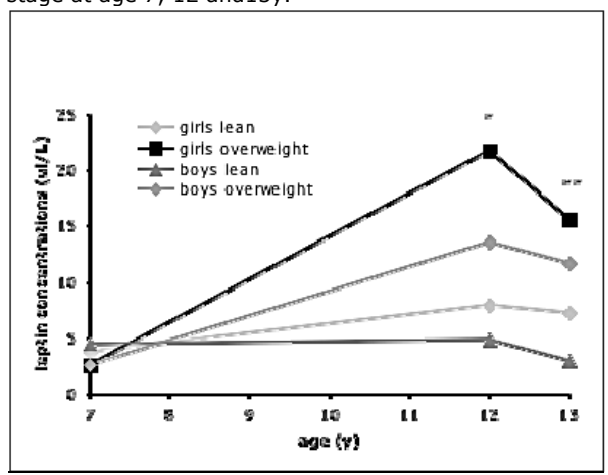

* overall group $x$ group interaction at age 12 , was significant $(p<0.05)$

$* *$ overall group $\times$ group interaction at age 13 , was significant $(p<0.05)$

At age 7 no significant differences in leptin levels were shown between the four groups. At age 12 and $13 y$ leptin levels were significantly different between all four groups ( $p<0.001)$, except between the overweight boys and girls at age 13 . The increase in leptin concentrations between 7 to $12 y$ was significant in lean girls $(4.3 \pm 3.9 \mu \mathrm{l} / \mathrm{L})$, overweight girls $(19.2 \pm 8.6 \mu \mathrm{l} / \mathrm{L})$, overweight boys (10.9 \pm $6.2 \mu \mathrm{l} / L)(p<0.001)$, except in the lean boys $(0.5 \pm 6.4 \mu \mathrm{l} / \mathrm{L})$. The decrease in leptin concentrations from 12 to $13 y$ was significant in the lean boys $(-2.1 \pm 3.3$ $\mu \mathrm{l} / \mathrm{L})(\mathrm{p}<0.01)$, but not in lean girls $(-$ $0.6 \pm 2.9 \mu \mathrm{l} / \mathrm{L})$, overweight girls $(-6.3 \pm 6.1$ $\mu \mathrm{l} / \mathrm{L})$ and overweight boys $(-1.8 \pm 3.6$ $\mu \mathrm{l} / \mathrm{L})$. The differences between the increase from 7 to $12 y$ and the decrease from 12 to $13 y$ were significant $(p<0.01)$ in all four groups, suggesting a peak value of leptin at $12 y$ in boys and girls.

A simple linear regression was used to test the association between the leptin concentrations $(\mu \mathrm{l} / \mathrm{L})$ and fat mass $(\mathrm{kg})$ at age 12 and $13 y$ for lean overweight boys and girls. Leptin was associated to fat mass at age 12 and $13 y$ in lean boys $\left(R^{2}\right.$ $=0.36, p<0.01$ and $R^{2}=0.35, p<$ $0.01)$ and in lean girls $\left(R^{2}=0.31, p<\right.$
0.01 and $\left.R^{2}=0.35, p<0.01\right)$. No associations were found in overweight boys and girls.

The multiple linear regression analyses at age 12 and $13 y$ with body weight $(\mathrm{kg})$ as the dependent variable and the behavioral, parental and physiological factors that were related to body weight (leptin concentrations, dietary restraint score of the child, disinhibition score of the child, BMI of the father and disinhibition score of the mother) as the independent variables are presented in table 5. From the model at age $12 y$, we concluded that the five variables together predicted $18,7 \%$ of the variance in body weight at age $12 y$, however only the leptin concentrations $(p<0.009)$ at age $12 y$ contributed significantly to the model. From the model at age $13 y$, we concluded that the five variables together predicted $18,1 \%$ of the variance in body weight at age $13 y$, however only the leptin concentrations $(p<0.03)$ and disinhibition score $(p<0.02)$ at age $13 y$ contributed significantly to the model.

\section{Discussion}

The objective of our study was to investigate whether genetic, behavioral, parental and physiological factors are involved and the extent of involvement in the development of body weight at age 12 and $13 y$ in a Dutch children cohort. We showed that in our cohort, $11 \%$ of the children were overweight. In 2006, the overall prevalence of childhood obesity in the Netherlands was $14.3 \%$, which is the still the lowest in Europe. Like in adults [8], overweight in the children coincided with higher BW, waist circumference, $\mathrm{BF} \%$, fat mass and leptin levels.

With respect to the genetic influences on the development of body weight, previous studies showed in adults an association between body weight and the genetic polymorphisms PPARY2, BCLI and CNTF $[7,9,10]$, however the genotype frequency distributions of the genes at age 12 and $13 y$ were not significantly different for the overweight children compared to the lean children. Possible 
reasons why we did not observe such associations could be the rather small sample size of the cohort, the small percentage of overweight in this cohort, or age-dependent expression of genotype.

With respect to the behavioral factors involved in the development of body weight, previous studies showed that adults with high levels of both restraint and disinhibition are often overweight, since they are 'unsuccessfully dietary restraint', which beholds that their high restraint scores do not help them to control their weight [31]. In our cohort overweight boys and girls showed higher dietary restraint and disinhibition scores, which suggest they are also 'unsuccessfully dietary restraint'. Consequently, since overweight leads to dietary restraint, subsequent disinhibition of restraint leads to overeating, which leads to storing of excessive energy and thereby results in a vicious circle in which the children are caught that will lead to further increases in body weight. Lean girls showed an increase in dietary restraint scores between 12 and 13y, but since they have a normal weight, this might indicate that they are 'successfully dietary restraint, which beholds that their high restraint scores help them to control their weight $[6,31]$. No differences were found however, between lean and overweight boys and girls in physical activity measured by the Baecke questionnaire. We have shown previously in a study by Vogels 2007 et al. that this was caused by overestimation of activity by overweight children [18], when daily physical activity measured by tri-axial accelerometers was compared to estimation of physical activity measured by the Baecke questionnaire.

With respect to the parental influences on the development of body weight, previous studies showed that children of overweight parents are more likely to be overweight themselves $[6,19]$. In the current study the fathers of overweight children showed higher body weight, BMI and dietary restraint score; having an overweight and restraint father in the current cohort of children is therefore an important predictor for children to become overweight. In accordance to previous findings $[6,32]$ the mothers of overweight children showed a higher disinhibition score. The overall high restraint scores of the mothers and the association between the mother's dietary restraint score and the BMI of the child may be a possible explanation for the fact that we found no association between BMI of the mother and the weight status of the child [6]. In general, one could state that the eating behavior of the parents may serve as a source of information for children what cues should trigger eating and how much to eat [32].

With respect to the physiological influences on the development of body weight, literature showed these are more pronounced during puberty. The hormone leptin is thought to be involved in the start of the changes in the endocrine milieu during puberty. Several transversal studies showed [22,33-37] a rise in leptin levels progressively from 5 to $15 y$ in girls, whereas in boys, levels increased between 5 and $10 y$ and declined thereafter. In the current longitudinal study we described the leptin levels at age 7, 12 and 13y, and showed an increase in leptin levels between 7 and $12 y$ and a decrease, although only significant for the lean boys between 12 and 13y. Further analysis suggested a peak value of leptin at $12 y$ in all children, which has been suggested to be a physiological trigger to the start of the increase in LH and FSH production; the first recognizable hormonal changes of puberty [38].

In the current longitudinal study we also showed that the positive association between leptin concentrations and fat mass did not change in the lean boys between age 12 and $13 y$, but became stronger in the lean girls. No significant relationship between leptin concentrations and fat mass at age 12 and $13 y$ was found in the overweight boys and girls, because the small percentage of overweight children in this cohort. Several explanations have been suggested for the 
divergent correlations between leptin concentrations and fat mass in lean boys and girls during pubertal development. One explanation is the difference in body fat distribution, since in adipocytes taken from subcutaneous abdominal fat produce greater leptin concentrations compared to adipocytes taken from visceral fat.

Therefore, increased serum concentrations of leptin in pubertal girls may be due to greater amounts of subcutaneous fat [39]. A second explanation is the rise in androgens levels in boys at the start of puberty. In vitro, when androgens are added to a culture medium of adipocytes, the leptin secretions are reduced by $62 \%$, which suggests that in androgens suppresses leptin concentrations in boys during puberty [34]. A third explanation is that in boys the ratio of fat free mass/fat mass changes and becomes higher during puberty, when compared to girls [40], which is also shown in our cohort.

With respect to the genetic, parental, behavioral and physiological factors only the last three factors seemed to have an effect on the development of body weight at age 12 and $13 y$. To determine whether these factors were predictors for body weight, we performed multiple linear regression analyses at age 12 and $13 y$ with body weight as the dependent variable and the behavioral, parental and physiological factors that were related to body weight (leptin concentrations, dietary restraint score of the child, disinhibition score of the child, BMI of the father and disinhibition score of the mother) as the independent variables.
From the model at age $12 y$, we concluded that only the leptin concentrations at age $12 y$ contributed significantly to the model and from the model at age $13 y$, that only the leptin concentrations and disinhibition scores of the child at age $13 y$ contributed significantly to the model. These results imply that at the age of $12 y$ predominantly the physiological factors were predictors for body weight, and at the age of $13 y$ both the physiological and behavioral factors were predictors for body weight.

The strengths of the present study is that we found associations between several factors and childhood overweight in this relativity small cohort and the accurate measurement method to determine body composition. We conclude from this longitudinal study, that leptin appeared to play an important role in the development of body weight during puberty, in addition to behavioral and parental factors.

\section{Acknowledgements}

We want to thank our subjects for their participation in our cohort study. We gratefully thank Loek Wouters and Wendy Sluijsmans for their assistance. FR and NV carried out the study, collected and analyzed the data, and wrote the largest part of the manuscript. FB (supervised by EM) contributed to the practical work. MW and AN supervised FR. Planning, processing the results and writing the manuscript were done under general supervision by MW. The authors had no conflict of interest. 


\section{Literature}

1. Reilly, J.J., Obesity in childhood and adolescence: evidence based clinical and public health perspectives. Postgrad Med J, 2006. 82(969): p. 429-37.

2. Cole, T.J., M.C. Bellizzi, K.M. Flegal, and W.H. Dietz, Establishing a standard definition for child overweight and obesity worldwide: international survey. Bmj, 2000. 320(7244): p. 1240-3.

3. Mossberg, H.O., 40-year follow-up of overweight children. Lancet, 1989. 2(8661): p. 491-3.

4. Magarey, A.M., L.A. Daniels, T.J. Boulton, and R.A. Cockington, Predicting obesity in early adulthood from childhood and parental obesity. Int J Obes Relat Metab Disord, 2003. 27(4): p. 505-13.

5. Ong, K.K., M.L. Ahmed, P.M. Emmett, M.A. Preece, and D.B. Dunger, Association between postnatal catch-up growth and obesity in childhood: prospective cohort study. Bmj, 2000. 320(7240): p. 967-71.

6. Vogels, N., D.L. Posthumus, E.C. Mariman, F. Bouwman, A.D. Kester, P. Rump, et al., Determinants of overweight in a cohort of Dutch children. Am J Clin Nutr, 2006. 84(4): p. 717-24.

7. Rosmond, R., M. Chagnon, and C. Bouchard, The Pro12Ala PPARgamma2 gene missense mutation is associated with obesity and insulin resistance in Swedish middle-aged men. Diabetes Metab Res Rev, 2003. 19(2): p. $159-63$.

8. Vogels, N., E.C. Mariman, F.G. Bouwman, A.D. Kester, K. Diepvens, and M.S. Westerterp-Plantenga, Relation of weight maintenance and dietary restraint to peroxisome proliferator-activated receptor gamma2, glucocorticoid receptor, and ciliary neurotrophic factor polymorphisms. Am J Clin Nutr, 2005. 82(4): p. 740-6.

9. Nicklas, B.J., E.F. van Rossum, D.M. Berman, A.S. Ryan, K.E. Dennis, and A.R. Shuldiner, Genetic variation in the peroxisome proliferator-activated receptor-gamma2 gene (Pro12Ala) affects metabolic responses to weight loss and subsequent weight regain. Diabetes, 2001. 50(9): p. 2172-6.

10. Cecil, J.E., B. Fischer, A.S. Doney, M. Hetherington, P. Watt, W. Wrieden, et al., The Pro12Ala and C-681G variants of the PPARG locus are associated with opposing growth phenotypes in young schoolchildren. Diabetologia, 2005. 48(8): p. 1496-502.

11. Rosmond, R., Y.C. Chagnon, G. Holm, M. Chagnon, L. Perusse, K. Lindell, et al., A glucocorticoid receptor gene marker is associated with abdominal obesity, leptin, and dysregulation of the hypothalamic-pituitary-adrenal axis. Obes Res, 2000. 8(3): p. 211-8.

12. Ukkola, O., L. Perusse, Y.C. Chagnon, J.P. Despres, and C. Bouchard, Interactions among the glucocorticoid receptor, lipoprotein lipase and adrenergic receptor genes and abdominal fat in the Quebec Family Study. Int J Obes Relat Metab Disord, 2001. 25(9): p. 1332-9.

13. Tremblay, A., L. Bouchard, C. Bouchard, J.P. Despres, V. Drapeau, and L. Perusse, Long-term adiposity changes are related to a glucocorticoid receptor polymorphism in young females. J Clin Endocrinol Metab, 2003. 88(7): p. 3141-5.

14. O'Dell, S.D., H.E. Syddall, A.A. Sayer, C. Cooper, C.H. Fall, E.M. Dennison, et al., Null mutation in human ciliary neurotrophic factor gene confers higher body mass index in males. Eur J Hum Genet, 2002. 10(11): p. 749-52.

15. Stunkard, A.J. and S. Messick, The three-factor eating questionnaire to measure dietary restraint, disinhibition and hunger. J Psychosom Res, 1985. 29(1): p. 71-83.

16. Bellisle, F. and A.M. Dalix, Cognitive restraint can be offset by distraction, leading to increased meal intake in women. Am J Clin Nutr, 2001. 74(2): p. 197-200.

17. Brownson, R.C., T.K. Boehmer, and D.A. Luke, Declining rates of physical activity in the United States: what are the contributors? Annu Rev Public Health, 2005. 26: p. 421-43.

18. Vogels, N., K.R. Westerterp, D.L. Posthumus, F. Rutters, and M.S. Westerterp-Plantenga, Daily physical activity counts vs structured activity counts in lean and overweight Dutch children. Physiol Behav, 2007. 92(4): p. 611-6.

19. Parsons, T.J., C. Power, S. Logan, and C.D. Summerbell, Childhood predictors of adult obesity: a systematic review. Int J Obes Relat Metab Disord, 1999. 23 Suppl 8: p. S1-107.

20. Birch, L.L. and J.O. Fisher, Mothers' child-feeding practices influence daughters' eating and weight. Am J Clin Nutr, 2000. 71(5): p. 1054-61.

21. Mann, D.R., A.O. Johnson, T. Gimpel, and V.D. Castracane, Changes in circulating leptin, leptin receptor, and gonadal hormones from infancy until advanced age in humans. J Clin Endocrinol Metab, 2003. 88(7): p. 3339-45.

22. Ahmed, M.L., K.K. Ong, D.J. Morrell, L. Cox, N. Drayer, L. Perry, et al., Longitudinal study of leptin concentrations during puberty: sex differences and relationship to changes in body composition. J Clin Endocrinol Metab, 1999. 84(3): p. 899-905.

23. Rump, P., R.P. Mensink, A.D. Kester, and G. Hornstra, Essential fatty acid composition of plasma phospholipids and birth weight: a study in term neonates. Am J Clin Nutr, 2001. 73(4): p. 797-806.

24. Rump, P., C. Popp-Snijders, R.J. Heine, and G. Hornstra, Components of the insulin resistance syndrome in sevenyear-old children: relations with birth weight and the polyunsaturated fatty acid content of umbilical cord plasma phospholipids. Diabetologia, 2002. 45(3): p. 349-55.

25. van Marken Lichtenbelt, W.D., K.R. Westerterp, and L. Wouters, Deuterium dilution as a method for determining total body water: effect of test protocol and sampling time. Br J Nutr, 1994. 72(4): p. 491-7.

26. Schoeller, D.A., E. van Santen, D.W. Peterson, W. Dietz, J. Jaspan, and P.D. Klein, Total body water measurement in humans with 180 and 2H labeled water. Am J Clin Nutr, 1980. 33(12): p. 2686-93.

27. Westerterp, K.R., L. Wouters, and W.D. van Marken Lichtenbelt, The Maastricht protocol for the measurement of body composition and energy expenditure with labeled water. Obes Res, 1995. 3 Suppl 1: p. 49-57.

28. Baecke, J.A., J. Burema, and J.E. Frijters, A short questionnaire for the measurement of habitual physical activity in epidemiological studies. Am J Clin Nutr, 1982. 36(5): p. 936-42.

29. Philippaerts, R.M., K.R. Westerterp, and J. Lefevre, Doubly labelled water validation of three physical activity questionnaires. Int J Sports Med, 1999. 20(5): p. 284-9.

30. Filozof, C.M., C. Murua, M.P. Sanchez, C. Brailovsky, M. Perman, C.D. Gonzalez, et al., Low plasma leptin concentration and low rates of fat oxidation in weight-stable post-obese subjects. Obes Res, 2000. 8(3): p. 20510.

31. Yeomans, M.R., H.M. Tovey, E.M. Tinley, and C.J. Haynes, Effects of manipulated palatability on appetite depend on restraint and disinhibition scores from the Three-Factor Eating Questionnaire. Int J Obes Relat Metab Disord, 2004. 28(1): p. 144-51.

32. Cutting, T.M., J.O. Fisher, K. Grimm-Thomas, and L.L. Birch, Like mother, like daughter: familial patterns of overweight are mediated by mothers' dietary disinhibition. Am J Clin Nutr, 1999. 69(4): p. 608-13. 
33. Ahmed, M.L., K.K. Ong, A.P. Watts, D.J. Morrell, M.A. Preece, and D.B. Dunger, Elevated leptin levels are associated with excess gains in fat mass in girls, but not boys, with type 1 diabetes: longitudinal study during adolescence. J Clin Endocrinol Metab, 2001. 86(3): p. 1188-93.

34. Blum, W.F., P. Englaro, S. Hanitsch, A. Juul, N.T. Hertel, J. Muller, et al., Plasma leptin levels in healthy children and adolescents: dependence on body mass index, body fat mass, gender, pubertal stage, and testosterone. J Clin Endocrinol Metab, 1997. 82(9): p. 2904-10.

35. Roemmich, J.N., P.A. Clark, S.S. Berr, V. Mai, C.S. Mantzoros, J.S. Flier, et al., Gender differences in leptin levels during puberty are related to the subcutaneous fat depot and sex steroids. Am J Physiol, 1998. 275(3 Pt 1): p. E543-51.

36. Roemmich, J.N., P.A. Clark, K. Walter, J. Patrie, A. Weltman, and A.D. Rogol, Pubertal alterations in growth and body composition. V. Energy expenditure, adiposity, and fat distribution. Am J Physiol Endocrinol Metab, 2000. 279(6): p. E1426-36.

37. Roemmich, J.N. and A.D. Rogol, Hormonal changes during puberty and their relationship to fat distribution. Am J Human Biol, 1999. 11(2): p. 209-224.

38. Mantzoros, C.S., J.S. Flier, and A.D. Rogol, A longitudinal assessment of hormonal and physical alterations during normal puberty in boys. V. Rising leptin levels may signal the onset of puberty. J Clin Endocrinol Metab, 1997. 82(4): p. $1066-70$

39. Garnett, S.P., W. Hogler, B. Blades, L.A. Baur, J. Peat, J. Lee, et al., Relation between hormones and body composition, including bone, in prepubertal children. Am J Clin Nutr, 2004. 80(4): p. 966-72.

40. Rico, H., M. Revilla, L.F. Villa, E.R. Hernandez, M. Alvarez de Buergo, and M. Villa, Body composition in children and Tanner's stages: a study with dual-energy x-ray absorptiometry. Metabolism, 1993. 42(8): p. 967-70. 


\section{Chapter 4}

Sleep duration and body-weight development during puberty in a Dutch children cohort

F. Rutters, A.G. Nieuwenhuizen, S.P.M. Verhoef, M.S. Westerterp-Plantenga

Submitted 


\begin{abstract}
Background: Short sleep duration is associated with obesity during childhood and adulthood.

Objective: the objective of our study was to investigate the relationship between sleep duration and body mass index (BMI) from Tanner stage 1 to 5 in a Dutch children cohort. Design: we determined in 96 children, sleep duration, anthropometric measurements, body composition, physical activity (Baecke questionnaire), and leptin concentrations, from age 7 to $16 y$.

Results: at Tanner stage 1, 2, 3, 4 and 5 sex differences were observed in height, body weight, waist circumference, fat mass per squared meter (FMI), and leptin concentrations per $\mathrm{kg}$ fat mass. From Tanner stage 1 to 5 an increase was observed in both boys and girls in height $(0.25 \pm 0.15$ and $0.25 \pm 0.15 \mathrm{~m})$, body weight $(24 \pm 12.5$ and $26.4 \pm 12.5 \mathrm{~kg})$, BMI $\left(3.5 \pm 2.7\right.$ and $\left.4.9 \pm 3.1 \mathrm{~kg} / \mathrm{m}^{2}\right)$, waist circumference $(7.6 \pm 11.5$ and $11.6 \pm 7.7 \mathrm{~cm})$, as well as an increase over time in FMI $\left(1.8 \pm 2.3 \mathrm{~kg} / \mathrm{m}^{2}\right)$ in girls. A decrease was observed in boys and girls in hours sleep per night $(-1.2 \pm 0.4$ and $-1.4 \pm 0.5 \mathrm{~h})$ and leptin concentrations per $\mathrm{kg}$ fat mass $(-0.33 \pm 0.15$ and $-0.17 \pm 0.2 \mathrm{ng} / \mathrm{ml} / \mathrm{kg})$. Inverse relationships were observed between the change in BMI $\left(\mathrm{kg} / \mathrm{m}^{2}\right)$ and the change in hours of sleep per night ( $h$ ) from Tanner stage 1 to $4(r=0.68, p<0.001)$, from Tanner stage 2 to $5(r=0.35, p<0.05)$, and from Tanner stage 1 to $5(r=0.33, p<0.05)$.
\end{abstract}

Conclusion: Development of BMI during puberty is inversely related to change in sleep duration. 


\section{Introduction}

The prevalence of childhood obesity is emerging as a major health problem (1). The increase in childhood obesity has developed over the same time period as the progressive decrease in self-reported sleep duration $(2,3)$. Several crosssectional studies reported on a negative relationship between sleep duration and body mass index (BMI) during childhood (4-9), while some even reported a curvilinear relationship between sleep duration and BMI $(10,11)$. Additionally, short sleep duration in children was linked to insulin resistance, a larger body fat percentage, a larger waist circumference, decreased physical activity and increased television watching (12-16).

Sleep duration during childhood is however subjected to developmental changes, in particular during puberty when a significant decrease in sleep duration has been observed $(17,18)$. Until now only 4 studies have been described that study sleep duration and BMI development longitudinally $(1,19-21)$, which measured either only children from age 3 to $9 y(1,20,21)$, or measured a group of 3 to 12 year old children twice with a 5-year interval not taking pubertal stage into account (19). Pubertal stage may however alter the relationship between sleep duration and BMI as well as other determinants of overweight in children, such as body composition, and waist circumference (22). This however has not been investigated until now. Consequently, the objective of our longitudinal study was to investigate the relationship between sleep duration and BMI from Tanner stage 1 to 5 .

Therefore, we determined in a Dutch cohort of 96 children, sleep duration, anthropometric measurements, body composition, Baecke questionnaire, and leptin concentrations, from age 7 to $16 y$.

\section{Subjects and methods Subjects}

Subjects were recruited from a Dutch

Caucasian cohort of children born between 1990 and $1993(23,24)$. As infants, these children and their mothers participated in i) a study of essential fatty acids during pregnancy and pregnancy outcome (23), and ii) a study, performed between 1997 and 2000, about the long-term effects of fetal essential fatty acid availability (25). Anthropometric data were available from these children, no interventions were executed, and follow-up studies were performed with 96 children (24).

Exclusion criteria for follow-up measurements were chronic illness and depression. Each child and their parents gave written informed consent to participate in the study, which was approved by the CCMO (Central Committee Human Research) and by the MEC (Medical Ethical Committee) of the Maastricht University.

\section{Study design}

Every year the follow-up measurements were performed in the months November and December to exclude seasonal effects. At 4 p.m. after a 3-hour fast children's body weight (BW), height, body mass index (BMI), waist circumference, body composition $(24,26)$, leptin concentrations, physical activity, as well as sleep duration were determined at ages 7 to $16 y$.

\section{Measurements \\ Anthropometry}

The children's BW was determined using a digital balance accurate to $0.1 \mathrm{~kg}$ (Sauter D7470, Ebingen, Germany) and height was determined using a wall-mounted stadiometer (Seca, model 220, Hamburg, Germany). Measurements were executed in underwear, after an overnight fast and after voiding the bladder. BMI was calculated by BW/height ${ }^{2}\left(\mathrm{~kg} / \mathrm{m}^{2}\right)$ and BMI in childhood changes substantially with age. To define normal, overweight and obesity in children, we used the specific cut off points described by Cole et al. 2000 (27). The waist circumference was measured at the site of the smallest circumference between the rib cage and the ileac crest, with the subjects in standing position. The pubertal stage was documented in all children according to 
the classification by Tanner (28). The Tanner stage is defined based on physical measurements of external primary and secondary sex characteristics, namely development of breast and pubic hair in girls or development of genitalia and pubic hair in boys (28). Boys with Tanner stage 1 had LH and FSH levels of $1.7 \pm 1.4$ and $2.9 \pm 2.3 \mathrm{IU} / \mathrm{I}$ and boys with Tanner stage 5 had $\mathrm{LH}$ and FSH levels of $5.7 \pm 2.8$ and $3.3 \pm 1.7 \mathrm{IU} / \mathrm{l}$. Girls with Tanner stage 1 had LH and FSH levels of $3.0 \pm 2.9$ and $3.8 \pm 2.1 \mathrm{IU} / \mathrm{l}$ and girls with Tanner stage 5 had LH and FSH levels of $4.4 \pm 4.6$ and $5.0 \pm 4.4 \mathrm{IU} / \mathrm{l}$. Tanner stage definition was thus supported by plasma LH and FSH measurements. Anthropometric measurements were determined at age 7 , $12,13,14,15$ and $16 y$.

\section{Body composition}

Body composition was measured using the deuterium dilution technique $\left(D_{2} O\right) . D_{2} \mathrm{O}$ dilution was used to measure total body water (TBW). Subjects were asked to collect a urine sample in the evening just before drinking the deuterium-enriched water solution. After ingestion of this solution, no further consumption was allowed. In the morning the first urine sample was discarded, the whole second urine sample (about ten hours after drinking the water solution) was collected. The dilution of the deuterium isotope is a measure of the TBW of the subject. Deuterium was measured in the urine samples with an isotope ratio mass spectrometer (VG-Isogas Aqua Sira, VG Isogas, Middlewich, Cheshire, England). TBW was obtained by dividing the measured deuterium dilution space by 1.04. Fat free mass (FFM) was calculated by dividing TBW by the hydration factor 0.73 as defined by Fomon et al. 1982 (29). Fat mass (FM) was determined as BW-FFM. Fat mass index (FMI) was calculated by fat mass $/$ height ${ }^{2}\left(\mathrm{~kg} / \mathrm{m}^{2}\right)$ and fat free mass index (FFMI) was calculated by fat free mass/height ${ }^{2}$ $\left(\mathrm{kg} / \mathrm{m}^{2}\right)(30-32)$. Body composition was measured at age $12,13,14,15$ and $16 y$.
Plasma leptin concentrations were measured with a double-antibody, sandwich-type enzyme-linked immunosorbent assay that used a monoclonal antibody specific for human leptin. The lower limit of detection is 0.5 $\mu \mathrm{g} / \mathrm{L}$ and the upper limit is $50 \mu \mathrm{g} / \mathrm{L}$. The intra- and inter assay CVs were $9 \%$ and $12 \%$, respectively. The leptin concentrations of normal-weight subject's range from 2 to $12 \mu \mathrm{g} / \mathrm{L}$. Plasma leptin concentrations were measured at age 7 , $12,13,14,15$ and $16 y$.

\section{Physical activity}

Physical activity was measured with the Baecke questionnaire. Responses to 19 questions were scored on a five-point scale and resulted in three scores: work activity score, sports activity score and leisure activity score, and has been validated using doubly labeled water (33). For the children, the work index was replaced by a school index with similar questions (e.g. 'When I am at school, I walk: never/seldom/sometimes/often/all the time?'). The Baecke questionnaire for children was validated by Vogels et al. 2007 (34). Physical activity was determined at age 12,13,14, 15 and $16 y$.

\section{Sleep duration}

Sleep duration was measured using the question: 'how many hours do you usually sleep per night?' which would represent their habitual sleep duration $(7,9,21$, 35). Sleep duration was determined at age $12,13,14,15$, and $15 y$.

\section{Statistical analysis}

Differences between boys and girls per Tanner stage were determined using unpaired t-tests. As hours of sleep per night were measured at age 12 to $16 y$, and not all children were at Tanner stage 1 at age $12 y$ or Tanner stage 5 at age $16 y$, three groups appeared, namely from one with data from Tanner stage 1 to 4 $(17 \mathrm{~m} / 7 \mathrm{f})$, one with data from Tanner stage 2 to $5(23 \mathrm{~m} / 19 \mathrm{f})$, and one with data from Tanner stage 1 to 5 (14m/18f). Relationships between the changes in BMI 
and changes in sleep duration during the progressive Tanner stages were assessed using simple linear regression models. Relationships between the changes in BMI and changes in waist circumference and FMI during the progressive Tanner stages were assessed using simple linear regression models. Statistical analyses were performed with Statview SE GraphicsTM for Macintosh. All tests were two-sided and differences were considered significant at $P<0.05$. Values are expressed as mean \pm standard deviation (s.d.).

\section{Results}

Data from 57 boys and 39 girls on height, body weight, BMI, waist circumference, fat mass per squared meter (FMI), leptin concentrations per $\mathrm{kg}$ fat mass, Baecke sport score, and hours sleep per night were collected from age 7 to $16 y$. The characteristics of the boys and girls from Tanner stage 1 to 5 are represented in table 1. At Tanner stage 1, 2, 3, 4 and 5 sex differences were observed in height, body weight, waist circumference, fat mass per squared meter (FMI), and leptin concentrations per $\mathrm{kg}$ fat mass. No differences were found in BMI, Baecke sport score, and hours sleep per night between boys and girls. From Tanner stage 1 to 5 an increase was observed in both boys and girls in respectively height $(0.25 \pm 0.15$ and $0.25 \pm 0.15 \mathrm{~m})$, body weight (24 \pm 12.5 and $26.4 \pm 12.5 \mathrm{~kg})$, BMI $\left(3.5 \pm 2.7\right.$ and $\left.4.9 \pm 3.1 \mathrm{~kg} / \mathrm{m}^{2}\right)$, waist circumference $(7.6 \pm 11.5$ and $11.6 \pm 7.7$ $\mathrm{cm})$, as well as an increase over time in
FMI $\left(1.8 \pm 2.3 \mathrm{~kg} / \mathrm{m}^{2}\right)$ in girls. A decrease was observed in boys and girls in hours sleep per night $(-1.2 \pm 0.4$ and $-1.4 \pm 0.5 \mathrm{~h})$ and leptin concentrations per $\mathrm{kg}$ fat mass $(-0.33 \pm 0.15$ and $-0.17 \pm 0.2 \mathrm{ng} / \mathrm{ml} / \mathrm{kg})$. No alterations over time were observed in FMI and Baecke sport scores in boys, while in girls no alterations were observed in Baecke sport score.

As hours of sleep per night were measured at age 12 to $16 y$, and not all children were at Tanner stage 1 at age $12 y$ or Tanner stage 5 at age $16 y$, three groups appeared, namely from one with data from Tanner stage 1 to $4(17 \mathrm{~m} / 7 \mathrm{f})$, one with data from Tanner stage 2 to 5 $(23 \mathrm{~m} / 19 \mathrm{f})$, and one with data from Tanner stage 1 to $5(14 \mathrm{~m} / 18 \mathrm{f})$. In all three groups we tested whether changes in BMI over time were related to changes in hours of sleep per night over time. Inverse relationships were observed between the change in BMI $\left(\mathrm{kg} / \mathrm{m}^{2}\right)$ and the change in hours of sleep per night $(\mathrm{h})$ from Tanner stage 1 to $4(r=0.68$, $p<0.001)$, from Tanner stage 2 to $5(r=$ $0.35, p<0.05)$, and from Tanner stage 1 to $5(r=0.33, p<0.05)$.

In all three groups positive relationships were found between the change in BMI over time and the change in waist circumference over time $(r=0.79$, $p<0.0001 ; r=0.85, p<0.0001 ; r=0.81$, $p<0.0001)$, and the change in FMI over time $(r=0.71, p<0.001 ; r=0.62$, $\mathrm{p}<0.001 ; \mathrm{r}=0.85, \mathrm{p}<0.0001)$.

Table 1: Characteristics of the boys and girls at Tanner stage 1 to 5

\begin{tabular}{|c|c|c|c|c|c|c|c|c|c|c|}
\hline & \multicolumn{2}{|c|}{ Tanner stage 1} & \multicolumn{2}{|c|}{ Tanner stage 2} & \multicolumn{2}{|c|}{ Tanner stage 3} & \multicolumn{2}{|c|}{ Tanner stage 4} & \multicolumn{2}{|c|}{ Tanner stage 5} \\
\hline & Boys & Girls & Boys & Girls & Boys & Girls & Boys & Girls & Boys & Girls \\
\hline Number & 57 & 39 & 53 & 40 & 52 & 40 & 51 & 41 & 35 & 36 \\
\hline Height (m) & $1.51 \pm 0.2$ & $1.43 \pm 0.2^{\#}$ & $1.66 \pm 0.1$ & $1.61 \pm 0.1^{\#}$ & $1.72 \pm 0.1$ & $1.64 \pm 0.1^{\#}$ & $1.74 \pm 0.1$ & $1.67 \pm 0.1^{\#}$ & $1.76 \pm 0.1$ & $1.68 \pm 0.1^{\#}$ \\
\hline BMI $\left(\mathrm{kg} / \mathrm{m}^{2}\right)$ & $18.0 \pm 2.5$ & $17.4 \pm 2.9$ & $19.5 \pm 2.5$ & $19.7 \pm 2.9$ & $20.4 \pm 2.5$ & $20.5 \pm 3.0$ & $21.3 \pm 2.4$ & $21.3 \pm 2.8$ & $21.5 \pm 2.8$ & $22.3 \pm 3.3$ \\
\hline $\begin{array}{l}\text { Waist circumference } \\
(\mathrm{cm})\end{array}$ & $66.7 \pm 17$ & $60.6 \pm 7.5^{\#}$ & $69.7 \pm 5.8$ & $66.4 \pm 5.9^{\#}$ & $71.7 \pm 5.5$ & $68.1 \pm 6.5^{\#}$ & $74.0 \pm 6.9$ & $70.4 \pm 5.9^{\#}$ & $74.3 \pm 6.1$ & $72.2 \pm 7.8^{\#}$ \\
\hline $\begin{array}{l}\text { Leptin/fat mass } \\
(\mathrm{ng} / \mathrm{ml} / \mathrm{kg})\end{array}$ & $0.50 \pm 0.2$ & $0.73 \pm 0.2^{\#}$ & $0.51 \pm 0.4$ & $0.73 \pm 0.3^{\#}$ & $0.38 \pm 0.4$ & $0.55 \pm 0.3^{\#}$ & $0.26 \pm 0.3$ & $0.39 \pm 0.2^{\#}$ & $0.17 \pm 0.1$ & $0.56 \pm 0.2^{\#}$ \\
\hline Baecke sport score & $2.7 \pm 1.2$ & $2.6 \pm 1.6$ & $2.7 \pm 0.9$ & $2.9 \pm 1.1$ & $3.1 \pm 0.6$ & $2.9 \pm 1.1$ & $3.1 \pm 0.6$ & $2.8 \pm 0.6$ & $3.1 \pm 0.7$ & $2.8 \pm 0.7$ \\
\hline $\begin{array}{l}\text { Hours sleep per night } \\
\text { (h) }\end{array}$ & $8.9 \pm 0.2$ & $8.9 \pm 0.3$ & $8.6 \pm 0.6$ & $8.7 \pm 0.6$ & $8.3 \pm 0.7$ & $8.3 \pm 0.8$ & $7.8 \pm 0.9$ & $7.8 \pm 0.8$ & $7.7 \pm 0.7$ & $7.5 \pm 0.8$ \\
\hline
\end{tabular}




\section{Discussion}

The objective of our longitudinal study was to investigate the relationship between sleep duration and BMI from Tanner stage 1 to 5 . We observed sex differences from Tanner stage 1 onwards in height, body weight, waist circumference, body composition, and leptin concentrations per $\mathrm{kg}$ fat mass. This was in concordance with previous literature on developmental changes in anthropometry and leptin concentrations normalized to fat mass during puberty $(36,37)$.

In concordance with previous longitudinal studies on sleep duration (17-19), a significant decrease in sleep duration during puberty was observed in our cohort. Previous studies however have not corrected for pubertal stage, and we observed that the decrease in sleep duration is related to increasing Tanner stage. These results illustrate the importance for longitudinal and transversal studies on sleep duration to correct for pubertal stage and not for age.

Previous longitudinal studies on sleep duration and BMI in children have observed a consistent negative linear association between baseline habitual sleep duration and later obesity $(1,19$ 21 ). None of the longitudinal studies in children have however investigated whether changes in sleep duration are associated with changes in BMI. Our study is therefore the first to show that with progressive Tanner stages BMI increases and sleep duration decreases in an interrelated way. The increase in BMI from Tanner stage 1 to 5 is furthermore related to the increase in waist circumference and FMI, which suggest that the decrease in sleep duration leads to an increase in obesity related characteristics.
From the observed correlations between development of BMI and changes in sleep duration cause and effect cannot be completely disentangled. Nevertheless, a larger increase in BMI following a larger reduction in sleep duration seems to be plausible based upon the longitudinal study from Snell et al. 2002 (19) that showed a relationship between sleep duration measured at the first time point and BMI measured after a 5-year interval, and not vice versa. On the other hand if sleep duration were to be reduced following an increase in BMI, a plausible theory would be sleep apnea. Sleep apnea however is only present in $1-3 \%$ of the children in a normal population and strongly related to obesity (38), and is therefore an unlikely explanation in our cohort as only $11 \%$ of the children were overweight and with no known cases of sleep apnea.

We therefore suggest that based upon our data, that reduction of sleep duration may contribute to development of overweight during puberty. Taken together, we conclude that development of BMI during puberty is inversely related to change in sleep duration.

\section{Acknowledgements}

We want to thank our subjects for their participation in our cohort study. We gratefully thank Loek Wouters and Wendy Sluijsmans for their assistance. FR and SV carried out the study, collected and analyzed the data, and wrote the largest part of the manuscript. MW and AN supervised FR and SV. Planning, processing the results and writing the manuscript were done under general supervision by AN and MW. The authors had no conflict of interest. 


\section{Literature}

1. Reilly JJ. Obesity in childhood and adolescence: evidence based clinical and public health perspectives. Postgrad Med J 2006;82:429-37.

2. Patel SR, Hu FB. Short sleep duration and weight gain: a systematic review. Obesity (Silver Spring) $2008 ; 16: 643-$ 53.

3. Cappuccio FP, Taggart FM, Kandala NB, et al. Meta-analysis of short sleep duration and obesity in children and adults. Sleep 2008;31:619-26.

4. Nixon GM, Thompson JM, Han DY, et al. Short sleep duration in middle childhood: risk factors and consequences. Sleep 2008; 31:71-8.

5. Gupta NK, Mueller WH, Chan W, Meininger JC. Is obesity associated with poor sleep quality in adolescents? Am J Hum Biol 2002;14:762-8.

6. Sekine M, Yamagami T, Handa $\mathrm{K}$, et al. A dose-response relationship between short sleeping hours and childhood obesity: results of the Toyama Birth Cohort Study. Child Care Health Dev 2002;28:163-70.

7. Eisenmann JC, Ekkekakis P, Holmes M. Sleep duration and overweight among Australian children and adolescents. Acta Paediatr 2006;95:956-63.

8. Vioque J, Torres A, Quiles J. Time spent watching television, sleep duration and obesity in adults living in Valencia, Spain. Int J Obes Relat Metab Disord 2000;24:1683-8.

9. Chaput JP, Brunet M, Tremblay A. Relationship between short sleeping hours and childhood overweight/obesity: results from the 'Quebec en Forme' Project. Int J Obes (Lond) 2006;30:1080-5.

10. Gillman MW, Rifas-Shiman SL, Kleinman K, Oken E, Rich-Edwards JW, Taveras EM. Developmental Origins of Childhood Overweight: Potential Public Health Impact. Obesity (Silver Spring) 2008.

11. Knutson KL, Turek FW. The U-shaped association between sleep and health: the 2 peaks do not mean the same thing. Sleep 2006;29:878-9.

12. Yu Y, Lu BS, Wang B, et al. Short sleep duration and adiposity in Chinese adolescents. Sleep 2007;30:1688-97.

13. Chaput JP, Tremblay A. Does short sleep duration favor abdominal adiposity in children? Int J Pediatr Obes 2007; 2:188-91.

14. Zhou F, Fu JF, Wang CL, Liang $L$, Zhao ZY. [Study on the relationships of childhood obesity and the duration of sleep as well as insulin resistance]. Zhonghua Liu Xing Bing Xue Za Zhi 2007;28:910-3.

15. Wells JC, Hallal PC, Reichert FF, Menezes AM, Araujo CL, Victora CG. Sleep patterns and television viewing in relation to obesity and blood pressure: evidence from an adolescent Brazilian birth cohort. Int J Obes (Lond) 2008.

16. Kuriyan R, Bhat S, Thomas T, Vaz M, Kurpad AV. Television viewing and sleep are associated with overweight among urban and semi-urban South Indian children. Nutr J 2007;6:25.

17. Thorleifsdottir B, Bjornsson JK, Benediktsdottir B, Gislason T, Kristbjarnarson H. Sleep and sleep habits from childhood to young adulthood over a 10-year period. J Psychosom Res 2002;53:529-37.

18. Jenni OG, Carskadon MA. Spectral analysis of the sleep electroencephalogram during adolescence. Sleep 2004;27:774-83.

19. Snell EK, Adam EK, Duncan GJ. Sleep and the body mass index and overweight status of children and adolescents. Child Dev 2007;78:309-23.

20. Dieu HT, Dibley MJ, Sibbritt D, Hanh TT. Prevalence of overweight and obesity in preschool children and associated socio-demographic factors in Ho Chi Minh City, Vietnam. Int J Pediatr Obes 2007; 2:40-50.

21. Agras WS, Hammer LD, McNicholas F, Kraemer HC. Risk factors for childhood overweight: a prospective study from birth to 9.5 years. J Pediatr 2004;145:20-5.

22. Knutson KL. Sex differences in the association between sleep and body mass index in adolescents. J Pediatr 2005; 147:830-4.

23. Rump P, Mensink RP, Kester AD, Hornstra G. Essential fatty acid composition of plasma phospholipids and birth weight: a study in term neonates. Am J Clin Nutr 2001;73:797-806.

24. Vogels N, Posthumus DL, Mariman EC, et al. Determinants of overweight in a cohort of Dutch children. Am J Clin Nutr 2006;84:717-24.

25. Rump P, Popp-Snijders C, Heine RJ, Hornstra G. Components of the insulin resistance syndrome in seven-year-old children: relations with birth weight and the polyunsaturated fatty acid content of umbilical cord plasma phospholipids. Diabetologia 2002;45:349-55.

26. Rutters F, Nieuwenhuizen AG, Vogels N, Bouwman F, Mariman E, Westerterp-Plantenga MS. Leptin-adiposity relationship changes, plus behavioral and parental factors, are involved in the development of body weight in a Dutch children cohort. Physiol Behav 2008;93:967-74.

27. Cole TJ, Bellizzi MC, Flegal KM, Dietz WH. Establishing a standard definition for child overweight and obesity worldwide: international survey. Bmj 2000;320:1240-3.

28. Rico H, Revilla M, Villa LF, Hernandez ER, Alvarez de Buergo M, Villa M. Body composition in children and Tanner's stages: a study with dual-energy X-ray absorptiometry. Metabolism 1993;42:967-70.

29. Fomon SJ, Haschke F, Ziegler EE, Nelson SE. Body composition of reference children from birth to age 10 years. Am J Clin Nutr 1982;35:1169-75.

30. van Marken Lichtenbelt WD, Westerterp KR, Wouters L. Deuterium dilution as a method for determining total body water: effect of test protocol and sampling time. $\mathrm{Br}$ J Nutr 1994;72:491-7.

31. Schoeller DA, van Santen E, Peterson DW, Dietz W, Jaspan J, Klein PD. Total body water measurement in humans with 180 and $2 \mathrm{H}$ labeled water. Am J Clin Nutr 1980;33:2686-93.

32. Westerterp KR, Wouters $L$, van Marken Lichtenbelt WD. The Maastricht protocol for the measurement of body composition and energy expenditure with labeled water. Obes Res 1995;3 Suppl 1:49-57.

33. Philippaerts RM, Westerterp KR, Lefevre J. Doubly labelled water validation of three physical activity questionnaires. Int J Sports Med 1999;20:284-9.

34. Vogels N, Westerterp KR, Posthumus DL, Rutters F, Westerterp-Plantenga MS. Daily physical activity counts vs structured activity counts in lean and overweight Dutch children. Physiol Behav 2007;92:611-6.

35. Knutson $\mathrm{KL}$, Ryden $\mathrm{AM}$, Mander $\mathrm{BA}$, Van Cauter $\mathrm{E}$. Role of sleep duration and quality in the risk and severity of type 2 diabetes mellitus. Arch Intern Med 2006;166:1768-74.

36. Horlick MB, Rosenbaum M, Nicolson M, et al. Effect of puberty on the relationship between circulating leptin and body composition. J Clin Endocrinol Metab 2000;85:2509-18.

37. Veldhuis JD, Roemmich JN, Richmond EJ, et al. Endocrine control of body composition in infancy, childhood, and puberty. Endocr Rev 2005;26:114-46.

38. Lumeng JC, Chervin RD. Epidemiology of pediatric obstructive sleep apnea. Proc Am Thorac Soc 2008;5:242-52. 



\section{Chapter 5}

The relationship between leptin, gonadotropic hormones, and body composition during puberty in a Dutch children cohort

F. Rutters, A.G. Nieuwenhuizen, S.P.M. Verhoef, S. G. T. Lemmens, N. Vogels, M.S. Westerterp-Plantenga

European Journal of endocrinology 2009 Jun;160(6):973-8 


\begin{abstract}
Objective: to investigate the relationship between leptin concentrations, gonadotropic hormone concentrations, and body composition during puberty in a Dutch children cohort. Design: In a cohort of 98 children, we determined anthropometric measurements, body composition, and concentrations of leptin, $\mathrm{FSH}$, and $\mathrm{LH}$.
\end{abstract}

Results: sex differences were observed from Tanner stage 1 onwards in weight, body fat percentage, and leptin/fat mass ratio. In boys and girls the relationship between leptin concentrations and fat mass was weaker at Tanner stage $2\left(R^{2}=0.33\right.$ and $R^{2}=0.39$, $p<0.001), 3\left(R^{2}=0.27\right.$ and $\left.R^{2}=0.36, p<0.002\right)$, and $4\left(R^{2}=0.21\right.$ and $\left.R^{2}=0.28, p<0.03\right)$ than at Tanner stage $1\left(R^{2}=0.51\right.$ and $\left.R^{2}=0.67, p<0.001\right)$ and $5\left(R^{2}=0.46\right.$ and $R^{2}=0.78, p<$ $0.01)$. In girls, a peak in leptin concentrations $(8.5 \pm 6.0 \mathrm{ng} / \mathrm{ml})$ preceded a peak in $\mathrm{LH}$ and $\mathrm{FSH}$ concentrations $(15.1 \pm 3.5$ and $5.0 \pm 4.5 \mathrm{IU} / \mathrm{I})$. A lead/lag relationship was observed of leptin at Tanner stage 1 to $\mathrm{LH}$ and FSH at Tanner stage $2\left(R^{2}=0.12, p<0.05\right.$ and $\left.R^{2}=0.18, p<0.05\right)$. In boys, there was no peak in leptin, $\mathrm{LH}$, and FSH and additionally, leptin at Tanner stage 3 was related FSH at Tanner stage $4\left(R^{2}=0.17, p<0.04\right)$.

Conclusion: in boys and girls during puberty factors independent of fat mass become (transiently) more important in the regulation of plasma leptin concentrations. Moreover, in girls leptin is suggested to act as a permissive factor for the onset of puberty, while in boys leptin has a different timing and possibly different function. 


\section{Introduction}

The achievement of a critical body weight or fat mass is thought to play a prominent role in the start of sexual maturation [1, $2]$, since underfeeding and malnutrition in humans, as seen in anorexia, is related to a delay in the onset puberty [1-3]. Leptin has been proposed as a physiological link between adiposity status and the start of sexual maturation [1-5]. Several crosssectional studies and three small longitudinal studies support this theory since they have found that leptin concentrations rose prepubertally, but then decreased at the initiation of puberty, as gonadal hormone concentrations began to increase $[1,4,6$ 11].

The proposed mechanism behind leptin as a trigger to puberty, beholds that leptin independently of fat mass acts on the hypothalamic luteinizing hormonereleasing hormone (LHRH) pulse generator [12-14]. Consequently, LHRH stimulates the release of luteinizing hormone ( $\mathrm{LH})$ and follicle-stimulating hormone (FSH) from the pituitary, which in turn stimulate the gonads to release testosterone and estradiol [12-14]. Testosterone and estradiol inhibit the secretion of $\mathrm{LHRH}$ and respectively $\mathrm{LH}$ and $\mathrm{FSH}$, which thereby form a negative feedback loop [13, 14]. Moreover, testosterone inhibits leptin secretion from the adipocytes, which forms a second negative feedback loop [14-16]. A positive feedback loop is formed by estradiol, which stimulates leptin secretion from the adipocytes [14, 16]. This proposed mechanism suggests that increased gonadotrophic and gonadal hormones concentrations may alter the relationship between leptin concentrations and body fat during puberty.

Most studies, however, that investigated the role of leptin as a trigger to puberty, did not determine body composition [6], or were done in transversal cohorts $[1,6$, $8,9]$ and relatively small longitudinal cohorts [4, 10, 11]. Consequently, previous studies have been unable to test the hypothesis that leptin and gonadotropic hormones are temporarily related during puberty, and whether consequently the relationship between leptin and body composition is temporarily altered. Therefore, the objective of our longitudinal study was to investigate the relationship between leptin concentrations, gonadotropic hormone concentrations, and body composition during puberty in a Dutch children cohort. Therefore, we determined in 98 children anthropometric measurements, body composition, and concentrations of leptin, $\mathrm{FSH}$, LH, testosterone and estradiol.

\section{Subjects and methods Subjects}

Subjects were recruited from a Dutch

Caucasian cohort of children born between 1990 and 1993 [17, 18]. As infants, these children and their mothers participated in i) a study of essential fatty acids during pregnancy and pregnancy outcome [17], and ii) a study, performed between 1997 and 2000, about the long-term effects of fetal essential fatty acid availability [19]. Anthropometric data were available from these children and no interventions were implemented. To evaluate the development of obesity and related parameters, follow-up studies were performed with 98 children, and the dropout rate was $0 \%$ [18]. Each child and one of his or her parents gave written informed consent to participate in the study, which was approved by the Central Committee Human Research and by the Medical Ethical Committee of the Maastricht University.

\section{Study design}

At 4 p.m. after a 3-hour fast children's age, body weight (BW), height, body mass index (BMI), body composition [7, 18], leptin concentrations, folliclestimulating hormone (FSH) concentrations, luteinizing hormone (LH) concentrations, testosterone concentrations and estradiol concentrations were determined. 


\section{Measurements}

Anthropometry

The children's BW was determined using a digital balance accurate to $0.1 \mathrm{~kg}$ (Sauter D7470, Ebingen, Germany) and height was determined using a wall-mounted stadiometer (Seca, model 220, Hamburg, Germany). Measurements were executed in underwear and after voiding the bladder. BMI in childhood changes substantially with age and was calculated by $\mathrm{BW} / \mathrm{height}^{2}\left(\mathrm{~kg} / \mathrm{m}^{2}\right)$. Therefore to define normal, overweight and obesity in children, we used the specific cut off points described by Cole et al. 2000 [20]. For example, at age $12 \mathrm{y}$ a BMI of 21.22 and $21.68 \mathrm{~kg} / \mathrm{m}^{2}$ in boys and girls is defined as overweight, and a BMI of 26.02 and $26.67 \mathrm{~kg} / \mathrm{m}^{2}$ as obese. The pubertal stage was documented in all children according to the classification by Tanner [21]. The Tanner stage is defined based on physical measurements of external primary and secondary sex characteristics, namely development of breast and pubic hair in girls or development of genitalia and pubic hair in boys [21]. At age 15y, boys in Tanner stage 3 had testosterone levels of $8.3 \pm$ $5.1 \mathrm{ng} / \mathrm{l}$ and boys with Tanner stage $5 \mathrm{had}$ testosterone levels of $16.5 \pm 5.4 \mathrm{ng} / \mathrm{l}$. At age 15, girls in Tanner stage 3 had estradiol levels of $14.8 \pm 15.8 \mathrm{ng} / \mathrm{l}$ and girls with Tanner stage 5 had estradiol levels of $32.7 \pm 32.4 \mathrm{ng} / \mathrm{l}$. Tanner stage definition was thus supported by plasma testosterone and estradiol measurements $(\mathrm{ng} / \mathrm{l})$ at age 15 . Anthropometric measurements were determined at ages $7,12,13,14$ and $15 y$.

\section{Body composition}

Body composition was measured using the deuterium dilution technique $\left(D_{2} O\right) . D_{2} \mathrm{O}$ dilution was used to measure total body water (TBW). Subjects were asked to collect a urine sample in the evening just before drinking the deuterium-enriched water solution. After ingestion of this solution, no further consumption was allowed. Ten hours after drinking the water solution, another urine sample was collected. The dilution of the deuterium isotope is a measure of the TBW of the subject. Deuterium was measured in the urine samples with an isotope ratio mass spectrometer (VG-Isogas Aqua Sira, VG Isogas, Middlewich, Cheshire, England). TBW was obtained by dividing the measured deuterium dilution space by 1.04. Fat free mass (FFM) was calculated by dividing TBW by the hydration factor 0.73 [22-24]. Fat mass (FM) was determined as BW-FFM. Body composition was measured at ages $12,13,14$ and $15 y$.

\section{Leptin}

At 4 p.m. after a 3-hour fast blood was drawn for determination of leptin concentrations. Plasma leptin concentrations were measured with a double-antibody, sandwich-type enzymelinked immunosorbent assay that used a monoclonal antibody specific for human leptin. The lower limit of detection is 0.5 $\mu \mathrm{g} / \mathrm{L}$ and the upper limit is $50 \mu \mathrm{g} / \mathrm{L}$. The intra- and inter assay CVs were $9 \%$ and $12 \%$, respectively. The leptin concentrations of normal-weight subjects' range from 2 to $12 \mu \mathrm{g} / \mathrm{L}$. Plasma leptin concentrations $(\mathrm{ng} / \mathrm{ml})$ were measured at ages $7,12,13,14$ and $15 y$.

\section{Follicle-stimulating hormone (FSH)}

At 4 p.m. after a 3-hour fast blood was drawn for determination of FSH

concentrations. Plasma FSH concentrations were measured with a double-antibody, sandwich-type enzymelinked immunosorbent assay that used a monoclonal antibody specific for human $\mathrm{FSH}$. The lower limit of detection is 0.100 IU /L and the upper limit is $200.0 \mathrm{IU} / \mathrm{L}$. The intra- and inter assay CVs were $1.8 \%$ and $5.1 \%$, respectively. The FSH concentrations range from 1.5 to $12.4 \mathrm{IU}$ $/ L$ in boys and from 1.7 to $21.5 \mathrm{IU} / \mathrm{L}$ in girls. Plasma FSH concentrations (IU /L) were measured at ages 12,13, 14 and $15 y$.

\section{Luteinizing hormone ( $L H$ )}

At 4 p.m. after a 3-hour fast blood was drawn for determination of $\mathrm{LH}$ concentrations. Plasma LH concentrations were measured with a double-antibody, sandwich-type enzyme-linked immunosorbent assay that used a 
monoclonal antibody specific for human $\mathrm{LH}$. The lower limit of detection is 0.100 IU / L and the upper limit is $200 \mathrm{IU} / \mathrm{L}$. The intra- and inter assay CVs were $0.8 \%$ and $2.0 \%$, respectively. The LH concentrations range from 1.7 to $8.6 \mathrm{IU} / \mathrm{L}$ in boys and from 1.0 to $95.6 \mathrm{IU} / \mathrm{L}$ in girls. Plasma $\mathrm{LH}$ concentrations (IU /L) were measured at ages 12, 13, 14 and 15y.

\section{Statistical analysis}

Differences between two groups were determined using unpaired t-tests. Differences over time and between conditions were determined using twofactor ANOVA with repeated measures. Relationships between dependent and independent variables were determined using simple linear regression models. To investigate a time-dependent relationship in the sequence of the hormonal changes during puberty, we used the lead/lag technique, which correlates hormones secreted in one stage, with those secreted in the next stage [11]. All tests were twosided and differences were considered significant at $P<0.05$. Values are expressed as mean \pm standard deviation (s.d.).

\section{Results}

At Tanner stage 1 we collected data from 95 (57 m/38f) children, at Tanner stage 2 from 95 children ( $54 \mathrm{~m} / 41 \mathrm{f})$, at Tanner stage 3 from 95 children ( $55 \mathrm{~m} / 40 \mathrm{f})$, at Tanner stage 4 from 63 children $(35 \mathrm{~m} / 28 \mathrm{f})$, as well as from 33 children $(14 \mathrm{~m} / 19 \mathrm{f})$ at Tanner stage $5.11 \%$ of the children were classified as overweight using specific cut off points described by Cole et al. 2000 [20]. In our cohort annual height velocity in boys and girls was $5.7 \pm 1.3$ and $5.7 \pm 1.2 \mathrm{~cm} / \mathrm{y}$ at Tanner stage $1 ; 6.5 \pm 1.8$ and $5.7 \pm 1.2$ $\mathrm{cm} / \mathrm{y}$ at Tanner stage 2; $6.9 \pm 2.6$ and $5.7 \pm 2.4 \mathrm{~cm} / \mathrm{y}$ at Tanner stage 3; $6.1 \pm$ 3.0 and $3.1 \pm 2.3 \mathrm{~cm} / \mathrm{y}$ at Tanner stage 4 ; and $3.7 \pm 3.1$ and $1.5 \pm 1.4 \mathrm{~cm} / \mathrm{y}$ Tanner stage 5. Figure 1 shows sex differences (boys vs. girls) in weight at Tanner stage $1,3,4$, and 5 (43.1 \pm 12.5 vs. $36.9 \pm 14.2 \mathrm{~kg}, \mathrm{p}<0.02 ; 61.5 \pm 10.5$ vs. $56.2 \pm 9.7 \mathrm{~kg}, \mathrm{p}<0.01 ; 66.1 \pm 9.5$ vs. $59.9 \pm 9.7 \mathrm{~kg}, \mathrm{p}<0.01 ; 68.5 \pm 9.2$ vs. $60.7 \pm 8.8 \mathrm{~kg}, \mathrm{p}<0.02)$. Differences were absent at Tanner stage 2 , caused by a larger increase in weight in girls when compared to boys between Tanner stage 1 to $2(15.6 \pm 12.4$ vs. $12.4 \pm 10.4 \mathrm{~kg}, \mathrm{p}<$ 0.18 ), and a significant larger increase in weight in boys when compared to girls between Tanner stage 2 to $3(6.6 \pm 3.2$ vs. $3.9 \pm 2.2 \mathrm{~kg}, \mathrm{p}<0.001$ ). Additionally, sex differences in body fat percentage were shown at all Tanner stages (16.9 \pm 7.2 vs. $23.8 \pm 8.1 \%, p<0.05 ; 18.1 \pm 7.9$ vs. $22.9 \pm 5.9 \%, p<0.002 ; 16.6 \pm 6.7$ vs. $24.9 \pm 6.3 \%, p<0.001 ; 17.1 \pm 6.9$ vs. $25.9 \pm 5.7 \%, p<0.001 ; 16.7 \pm 5.9$ vs. $27.9 \pm 6.3 \%, p<0.001)$. Because of sex differences, the results on body composition, leptin concentrations, and gonadotropic hormone concentrations were analyzed separately for boys and girls.

Figure 1: Mean of weight $(\mathrm{kg})$ and body fat percentage $(\%)$ in the boys $(n=57)$ and girls $(n=41)$ as a function of Tanner stage.

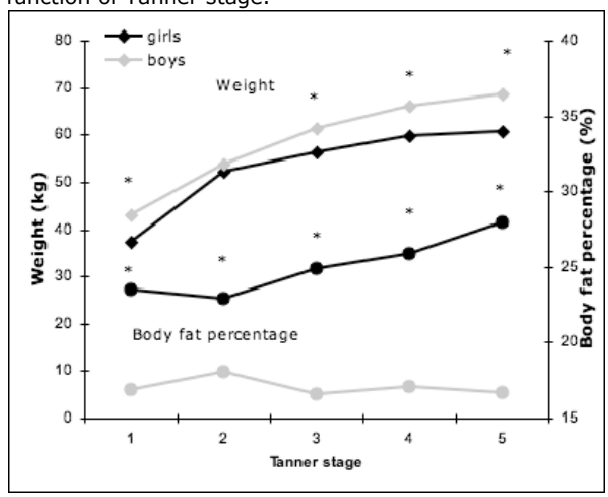

$* p<0.05$ for differences between boys and girls (ANOVA repeated measures)

Figure $\mathbf{2 a}$ shows the mean of plasma leptin concentrations $(\mathrm{ng} / \mathrm{ml}), \mathrm{LH}$ concentrations (IU/I) and FSH concentrations (IU/I) in the boys $(n=57)$ as a function of Tanner stage. In lean and overweight boys no differences were found in the leptin and gonadotropic hormone patterns. The leptin concentrations increased from Tanner stage 1 to $2(3.9 \pm 2.3$ to $4.9 \pm 5.1$ $\mathrm{ng} / \mathrm{ml}, \mathrm{p}<0.5)$, and decreased significantly from Tanner stage 2 to 5 (4.9 \pm 5.1 to. $2.1 \pm 1.9 \mathrm{ng} / \mathrm{ml}, \mathrm{p}<0.01)$. FSH 
concentrations increased from Tanner stage 1 to $4(2.9 \pm 2.3$ to $3.6 \pm 1.9 \mathrm{IU} / \mathrm{l}$, $\mathrm{p}<0.09$ ), and LH concentrations significantly increased from Tanner stage 1 to $5(1.8 \pm 1.4$ to $5.7 \pm 2.8 \mathrm{IU} / \mathrm{l}, \mathrm{p}<$ $0.01)$.

Figure 2a: Mean of plasma leptin concentrations $(\mathrm{ng} / \mathrm{ml})$, LH concentrations (IU/I), and FSH concentrations (IU/I) in the boys $(n=57)$ as a function of Tanner stage.

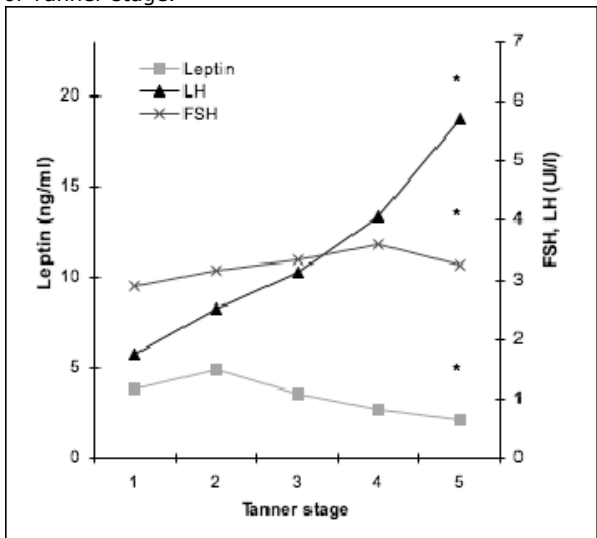

$* \mathrm{p}<0.05$ for differences in time in the leptin and $\mathrm{LH}$ concentrations (ANOVA repeated measures)

Figure 2b: Mean of plasma leptin concentrations $(\mathrm{ng} / \mathrm{ml})$, LH concentrations (IU/I), and FSH concentrations (IU/I) in the girls $(n=41)$ as a function of Tanner stage.

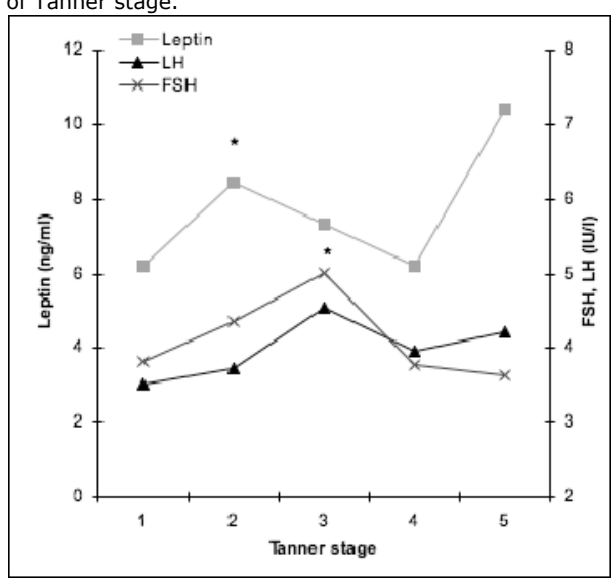

$* \mathrm{p}<0.05$ for differences in time in the leptin and LH concentrations (ANOVA repeated measures)

Figure $\mathbf{2 b}$ shows the mean of plasma leptin concentrations $(\mathrm{ng} / \mathrm{ml})$, $\mathrm{LH}$ concentrations (IU/I) and FSH concentrations $(I U / I)$ in girls $(n=41)$ as a function of Tanner stage. In lean and overweight girls no differences were found in the leptin and gonadotropic hormone patterns. The leptin concentrations increased significantly from Tanner stage 1 to $2(6.2 \pm 4.9$ to $8.5 \pm 6.0 \mathrm{ng} / \mathrm{ml}, \mathrm{p}<$ $0.02)$, decreased significantly from Tanner stage 2 to $4(8.5 \pm 6.0$ to $6.2 \pm 3.3$ $\mathrm{ng} / \mathrm{ml}, \mathrm{p}<0.04)$, and significantly increased again from Tanner stage 4 to 5 $(6.2 \pm 3.3$ vs. $10.4 \pm 6.6 \mathrm{ng} / \mathrm{ml} \mathrm{p}<$ $0.01)$. The peak in leptin concentrations was followed by an increase $\mathrm{LH}$ and $\mathrm{FSH}$ concentrations from Tanner stage 2 to 3 $(3.4 \pm 2.3$ to $5.1 \pm 3.5 \mathrm{IU} / \mathrm{l}, \mathrm{p}<0.05$ and $5.1 \pm 3.5$ to $3.9 \pm 4.3 \mathrm{IU} / \mathrm{l}, \mathrm{p}<0.14$ ), and a decrease in LH and FSH concentrations from Tanner stage 3 to 4 $(4.4 \pm 5.0$ to $5.0 \pm 4.5 \mathrm{IU} / \mathrm{l}, \mathrm{p}<0.24$ and $5.0 \pm 4.5$ to $3.8 \pm 2.1 \mathrm{IU} / \mathrm{l}, \mathrm{p}<0.33)$.

Figure 3 shows the mean leptin concentrations per kilogram of fat mass (FM) of the boys and girls as a function of Tanner stage. Sex differences in leptin/fat mass ratio were observed at Tanner stage $1,2,3,4$, and $5(0.49 \pm 0.2$ vs. $0.70 \pm$ $0.2 \mathrm{ng} / \mathrm{ml} / \mathrm{kg}, \mathrm{p}<0.009 ; 0.51 \pm 0.4 \mathrm{vs}$. $0.73 \pm 0.3 \mathrm{ng} / \mathrm{ml} / \mathrm{kg}, \mathrm{p}<0.005 ; 0.38 \pm$ 0.4 vs. $0.55 \pm 0.3 \mathrm{ng} / \mathrm{ml} / \mathrm{kg}, \mathrm{p}<0.04$; $0.26 \pm 0.3$ vs. $0.39 \pm 0.2 \mathrm{ng} / \mathrm{ml} / \mathrm{kg}, \mathrm{p}<$ $0.04 ; 0.17 \pm 0.1$ vs. $0.56 \pm 0.2 \mathrm{ng} / \mathrm{ml} / \mathrm{kg}$ ， $\mathrm{p}<0.001)$.

Figure 3: Mean leptin concentrations $(\mathrm{ng} / \mathrm{ml})$ per kilogram of fat mass (FM) of the boys and girls as a function of Tanner stage.

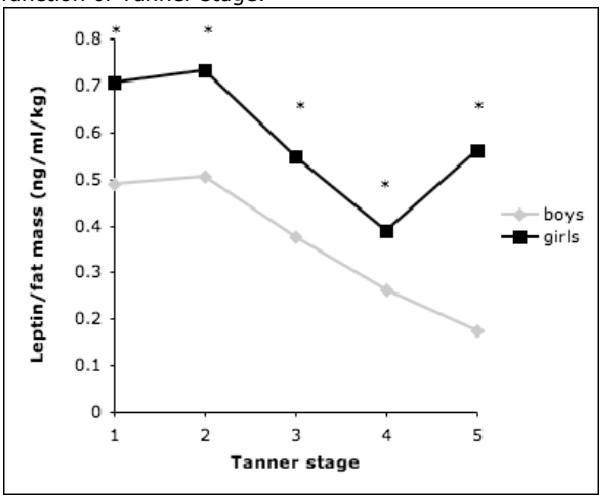

$* p<0.05$ for differences between boys and girls (ANOVA repeated measures)

Table 1 shows regression analyses between plasma leptin concentrations $(\mathrm{ng} / \mathrm{ml})$ as the dependent variable and fat mass $(\mathrm{kg})$ as the independent variable in boys $(n=57)$ and girls $(n=41)$ at 
Tanner stage 1-5. In both boys and girls a positive relationship was observed between leptin concentrations and fat mass from Tanner stage 1 onwards. In the girls only at Tanner stage 2, 3, and 4 a smaller proportion of the variance in the leptin concentrations was accounted for by using fat mass as the independent variable.

Table 1: Regression between plasma leptin concentrations $(\mathrm{ng} / \mathrm{ml})$ as the dependent variable and fat mass $(\mathrm{kg})$ as the independent variable in boys $(\mathrm{n}=$ 57) and girls $(n=41)$ at Tanner stage $1-5$.

\begin{tabular}{lll}
\hline Boys & & \\
\hline Tanner stage & $\mathrm{R}^{2}$ & $\mathrm{P}$ value \\
1 & 0.51 & 0.001 \\
2 & 0.33 & 0.001 \\
3 & 0.27 & 0.001 \\
4 & 0.21 & 0.01 \\
5 & 0.46 & 0.01 \\
\hline Girls & & \\
\hline Tanner stage & $\mathrm{R}^{2}$ & $\mathrm{P}$ value \\
1 & 0.67 & 0.001 \\
2 & 0.39 & 0.001 \\
3 & 0.36 & 0.002 \\
4 & 0.28 & 0.03 \\
5 & 0.78 & 0.001 \\
\hline
\end{tabular}

To test whether leptin can be considered as the 'lead' hormone in relation to $\mathrm{LH}$, and $\mathrm{FSH}$ or vice versa, in boys and girls leptin concentrations in a certain Tanner stage were paired with the other hormones in the following Tanner stage and vice versa, which results in 32 sets of paired data per child. In boys at Tanner stage $1 \mathrm{LH}$ and FSH concentrations were related to Tanner stage 2 leptin concentrations $\left(R^{2}=0.16, p<0.02\right.$ and $\left.\mathrm{R}^{2}=0.13, \mathrm{p}<0.03\right)$, in turn Tanner stage 3 leptin concentrations were related to Tanner stage $4 \mathrm{FSH}$ concentrations $\left(\mathrm{R}^{2}=\right.$ $0.17, \mathrm{p}<0.04)$.

In girls at Tanner stage 1 leptin concentrations were related to Tanner stage $2 \mathrm{LH}$ and FSH concentrations $\left(\mathrm{R}^{2}=\right.$ $0.12, \mathrm{p}<0.05$ and $\left.\mathrm{R}^{2}=0.18, \mathrm{p}<0.05\right)$.

\section{Discussion}

The objective of our longitudinal study was to investigate the relationship between leptin concentrations, gonadotropic hormone concentrations, and body composition during puberty in a Dutch children cohort. We observed sex differences from Tanner stage 1 onwards in weight, body composition, and leptin concentrations per $\mathrm{kg}$ fat mass. This was in concordance with previous literature on developmental changes in anthropometry and leptin concentrations normalized to fat mass during puberty $[8,25]$.

Sex differences were also observed in the development of leptin, LH, and FSH concentrations over time. In girls a peak in leptin concentrations was observed at Tanner stage 2, followed by a peak in LH and FSH concentrations at Tanner stage 3, thereby confirming results from previous cross-sectional and small longitudinal studies [1, 4, 6-11]. In boys no peak in leptin was observed at Tanner stage 2 , as leptin decreased from Tanner stage 2 onwards and $\mathrm{LH}$ and FSH concentrations increased from Tanner stage 1 to 4, thereby confirming results from previous small longitudinal studies [4, 26]. Transversal studies, however, did show a leptin peak in boys during puberty $[1,6]$, which may be explained by methodological differences as well as presentation of the data by age group instead of by pubertal stage.

The observations of our longitudinal study shed more light on the temporal alterations in the relationship between leptin and body composition [8]. Both in boys and girls, the leptin/fat mass ratio decreased from Tanner stage 2 onwards. In boys, this decrease continued throughout puberty, while in girls this ratio increased again at Tanner stage 5, which confirms results by Horlick et al [8]. These results imply that during puberty factors independent of fat mass become (transiently) more important in the regulation of plasma leptin concentrations.

To investigate a time-dependent relationship in the sequence of the hormonal changes during puberty, we used the lead/lag technique, which correlates hormones secreted in one stage, with those secreted in the next stage [11]. In girls we observed that prepubertal leptin concentrations (Tanner stage 1 ), when acting as a lead, related to early pubertal LH and FSH concentrations (Tanner stage 2 ), as observed in both 
boys and girls by Masqood et al [11].

These results imply a temporal

relationship between leptin and gonadotropic hormones during early puberty.

In boys, opposing results were found: prepubertal LH and FSH concentrations (Tanner stage 1 ) were related to early pubertal leptin concentrations (Tanner stage 2), as observed in boys and girls by Masqood et al [11]. They however observed prepubertal leptin concentrations to be related to early pubertal gonadotropic hormones and vice versa in both boys and girls [11], while we observed the first relationship in girls and the second one in boys. The discrepancy between the two studies is presumably caused by the difference in study population, because we analyzed boys and girls separately, each group consisting of about 40 children, and Masqood et al. [11] analyzed only 13 boys and 7 girls, 20 children together as one group, thereby being unable to separate the two different relationships. It should be noted that in both studies LH and FSH concentrations were determined in morning urine or plasma samples. Both methods do not provide information on the night-day rhythm and on pulsatile secretory patterns, typical for the gonadotropic hormones [27]. Moreover, we observed in boys a lead/lag relationship of leptin concentrations Tanner stage 3 and FSH concentrations at Tanner stage 4 . Our results show that during puberty the relationship between leptin and gonadotropic hormones is sex specific, since during puberty in boys leptin seems to have a different function and different timing. Still, previous studies have shown that leptin is essential in reproductive functioning in both boys and girls, as male and female sterile ob/ob mice that became fertile again by leptin treatment [28]. The observations from our and other studies show that in a deficiency in leptin and fat mass as seen in anorexia nervosa or hyperleptinemia as seen in morbid obesity, will disturb the role of leptin during puberty, and thereby the start and progression of puberty [3].

Thus, we observed in our longitudinal cohort that during puberty the leptin/fat mass ratio decreased from Tanner stage 2 onwards. In girls, a peak in plasma leptin concentrations precedes a peak in $\mathrm{LH}$ and FSH concentrations, which supports a permissive role for leptin in the onset of puberty in girls. In girls, temporal relationships were observed between leptin and gonadotropic hormones during early puberty. In boys, however there were no peaks in leptin, $\mathrm{LH}$, and $\mathrm{FSH}$, and leptin was only related to $\mathrm{LH}$ and $\mathrm{FSH}$ during late puberty. We therefore conclude that in boys and girls during puberty factors independent of fat mass become (transiently) more important in the regulation of plasma leptin concentrations. Moreover, in girls leptin is suggested to act as a permissive factor for the onset of puberty, while in boys leptin has a different timing and possibly different function.

\section{Acknowledgements}

FR, SV, SL and NV carried out the study, collected and analyzed the data, and wrote the largest part of the manuscript. MW and AN supervised FR, SV, SL and NV. Planning, processing the results and writing the manuscript were done under general supervision by MW and AN. We want to thank our subjects for their participation in our cohort study. We gratefully thank Loek Wouters and Wendy Sluijsmans for their assistance. 


\section{Literature}

1. Mann, D.R., A.O. Johnson, T. Gimpel, and V.D. Castracane, Changes in circulating leptin, leptin receptor, and gonadal hormones from infancy until advanced age in humans. J Clin Endocrinol Metab, 2003. 88(7): p. 3339-45

2. Chan, J.L. and C.S. Mantzoros, Role of leptin in energy-deprivation states: normal human physiology and clinical implications for hypothalamic amenorrhoea and anorexia nervosa. Lancet, 2005. 366(9479): p. 74-85.

3. Bluher, S. and C.S. Mantzoros, Leptin in reproduction. Curr Opin Endocrinol Diabetes Obes, 2007. 14(6): p. 45864.

4. Ahmed, M.L., K.K. Ong, D.J. Morrell, L. Cox, N. Drayer, L. Perry, et al., Longitudinal study of leptin concentrations during puberty: sex differences and relationship to changes in body composition. J Clin Endocrinol Metab, 1999. 84(3): p. 899-905.

5. Kaplowitz, P.B., Link between body fat and the timing of puberty. Pediatrics, 2008. 121 Suppl 3: p. S208-17.

6. Garcia-Mayor, R.V., M.A. Andrade, M. Rios, M. Lage, C. Dieguez, and F.F. Casanueva, Serum leptin levels in normal children: relationship to age, gender, body mass index, pituitary-gonadal hormones, and pubertal stage. J Clin Endocrinol Metab, 1997. 82(9): p. 2849-55.

7. Rutters, F., A.G. Nieuwenhuizen, N. Vogels, F. Bouwman, E. Mariman, and M.S. Westerterp-Plantenga, Leptinadiposity relationship changes, plus behavioral and parental factors, are involved in the development of body weight in a Dutch children cohort. Physiol Behav, 2008. 93(4-5): p. 967-74.

8. Horlick, M.B., M. Rosenbaum, M. Nicolson, L.S. Levine, B. Fedun, J. Wang, et al., Effect of puberty on the relationship between circulating leptin and body composition. J Clin Endocrinol Metab, 2000. 85(7): p. 2509-18.

9. Blum, W.F., P. Englaro, S. Hanitsch, A. Juul, N.T. Hertel, J. Muller, et al., Plasma leptin levels in healthy children and adolescents: dependence on body mass index, body fat mass, gender, pubertal stage, and testosterone. J Clin Endocrinol Metab, 1997. 82(9): p. 2904-10.

10. Mantzoros, C.S., J.S. Flier, and A.D. Rogol, A longitudinal assessment of hormonal and physical alterations during normal puberty in boys. V. Rising leptin levels may signal the onset of puberty. J Clin Endocrinol Metab, 1997. 82(4): p. $1066-70$.

11. Maqsood, A.R., J.A. Trueman, A.J. Whatmore, M. Westwood, D.A. Price, C.M. Hall, et al., The relationship between nocturnal urinary leptin and gonadotrophins as children progress towards puberty. Horm Res, 2007. 68(5): p. 225-30.

12. Dunkel, L., H. Alfthan, U.H. Stenman, G. Selstam, S. Rosberg, and K. Albertsson-Wikland, Developmental changes in 24-hour profiles of luteinizing hormone and follicle-stimulating hormone from prepuberty to midstages of puberty in boys. J Clin Endocrinol Metab, 1992. 74(4): p. 890-7.

13. Grumbach, M.M., The neuroendocrinology of human puberty revisited. Horm Res, 2002. 57 Suppl 2: p. 2-14.

14. Roemmich, J.N. and A.D. Rogol, Hormonal changes during puberty and their relationship to fat distribution. Am J Human Biol, 1999. 11(2): p. 209-224.

15. Kristensen, K., S.B. Pedersen, and B. Richelsen, Regulation of leptin by steroid hormones in rat adipose tissue. Biochem Biophys Res Commun, 1999. 259(3): p. 624-30.

16. Machinal-Quelin, F., M.N. Dieudonne, R. Pecquery, M.C. Leneveu, and Y. Giudicelli, Direct in vitro effects of androgens and estrogens on ob gene expression and leptin secretion in human adipose tissue. Endocrine, 2002. 18(2): p. 179-84.

17. Rump, P., R.P. Mensink, A.D. Kester, and G. Hornstra, Essential fatty acid composition of plasma phospholipids and birth weight: a study in term neonates. Am J Clin Nutr, 2001. 73(4): p. 797-806.

18. Vogels, N., D.L. Posthumus, E.C. Mariman, F. Bouwman, A.D. Kester, P. Rump, et al., Determinants of overweight in a cohort of Dutch children. Am J Clin Nutr, 2006. 84(4): p. 717-24.

19. Rump, P., C. Popp-Snijders, R.J. Heine, and G. Hornstra, Components of the insulin resistance syndrome in sevenyear-old children: relations with birth weight and the polyunsaturated fatty acid content of umbilical cord plasma phospholipids. Diabetologia, 2002. 45(3): p. 349-55.

20. Cole, T.J., M.C. Bellizzi, K.M. Flegal, and W.H. Dietz, Establishing a standard definition for child overweight and obesity worldwide: international survey. Bmj, 2000. 320(7244): p. 1240-3.

21. Rico, H., M. Revilla, L.F. Villa, E.R. Hernandez, M. Alvarez de Buergo, and M. Villa, Body composition in children and Tanner's stages: a study with dual-energy x-ray absorptiometry. Metabolism, 1993. 42(8): p. 967-70.

22. van Marken Lichtenbelt, W.D., K.R. Westerterp, and L. Wouters, Deuterium dilution as a method for determining total body water: effect of test protocol and sampling time. Br J Nutr, 1994. 72(4): p. 491-7.

23. Schoeller, D.A., E. van Santen, D.W. Peterson, W. Dietz, J. Jaspan, and P.D. Klein, Total body water measurement in humans with 180 and $2 \mathrm{H}$ labeled water. Am J Clin Nutr, 1980. 33(12): p. 2686-93.

24. Westerterp, K.R., L. Wouters, and W.D. van Marken Lichtenbelt, The Maastricht protocol for the measurement of body composition and energy expenditure with labeled water. Obes Res, 1995. 3 Suppl 1: p. 49-57.

25. Veldhuis, J.D., J.N. Roemmich, E.J. Richmond, A.D. Rogol, J.C. Lovejoy, M. Sheffield-Moore, et al., Endocrine control of body composition in infancy, childhood, and puberty. Endocr Rev, 2005. 26(1): p. 114-46.

26. Ahmed, M.L., K.K. Ong, A.P. Watts, D.J. Morrell, M.A. Preece, and D.B. Dunger, Elevated leptin levels are associated with excess gains in fat mass in girls, but not boys, with type 1 diabetes: longitudinal study during adolescence. J Clin Endocrinol Metab, 2001. 86(3): p. 1188-93.

27. Mitamura, R., K. Yano, N. Suzuki, Y. Ito, Y. Makita, and A. Okuno, Diurnal rhythms of luteinizing hormone, folliclestimulating hormone, and testosterone secretion before the onset of male puberty. J Clin Endocrinol Metab, 1999. 84(1): p. 29-37.

28. Mounzih, K., R. Lu, and F.F. Chehab, Leptin treatment rescues the sterility of genetically obese ob/ob males. Endocrinology, 1997. 138(3): p. 1190-3. 



\section{Chapter 6}

The hypothalamic-pituitary-adrenal axis in the regulation of energy balance

F. Rutters, A.G. Nieuwenhuizen

Physiology and Behavior 2008 May 23; 94 (2): 169-77 


\begin{abstract}
Human (visceral) obesity is associated with alterations hypothalamus-pituitary-adrenal (HPA) axis functioning. It is however not completely clear whether the HPA axis is causally or co-incidentally related to (visceral) obesity. This review summarizes supporting data of an involvement of the HPA axis in the development of (visceral) obesity. First, several DNA polymorphisms related to HPA axis functioning are correlated to the development of obesity. Second, chronic elevation of circulatory glucocorticoid concentrations, as in Cushing's disease, results in increased abdominal adiposity. Third, (visceral) obesity is associated with a diminished capacity of cortisol to suppress its own secretion. HPA axis functioning might affect energy balance through affecting energy intake. Both CRH and cortisol influence physiological, central mechanisms involved in the regulation of food intake. Still, general activation of the HPA axis has shown to have inconsistent effects on food intake in humans. This inconsistency may partially be explained by gender differences, individual differences in the functioning of the HPA axis, as well as differences in attitude towards eating. In particular, women with high scores on dietary restraint are prone to stress-induced hyperphagia. Dietary restraint scores, in turn, are positively correlated to basal and dexamethasone-suppressed cortisol levels, indicating a complex dual relationship between stress, HPA axis functioning, attitude towards eating and the risk for stress-induced hyperphagia. In the Western society, with chronically high ambient levels of stress and the availability of high caloric foods, this relationship may imply a risk for the development of (visceral) obesity and the metabolic syndrome.
\end{abstract}




\section{Introduction}

Evidence suggests that the HPA axis is involved in the pathogenesis of human obesity, in particular characterized by visceral fat distribution. The HPA axis functioning plays an important role in the regulation of energy balance and body weight; it is, however, not completely clear whether the HPA axis is causally or co-incidentally related to the development of (visceral) obesity.

The hypothalamus-pituitary-adrenal (HPA) axis is a neuro-endocrine system involved in the stress-response, by regulating the secretion of cortisol [1]. The cascade of the HPA axis beholds that first the hypothalamus produces and releases corticotropin-releasing hormone $(\mathrm{CRH})$, which subsequently stimulates the synthesis and release of adrenocortiocotropin ( $\mathrm{ATCH}$ ) from the anterior pituitary. ACTH is produced from a larger precursor namely the proopiomelanocortin (POMC) protein, and stimulates the synthesis and release of cortisol by the adrenal cortex. In the circulation, cortisol is bound to corticosteroid-binding globulin (CBG) with high affinity, facilitating transport of cortisol in blood, followed by conversion of cortisol at the peripheral level by $11 \mathrm{~b}$ hydroxysteroid dehydrogenase (11b-HSD) 1 and $11 \mathrm{~b}-\mathrm{HSD} 11$. The $11 \mathrm{~b}-\mathrm{HSD} 1$ enzyme, converts cortisone into the active form, and 11b-HSD 11 inactivates cortisol by conversion into cortisone. Cortisol exerts his actions through binding to and activation of two types of intracellular receptors, the glucocorticoid receptor (GR) and mineralocorticoid receptor (MR). The GR initiates or represses gene transcription, and induces negative feedback of the HPA axis through GR on the hypothalamus and pituitary level. The MR regulates basal activity of the HPA axis. Physiological cortisol levels follow a circadian rhythm; an early morning peak after awakening, a rapid decrease over the next few hours, and then a more gradual decline over the course of the day, to very low levels by bedtime [2].
Addison's disease and Cushing's syndrome represent two extremes of plasma cortisolism in human pathology. Addison's disease shows hypocortisolism, which causes symptoms such as fatigue, muscle weakness, changes in mood, and weight loss [3]. Also hypocortisolism caused by adrenalectomy will induce body weight loss in humans [4]. In animals, adrenalectomy will even prevent genetic as well as diet-induced form of obesity [5]. Cushing's syndrome is characterized by hypercortisolism, which causes symptoms such as hypertension, insulin resistance, hyperglycemia and rapid weight gain, particularly of the trunk and face with sparing of the limbs [6]. In the adipose tissue the glucocorticoids promote differentiation of pre-adipocytes into mature adipocytes and increase lipoprotein lipase activity, thus promoting adipose tissue increase and weight gain [7]. The clinical observations in Addison's disease and Cushing's syndrome clearly demonstrate a role for the HPA axis in the regulation of energy balance [8].

The pathology of visceral obesity shows a marked resemblance with Cushing's syndrome, including a central fat distribution of excess body-fat mass, elevated blood pressure, insulin resistance, and dyslipidemia. This form of obesity is associated with hypercortisolism, which becomes more pronounced when the HPA axis is stimulated (physiological or psychological) [9-11] and is associated with a diminished capacity of a low-dose $(0.5 \mathrm{mg})$ dexamethasone (a GR agonist) to suppress plasma cortisol concentrations [12]. The latter finding suggest that the negative feedback loop, with cortisol activity on GR in both the hypothalamus and pituitary to inhibit HPA axis activity, is impaired in visceral obese subjects. This might explain (partially) the HPA hyperactivity and hypercortisolism of visceral obesity. In contrast, obese with a more peripheral body fat distribution do not show health risk markers, hypercortisolism, and diminished feedback capacity. 
This review summarizes supporting data of an involvement of HPA axis hyperactivity in the development of (visceral) obesity. We start by describing physiological consequences of polymorphisms related to HPA axis functioning and the development of obesity. This will be followed by description of pathways through which the HPA axis might affect energy balance, and ultimately body weight, which will lead to a proposal of a model on the relationship between alterations in HPA axis functioning and (visceral) obesity.

\section{Physiological consequences of polymorphisms related to HPA axis functioning}

Visceral obesity shows considerable heritability, which results from contributions from many genes, so it is plausible that genetic variation in the cascade of the HPA axis may be involved in visceral obesity development [13]. Several polymorphisms in the cascade of the HPA axis have been described in the literature, which cause differences in HPA functioning and/or are involved in obesity development. In table 1 the polymorphisms, the functional variation in HPA axis functioning caused by the mutations, and the possible association to obesity have been described.

Regarding the initial step of the HPA axis cascade, a variant in the $5^{\prime}$-flaking region of the corticotropin-releasing hormone (CRH) gene (T255G) the of ( $\mathrm{CRH}$ ) has been found. This polymorphism has been associated with increased cortisol levels during physiological stress and total diurnal cortisol secretion, when combined with a variant in the gene of the GR. Still, no association between the T255G mutation and obesity has been shown yet [14].

With respect to functional variations of the POMC gene related to ACTH production, a rare mutation in exon 2 (C3804A) of the POMC gene, that causes ACTH insufficiency, has been associated with early-onset obesity [15].

Several polymorphisms have been described that can be linked to glucocorticoid action and may be related to specific aspects of obesity. Thus, a (GTTT)n repeat in intron 1 of the corticosteroid-binding globulin (CBG) has been associated with increased proliferation/differentiation of preadipocytes, higher salivary cortisol after dexamethasone suppression test, higher waist-to-hip ratio and a higher risk on obesity development $[16,17]$.

At the level of cortisol conversion, the ns4436A polymorphism of the $11 \mathrm{~b}-$ hydroxysteroid dehydrogenase (11b-HSD) 1 gene has been associated with increased waist-to-hip ratio in women and pediatric obesity. No functional variation in HPA axis functioning caused by the ns $4436 \mathrm{~A}$ polymorphism has been described yet [18]. Additionally, a polymorphism at the (CA)n repeat in the first intron of the $11 \mathrm{~b}$ HSD 11 gene has been associated with increased activity of the $11 \mathrm{~b}-\mathrm{HSD} 11$ enzyme in vitro, which was observed in the subcutaneous adipose tissue of obese men. This results in higher local cortisol levels in adipose tissue and an increase in the ratio of urinary free cortisol/urinary free cortisone [19].

At the level of cortisol binding by the glucocorticoid receptor (GR) and mineralocorticoid receptor (MR) several polymorphisms have been described [20]. Three of the most prominent polymorphisms in the GR gene are the N363S, ER22/23EK and BclI polymorphisms, which all have been associated to obesity. The N363S polymorphism has been associated with increased glucocorticoid sensitivity, increased BMI, increased waist-hip ratio, and increased cholesterol levels [21, 22]. Secondly, the ER22/23EK polymorphism, which has been associated with decreased glucocorticoid sensitivity, decreased cholesterol levels, decreased insulin levels, and increased fat free mass [23]. Thirdly, the BclI polymorphism which has been associated with increased glucocorticoid sensitivity, increased insulin levels, increased blood pressure, increased abdominal visceral fat, and increased cholesterol levels [14, 24-26]. The most common described polymorphism in the MR gene is the 
Table 1: Description of polymorphisms in the cascade of the HPA axis

\begin{tabular}{llll}
\hline Gene & Name & Obesity & Functional genetic variant \\
\hline Corticotropin-releasing hormone (CRH) & T255G & No & increase cortisol levels \\
Proopiomelanocortin (POMC) & Exon 3 (AAC) (AGC) $)_{2}(\mathrm{GGC})$ & No & No influence \\
Proopiomelanocortin (POMC) & C3804A & yes & ACTH insufficiency \\
Corticosteroid binding globulin (CBG) & Intron 1 (GTT) $)_{n}$ repeat & yes & Decrease feedback functioning \\
11 b-HSD 1 & ns4436A & yes & No influence \\
11 b-HSD 11 & Intron 1 (CA) repeat & yes & increase local cortisol levels \\
Glucocorticoid receptor (GR) & N363S & yes & Increase cortisol sensitivity \\
Glucocorticoid receptor (GR) & ER22/23EK & yes & Decrease cortisol sensitivity \\
Glucocorticoid receptor (GR) & BclI & yes & increase cortisol sensitivity \\
Mineralocorticoid receptor (MR) & M180V & no & increase cortisol secretion \\
\hline
\end{tabular}

MR180V polymorphism, which has been shown to enhance responses in cortisol secretion to a psychological stressor. In vitro studies showed a mild loss of function of the MR180V polymorphism, when cortisol was used as a ligand [27]. No associations have been found between the MR180V allele and the prevalence of obesity.

One can conclude that genetic variation in the cascade of the HPA axis does not only influence HPA axis functioning, but is also frequently related to differences in body composition and metabolic parameters. These findings stress that the HPA axis plays an essential role in the regulation of body weight, body composition and energy balance. The next paragraphs will extend on the physiological role of the HPA axis in the regulation of energy balance.

\section{HPA axis functioning and energy balance}

In the literature several possible mechanisms have been described through which the HPA axis might affect energy balance, which is composed of energy intake and energy expenditure. Obesity results from a chronic deregulation of energy balance, with energy intake exceeding energy expenditure, which leads to the storage of the excessive energy as fat.

\section{HPA axis functioning and energy intake}

The literature consists of ample human data on the effects of stress on food intake [28]; however, these data are difficult to interpret with respect to the role of the HPA axis for various reasons.
First of all, a wide variation in the type of stressor is used, resulting in different outcomes. Thus, stress in the workplace has been associated with higher energy intake $[29,30]$ while examination stress and surgical stress have produced mixed results $[31,32]$. Secondly, there is a large inter-individual variance in HPA axis responses, i.e., plasma ACTH and cortisol production, to stress $[8,33]$. A few studies on the effects of stress on food intake included measurements of plasma cortisol levels [34, 35]. Both studies showed a higher increase in stressinduced food intake in women who showed high cortisol responses to the stressor, suggesting a relationship between cortisol responses and food intake.

Most of the data directly indicating a crucial role of the HPA axis in the regulation of food intake are derived from animal studies, showing that the anorectic effects of adrenalectomy can be reversed by glucocorticoid (corticosterone) replacement $[36,37]$. Human studies on the effects of glucocorticoids on food intake are limited, but generally support the findings in laboratory animals of an orexigenic effect of glucocorticoids [7, 33]. The stimulation of food intake by glucocorticoids seems to be macronutrient specific: when rats had a free choice for different chow compositions, corticosterone withdrawal (adrenalectomy) and subsequent replacement principally affected carbohydrate intake $[38,39]$. In another paradigm, where adrenalectomized rats were offered a choice between chow and lard, corticosterone replacement dosedependently increased intake of the more 
palatable lard, but only in the presence of insulin [37]. These actions of glucocorticoids may underlie the preference for certain macronutrients and kinds of foods in humans after stress, in particular high saturated fat and sweet food items [30, 34, 40, 41]. Additionally, studies have shown that snack consumption may be more susceptible to stress-induced eating than meals [42]. Such foods may be preferred during stressful conditions, through learning that small energy-dense snacks are more easily ingested and digested when gut activity is suppressed by sympathetic arousal [43]. Several homeostatic and non-homeostatic mechanisms have been proposed through which HPA axis functioning may regulate food intake, and they will be discussed below.

\section{HPA axis functioning and homeostatic regulation of food intake}

The HPA axis seems to have many crosslinks with the neuro-endocrine pathways that control the homeostatic regulation of food intake [44]. First of all, the CRH containing neurons, which comprise the initial component of the HPA axis, are located in the paraventricular nucleus (PVN) of the hypothalamus, which is also considered to be a major centre in the control of feeding behavior [45]. Central (intraventricular) administration of $\mathrm{CRH}$ inhibits feeding in rats $[45,46]$, and $\mathrm{CRH}$ is suggested to be an important intermediate in the anorectic effects of leptin [46-48] The hypophagic effect of central CRH may (in part) result from inhibitory control of the orexigenic neural pathways involving neuropeptide Y (NPY), as paraventricular administration of the CRH-antagonist, alpha-helical CRF9-41, potentiated NPY-induced food intake [49]. $\mathrm{CRH}$ may be involved in the pathogenesis of obesity, at least in specific animal models: in the obese $\mathrm{fa} / \mathrm{fa}$ zucker rat a reduced level of CRH mRNA expression has been found [50]. Whether $\mathrm{CRH}$ is also involved in the pathogenesis of human obesity is unknown, but when subcutaneous fat cells from humans were incubated in vitro with $\mathrm{CRH}$, it decreased 11b-HSD 11 enzyme activity, thereby reducing local cortisol production and reducing adiposity [48].

Thus, CRH exerts an opposite effect on appetite when compared to glucocorticoids. Physiologically, the (later) orexigenic effect of glucocorticoids, following the anorectic effect of $\mathrm{CRH}$ at the beginning of the stress response, may play a role in the recovery stage for the replacement of the replenishment of energy required during the 'fight of flight response'. The inhibitory effects of glucocorticoids on hypothalamic $\mathrm{CRH}$ release [46] may be involved in the stimulatory effect of glucocorticoids on food intake.

The opposite effects of $\mathrm{CRH}$ and glucocorticoids on food intake also emerge at a mechanistic level: where $\mathrm{CRH}$ exerts inhibitory control on NPY-induced food intake [49], (central) glucocorticoids potentiate the orexigenic actions of NPY. Additionally, dexamethasone stimulated NPY release in the mediobasal hypothalamus of female rats, and NPY production of cultured hypothalamic neurons [47]. In addition, recent research shows that cortisol up regulates the NPY Y2 receptor in the abdominal fat. Release of NPY and activation of the NPY Y2 receptor stimulates fat angiogenesis, proliferation and differentiation of new adipocytes, thereby linking HPA axis activation, NPY and increased abdominal fat storage [51].

The HPA axis interferes with leptin release, in that glucocorticoids stimulate secretion of leptin by (rat) adipocytes [52]. This stimulatory effect of cortisol on leptin secretion has also been shown in vivo $[53,54]$. On the other hand, glucocorticoids may reduce the efficacy of leptin to suppress food intake, hence, induce leptin resistance. In rats, adrenalectomy has shown to increase the anorectic potency of leptin, while this effect was reversed by glucocorticoid replacement [55]. Leptin exerts its anorectic actions in part through activation of the central melanocortin system [56]. Similar to the results on leptin, the anorectic response to the melanocortin agonist, melanotan II, in 
rats is enhanced by adrenalectomy, which can be reversed by glucocorticoid replacement [39]. These data suggest that glucocorticoids potentially decrease leptin sensitivity, partially through inducing insensitivity to central melanocortins. Induction of leptin resistance may also explain why glucocorticoid administration in humans results in elevated leptin concentrations on the one hand, and an increased food intake on the other [7]. Indeed, HPA axis hyperactivity, and a subsequent elevation of glucocorticoid concentrations, has been hypothesized to be involved in the leptin resistance of human obesity $[57,58]$.

Glucocorticoids also interact with the action and secretion of insulin, another endocrine adiposity signal. In vitro, glucocorticoids interfere with insulininduced glucose uptake and metabolism in both cultured myocytes and adipocytes [59-62]. In vivo, dexamethasone administration to humans decreases whole body insulin sensitivity $[63,64]$. This is associated with a compensatory increase in plasma insulin concentrations [65]. Since intraventricular administration of insulin has shown to suppress food intake [66], one might speculate that insulin (or insulin resistance) is involved in the effects of glucocorticoids on energy intake. Still, studies in glucocorticoidtreated adrenalectomized, streptozotocindiabetic rats showed that total energy intake was not affected by insulin supplementation [36, 37], although insulin did dose-dependently increase the relative contribution of palatable high-fat food to total energy consumption [37]. Thus, insulin is likely to be involved in the effects of glucocorticoids on feeding behavior through modulation of food choice, rather than energy intake. Furthermore, through its anabolic actions on adipocytes, the hyperinsulinaemia caused by glucocorticoids may facilitate fat deposition. Remarkably, dexamethasone and insulin synergistically stimulate lipoprotein lipase activity in human adipose tissues, thereby facilitating free fatty acid uptake and lipogenesis [67].

\section{HPA axis functioning and non- homeostatic regulation of food intake}

In addition to the hypothalamic homeostatic pathways involved in food intake regulation, cortico-limbic brain areas are important structures for determining non-homeostatic regulation of food intake. These brain areas are involved in processes such as cognition, reward, memory and cognition, which are able to overrule the above-mentioned homeostatic regulatory mechanisms [44].

To a certain extent, humans show tendencies to cognitively moderate their food intake, a phenomenon that has been called "dietary restraint". Under some conditions, however, some subjects loose their cognitive control of caloric intake, which is called "disinhibition". The level of dietary restraint and disinhibition can be assessed by using specific questionnaires, such as the Three Factor Eating Questionnaire (TFEQ) [68]. We previously showed [Rutters, submitted] that the level of dietary restraint was positively correlated to 5-hour plasma cortisol patterns, and negatively correlated to the ability of the GR-agonist, dexamethasone, to suppress cortisol release under a strenuous exercise protocol. Accordingly, three studies reported that salivary cortisol at one time point (time point not specified) and 24-hour cortisol excretion were significantly higher in restrained women compared to unrestrained women [69-71]. Notably, some other studies did not find this relationship [72-74], possibly because cortisol concentrations where only measured at one time point or during the night.

One can speculate about the causality of this relationship. Although it cannot be excluded that high ambient cortisol levels increase cognitive awareness of caloric intake, the opposite (i.e., high level of dietary stress causes HPA axis activity) seems a somewhat more tempting hypothesis. Dietary restraint is positively correlated with body fat percentage [73, $75,76]$, and the load of continuously restrained eating behavior is reportedly perceived as stressful [77]. Still, dietary restraint may be a risk factor for stress- 
induced hyperphagia, as studies showed that restrained eaters experiencing psychological stress increased their food intake, while unrestrained eaters decreased food intake [30, 78-80]. Also, women with high disinhibition scores showed an increase in food intake following psychological stress [81, 82].

In the concept of non-homeostatic regulation of food intake, as lined out by Berthoud [44], food reward plays an important role. Like addictive drugs, palatable foods may act as a reinforcer, thereby influencing their own intake. Berridge and Robinson defined two distinct psychological processes determining the reinforcing value: "liking" and "wanting" [83]. These processes are regulated by different neural networks and mediated by different neurotransmitters [84]. In the process of "liking", mu-opioid systems in the nucleus accumbens seem to play an important role $[85,86]$. Thus, local administration of the opioid agonist, morphine, or the mu-opioid agonist, (dAla(2), N-Me-Phe(4), Glycinol(5))enkephalin (DAMGO), into the nucleus accumbens of rats increased food intake $[85,87]$. In humans, the opioid antagonist, naltrexone, results in a reduction of both the intake and the reported pleasantness of food [88-90]. The expression of the mu-opioid receptor, and, hence, opioid sensitivity, is modulated by glucocorticoids: its expression is diminished in $\mathrm{CRH}$-deficient mice and increased by corticosterone administration [91]. Indeed, activation of the endogenous opioid system has been suggested to be involved in stress-induced eating [92].

The endogenous opioid system may exert its effects in interaction with the endocannabinoid system, which has also been shown to be involved in the regulation of feeding behavior [93] and reward [94]. Endocannabinoid receptors of the CB1 type are abundantly expressed in the nucleus accumbens [95], and combined administration of the opioid antagonist, naloxone, and the CB1 receptor antagonist SR141716 decrease food intake in rats in a synergistic fashion [96]. Direct evidence for a role of endocannabinoids in the orexigenic effects of glucocorticoids is lacking at present, but it is noteworthy that the endocannabinoid antagonist, AM281, antagonizes the effects of corticosterone on neuronal activity and on sexual behavior in amphibians [97].

With respect to the "wanting" or motivational aspect of reward, it is thought that dopamineric neurons, originating the ventral tegmental area (VTA) of the mid brain, and projecting to forebrain areas such as the orbitofrontal cortex and the nucleus accumbens or ventral striatum play a crucial role [83]. In rats, peripheral administration of corticosterone increases dopamine outflow in the nucleus accumbens [98]. Hence, both in rats [99] and in humans [100] glucocorticoids are suggested to contribute to the stress-induced increase of dopamine release in this brain area. The relationship between (striatal) dopamine and food intake seems, however, rather complex. Dopamine acts through several dopamine receptors (D1D5), which seem to mediate distinct effects on food intake and food preference: selective D1 receptor activation resulted in increased caloric intake and preference for highly palatable foods, whereas combined D2/D3 activation showed an opposite effect [101]. Human studies showed that a single bolus administration the dopamine transporter protein (DAT)-inhibitor, methylphenidate, results in a reduction of food intake, suggesting that high synaptic dopamine levels reduce the reinforcing value of food [102]. In contrast to acute effects, chronic elevation of synaptic dopamine may result in an increased wanting for rewarding foods, as indicated by the increased efforts and motivation of DAT-knockdown mice to obtain a sweet reward [103]. Possibly, shifts in the sensitivity and/or distribution of the different dopamine receptors may underlie this apparent discrepancy. In this case, it is noteworthy that obese subjects exhibit lower striatal D2 receptor availability [104], hence, it cannot be excluded that 
in obesity the orexigenic effect of D1 activation may become considerably more predominant in the effects of dopamine on food intake. Whether this mechanism is also involved in the effects of glucocorticoids or stress on food intake in obesity, however, needs to be established. It should be noted, however, that above homeostatic and non-homeostatic pathways regulating feeding behavior are not 2 completely separate neural systems: significant interaction at different levels exists. In this respect, the adipocytederived hormone, leptin, has gained a particular interest. Leptin receptors have been found in the VTA, leptin has been shown to reduce firing rate of VTA dopaminergic neurons in brain slices, and direct administration of leptin into the VTA of rats decreased food intake [105]. Notably, a decreased performance in behavioral paradigms that assess the rewarding properties of food has also been observed when leptin was administered intracerebroventricular [106] and even intrahypothalamic [107]. Thus, leptin may reduce food intake by lowering the rewarding value of food. It is tempting to speculate that the leptin resistance following glucocorticoid suppletion [55] is also represented by a diminished influence of leptin on the neuronal pathways involved in food reward $[43,56]$. In conclusion we described several mechanisms such as hormonal pathways, food reward and dietary restraint, through which HPA axis functioning influences energy intake, but also energy expenditure is influenced.

\section{HPA axis functioning and energy expenditure}

With respect to the effect of HPA axis functioning on energy expenditure, the literature is not as extensive as on the effect on energy intake. Like with the regulation of food intake, $\mathrm{CRH}$ and cortisol may exert distinct effects on energy expenditure. CRH infusion in humans resulted in a $14 \%$ increase in resting energy expenditure [108]. CRH may act through activation of the central sympathetic system, both in the hypothalamus as well as in the locus ceruleus of the brain stem [1]. However, as the increase in energy expenditure following $\mathrm{CRH}$ infusion was not associated with increases in plasma catecholamines, other mechanisms may also be involved.

With respect to the effects of glucocorticoids on energy expenditure, the literature shows a dichotomous response. When hydrocortisone was infused for 60 $h$, it led to an increase in resting energy expenditure [109]. Also, when hydrocortisone was infused for $16 \mathrm{~h}$ at two different concentrations, it lead to an increase in resting energy expenditure of $9-15 \%$ [110]. On the contrary, two other studies showed that infusion of glucocorticoids for $168 \mathrm{~h}$ did not alter energy expenditure [111]. In addition, chronic dexamethasone treatment in infants did not affect energy expenditure [112]. Also, no difference in resting energy expenditure (corrected for the amount of lean body mass) was found between normal and patients with Cushing's syndrome $[113,114]$. It may be hypothesized that glucocorticoids exert dual effects on energy expenditure, and that the stimulatory actions of glucocorticoids on energy expenditure $[109,110]$ are overruled by other, inhibitory actions during prolonged or chronic exposure [115].

Several mechanisms may underlie the inhibition of energy expenditure by glucocorticoids. Firstly, suppression of $\mathrm{CRH}$ release by glucocorticoids as part of the negative feedback regulation of HPA axis functioning [1]. Secondly, it has been shown that chronic increased levels of cortisol in Cushing's disease leads to inhibition and promotes breakdown of muscle, resulting in muscle wastage. Since the amount of muscle mass is positively correlated to (resting) energy expenditure, chronic hypercortisolism, as in patients with Cushing's disease, may ultimately result in lower energy expenditure [61]. Thirdly, glucocorticoids have shown to affect the hypothalamuspituitary-thyroid axis. Glucocorticoids inhibit the production of thyrotropinreleasing hormone as well as thyroid- 
stimulating hormone, and the conversion of thyroxine (T4) to triiodothyronine (T3), ultimately resulting in decreased plasma T3 levels $[1,116]$, which may subsequently result in a reduced basal metabolic rate [115].

In summary we described that glucocorticoids exert dual effects on energy expenditure, and that the stimulatory actions of glucocorticoids on energy expenditure are overruled by other, inhibitory actions during prolonged or chronic exposure.

\section{Summary and conclusions}

The hypothalamus-pituitary-adrenal axis affects energy balance on different levels, at different ways, and with different underlying mechanisms. All in all, prolonged exposure to elevated glucocorticoid levels may result in a positive energy balance, by increasing energy intake, without affecting resting energy expenditure. The stimulatory effects of glucocorticoids on energy intake may involve both homeostatic and nonhomeostatic pathways involved in the regulation of eating behavior. The homeostatic pathways may include a suppression of $\mathrm{CRH}$ release, induction of leptin resistance and the stimulation of NPY release. Non-homeostatic pathways may include the individuals' attitude towards eating, as well as neural systems involved in both the "wanting"

(dopaminergic) and "liking" (opioidergic) aspects of food reward. The latter systems may, just such as insulin [37], also be involved in a shift in food choice towards high energetic sweet and high fat foods. The effects of glucocorticoids on energy expenditure may depend on the duration of exposure, with mechanisms such as a decrease in $\mathrm{CRH}$ release, increased loss of lean body mass and decreased circulating T3 levels ultimately counteracting an initial stimulation of resting metabolic rate.

The resulting positive energy balance is likely to result in increased lipogenesis and fat storage, under influence of glucocorticoids and elevated concentrations of insulin. In addition, glucocorticoids may even increase adipogenesis due to an up-regulation of the NPY Y2 receptor in abdominal adipose tissue [51]. Notably, visceral adipocytes have a fourfold higher number of glucorticoid receptors than adipocytes in other fat depots [8]. Accordingly, the stimulatory effects of dexamethasone on lipoprotein lipase activity were more pronounced in visceral adipocytes than in subcutaneous adipocytes [67]. Thus, the increased fat storage due to prolonged hypercortisolism may show some sitespecificity, with a preference for the visceral regions.

The increased adiposity may lead to an increase in weight dissatisfaction [75], which will lead to dieting in an attempt achievement and maintenance of desired body weight. Dieting is done through cognitively controlling eating behavior and, hence, is accompanied with an increase in dietary restraint [117]. However, dietary restraint can act as a chronic physiological stressor, and like all other chronic stress will lead to alterations in HPA axis functioning. We found that the level of dietary restraint was positively correlated to 5-hour plasma cortisol patterns, and negatively correlated to the ability of the GR-agonist, dexamethasone, to suppress cortisol release under a strenuous exercise protocol [Rutters, in press].

Therefore, we propose that chronic hyperactivity of the HPA axis initiates a vicious circle (figure 1), which puts chronic stress as a major risk factor for excessive weight gain and (visceral) obesity. Whether this mechanism is the primary cause for the obese state in the visceral obese remains to be elucidated, but it should be noted that HPA axis hyperactivity is typical in visceral obese subjects [9-11] and that HPA axis functioning in obese women was not significantly affected by weight loss [118]. Therefore, the HPA axis may therefore be an important causal factor in to the obesity epidemics of the Western society, where high levels of ambient stress and availability of high fat, sweet foods are abundantly present. 
Figure 1: a model for the possible relationship between HPA axis functioning, eating behavior, energy balance, and body composition (solid lines represent stimulation and dashed lines represent inhibition).

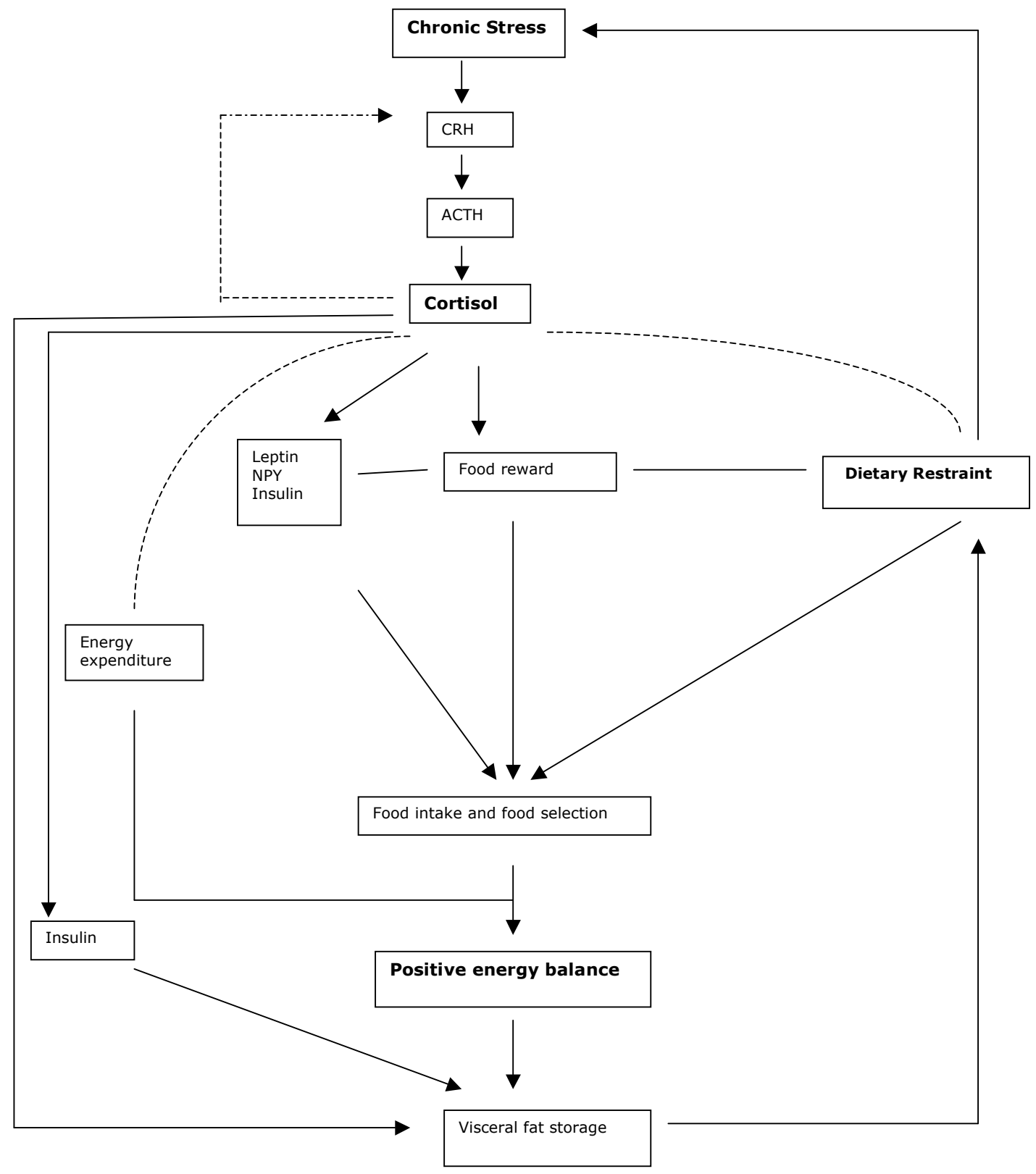




\section{References}

1. Tsigos, C. and G.P. Chrousos, Hypothalamic-pituitary-adrenal axis, neuroendocrine factors and stress. J Psychosom Res, 2002. 53(4): p. 865-71.

2. Kurina, L.M., L.A. Weiss, S.W. Graves, R. Parry, G.H. Williams, M. Abney, et al., Sex differences in the genetic basis of morning serum cortisol levels: genome-wide screen identifies two novel loci specific to women. J Clin Endocrinol Metab, 2005. 90(8): p. 4747-52.

3. Lovas, K. and E.S. Husebye, Continuous subcutaneous hydrocortisone infusion in Addison's disease. Eur J Endocrinol, 2007. 157(1): p. 109-12.

4. Bethune, J.E., Interpretation of thyroid function tests. Dis Mon, 1989. 35(8): p. 541-95.

5. Okada, S., T. Onai, G. Kilroy, D.A. York, and G.A. Bray, Adrenalectomy of the obese Zucker rat: effects on the feeding response to enterostatin and specific mRNA levels. Am J Physiol, 1993. 265(1 Pt 2): p. R21-7.

6. Hankin, M.E., H.M. Theile, and A.W. Steinbeck, An evaluation of laboratory tests for the detection and differential diagnosis of Cushing's syndrome. Clin Endocrinol (Oxf), 1977. 6(3): p. 185-96.

7. Tataranni, P.A., D.E. Larson, S. Snitker, J.B. Young, J.P. Flatt, and E. Ravussin, Effects of glucocorticoids on energy metabolism and food intake in humans. Am J Physiol, 1996. 271(2 Pt 1): p. E317-25.

8. Bjorntorp, P. and R. Rosmond, Obesity and cortisol. Nutrition, 2000. 16(10): p. 924-36.

9. Marin, P., N. Darin, T. Amemiya, B. Andersson, S. Jern, and P. Bjorntorp, Cortisol secretion in relation to body fat distribution in obese premenopausal women. Metabolism, 1992. 41(8): p. 882-6.

10. Pasquali, R., B. Anconetani, R. Chattat, M. Biscotti, G. Spinucci, F. Casimirri, et al., Hypothalamic-pituitary-adrenal axis activity and its relationship to the autonomic nervous system in women with visceral and subcutaneous obesity: effects of the corticotropin-releasing factor/arginine-vasopressin test and of stress. Metabolism, 1996. 45(3): p. 351-6.

11. Rosmond, R., M.F. Dallman, and P. Bjorntorp, Stress-related cortisol secretion in men: relationships with abdominal obesity and endocrine, metabolic and hemodynamic abnormalities. J Clin Endocrinol Metab, 1998. 83(6): p. 1853-9.

12. Ljung, T., B. Andersson, B.A. Bengtsson, P. Bjorntorp, and P. Marin, Inhibition of cortisol secretion by dexamethasone in relation to body fat distribution: a dose-response study. Obes Res, 1996. 4(3): p. 277-82.

13. Bjorntorp, P., Thrifty genes and human obesity. Are we chasing ghosts? Lancet, 2001. 358(9286): p. 1006-8

14. Rosmond, R., Y.C. Chagnon, M. Chagnon, L. Perusse, C. Bouchard, and P. Bjorntorp, A polymorphism of the 5'flanking region of the glucocorticoid receptor gene locus is associated with basal cortisol secretion in men. Metabolism, 2000. 49(9): p. 1197-9.

15. Krude, H., H. Biebermann, W. Luck, R. Horn, G. Brabant, and A. Gruters, Severe early-onset obesity, adrenal insufficiency and red hair pigmentation caused by POMC mutations in humans. Nat Genet, 1998. 19(2): p. 155-7.

16. Joyner, J.M., L.J. Hutley, A.W. Bachmann, D.J. Torpy, and J.B. Prins, Greater replication and differentiation of preadipocytes in inherited corticosteroid-binding globulin deficiency. Am J Physiol Endocrinol Metab, 2003. 284(5): p. E1049-54.

17. Barat, P., M. Duclos, B. Gatta, P. Roger, P. Mormede, and M.P. Moisan, Corticosteroid binding globulin gene polymorphism influences cortisol driven fat distribution in obese women. Obes Res, 2005. 13(9): p. 1485-90.

18. Gelernter-Yaniv, L., N. Feng, N.G. Sebring, Z. Hochberg, and J.A. Yanovski, Associations between a polymorphism in the 11 beta hydroxysteroid dehydrogenase type I gene and body composition. Int J Obes Relat Metab Disord, 2003. 27(8): p. 983-6.

19. White, P.C., Genotypes at 11beta-hydroxysteroid dehydrogenase type 11B1 and hexose-6-phosphate dehydrogenase loci are not risk factors for apparent cortisone reductase deficiency in a large population-based sample. J Clin Endocrinol Metab, 2005. 90(10): p. 5880-3.

20. van Rossum, E.F. and S.W. Lamberts, Polymorphisms in the glucocorticoid receptor gene and their associations with metabolic parameters and body composition. Recent Prog Horm Res, 2004. 59: p. 333-57.

21. Huizenga, N.A., J.W. Koper, P. De Lange, H.A. Pols, R.P. Stolk, H. Burger, et al., A polymorphism in the glucocorticoid receptor gene may be associated with and increased sensitivity to glucocorticoids in vivo. J Clin Endocrinol Metab, 1998. 83(1): p. 144-51.

22. Dobson, M.G., C.P. Redfern, N. Unwin, and J.U. Weaver, The N363S polymorphism of the glucocorticoid receptor: potential contribution to central obesity in men and lack of association with other risk factors for coronary heart disease and diabetes mellitus. J Clin Endocrinol Metab, 2001. 86(5): p. 2270-4.

23. van Rossum, E.F., J.W. Koper, N.A. Huizenga, A.G. Uitterlinden, J.A. Janssen, A.O. Brinkmann, et al., A polymorphism in the glucocorticoid receptor gene, which decreases sensitivity to glucocorticoids in vivo, is associated with low insulin and cholesterol levels. Diabetes, 2002. 51(10): p. 3128-34.

24. Weaver, J.U., G.A. Hitman, and P.G. Kopelman, An association between a Bc1I restriction fragment length polymorphism of the glucocorticoid receptor locus and hyperinsulinaemia in obese women. J Mol Endocrinol, 1992. 9(3): p. 295-300.

25. Watt, G.C., S.B. Harrap, C.J. Foy, D.W. Holton, H.V. Edwards, H.R. Davidson, et al., Abnormalities of glucocorticoid metabolism and the renin-angiotensin system: a four-corners approach to the identification of genetic determinants of blood pressure. J Hypertens, 1992. 10(5): p. 473-82.

26. Ukkola, O., R. Rosmond, A. Tremblay, and C. Bouchard, Glucocorticoid receptor Bcl I variant is associated with an increased atherogenic profile in response to long-term overfeeding. Atherosclerosis, 2001. 157(1): p. 221-4.

27. DeRijk, R.H., S. Wust, O.C. Meijer, M.C. Zennaro, I.S. Federenko, D.H. Hellhammer, et al., A common polymorphism in the mineralocorticoid receptor modulates stress responsiveness. J Clin Endocrinol Metab, 2006. 91(12): p. 5083-9.

28. Adam, T.C. and E.S. Epel, Stress, eating and the reward system. Physiol Behav, 2007. 91(4): p. 449-58.

29. McCann, B.S., G.R. Warnick, and R.H. Knopp, Changes in plasma lipids and dietary intake accompanying shifts in perceived workload and stress. Psychosom Med, 1990. 52(1): p. 97-108.

30. Wardle, J., A. Steptoe, G. Oliver, and Z. Lipsey, Stress, dietary restraint and food intake. J Psychosom Res, 2000. 48(2): p. 195-202.

31. Pollard, T.M., A. Steptoe, L. Canaan, G.J. Davies, and J. Wardle, Effects of academic examination stress on eating behavior and blood lipid levels. Int J Behav Med, 1995. 2(4): p. 299-320.

32. Greeno, C.G. and R.R. Wing, Stress-induced eating. Psychol Bull, 1994. 115(3): p. 444-64.

33. Singh, A., J.S. Petrides, P.W. Gold, G.P. Chrousos, and P.A. Deuster, Differential hypothalamic-pituitary-adrenal axis reactivity to psychological and physical stress. J Clin Endocrinol Metab, 1999. 84(6): p. 1944-8. 
34. Epel, E., R. Lapidus, B. McEwen, and K. Brownell, Stress may add bite to appetite in women: a laboratory study of stress-induced cortisol and eating behavior. Psychoneuroendocrinology, 2001. 26(1): p. 37-49.

35. Newman, E., D.B. O'Connor, and M. Conner, Daily hassles and eating behaviour: the role of cortisol reactivity status. Psychoneuroendocrinology, 2007. 32(2): p. 125-32.

36. la Fleur, S.E., The effects of glucocorticoids on feeding behavior in rats. Physiol Behav, 2006. 89(1): p. 110-4

37. la Fleur, S.E., S.F. Akana, S.L. Manalo, and M.F. Dallman, Interaction between corticosterone and insulin in obesity: regulation of lard intake and fat stores. Endocrinology, 2004. 145(5): p. 2174-85.

38. Tempel, D.L. and S.F. Leibowitz, PVN steroid implants: effect on feeding patterns and macronutrient selection. Brain Res Bull, 1989. 23(6): p. 553-60.

39. Drazen, D.L., M.D. Wortman, M.W. Schwartz, D.J. Clegg, G. van Dijk, S.C. Woods, et al., Adrenalectomy alters the sensitivity of the central nervous system melanocortin system. Diabetes, 2003. 52(12): p. 2928-34.

40. Zellner, D.A., S. Loaiza, Z. Gonzalez, J. Pita, J. Morales, D. Pecora, et al., Food selection changes under stress. Physiol Behav, 2006. 87(4): p. 789-93.

41. Kramlik, S.K., M. Altemus, and T.W. Castonguay, The effects of the acute administration of RU 486 on dietary fat preference in fasted lean and obese men. Physiol Behav, 1993. 54(4): p. 717-24.

42. Oliver, G. and J. Wardle, Perceived effects of stress on food choice. Physiol Behav, 1999. 66(3): p. 511-5.

43. Lowe, M.R. and E.B. Fisher, Jr., Emotional reactivity, emotional eating, and obesity: a naturalistic study. J Behav Med, 1983. 6(2): p. 135-49.

44. Berthoud, H.R., Mind versus metabolism in the control of food intake and energy balance. Physiol Behav, 2004. 81(5): p. 781-93.

45. Richardson, R.D., K. Omachi, R. Kermani, and S.C. Woods, Intraventricular insulin potentiates the anorexic effect of corticotropin releasing hormone in rats. Am J Physiol Regul Integr Comp Physiol, 2002. 283(6): p. R1321-6.

46. Benoit, S.C., T.E. Thiele, S.C. Heinrichs, P.A. Rushing, K.A. Blake, and R.J. Steeley, Comparison of central administration of corticotropin-releasing hormone and urocortin on food intake, conditioned taste aversion, and cFos expression. Peptides, 2000. 21(3): p. 345-51.

47. Corder, R., B. Waeber, D. Evequoz, J. Nussberger, R. Gaillard, and H. Brunner, Effect of ganglion blockade with pentolinium on circulating neuropeptide $Y$ levels in conscious rats. J Cardiovasc Pharmacol, 1988. 12(2): p. 140-3.

48. Uehara, Y., H. Shimizu, K. Ohtani, N. Sato, and M. Mori, Hypothalamic corticotropin-releasing hormone is a mediator of the anorexigenic effect of leptin. Diabetes, 1998. 47(6): p. 890-3.

49. Heinrichs, S.C., F. Menzaghi, E.M. Pich, R.L. Hauger, and G.F. Koob, Corticotropin-releasing factor in the paraventricular nucleus modulates feeding induced by neuropeptide Y. Brain Res, 1993. 611(1): p. 18-24.

50. Friedberg, M., E. Zoumakis, N. Hiroi, T. Bader, G.P. Chrousos, and Z. Hochberg, Modulation of 11 betahydroxysteroid dehydrogenase type 1 in mature human subcutaneous adipocytes by hypothalamic messengers. J Clin Endocrinol Metab, 2003. 88(1): p. 385-93.

51. Kuo, L.E., J.B. Kitlinska, J.U. Tilan, L. Li, S.B. Baker, M.D. Johnson, et al., Neuropeptide Y acts directly in the periphery on fat tissue and mediates stress-induced obesity and metabolic syndrome. Nat Med, 2007. 13(7): p. 803-11.

52. Slieker, L.J., K.W. Sloop, P.L. Surface, A. Kriauciunas, F. LaQuier, J. Manetta, et al., Regulation of expression of ob mRNA and protein by glucocorticoids and cAMP. J Biol Chem, 1996. 271(10): p. 5301-4.

53. Laferrere, B., S.K. Fried, K. Hough, S.A. Campbell, J. Thornton, and F.X. Pi-Sunyer, Synergistic effects of feeding and dexamethasone on serum leptin levels. J Clin Endocrinol Metab, 1998. 83(10): p. 3742-5.

54. Askari, H., J. Liu, and S. Dagogo-Jack, Hormonal regulation of human leptin in vivo: effects of hydrocortisone and insulin. Int J Obes Relat Metab Disord, 2000. 24(10): p. 1254-9.

55. Zakrzewska, K.E., I. Cusin, A. Sainsbury, F. Rohner-Jeanrenaud, and B. Jeanrenaud, Glucocorticoids as counterregulatory hormones of leptin: toward an understanding of leptin resistance. Diabetes, 1997. 46(4): p. 717-9.

56. Adan, R.A. and G. van Dijk, Melanocortin receptors as drug targets for disorders of energy balance. CNS Neurol Disord Drug Targets, 2006. 5(3): p. 251-61.

57. Bjorntorp, P., Do stress reactions cause abdominal obesity and comorbidities? Obes Rev, 2001. 2(2): p. 73-86.

58. Jeanrenaud, B. and F. Rohner-Jeanrenaud, CNS-periphery relationships and body weight homeostasis: influence of the glucocorticoid status. Int J Obes Relat Metab Disord, 2000. 24 Suppl 2: p. S74-6.

59. Brown, P.D., S. Badal, S. Morrison, and D. Ragoobirsingh, Acute impairment of insulin signalling by dexamethasone in primary cultured rat skeletal myocytes. Mol Cell Biochem, 2007. 297(1-2): p. 171-7.

60. Sakoda, H., T. Ogihara, M. Anai, M. Funaki, K. Inukai, H. Katagiri, et al., Dexamethasone-induced insulin resistance in 3T3-L1 adipocytes is due to inhibition of glucose transport rather than insulin signal transduction. Diabetes, 2000. 49(10): p. 1700-8.

61. Dallman, M.F., A.M. Strack, S.F. Akana, M.J. Bradbury, E.S. Hanson, K.A. Scribner, et al., Feast and famine: critical role of glucocorticoids with insulin in daily energy flow. Front Neuroendocrinol, 1993. 14(4): p. 303-47.

62. Kolterman, O.G., J. Insel, M. Saekow, and J.M. Olefsky, Mechanisms of insulin resistance in human obesity: evidence for receptor and postreceptor defects. J Clin Invest, 1980. 65(6): p. 1272-84.

63. Binnert, C., S. Ruchat, N. Nicod, and L. Tappy, Dexamethasone-induced insulin resistance shows no gender difference in healthy humans. Diabetes Metab, 2004. 30(4): p. 321-6.

64. van Dijk, G., K. de Vries, L. Benthem, C. Nyakas, B. Buwalda, and A.J. Scheurink, Neuroendocrinology of insulin resistance: metabolic and endocrine aspects of adiposity. Eur J Pharmacol, 2003. 480(1-3): p. 31-42.

65. Nicod, N., V. Giusti, C. Besse, and L. Tappy, Metabolic adaptations to dexamethasone-induced insulin resistance in healthy volunteers. Obes Res, 2003. 11(5): p. 625-31.

66. Benoit, S.C., D.J. Clegg, R.J. Seeley, and S.C. Woods, Insulin and leptin as adiposity signals. Recent Prog Horm Res, 2004. 59: p. 267-85.

67. Fried, S.K., C.D. Russell, N.L. Grauso, and R.E. Brolin, Lipoprotein lipase regulation by insulin and glucocorticoid in subcutaneous and omental adipose tissues of obese women and men. J Clin Invest, 1993. 92(5): p. 2191-8.

68. Stunkard, A.J. and S. Messick, The three-factor eating questionnaire to measure dietary restraint, disinhibition and hunger. J Psychosom Res, 1985. 29(1): p. 71-83.

69. Anderson, D.A., J.R. Shapiro, J.D. Lundgren, L.E. Spataro, and C.A. Frye, Self-reported dietary restraint is associated with elevated levels of salivary cortisol. Appetite, 2002. 38(1): p. 13-7.

70. McLean, J.A., S.I. Barr, and J.C. Prior, Cognitive dietary restraint is associated with higher urinary cortisol excretion in healthy premenopausal women. Am J Clin Nutr, 2001. 73(1): p. 7-12.

71. Rideout, C.A., W. Linden, and S.I. Barr, High cognitive dietary restraint is associated with increased cortisol excretion in postmenopausal women. J Gerontol A Biol Sci Med Sci, 2006. 61(6): p. 628-33. 
72. Pirke, K.M., R.J. Tuschl, B. Spyra, R.G. Laessle, U. Schweiger, A. Broocks, et al., Endocrine findings in restrained eaters. Physiol Behav, 1990. 47(5): p. 903-6.

73. Beiseigel, J.M. and S.M. Nickols-Richardson, Cognitive eating restraint scores are associated with body fatness but not with other measures of dieting in women. Appetite, 2004. 43(1): p. 47-53.

74. Nickols-Richardson, S.M., J.M. Beiseigel, and F.C. Gwazdauskas, Eating restraint is negatively associated with biomarkers of bone turnover but not measurements of bone mineral density in young women. J Am Diet Assoc, 2006. 106(7): p. 1095-101.

75. Davis, C., J.V. Durnin, M. Gurevich, A. Le Maire, and M. Dionne, Body composition correlates of weight dissatisfaction and dietary restraint in young women. Appetite, 1993. 20(3): p. 197-207.

76. de Lauzon-Guillain, B., A. Basdevant, M. Romon, J. Karlsson, J.M. Borys, and M.A. Charles, Is restrained eating a risk factor for weight gain in a general population? Am J Clin Nutr, 2006. 83(1): p. 132-8.

77. Tanofsky-Kraff, M., D.E. Wilfley, and E. Spurrell, Impact of interpersonal and ego-related stress on restrained eaters. Int J Eat Disord, 2000. 27(4): p. 411-8.

78. Herman, C.P. and J. Polivy, Anxiety, restraint, and eating behavior. J Abnorm Psychol, 1975. 84(6): p. 66-72.

79. Heatherton, T.F., C.P. Herman, and J. Polivy, Effects of physical threat and ego threat on eating behavior. $\mathrm{J}$ Pers Soc Psychol, 1991. 60(1): p. 138-43.

80. Mitchell, S.L. and L.H. Epstein, Changes in taste and satiety in dietary-restrained women following stress. Physiol Behav, 1996. 60(2): p. 495-9.

81. Weinstein, S.E., D.J. Shide, and B.J. Rolls, Changes in food intake in response to stress in men and women: psychological factors. Appetite, 1997. 28(1): p. 7-18.

82. Oliver, G., J. Wardle, and E.L. Gibson, Stress and food choice: a laboratory study. Psychosom Med, 2000. 62(6): p. 853-65.

83. Berridge, K.C. and T.E. Robinson, What is the role of dopamine in reward: hedonic impact, reward learning, or incentive salience? Brain Res Brain Res Rev, 1998. 28(3): p. 309-69.

84. Barbano, M.F. and M. Cador, Differential regulation of the consummatory, motivational and anticipatory aspects of feeding behavior by dopaminergic and opioidergic drugs. Neuropsychopharmacology, 2006. 31(7): p. 1371-81.

85. Pecina, S. and K.C. Berridge, Opioid site in nucleus accumbens shell mediates eating and hedonic 'liking' for food: map based on microinjection Fos plumes. Brain Res, 2000. 863(1-2): p. 71-86.

86. Pecina, S., K.S. Smith, and K.C. Berridge, Hedonic hot spots in the brain. Neuroscientist, 2006. $12(6):$ p. $500-11$.

87. Zhang, M. and A.E. Kelley, Enhanced intake of high-fat food following striatal mu-opioid stimulation: microinjection mapping and fos expression. Neuroscience, 2000. 99(2): p. 267-77.

88. Yeomans, M.R. and R.W. Gray, Effects of naltrexone on food intake and changes in subjective appetite during eating: evidence for opioid involvement in the appetizer effect. Physiol Behav, 1997. 62(1): p. 15-21.

89. Mercer, M.E. and M.D. Holder, Food cravings, endogenous opioid peptides, and food intake: a review. Appetite, 1997. 29(3): p. 325-52.

90. Johnson, R.D., Opioid involvement in feeding behaviour and the pathogenesis of certain eating disorders. Med Hypotheses, 1995. 45(5): p. 491-7.

91. Yoshida, M., S. Koyanagi, A. Matsuo, T. Fujioka, H. To, S. Higuchi, et al., Glucocorticoid hormone regulates the circadian coordination of micro-opioid receptor expression in mouse brainstem. J Pharmacol Exp Ther, 2005. 315(3): p. 1119-24.

92. O'Hare, E., D.L. Shaw, K.J. Tierney, K. E-M, A.S. Levine, and R.A. Shephard, Behavioral and neurochemical mechanisms of the action of mild stress in the enhancement of feeding. Behav Neurosci, 2004. 118(1): p. 173-7.

93. Cota, D., M.H. Tschop, T.L. Horvath, and A.S. Levine, Cannabinoids, opioids and eating behavior: the molecular face of hedonism? Brain Res Rev, 2006. 51(1): p. 85-107.

94. Solinas, M., S. Yasar, and S.R. Goldberg, Endocannabinoid system involvement in brain reward processes related to drug abuse. Pharmacol Res, 2007.

95. Harrold, J.A. and G. Williams, The cannabinoid system: a role in both the homeostatic and hedonic control of eating? Br J Nutr, 2003. 90(4): p. 729-34.

96. Kirkham, T.C. and C.M. Williams, Synergistic efects of opioid and cannabinoid antagonists on food intake. Psychopharmacology (Berl), 2001. 153(2): p. 267-70.

97. Coddington, E., C. Lewis, J.D. Rose, and F.L. Moore, Endocannabinoids mediate the effects of acute stress and corticosterone on sex behavior. Endocrinology, 2007. 148(2): p. 493-500.

98. Barrot, M., D.N. Abrous, M. Marinelli, F. Rouge-Pont, M. Le Moal, and P.V. Piazza, Influence of glucocorticoids on dopaminergic transmission in the rat dorsolateral striatum. Eur J Neurosci, 2001. 13(4): p. 812-8.

99. Rouge-Pont, F., V. Deroche, M. Le Moal, and P.V. Piazza, Individual differences in stress-induced dopamine release in the nucleus accumbens are influenced by corticosterone. Eur J Neurosci, 1998. 10(12): p. 3903-7.

100. Pruessner, J.C., F. Champagne, M.J. Meaney, and A. Dagher, Dopamine release in response to a psychological stress in humans and its relationship to early life maternal care: a positron emission tomography study using [11C]raclopride. ] Neurosci, 2004. 24(11): p. 2825-31.

101. Cooper, S.J., H.A. Al-Naser, and P.G. Clifton, The anorectic effect of the selective dopamine D1-receptor agonist A77636 determined by meal pattern analysis in free-feeding rats. Eur J Pharmacol, 2006. 532(3): p. 253-7.

102. Leddy, J.J., L.H. Epstein, J.L. Jaroni, J.N. Roemmich, R.A. Paluch, G.S. Goldfield, et al., Influence of methylphenidate on eating in obese men. Obes Res, 2004. 12(2): p. 224-32.

103. Pecina, S., B. Cagniard, K.C. Berridge, J.W. Aldridge, and X. Zhuang, Hyperdopaminergic mutant mice have higher "wanting" but not "liking" for sweet rewards. J Neurosci, 2003. 23(28): p. 9395-402.

104. Wang, G.J., N.D. Volkow, J. Logan, N.R. Pappas, C.T. Wong, W. Zhu, et al., Brain dopamine and obesity. Lancet, 2001. 357(9253): p. 354-7.

105. Hommel, J.D., R. Trinko, R.M. Sears, D. Georgescu, Z.W. Liu, X.B. Gao, et al., Leptin receptor signaling in midbrain dopamine neurons regulates feeding. Neuron, 2006. 51(6): p. 801-10.

106. Figlewicz, D.P., A. MacDonald Naleid, and A.J. Sipols, Modulation of food reward by adiposity signals. Physiol Behav, 2007. 91(5): p. 473-8.

107. Fulton, S., B. Woodside, and P. Shizgal, Modulation of brain reward circuitry by leptin. Science, 2000. 287(5450): p. $125-8$.

108. Smith, S.R., L. de Jonge, M. Pellymounter, T. Nguyen, R. Harris, D. York, et al., Peripheral administration of human corticotropin-releasing hormone: a novel method to increase energy expenditure and fat oxidation in man. J Clin Endocrinol Metab, 2001. 86(5): p. 1991-8.

109. Bessey, P.Q., J.M. Watters, T.T. Aoki, and D.W. Wilmore, Combined hormonal infusion simulates the metabolic response to injury. Ann Surg, 1984. 200(3): p. 264-81. 
110. Brillon, D.J., B. Zheng, R.G. Campbell, and D.E. Matthews, Effect of cortisol on energy expenditure and amino acid metabolism in humans. Am J Physiol, 1995. 268(3 Pt 1): p. E501-13.

111. Short, K.R., J. Nygren, M.L. Bigelow, and K.S. Nair, Effect of short-term prednisone use on blood flow, muscle protein metabolism, and function. J Clin Endocrinol Metab, 2004. 89(12): p. 6198-207.

112. Leitch, C.A., J. Ahlrichs, C. Karn, and S.C. Denne, Energy expenditure and energy intake during dexamethasone therapy for chronic lung disease. Pediatr Res, 1999. 46(1): p. 109-13.

113. Burt, M.G., J. Gibney, and K.K. Ho, Characterization of the metabolic phenotypes of Cushing's syndrome and growth hormone deficiency: a study of body composition and energy metabolism. Clin Endocrinol (Oxf), 2006. 64(4): p. 436-43.

114. Burt, M.G., J. Gibney, and K.K. Ho, Protein metabolism in glucocorticoid excess: study in Cushing's syndrome and the effect of treatment. Am J Physiol Endocrinol Metab, 2007. 292(5): p. E1426-32.

115. Silva, J.E., Thyroid hormone control of thermogenesis and energy balance. Thyroid, 1995. 5(6): p. 481-92.

116. Kyrou, I., G. Valsamakis, and C. Tsigos, The endocannabinoid system as a target for the treatment of visceral obesity and metabolic syndrome. Ann N Y Acad Sci, 2006. 1083: p. 270-305.

117. Vogels, N. and M.S. Westerterp-Plantenga, Successful long-term weight maintenance: a 2-year follow-up. Obesity (Silver Spring), 2007. 15(5): p. 1258-66.

118. Yanovski, J.A., S.Z. Yanovski, P.W. Gold, and G.P. Chrousos, Differences in corticotropin-releasing hormonestimulated adrenocorticotropin and cortisol before and after weight loss. J Clin Endocrinol Metab, 1997. 82(6): p. 1874-8. 



\section{Chapter 7}

Sex specific associations between the BclI polymorphism in the glucocorticoid receptor gene and HPA axis exposure as well as feedback sensitivity under stress

F. Rutters, A.G. Nieuwenhuizen, S.G.T. Lemmens, J.M. Born, F. Bouwman, E. Mariman, M.S. Westerterp-Plantenga

Submitted 


\begin{abstract}
Objective: to investigate, in men and women, the relationship between the BclI genotypes and circulating cortisol concentrations, HPA axis feedback sensitivity, as well as HPA axis feedback sensitivity under stress.

Methods: we assessed in 77 men and 89 women, aged between 18 to 55 y and BMI between 19.8 and $41.2 \mathrm{~kg} / \mathrm{m}^{2}$, HPA axis functioning through measuring 5-hour cortisol exposure as well as cortisol feedback sensitivity under stress through a standardized high intensity test with $4 \mathrm{mg}$ dexamethasone.

Results: the BclI genotype frequency distribution (CC/CG/GG) was 41/42/17 in men and $45 / 42 / 13$ in women. The G/G BclI genotype had higher cortisol concentrations after dexamethasone exposure when compared to the $\mathrm{C} / \mathrm{C}$ genotype in men (42.2 $\pm 8.7 \mathrm{vs}$.

$27.3 \pm 2.2 \mathrm{nmol} / \mathrm{L}, \mathrm{p}<0.05)$, and to the $\mathrm{C} / \mathrm{G}$ genotypes in women $(70.5 \pm 14.6$ vs $47.1 \pm 9.1$ $\mathrm{nmol} / \mathrm{L}, \mathrm{p}<0.05)$. Only in women, the $\mathrm{G} / \mathrm{G}$ BclI genotype had a higher area under the curve (AUC) of the cortisol concentrations over a 5-hour time period when compared to the C/G genotype (178458 \pm 85818 vs. $135063.7 \pm 65511 \mathrm{nmol} / \mathrm{L} \cdot \mathrm{min}, \mathrm{p}<0.05)$. Additionally, women with the G/G BclI genotype had a higher AUC of the cortisol concentrations over a 70 minutes time period after a high intensity test with dexamethasone suppression when compared to the $\mathrm{C} / \mathrm{G}$ and $\mathrm{C} / \mathrm{C}$ genotypes
\end{abstract} ( $3788.7 \pm 2248$ vs. $3323.2 \pm 1716$ and $5392.9 \pm 3545 \mathrm{nmol} /$ L. $\mathrm{min}, \mathrm{p}<0.05$ ).

Conclusion: the BclI genotype is sex specifically associated with increased cortisol exposure as well as decreased cortisol feedback sensitivity under stress. 


\section{Introduction}

The hypothalamus/pituitary/adrenal (HPA) axis is a neuro-endocrine system involved in the stress-response and homeostasis, by regulating the secretion of cortisol [1]. Cortisol affects several systems, such as the cardiovascular system, the immune system, metabolism, cell growth, behavior, and the HPA axis itself through negative feedback [2]. Literature has shown large intra-individual and interindividual variation in HPA axis functioning, such as the efficacy of cortisol to suppress its own secretion (negative feedback). This results in considerable variation in circulation cortisol concentrations [3]. The variation has been related to several polymorphisms of the glucocorticoid receptor gene, such as N363S [4], the ER22/23EK [5], Tth111I [6], and BclI polymorphisms [3]. The latter polymorphism, BclI (rs41423247), has been related to insulin resistance in obese women [7], increased BMI, waisthip ratio, leptin levels $[6,8-10]$, as well as better weight loss during a very low calorie diet $[11,12]$. Additionally, in men, the $\mathrm{BclI} \mathrm{G} / \mathrm{G}$ genotype has been associated with increased salivary concentrations of cortisol [6], increased levels of salivary cortisol after a standardized lunch [6], increased levels of cortisol after a $0.5 \mathrm{mg}$ dexamethasone suppression test [6], as well as a diminished cortisol response to psychosocial stress [2]. In women, however the BclI G/G genotype has been associated with an increased cortisol response to psychosocial stress [13], which suggests possible sex specific associations between the BclI genotypes and HPA axis functioning. Besides the study from Kumsta et al. 2007 [13], no previous studies have examined the possible sex specific associations, since other studies only included males $[2,6]$. Furthermore, HPA axis functioning was studied via basal cortisol levels, a dexamethasone suppression test, or subjection to a psychosocial test, never via a combination of physical stress and dexamethasone suppression, which indicates sensitivity of the HPA axis to negative feedback under stress [14]. Consequently, the objective of our study was to investigate, in men and women, the relationship between the BclI genotypes and circulating cortisol concentrations, HPA axis feedback sensitivity, as well as HPA axis feedback sensitivity under stress.

\section{Materials and methods Protocol}

The Medical Ethical Committee of the University of Maastricht approved of the study, and written consent was obtained from all participants. Healthy, medicationfree, non-smoking men $(n=80)$ and women $(n=90)$ aged between 18 to $55 y$ and BMI between 19.8 and $41.2 \mathrm{~kg} / \mathrm{m} 2$ were recruited to complete all phases of the study. A medical history was obtained from each participant before entry into the study and exclusion criteria were menopause, chronic illness, depression, and a history of eating disorders or current dieting. From 170 participants recruited, 77 men and 89 women completed the study, 4 participants dropped out before the actual start of the study. From each participant we obtained: 5hour cortisol exposure, a progressive maximal cycling test to volitional exhaustion and a high intensity test under $4 \mathrm{mg}$ dexamethasone, anthropometry, and BclI genotypes.

\section{Measurements}

5-hour cortisol exposure

At 8 a.m. after an overnight fast an intravenous catheter for blood sampling was inserted into the forearm vein. Direct after insertion of the catheter the first blood sample $(9 \mathrm{ml})$ was drawn $(0$ minutes), and after 15 minutes the participants received their breakfast (20 $\%$ of the participants' daily energy requirement). At 45, 90 and 210 minutes the second, third and fourth blood samples were drawn. At 225 minutes the participants received their lunch (30\% of the participants' daily energy 
requirement) and at 255 and 300 minutes the fifth and sixth blood samples were drawn. During the test participants were able to drink water ad libitum. Breakfast and lunch consisted of typical Dutch products namely brown bread (1.0 MJ per $100 \mathrm{~g}$; en\% C/P/F: 74/15/11) with young cheese (1.6 MJ per $100 \mathrm{~g}$; en\% C/P/F: $0 / 26 / 74$ ) as well as ab libitum tea or water consumption. The daily energy requirements were calculated by multiplying the basal metabolic rate (BMR) by an activity index of 1.75 . The BMR (MJ/day) was calculated according to the equations of Harris-Benedict [15]. Participants remained seated during sampling, and daytime naps were not allowed. The participants' 5-hour cortisol exposure was measured by calculating the area under the curve (AUC) $(0-300$ minutes).

\section{Progressive maximal cycling test to volitional exhaustion}

The 5-hour cortisol exposure measurement and the progressive maximal cycling test $\left(\mathrm{VO}^{2} \mathrm{max}\right)$ were separated by at least one day. Each participant underwent a progressive maximal cycling test to volitional exhaustion for quantification of $\mathrm{VO}^{2} \max$ [16]. Participants cycled on an electromagnetically braked bicycle ergometer (Lode, Groningen, The Netherlands) at $80 \mathrm{rpm}$, at a workload of $75 \mathrm{~W}$ for women and $100 \mathrm{~W}$ for men [16]. After 5 minutes, the workload was increased every 2.5 minutes with $50 \mathrm{~W}$, until participants were no longer able to maintain a pedaling frequency above 80 rpm. Open-circuit spirometry was performed with an Oxycon (Mijnhardt Jaeger, Mannheim, Germany), and oxygen consumption $\left(\mathrm{VO}^{2}\right)$ and carbon dioxide production $\left(\mathrm{CO}^{2}\right)$ were measured in the breath-by-breath mode and averaged over 15 seconds [16]. Heart rate was monitored continuously throughout all exercise protocols (Polar s610). Verification that each participant actually achieved $\mathrm{VO}^{2}$ max consisted of meeting the following criteria: 1) achieving predicted maximal heart rate and 2) a respiratory exchange ratio of 1.10 or more
[16]. The results of the progressive maximal cycling test were used to measure the resistance to elicit an exercise intensity of $90 \%$ of each participants maximal workload (Wmax, V) for the high intensity test under $4 \mathrm{mg}$ dexamethasone.

\section{High intensity test under $4 \mathrm{mg}$} dexamethasone

The progressive maximal cycling test and high intensity test under $4 \mathrm{mg}$ dexamethasone [14] were separated by at least one week. Each participant received $4 \mathrm{mg}$ dexamethasone 8 hours before the high intensity test. Each participant participated in the treatment, and no adverse reactions were reported. Participants abstained from alcohol consumption and strenuous exercise $15 \mathrm{~h}$ before testing. At 8 a.m. after an overnight fast, an intravenous catheter for blood sampling was inserted into the forearm vein and the first blood sample was drawn for a baseline measurement ( 0 minutes). After 5 minutes the participants received their breakfast ( $20 \%$ of the participants' daily energy requirement). At 15 minutes the second blood sample was taken and the high intensity test was started. At 30 minutes the high intensity test ended and the third blood sample was taken. At 40, 50, 60 and 70 minutes, the fourth, fifth, sixth and seventh blood samples were taken [14].

The high intensity test consisted of 15 minutes of cycling. The initial 5 minutes served as a warming-up, during which each participant cycled at a workload of $40 \%$ of his/her Wmax (V), at $80 \mathrm{rpm}$. After the warming-up, the workload was increased with $50 \%$ of his/her Wmax (V) for $30 \mathrm{sec}$ at $80 \mathrm{rpm}$, followed by a decrease of the workload with $50 \%$ of his/her Wmax (V) for $30 \mathrm{sec}$ at $80 \mathrm{rpm}$. The increase and decrease of workload were repeated 10 times. After the third blood sample was drawn a 5 minutes cooling-down was performed at $30 \%$ of his/her Wmax (V) at $60 \mathrm{rpm}$ [14].

\section{Blood samples}

Blood samples were collected and mixed in serum tubes (BD Vacutainer, $9.5 \mathrm{ml}$ ). 
Serum was obtained by centrifugation $\left(4^{\circ} \mathrm{C}, 3000 \mathrm{rpm}, 10\right.$ minutes $)$, frozen in liquid nitrogen and stored at $-80^{\circ} \mathrm{C}$ until analysis of cortisol concentrations.

Serum cortisol concentrations were measured using RIA (Buhlmann Laboratories) and detection limits for cortisol concentrations were $2.9 \mathrm{ng} / \mathrm{ml}$. Intra-assay coefficient variation for cortisol concentrations was less than $6 \%$ for all samples.

\section{Anthropometry}

Measurements were carried out in the morning after voiding the bladder and before breakfast. Body weight and height were measured to the nearest $0.01 \mathrm{~kg}$ and $0.1 \mathrm{~cm}$ respectively. BMI $\left(\mathrm{kg} / \mathrm{m}^{2}\right)$ was calculated as body weight divided by height $(m)$ squared.

\section{Determination of BclI genotypes}

The genomic DNAs of 166 participants were isolated from peripheral blood leukocytes using a QIAamp kit (QIAgen, Germany). A 87 bp fragment of the GRL gene was generated from genomic DNA by PCR using forward primer $5^{\prime}$ -

GCTCACAGGGTTCTTGCCATA-3' and reverse primer $5^{\prime}$ -

TTGCACCATGTTGACACCAAT-3', which includes a $C / G$ polymorphism in intron 2, 646 nucleotides downstream from exon 2 [11]. The PCR products were digested with $\mathrm{BclI}$ at $50^{\circ} \mathrm{C}$ for 60 minutes, electrophoresed on a 3\% agarose gel and stained with ethidium bromide. The expected products after digestion with BclI are 87 bp for $\mathrm{G} / \mathrm{G}$ homozygotes, 47 and 40 bp for $\mathrm{C} / \mathrm{C}$ homozygotes, and 87 , 47 , and 40 bp for $\mathrm{G} / \mathrm{C}$ heterozygotes.

\section{Statistical analysis}

Student t-test and ANOVA (for continuous variables) were executed to determine differences in single variables between groups. Hardy-Weinberg equilibrium for BclI was calculated using the chi-square test. The BclI polymorphism was in HardyWeinberg equilibrium. The differences over time and between conditions were determined using three-factor ANOVA with repeated measures. All statistical tests were two-tailed, differences were considered significant at $p<0.05$ and values are expressed as mean \pm standard deviation.

\section{Results}

Table 1 shows the characteristics of the male $(n=77)$ and female $(n=89)$ participants. No significant differences were shown in age, BMI, and BclI genotype frequency distribution between men and women. Men showed a higher body weight, height, and maximal workload during the progressive maximal cycling test when compared to women. Women showed a higher area under the curve (AUC) of the cortisol concentrations over a 5-hour time period, as well as a higher AUC of the cortisol concentrations over a 70 minutes time period after a high intensity test with dexamethasone suppression. Therefore, the results of men and women were analyzed separately.

Table 1. Characteristics of the male $(n=77)$ and female $(n=89)$ participants

\begin{tabular}{|c|c|c|c|}
\hline & Male $(n=77)$ & Female $(n=89)$ & P value $^{1}$ \\
\hline Age (year) & $29 \pm 10$ & $26.9 \pm 9$ & 0.16 \\
\hline Body weight $(\mathrm{kg})$ & $81.4 \pm 13$ & $70.1 \pm 12.4$ & 0.001 \\
\hline Height (cm) & $181.6 \pm 6.8$ & $169.3 \pm 6.6$ & 0.001 \\
\hline BMI $\left(\mathrm{kg} / \mathrm{m}^{2}\right)$ & $24.4 \pm 23.6$ & $24.4 \pm 4.1$ & 0.99 \\
\hline Maximal workload (V) & $299.2 \pm 58$ & $208.9 \pm 43$ & 0.001 \\
\hline $\begin{array}{l}\text { AUC }{ }^{2} \text { of } 5 \text {-hour } \\
\text { cortisol exposure } \\
\text { (nmol/L.min) }\end{array}$ & $9.8\left(10^{5}\right) \pm 2.9$ & $14.9\left(10^{5}\right) \pm 7.3$ & 0.001 \\
\hline $\begin{array}{l}\text { AUC }{ }^{2} \text { cortisol after } \\
\text { high intensity test } \\
\text { (nmol/L.min) }\end{array}$ & $2556 \pm 1970$ & $4217 \pm 4445$ & 0.004 \\
\hline $\begin{array}{l}\text { BclI genotype } \\
\text { frequency distribution } \\
(\mathrm{CC} / \mathrm{CG} / \mathrm{GG})(\%)\end{array}$ & $41 / 42 / 17$ & $45 / 42 / 13$ & 0.80 \\
\hline
\end{tabular}

${ }^{1}$ Differences between men vs. women (t-test for continuous variables or Chi-square test for nominal variables)

${ }^{2} \mathrm{AUC}$, area under curve

Figure 1A shows the changes in cortisol concentrations (nmol/L. min) over a 5hour time period in men. No differences in cortisol concentrations were observed between the three BclI genotypes. Over time there was a significant decrease of cortisol concentrations in all men, however, over time no differences were seen between the three BclI genotypes. 
Figure 1A. Changes in cortisol concentrations ( $\mathrm{nmol} / \mathrm{I})$ over a 5-hour time period in men with the BclI G/G ( $n=$ $13), C C(n=32)$ or $C / G(n=33)$ genotype. Values are means with standard errors.

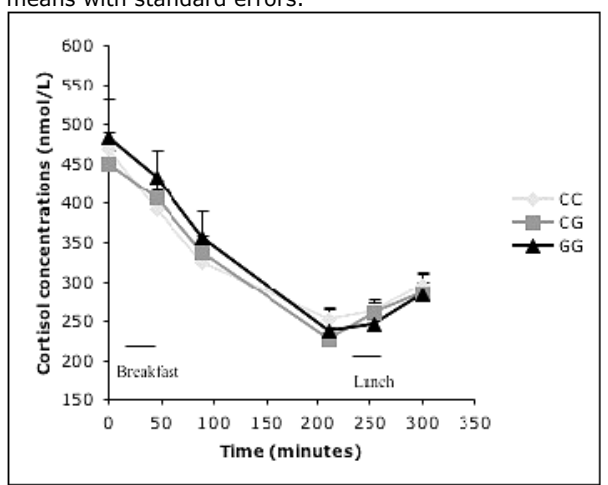

Figure 1B. Changes in cortisol concentrations ( $\mathrm{nmol} / \mathrm{l})$ over a 5 -hour time period in women with the BclI G/G ( $n$ $=12), C C(n=39)$ or $C / G(n=38)$ genotype. Values are means with standard errors.

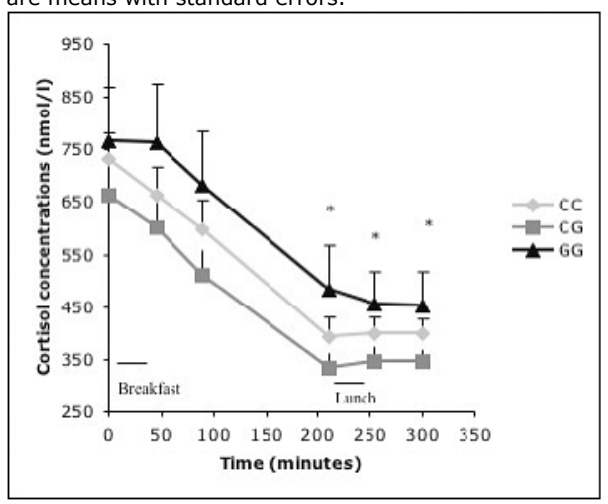

$* \mathrm{P}<0.05$ for differences between women with the BclI $\mathrm{G} / \mathrm{G}$ and the C/G genotype (ANOVA)

Figure 1B shows the changes in cortisol concentrations ( $\mathrm{nmol} / \mathrm{L}$. min) over a 5 hour time period in the women. The cortisol concentrations were significantly higher at 210, 255, and 300 minutes in women with the G/G genotype when compared to the C/G genotype. Over time there was a significant decrease of cortisol concentrations in all women, however, over time no differences were seen between the three BclI genotypes. The area under the curve (AUC) of the cortisol concentrations over a 5 -hour time period was significantly higher in women with the G/G genotype when compared to women with the C/G genotype (178458 \pm 85818 vs. $135063.7 \pm 65511 \mathrm{nmol} /$ L.min, $\mathrm{p}<$ $0.05)$.
Figure 2A shows the changes in cortisol concentrations (nmol/L.min) over time after a high intensity test with dexamethasone suppression in men. After dexamethasone exposure $(t=0)$, the cortisol concentrations were significantly higher in men with the G/G genotype when compared to men with the $\mathrm{C} / \mathrm{C}$ genotype (42.2 48.7 vs. $27.3 \pm 2.2 \mathrm{nmol} / \mathrm{L}$, $\mathrm{p}<0.05)$. After the high intensity test in combination with dexamethasone suppression, the cortisol concentrations were significantly higher at $15,30,40$, 50 , and 60 minutes in men with the $\mathrm{G} / \mathrm{G}$ genotype when compared to men with the $\mathrm{C} / \mathrm{C}$ genotype. Over time as well as between the three genotypes no differences were observed in the men.

Figure 2A: Cortisol concentrations (nmol/l) over time after a high intensity test with dexamethasone suppression in men with the BcII G/G $(n=13), C C$ ( $n=$ $32)$ or $C / G(n=33)$ genotype. Values are means with standard errors.

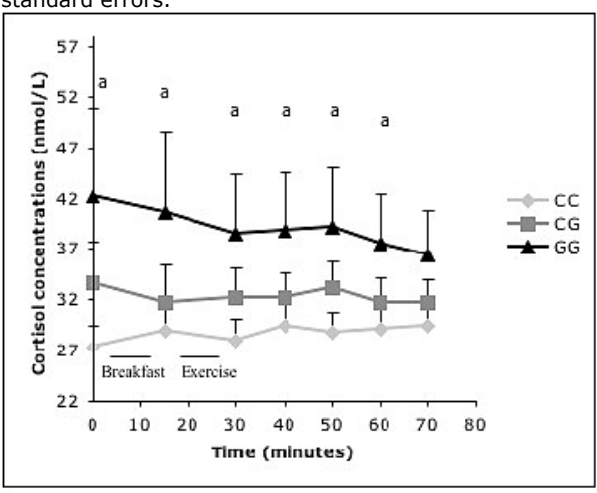

a $\mathrm{P}<0.05$ for differences between men with the BclI $\mathrm{G} / \mathrm{G}$ and the C/C genotype (ANOVA)

Figure 2B shows the changes in cortisol concentrations ( $\mathrm{nmol} /$ L.min) over time after a high intensity test with dexamethasone suppression in women. After dexamethasone exposure $(t=0)$, the cortisol concentrations were significantly higher in women with the $\mathrm{G} / \mathrm{G}$ genotype when compared to women with the C/G genotype (70.5 \pm 14.6 vs. $47.1 \pm 9.1$ $\mathrm{nmol} / \mathrm{L}, \mathrm{p}<0.05)$. After the high intensity test in combination with dexamethasone suppression, the cortisol concentrations were significantly higher at all time points in women with the G/G genotype when compared to women with the $\mathrm{C} / \mathrm{G}$ and $\mathrm{C} / \mathrm{C}$ genotype. From 0 to 40 minutes a 
significant increase in cortisol was seen in women with the $\mathrm{G} / \mathrm{G}$ genotype, while this was absent in women with the $\mathrm{C} / \mathrm{G}$ and $\mathrm{C} / \mathrm{C}$ genotypes $(13.1 \pm 15.1$ vs. $8.5 \pm 38$ and $3.1 \pm 9.4 \mathrm{nmol} / \mathrm{L}, \mathrm{p}<0.05)$.

Additionally, from 40 to 70 minutes a significant decrease in cortisol was seen in women with the G/G genotype, while an increase in cortisol was seen in women with the $\mathrm{C} / \mathrm{G}$ and $\mathrm{C} / \mathrm{C}$ genotype $(-8.2 \pm$ 21.6 vs. $0.6 \pm 12.6$ and $2.2 \pm 9.8 \mathrm{nmol} / \mathrm{L}$, $\mathrm{p}<0.01)$.

Figure 2B: Cortisol concentrations (nmol/l) over time after a high intensity test with dexamethasone suppression in women with the BCII G/G $(n=12)$, CC $(n=39)$ or $C / G(n=38)$ genotype. Values are means with standard errors.

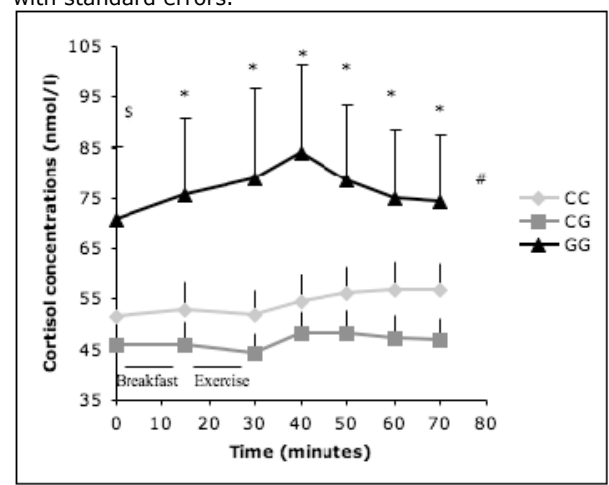

$* \mathrm{P}<0.05$ for differences between women with the BclI $\mathrm{G} / \mathrm{G}$ and the $\mathrm{C} / \mathrm{G}$ as well as C/C genotype (ANOVA) $\$ P<0.05$ for differences between men with the Bcll $\mathrm{G} / \mathrm{G}$ and the $\mathrm{C} / \mathrm{C}$ genotype (ANOVA)

\# $\mathrm{P}<0.05$ overall group $\mathrm{x}$ time interaction

The AUC of the cortisol concentrations corrected for baseline, over a 70 minutes time period after a high intensity test with dexamethasone suppression was significantly higher in women with the G/G genotype when compared to women with the $\mathrm{C} / \mathrm{G}$ genotype $(460 \pm 408$ vs. $38.3 \pm$ $666 \mathrm{nmol} /$ L.min, $\mathrm{p}<0.03)$.

\section{Discussion}

The objective of our study was to investigate, in men and women, the relationship between the BclI genotypes and circulating cortisol concentrations, HPA axis feedback sensitivity, as well as HPA axis feedback sensitivity under stress. In both men and women the G/G BclI genotype was associated with increased cortisol concentrations after a dexamethasone exposure test. Only in women the G/G BclI genotype was associated with increased cortisol concentrations over a 5-hour time period, and increases in cortisol concentrations after a high intensity test with dexamethasone suppression.

With these results, our study adds to the growing literature on the relationship between the BclI genotypes and HPA axis functioning, and this study is the first to analyze the effect of the BclI genotypes on HPA axis feedback sensitivity under stress, as well as sex specific associations. In our study, we measured cortisol concentrations (nmol/L. min) over a 5hour time period to determine cortisol exposure under resting conditions. We showed that women with the G/G BclI genotype had significant higher cortisol concentrations just before and after lunch, in addition to a higher AUC of the cortisol concentrations over a 5-hour time period when compared to the $\mathrm{C} / \mathrm{G}$ genotype. This suggests that women with the G/G BclI genotype have increased daily cortisol exposure.

Additionally, we measured feedback sensitivity through a dexamethasone exposure test [17], which determines the amount of cortisol that escapes from dexamethasone suppression (a type II glucocorticoid receptor agonist) [6]. When cortisol feedback is strong low amounts of cortisol will be present, and when high amounts of cortisol escape, cortisol feedback is decreased [17]. We showed that both in men and women the G/G BclI genotype was associated with higher cortisol concentrations after a dexamethasone exposure test, when compared to other genotypes. The results in men are in accordance with literature [6], and together these results imply that men and women with the G/G BclI genotype have decreased sensitivity to negative feedback of the HPA axis.

Furthermore, to assess HPA axis feedback sensitivity under stress, we measured cortisol concentrations ( $\mathrm{nmol} / \mathrm{L} . \mathrm{min}$ ) corrected for baseline, over a 70 minutes time period after a high intensity test in 
combination with dexamethasone suppression [14]. The high intensity exercise promotes the escape of cortisol from dexamethasone suppression, which indicates cortisol feedback sensitivity under stress [14]. We showed that after the high intensity test with dexamethasone suppression women with G/G BclI genotype had higher amounts of cortisol that escaped, as well as higher AUC of the cortisol concentrations, when compared to women with the C/G genotype. These results imply that women with the G/G BclI genotype have decreased sensitivity of the HPA axis to negative feedback under stress.

Besides our study and the study from Kumsta et al. 2007 [13], no previous studies examined possible sex specific associations between BclI polymorphisms and HPA axis functioning, since other studies only included males $[2,6]$. Kumstra et al. 2007 [13] have shown a sex specific association between BclI and HPA axis responses to psychosocial stress; together with the present study, these results point towards sex by genotype interactions, which suggests that the same genetic variant of the GR gene can have differential, or perhaps even opposite effects on HPA axis functioning depending on sex. The BclI polymorphism of the glucocorticoid receptor is thought to impact the efficacy of cortisol signaling and thereby influences the downstream biology of peripheral and central cortisol responsive systems [6]. The BclI polymorphism might therefore be one of the factors that underlie individual susceptibility to stress related disorders, such as depression and the metabolic syndrome [18]. From our study we conclude that the BclI genotype is sex specifically associated with increased cortisol exposure as well as decreased cortisol feedback sensitivity under stress.

\section{Acknowledgements}

We want to thank our subjects for their participation in this study. We gratefully thank José Sulon for his assistance. FR carried out the study, collected and analyzed the data, and wrote the largest part of the manuscript. FB (supervised by EM) contributed to the practical work. SL and JB reviewed the manuscript. AN and MW supervised FR. Planning, processing the results and writing the manuscript were done under general supervision by AN and MW. The authors had no conflict of interest. 


\section{Literature}

1. Bjorntorp, P. and R. Rosmond, Obesity and cortisol. Nutrition, 2000. 16(10): p. 924-36.

2. Wust, S., E.F. Van Rossum, I.S. Federenko, J.W. Koper, R. Kumsta, and D.H. Hellhammer, Common polymorphisms in the glucocorticoid receptor gene are associated with adrenocortical responses to psychosocial stress. J Clin Endocrinol Metab, 2004. 89(2): p. 565-73.

3. Derijk, R.H. and E.R. de Kloet, Corticosteroid receptor polymorphisms: determinants of vulnerability and resilience. Eur J Pharmacol, 2008. 583(2-3): p. 303-11.

4. Di Blasio, A.M., E.F. van Rossum, S. Maestrini, M.E. Berselli, M. Tagliaferri, F. Podesta, et al., The relation between two polymorphisms in the glucocorticoid receptor gene and body mass index, blood pressure and cholesterol in obese patients. Clin Endocrinol (Oxf), 2003. 59(1): p. 68-74.

5. van Rossum, E.F. and S.W. Lamberts, Polymorphisms in the glucocorticoid receptor gene and their associations with metabolic parameters and body composition. Recent Prog Horm Res, 2004. 59: p. 333-57.

6. Rosmond, R., Y.C. Chagnon, G. Holm, M. Chagnon, L. Perusse, K. Lindell, et al., A glucocorticoid receptor gene marker is associated with abdominal obesity, leptin, and dysregulation of the hypothalamic-pituitary-adrenal axis. Obes Res, 2000. 8(3): p. 211-8.

7. Weaver, J.U., G.A. Hitman, and P.G. Kopelman, An association between a Bc1I restriction fragment length polymorphism of the glucocorticoid receptor locus and hyperinsulinaemia in obese women. J Mol Endocrinol, 1992. 9(3): p. 295-300.

8. Buemann, B., M.C. Vohl, M. Chagnon, Y.C. Chagnon, J. Gagnon, L. Perusse, et al., Abdominal visceral fat is associated with a BclI restriction fragment length polymorphism at the glucocorticoid receptor gene locus. Obes Res, 1997. 5(3): p. 186-92.

9. Tremblay, A., L. Bouchard, C. Bouchard, J.P. Despres, V. Drapeau, and L. Perusse, Long-term adiposity changes are related to a glucocorticoid receptor polymorphism in young females. J Clin Endocrinol Metab, 2003. 88(7): p. 3141-5.

10. van Rossum, E.F., J.W. Koper, N.A. Huizenga, A.G. Uitterlinden, J.A. Janssen, A.O. Brinkmann, et al., A polymorphism in the glucocorticoid receptor gene, which decreases sensitivity to glucocorticoids in vivo, is associated with low insulin and cholesterol levels. Diabetes, 2002. 51(10): p. 3128-34.

11. Vogels, N., E.C. Mariman, F.G. Bouwman, A.D. Kester, K. Diepvens, and M.S. Westerterp-Plantenga, Relation of weight maintenance and dietary restraint to peroxisome proliferator-activated receptor gamma2, glucocorticoid receptor, and ciliary neurotrophic factor polymorphisms. Am J Clin Nutr, 2005. 82(4): p. 740-6.

12. Ukkola, O., R. Rosmond, A. Tremblay, and C. Bouchard, Glucocorticoid receptor Bcl I variant is associated with an increased atherogenic profile in response to long-term overfeeding. Atherosclerosis, 2001. 157(1): p. 221-4.

13. Kumsta, R., S. Entringer, J.W. Koper, E.F. van Rossum, D.H. Hellhammer, and S. Wust, Sex specific associations between common glucocorticoid receptor gene variants and hypothalamus-pituitary-adrenal axis responses to psychosocial stress. Biol Psychiatry, 2007. 62(8): p. 863-9.

14. Petrides, J.S., P.W. Gold, G.P. Mueller, A. Singh, C. Stratakis, G.P. Chrousos, et al., Marked differences in functioning of the hypothalamic-pituitary-adrenal axis between groups of men. J Appl Physiol, 1997. 82(6): p. 1979-88.

15. Lejeune, M.P., K.R. Westerterp, T.C. Adam, N.D. Luscombe-Marsh, and M.S. Westerterp-Plantenga, Ghrelin and glucagon-like peptide 1 concentrations, 24-h satiety, and energy and substrate metabolism during a high-protein diet and measured in a respiration chamber. Am J Clin Nutr, 2006. 83(1): p. 89-94.

16. Plasqui, G. and K.R. Westerterp, Accelerometry and heart rate as a measure of physical fitness: cross-validation. Med Sci Sports Exerc, 2006. 38(8): p. 1510-4.

17. Duclos, M., B. Gatta, J.B. Corcuff, M. Rashedi, F. Pehourcq, and P. Roger, Fat distribution in obese women is associated with subtle alterations of the hypothalamic-pituitary-adrenal axis activity and sensitivity to glucocorticoids. Clin Endocrinol (Oxf), 2001. 55(4): p. 447-54.

18. Bjorntorp, P., Stress and cardiovascular disease. Acta Physiol Scand Suppl, 1997. 640: p. 144-8. 



\section{Chapter 8}

Hypothalamus/Pituitary/Adrenal (HPA) axis functioning in relation to body fat distribution

F. Rutters, A.G. Nieuwenhuizen, S.G.T. Lemmens, J.M. Born and M.S. Westerterp-Plantenga

\section{Submitted}




\begin{abstract}
Objective: to relate HPA axis functioning and HPA feedback functioning to body fat distribution in normal weight to obese subjects.

Patients: 91 men and 103 women (age $18-45 y$, BMI $19-35 \mathrm{~kg} / \mathrm{m}^{2}$, waist-to-hip ratio (WHR) 0.6-1.1)

Measurements: we assessed anthropometry, body composition through

hydrodensitometry and deuterium dilution method, cortisol variability through measuring 5-hour cortisol concentrations, HPA axis feedback functioning through a dexamethasone suppression test, and HPA axis functioning under in a challenged condition through a standardized high intensity test under $4 \mathrm{mg}$ dexamethasone.
\end{abstract}

Results: in men an inverse relationship was observed between $5 \mathrm{~h}$ cortisol exposure $(\mathrm{nmol} / \mathrm{ml})$ and fat mass index $(\mathrm{FMI})\left(\mathrm{kg} / \mathrm{m}^{2}\right)(\mathrm{r}=0.55, \mathrm{p}<0.001)$. In women inverse relationships were observed between $5 \mathrm{~h}$ cortisol exposure $(\mathrm{nmol} / \mathrm{ml})$ and WHR $(r=0.49$, $p<0.001)$, maximal workload $(r=0.32, p<0.001)$ as well as oral contraceptive use $(r=0.38, p<0.001)$. Similarly, in men an inverse relationship was observed between negative feedback expressed as baseline cortisol concentrations minus post dexamethasone cortisol concentrations $(\mathrm{nmol} / \mathrm{ml})$ and FMI $(r=0.53, \mathrm{p}<0.001)$. In women an inverse relationship was observed between negative feedback expressed as baseline cortisol concentrations minus post dexamethasone cortisol concentrations $(\mathrm{nmol} / \mathrm{ml})$ and WHR $(r=0.43, p<0.001)$, maximal workload $(r=0.30, p<0.001)$ as well as oral contraceptive use $(r=0.43, p<0.001)$ in women. Moreover, an inverse relationship was observed between HPA axis functioning in a challenged condition expressed as percentage increase of cortisol concentrations after standardized high intensity test under $4 \mathrm{mg}$ dexamethasone $(\%)$ and waist $(r=0.21, p<0.10)$ in men and WHR $(r=0.21, p<0.05)$ in women. In male subjects, strong positive relationships were observed between FMI and waist circumference $(r=0.85, p<0.001)$, as well as waist-to-hip ratio $(r=0.70$, $\mathrm{p}<0.001)$.

Conclusion: disturbance of HPA axis functioning under basal and challenged conditions is related to visceral fat accumulation. 


\section{Introduction}

The hypothalamus-pituitary-adrenal (HPA) axis is a neuro-endocrine system that plays an important role in the regulation of the stress-response [1]. The HPA axis is suggested to be involved in the pathogenesis of human obesity, in particular characterized by visceral fat distribution (visceral obesity). Support for the involvement of the HPA axis in the regulation of body weight and body fat distribution is found in two extremes of plasma cortisol levels in humans; Addison's disease (hypocortisolism) that is related to weight loss, and Cushing's syndrome (hypercortisolism) that is related to rapid weight gain, particularly of the trunk and face with sparing of the limbs [2].

Additional support is found in obese subjects with visceral fat accumulation that show decreased salivary and serum cortisol levels [3-8], increased urinary secretion of cortisol $[6,9]$, decreased cortisol exposure $[3,4,10-12]$, and enhanced awakening cortisol response [13]. In both lean and obese subjects visceral fat distribution has been associated with increased cortisol secretion after physical and psychological stressors [3-6, 9, 14]. These conflicting findings, such as decreased exposure and increased secretion after stressors, suggest a reset of the HPA axis toward chronic hyper-activation [15].

The ability of cortisol to suppress its own secretion through activation of hypothalamic and pituitary glucocorticoid receptors (negative feedback) is an important part of adequate HPA axis functioning. Studies on the relationship between negative feedback and body fat distribution have however yielded inconclusive results. Some studies found an increased capacity of dexamethasone (a glucocorticoid receptor agonist) to suppress plasma cortisol concentrations $[4,16]$, some studies found no differences in the capacity of dexamethasone to suppress plasma cortisol concentrations $[3,5,6,10]$ and some even a decreased capacity $[17,18]$. This inconclusiveness possibly results from differences in techniques to test HPA feedback functioning.

Ten years ago, Petrides et al. (1997) [19] developed a more elaborate technique to test HPA axis functioning, using a physical challenge to promote escape of cortisol from dexamethasone suppression. Using this technique they observed even in a relative homogenous population of young men a large inter-individual variance in HPA functioning [19]. It remains unknown whether inter-individual variation in HPA axis functioning can be related to fat distribution in a normal-weight to obese population, and whether HPA axis functioning tested under $4 \mathrm{mg}$ dexamethasone in combination with a physical stressor is related to fat distribution. Therefore, the objective of our study was to relate HPA axis functioning and HPA feedback functioning to body fat distribution in normal weight to obese subjects.

\section{Subjects and methods Subjects and protocol}

The study was approved by the Medical Ethical Committee of Maastricht University, and a written consent was obtained from all subjects. Healthy, medication-free, non-smoking men ( $\mathrm{n}=$ $91)$ and women $(n=105)$ aged between 18 to 45 y and with a BMI between 19 and $35 \mathrm{~kg} / \mathrm{m}^{2}$ were recruited to complete all phases of this study. From 196 subjects recruited, 91 men and 103 women completed the study, 2 subjects dropped out before the actual start of the study. A medical history was obtained from each subject before entry into the study containing questions on illness, medicine use, smoking habits, daily coffee intake, weekly alcohol intake and food allergies. Exclusion criteria for our study were: smoking, excessive alcohol consumption, chronic illness, depression, and a history of eating disorders or current dieting. The women were examined regardless of the phase of the menstrual cycle. From each subject we obtained: 
anthropometry as well as body composition,5-hour cortisol exposure measurement, a progressive maximal cycling test to volitional exhaustion and a high intensity test under $4 \mathrm{mg}$ dexamethasone.

\section{Measurements}

Anthropometry and body composition Measurements were carried out in the morning after voiding the bladder and before breakfast. Body weight (Sauter D7470, Ebingen, Germany) and height (Seca, model 220, Hamburg, Germany) were measured to the nearest $0.01 \mathrm{~kg}$ and $0.1 \mathrm{~cm}$ respectively. BMI $\left(\mathrm{kg} / \mathrm{m}^{2}\right)$ was calculated as body weight $(\mathrm{kg})$ divided by height $(\mathrm{m})$ squared. The waist circumference was measured to the nearest $0.1 \mathrm{~cm}$ at the site of the smallest circumference between the rib cage and the ileac crest, whereas the hip circumference was measured to the nearest $0.1 \mathrm{~cm}$ at the level of maximum extension of the buttocks. The waist-tohip ratio (WHR) was calculated accordingly. Both measurements were done with the subjects in standing position. Additionally, both waist circumference and the WHR were used to define different patterns of body fat distribution. Waist circumference and waist-to-hip measurements were used as surrogates for body fat distribution measurements, as anthropometric measurements have been shown to predict total and abdominal fat content [20-22].

Body density was determined by hydrodensitometry with simultaneous measurements of residual lung volume with the helium dilution technique. Total body water (TBW) was determined with the deuterium dilution method following the Maastricht protocol [23]. Body composition was calculated from body density and TBW using the threecompartment model of Siri. Fat free mass (FFM) was calculated by dividing TBW by the hydration factor 0.73 . Fat mass (FM) was determined as BW-FFM. Fat mass index (FMI) was calculated by fat mass $/$ height $^{2}\left(\mathrm{~kg} / \mathrm{m}^{2}\right)$ and fat free mass index (FFMI) was calculated by fat free mass $/$ height ${ }^{2}\left(\mathrm{~kg} / \mathrm{m}^{2}\right)$.

\section{5-hour cortisol exposure measurement} At 8 a.m. after an overnight fast an intravenous catheter for blood sampling was inserted into the forearm vein. Direct after insertion of the catheter the first blood sample $(9 \mathrm{ml})$ was drawn ( 0 minutes), and after 15 minutes the subjects received their breakfast ( $20 \%$ of the subjects' daily energy requirement). The daily energy requirements were calculated by multiplying the basal metabolic rate (BMR) by an activity index of 1.75 . The BMR (MJ/day) was calculated according to the equations of HarrisBenedict [24]. At 45, 90 and 210 minutes the second, third and fourth blood samples were drawn. At 225 minutes the subjects received their lunch (30\% of the subjects' daily energy requirement) and at 255 and 300 minutes the fifth and sixth blood samples were drawn. During the test subjects were able to drink water ad libitum. The participants' 5-hour cortisol exposure was measured by calculating the area under the curve (AUC) $(0-300$ minutes).

\section{Progressive maximal cycling test to volitional exhaustion}

Each subject underwent a progressive maximal cycling test to volitional exhaustion for quantification of maximal workload (Wmax) [25]. Subjects cycled on an electromagnetically braked bicycle ergometer (Lode, Groningen, The Netherlands) at $80 \mathrm{rpm}$, at a workload of $75 \mathrm{~W}$ for women and $100 \mathrm{~W}$ for men. After 5 minutes, the workload was increased every 2.5 minutes with $50 \mathrm{~W}$, until subjects were no longer able to maintain a pedaling frequency above 80 rpm. Heart rate was monitored continuously throughout all exercise protocols (Polar s610). Verification that each subject actually achieved Wmax consisted of meeting the criteria of achieving predicted maximal heart rate. The results of the progressive maximal cycling test were used to measure the resistance to elicit an exercise intensity of 
$90 \%$ of each Wmax (V) for the high

intensity test under $4 \mathrm{mg}$ dexamethasone.

High intensity test under $4 \mathrm{mg}$

dexamethasone

The maximal cycling test and high

intensity test under $4 \mathrm{mg}$ dexamethasone

[19] were separated by at least one week.

Each subject received $4 \mathrm{mg}$

dexamethasone 8 hours before the high

intensity test. Each subject participated in

the treatment, and no adverse reactions

were reported. Subjects abstained from

alcohol consumption and strenuous

exercise $15 \mathrm{~h}$ before testing. At 8 a.m.

after an overnight fast, an intravenous

catheter for blood sampling was inserted

into the forearm vein and the first blood

sample was drawn for a baseline

measurement ( 0 minutes), and after 5

minutes the subjects received their

breakfast ( $20 \%$ of the subjects' daily energy requirement). At 15 minutes the second blood sample was taken and the high intensity test was started. At 30 minutes the high intensity test ended and the third blood sample was taken. At 40, 50,60 and 70 minutes, the fourth, fifth, sixth and seventh blood samples were taken.

The high intensity test consisted of 15 minutes of cycling. The initial 5 minutes served as a warming-up, during which each subject cycled at a workload of $40 \%$ of his/her Wmax (V), at $80 \mathrm{rpm}$. After the warming-up, the workload was increased with $50 \%$ of his/her Wmax (V) for $30 \mathrm{sec}$ at $80 \mathrm{rpm}$, followed by a decrease of the workload with $50 \%$ for $30 \mathrm{sec}$ at $80 \mathrm{rpm}$. The increase and decrease of workload was repeated 10 times. After the third blood sample was drawn a 5 minutes cooling-down was performed at $30 \%$ of Wmax (V) at $60 \mathrm{rpm}$.

Subjects' negative feedback functioning $(\mathrm{nmol} / \mathrm{ml})$ was calculated as the cortisol concentrations of the baseline sample of the cortisol exposure measurement ( 0 min) minus the cortisol concentrations of the baseline sample after dexamethasone ingestion $(0 \mathrm{~min})$. When low amounts of cortisol were present after dexamethasone suppression, cortisol feedback was strong and when high amounts of cortisol were present, cortisol feedback was decreased.

Subjects' HPA axis functioning in a challenged condition under $4 \mathrm{mg}$ dexamethasone (\%) was calculated as the difference between the highest cortisol concentrations after the high intensity test (30 or 40 minutes) and the cortisol concentration of the baseline sample after dexamethasone ingestion (0 $\mathrm{min}$ ), subsequently divided by the cortisol concentrations of the baseline sample after dexamethasone ingestion (0 $\mathrm{min}$ ). When low amounts of cortisol escaped during the high intensity test, cortisol feedback was strong and/or cortisol production was low, when high amounts of cortisol escaped, cortisol feedback was decreased and/or cortisol production was high [19].

\section{Blood samples}

Serum cortisol concentrations were measured using RIA (Buhlmann Laboratories) with a intra-assay coefficient variation of $<6 \%$.

\section{Statistical analysis}

Differences between two groups were determined using t-tests. Relationships between dependent and independent variables were determined using simple linear and multiple regression models. All statistical tests were two-tailed, differences were considered significant at $p<0.05$ and values are expressed as mean \pm standard deviation.

\section{Results}

Table 1 shows the characteristics of the male $(n=91)$ and female $(n=103)$ subjects. No significant differences were observed in age, BMI and hip circumference. The men showed significantly larger height, weight, waist circumference, waist-to-hip ratio (WHR) and maximal workload when compared to the women. The women showed significantly larger body fat percentage, and fat mass index when compared to the men. FMI $\left(\mathrm{kg} / \mathrm{m}^{2}\right)$ was used to define body composition, and waist circumference $(\mathrm{cm})$ as well as WHR was 
Table 1: Characteristics of the male $(n=91)$ and female subjects $(n=103)$

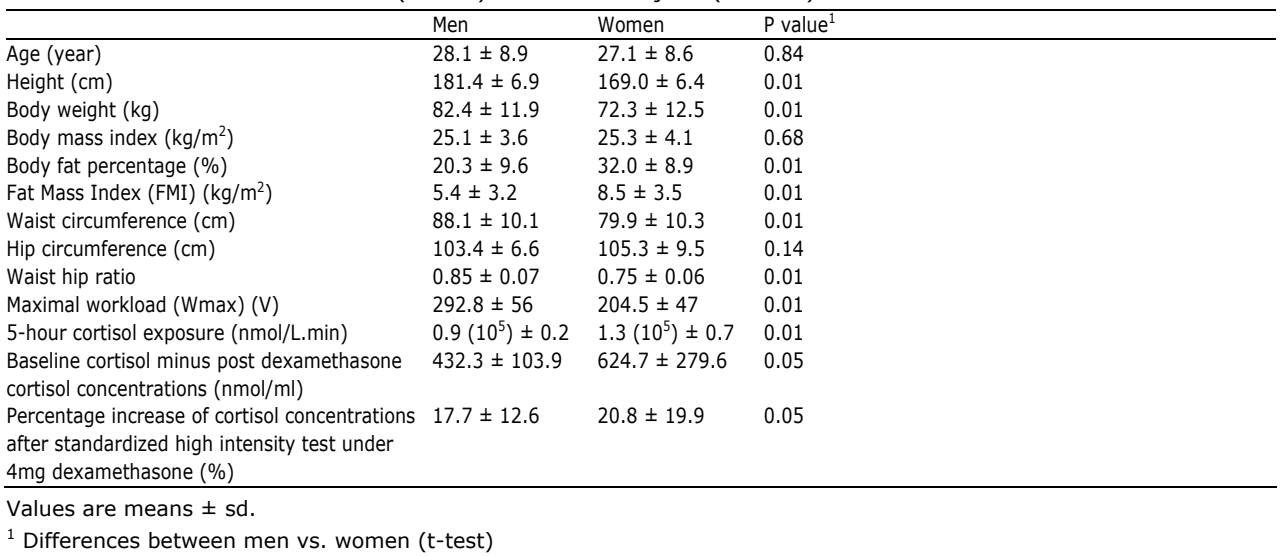

used to define different patterns of body fat distribution. Additionally, the women showed significantly higher 5-hour cortisol exposure (nmol/L.min), baseline cortisol minus post dexamethasone cortisol concentrations $(\mathrm{nmol} / \mathrm{ml})$, and percentage increase of cortisol concentrations after standardized high intensity test under 4 $\mathrm{mg}$ dexamethasone (\%) when compared to the men. Because of differences in HPA axis functioning the results for male and female subjects were analyzed separately. Subsequently, to study the relationship between HPA axis functioning and body fat distribution, the three parameters of HPA axis functioning were related to FMI, waist circumference, waist-to-hip ratio and possible confounders which have been related previously to HPA axis functioning, such as maximal workload, oral contraceptive intake and daily coffee intake.

\section{Subjects' 5-hour cortisol exposure (nmol/L.min)}

In male subjects, inverse relationships were observed between $5 \mathrm{~h}$ cortisol exposure and BMI $(r=0.43, p<0.001)$, FMI $(r=0.55, p<0.001)$, waist circumference $(r=0.23, p<0.001)$ and waist-to-hip ratio $(r=0.27, p<0.02)$. Multiple regression analysis with $5 \mathrm{~h}$ cortisol exposure as the dependent variable showed that only FMI significantly contributed to the explained variance.
In female subjects, inverse relationships were observed between $5 \mathrm{~h}$ cortisol exposure and BMI $(r=0.39, p<0.001)$, FMI $(r=0.38, p<0.001)$, waist circumference $(r=0.47, p<0.001)$, and waist-to-hip ratio $(r=0.49, p<0.001)$. Positive relationships were observed between $5 \mathrm{~h}$ cortisol exposure and maximal workload $(r=0.32, p<0.001)$ and oral contraceptive use $(r=0.39$, $p<0.001)$. Multiple regression analysis with $5 \mathrm{~h}$ cortisol exposure as the dependent variable showed that only waist-to-hip ratio, maximal workload and oral contraceptive use significantly contributed to the explained variance $(r=$ $0.60, p<0.001)$.

\section{Subjects' negative feedback functioning $(\mathrm{nmol} / \mathrm{ml})$ \\ In male subjects, inverse relationships were observed between baseline cortisol minus post dexamethasone cortisol concentrations and BMI $(r=0.43$, $p<0.001)$, FMI $(r=0.53, p<0.001)$} (figure 1a), waist circumference $(r=0.48, p<0.001)$ and waist-to-hip ratio $(r=0.36, p<0.002)$. Multiple regression analysis with baseline cortisol minus post dexamethasone cortisol concentrations as the dependent variable showed that only FMI significantly contributed to the explained variance. 
Figure 1a: relationship between baseline cortisol minus post dexamethasone cortisol concentrations $(\mathrm{nmol} / \mathrm{ml})$ and fat mass index (FMI) $\left(\mathrm{kg} / \mathrm{m}^{2}\right)(r=0.43, \mathrm{p}<0.001)$ in male subjects $(\mathrm{n}=91)$

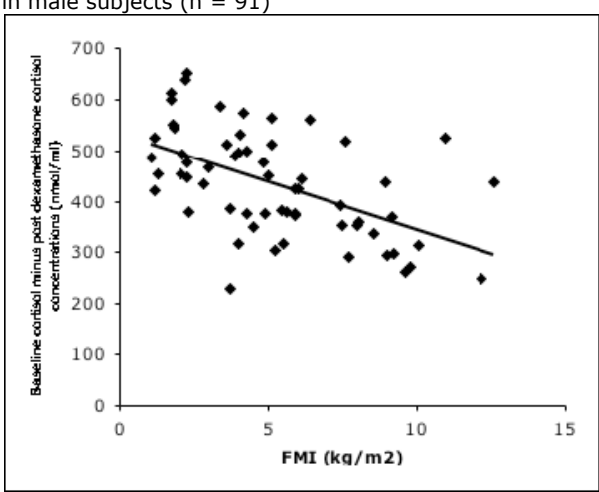

In female subjects, inverse relationships were observed between baseline cortisol minus post dexamethasone cortisol concentrations and BMI $(r=0.34$, $p<0.001)$, FMI $(r=0.32, p<0.001)$, waist circumference $(r=0.41, p<0.001)$, and waist-to-hip ratio $(r=0.43$, $\mathrm{p}<0.001$ )(figure 1b). Positive relationships were observed between baseline cortisol minus post dexamethasone cortisol concentrations and maximum workload $(r=0.30$, $p<0.001)$ and oral contraceptive use $(r=$ $0.43, \mathrm{p}<0.001)$.

Figure 1b: relationship between baseline cortisol minus post dexamethasone cortisol concentrations $(\mathrm{nmol} / \mathrm{ml})$ and waist-to-hip ratio $(r=0.43, p<0.001)$ in female subjects $(n=103)$

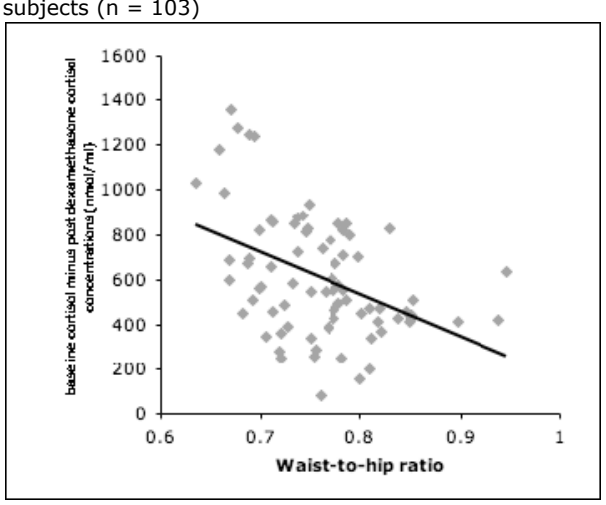

Multiple regression analysis with baseline cortisol minus post dexamethasone cortisol concentrations as the dependent variable showed that only waist-to-hip ratio, maximum workload and oral contraceptive use significantly contributed to the explained variance $(r=0.59$, $\mathrm{p}<0.001)$.

\section{Subjects' HPA axis functioning in a challenged condition under $4 \mathrm{mg}$ dexamethasone (\%)}

In male subjects, an inverse relationship was observed between percentage increase of cortisol concentrations after standardized high intensity test under 4 mg dexamethasone and waist circumference $(r=0.21, p<0.10)$. In female subjects, inverse relationships were observed between percentage increase of cortisol concentrations after standardized high intensity test under 4 $\mathrm{mg}$ dexamethasone and BMI $(r=0.19$, $p<0.05)$, waist circumference $(r=0.23$, $p<0.04)$, and waist-to-hip ratio $(r=0.21$, $\mathrm{p}<0.05)$. Multiple regression analysis with percentage increase of cortisol concentrations after standardized high intensity test under $4 \mathrm{mg}$ dexamethasone as the dependent variable showed that only waist-to-hip ratio significantly contributed to the explained variance.

In both male and female subjects, a positive relationship was observed between 5-hour cortisol exposure $(\mathrm{nmol} / \mathrm{ml}$ ) and baseline cortisol minus post dexamethasone cortisol concentrations $(\mathrm{nmol} / \mathrm{ml})(r=0.68$, $\mathrm{p}<0.001$ and $\mathrm{r}=0.86, \mathrm{p}<0.001)$.

In male subjects, strong positive relationships were observed between FMI and waist circumference $(r=0.85$, $p<0.001)$, as well as waist-to-hip ratio ( $r$ $=0.70, p<0.001$ ).

\section{Discussion}

The objective of our study was to relate HPA axis functioning and HPA feedback functioning to body fat distribution in normal weight to obese subjects. We therefore tested the relationship between several parameters of HPA axis functioning, body composition and body fat distribution measured as waist circumference and waist-to-hip ratio. Waist circumference and waist-to-hip 
measurements were used as surrogates for body fat distribution measurements, as anthropometric measurements have been shown to predict total and abdominal fat content[20-22].

Firstly, we investigated the relationships between cortisol exposure measured over 5 hours, body composition and body fat distribution. In accordance to the literature [3, 4, 10-12] we observed that cortisol exposure was related to a higher FMI in men and a higher waist-to-hip ratio in women. This sex difference is likely to be caused by the fact that men tend to progressively increase visceral fat depots with increasing adiposity, while women tend to develop different types of body fat distribution (visceral or peripheral) [26], which is supported by the strong relationship between FMI and waist circumference as well as waist-to-hip ratio in men in our study. This suggests that in both men and women low cortisol exposure is related to visceral fat distribution. Low cortisol exposure is a sign of a decreased HPA axis activity, which is for instance also observed in subjects with chronic stress and depression [4, 27]. As expected and in concordance with previous studies we observed that in the women HPA axis functioning was related to oral contraceptive use [28, 29], but also to baseline exercise levels. These relationships were however independent of the relationship between HPA axis functioning and visceral fat disposition. A limitation of the present study is that the women were examined regardless of the phase of their menstrual cycle, as previous studies have shown differences in basal cortisol concentrations between the luteal and follicular phase, which is about 3\% [28]. The women being in different phases of the menstrual cycle can thus not explain the differences in basal cortisol concentrations between women with a high or low waist-to-hip ratio. However, for future studies information on the menstrual cycle should be taken into account.
Secondly, we investigated the relationships between HPA axis feedback functioning, body composition and body fat distribution, measured through a $4 \mathrm{mg}$ dexamethasone suppression test. In accordance to part of the literature [17, 18] we observed that reduced negative feedback of the HPA axis in a nonchallenged condition (i.e. high amounts of cortisol present after dexamethasone suppression) was related to a higher FMI in men and a higher waist-to-hip ratio in women. Other studies however have shown an inverse $[4,16]$, no relationship $[3,5,6,10]$ or sex specific associations [16]; this inconclusiveness may result from different dosages of dexamethasone, as they used smaller dosages of dexamethasone ( 0.05 to $0.25 \mathrm{mg}$ ). Low dosages of dexamethasone may not be potent enough to detect possible differences in HPA axis feedback functioning, as Ljung et al 1996 [17] observe no differences in inhibition when using low dosages (0.05 and $0.125 \mathrm{mg}$ ) but did observe differences when using a higher dosage $(0.5 \mathrm{mg})$. We therefore suggest that a protocol that includes the range of dexamethasone dosage of 0.5 to $4 \mathrm{mg}$ is necessary to detect subtle differences in HPA axis feedback functioning. The relationship between $5-h$ cortisol exposure and the suppression of non-challenged cortisol levels by dexamethasone that was observed in both men and women, strongly suggest that a diminished negative HPA axis feedback is one of the mechanisms that is responsible for the relatively low 5-h cortisol exposure in visceral obesity.

Thirdly, we investigated the relationship between HPA axis functioning in a challenged condition under $4 \mathrm{mg}$ dexamethasone, body composition and body fat distribution, measured through a high intensity test under $4 \mathrm{mg}$ dexamethasone [19]. In accordance to previous studies that only measured lean subjects $[19,30]$ a significant sex difference was observed in HPA axis functioning in a challenged condition under $4 \mathrm{mg}$ dexamethasone. Moreover, we observed differences in HPA axis 
functioning i.e. relatively lower cortisol levels after a challenged condition under dexamethasone that related to a higher waist circumference in men and a higher waist-to-hip ratio in women. This is in contrast with the non-challenged condition under dexamethasone, where relatively higher cortisol levels after dexamethasone suppression were related to a higher fat mass index in men and a higher waist-tohip ratio in women. Several mechanisms are hypothesized that could underlie the discrepancy between the challenged and the non-challenged condition. Since dexamethasone is unable to cross the blood-rain barrier [31], cortisol levels after dexamethasone suppression reflect negative feedback functioning only at the level of the pituitary. Therefore, it cannot be excluded that the negative feedback mechanisms at the level of the pituitary and the hypothalamus are distinctly influenced by visceral obesity, and that visceral obesity is associated with an increased negative feedback at the level of the hypothalamus, which in the current study became predominant in the exercise-challenged condition.

Alternatively, it can be hypothesized that the decreased negative feedback signaling in visceral obesity, as shown in our nonchallenged condition and confirmed by others $[17,18]$, is associated with a decreased responsiveness of the HPA axis to (physical) stress. Under normal, dexamethasone-free conditions, where differences in feedback sensitivity may play a role, the increased cortisol response to stress $[3-6,9,14]$ could then be attributed to the decreased efficacy of cortisol to suppress its own secretion.

Taken together all our observations pointed into the same direction, as we observed that in lean to overweight subjects, low cortisol exposure, enhanced negative feedback, and altered HPA axis functioning in a challenged condition under $4 \mathrm{mg}$ dexamethasone is related to waist circumference in men and to waistto-hip ratio in women. Our results are thus consistent with previous work that suggests a deregulation of the HPA axis in humans with relative more visceral fat. It is however still not clear whether the HPA axis is causally or co-incidentally related to (visceral) obesity, which only can be determined using a longitudinal study. From our results, we conclude that disturbance of HPA axis functioning under basal and challenged conditions is related to visceral fat accumulation.

\section{Acknowledgements}

We want to thank our subjects for their participation in this study. We gratefully thank Loek Wouters and Jose Sulon for their assistance. FR (supervised by AN and MW) carried out the study, collected and analyzed the data, and wrote the largest part of the manuscript. SL and JB reviewed the manuscript. Planning, processing the results and writing the manuscript were done under general supervision by AN and MW. The authors had no conflict of interest. 


\section{Literature}

1. Tsigos, C. and G.P. Chrousos, Hypothalamic-pituitary-adrenal axis, neuroendocrine factors and stress. J Psychosom Res, 2002. 53(4): p. 865-71.

2. Hankin, M.E., H.M. Theile, and A.W. Steinbeck, An evaluation of laboratory tests for the detection and differential diagnosis of Cushing's syndrome. Clin Endocrinol (Oxf), 1977. 6(3): p. 185-96.

3. Ljung, T., G. Holm, P. Friberg, B. Andersson, B.A. Bengtsson, J. Svensson, et al., The activity of the hypothalamicpituitary-adrenal axis and the sympathetic nervous system in relation to waist/hip circumference ratio in men. Obes Res, 2000. 8(7): p. 487-95.

4. Duclos, M., B. Gatta, J.B. Corcuff, M. Rashedi, F. Pehourcq, and P. Roger, Fat distribution in obese women is associated with subtle alterations of the hypothalamic-pituitary-adrenal axis activity and sensitivity to glucocorticoids. Clin Endocrinol (Oxf), 2001. 55(4): p. 447-54.

5. Duclos, M., P. Marquez Pereira, P. Barat, B. Gatta, and P. Roger, Increased cortisol bioavailability, abdominal obesity, and the metabolic syndrome in obese women. Obes Res, 2005. 13(7): p. 1157-66.

6. Marin, P., N. Darin, T. Amemiya, B. Andersson, S. Jern, and P. Bjorntorp, Cortisol secretion in relation to body fat distribution in obese premenopausal women. Metabolism, 1992. 41(8): p. 882-6.

7. Travison, T.G., A.B. O'Donnell, A.B. Araujo, A.M. Matsumoto, and J.B. McKinlay, Cortisol levels and measures of body composition in middle-aged and older men. Clin Endocrinol (Oxf), 2007. 67(1): p. 71-7.

8. Misra, M., M.A. Bredella, P. Tsai, N. Mendes, K.K. Miller, and A. Klibanski, Lower growth hormone and higher cortisol are associated with greater visceral adiposity, intramyocellular lipids, and insulin resistance in overweight girls. Am J Physiol Endocrinol Metab, 2008. 295(2): p. E385-92.

9. Pasquali, R., S. Cantobelli, F. Casimirri, M. Capelli, L. Bortoluzzi, R. Flamia, et al., The hypothalamic-pituitaryadrenal axis in obese women with different patterns of body fat distribution. J Clin Endocrinol Metab, 1993. 77(2): p. 341-6.

10. Garcia-Prieto, M.D., F.J. Tebar, F. Nicolas, E. Larque, S. Zamora, and M. Garaulet, Cortisol secretary pattern and glucocorticoid feedback sensitivity in women from a Mediterranean area: relationship with anthropometric characteristics, dietary intake and plasma fatty acid profile. Clin Endocrinol (Oxf), 2007. 66(2): p. $185-91$.

11. Farag, N.H., W.E. Moore, W.R. Lovallo, P.J. Mills, S. Khandrika, and J.E. Eichner, Hypothalamic-pituitary-adrenal axis function: relative contributions of perceived stress and obesity in women. J Womens Health (Larchmt), 2008. 17(10): p. 1647-55.

12. Putignano, P., A. Dubini, P. Toja, C. Invitti, S. Bonfanti, G. Redaelli, et al., Salivary cortisol measurement in normalweight, obese and anorexic women: comparison with plasma cortisol. Eur J Endocrinol, 2001. 145(2): p. 165-71.

13. Therrien, F., V. Drapeau, J. Lalonde, S.J. Lupien, S. Beaulieu, A. Tremblay, et al., Awakening cortisol response in lean, obese, and reduced obese individuals: effect of gender and fat distribution. Obesity (Silver Spring), 2007. 15(2): p. 377-85.

14. Epel, E.S., B. McEwen, T. Seeman, K. Matthews, G. Castellazzo, K.D. Brownell, et al., Stress and body shape: stress-induced cortisol secretion is consistently greater among women with central fat. Psychosom Med, 2000. 62(5): p. 623-32.

15. Rosmond, R., M.F. Dallman, and P. Bjorntorp, Stress-related cortisol secretion in men: relationships with abdominal obesity and endocrine, metabolic and hemodynamic abnormalities. J Clin Endocrinol Metab, 1998. 83(6): p. 1853-9.

16. Pasquali, R., B. Ambrosi, D. Armanini, F. Cavagnini, E.D. Uberti, G. Del Rio, et al., Cortisol and ACTH response to oral dexamethasone in obesity and effects of sex, body fat distribution, and dexamethasone concentrations: a dose-response study. J Clin Endocrinol Metab, 2002. 87(1): p. 166-75.

17. Ljung, T., B. Andersson, B.A. Bengtsson, P. Bjorntorp, and P. Marin, Inhibition of cortisol secretion by dexamethasone in relation to body fat distribution: a dose-response study. Obes Res, 1996. 4(3): p. $277-82$.

18. Bjorntorp, P., Neuroendocrine factors in obesity. J Endocrinol, 1997. 155(2): p. 193-5.

19. Petrides, J.S., P.W. Gold, G.P. Mueller, A. Singh, C. Stratakis, G.P. Chrousos, et al., Marked differences in functioning of the hypothalamic-pituitary-adrenal axis between groups of men. J Appl Physiol, 1997. 82(6): p. $1979-88$.

20. Clasey, J.L., C. Bouchard, C.D. Teates, J.E. Riblett, M.O. Thorner, M.L. Hartman, et al., The use of anthropometric and dual-energy $\mathrm{X}$-ray absorptiometry (DXA) measures to estimate total abdominal and abdominal visceral fat in men and women. Obes Res, 1999. 7(3): p. 256-64.

21. Weerarathna, T.P., S. Lekamwasam, and M. Rodrigo, Prediction of total and visceral fat contents using anthropometric measures of adiposity in women. Ceylon Med J, 2008. 53(4): p. 128-32.

22. Snijder, M.B., M. Visser, J.M. Dekker, J.C. Seidell, T. Fuerst, F. Tylavsky, et al., The prediction of visceral fat by dual-energy X-ray absorptiometry in the elderly: a comparison with computed tomography and anthropometry. Int J Obes Relat Metab Disord, 2002. 26(7): p. 984-93.

23. Westerterp, K.R., L. Wouters, and W.D. van Marken Lichtenbelt, The Maastricht protocol for the measurement of body composition and energy expenditure with labeled water. Obes Res, 1995. 3 Suppl 1: p. 49-57.

24. Lejeune, M.P., K.R. Westerterp, T.C. Adam, N.D. Luscombe-Marsh, and M.S. Westerterp-Plantenga, Ghrelin and glucagon-like peptide 1 concentrations, 24-h satiety, and energy and substrate metabolism during a high-protein diet and measured in a respiration chamber. Am J Clin Nutr, 2006. 83(1): p. 89-94.

25. Borghouts, C., C.Q. Scheckhuber, A. Werner, and H.D. Osiewacz, Respiration, copper availability and SOD activity in P. anserina strains with different lifespan. Biogerontology, 2002. 3(3): p. 143-53.

26. Wajchenberg, B.L., Subcutaneous and visceral adipose tissue: their relation to the metabolic syndrome. Endocr Rev, 2000. 21(6): p. 697-738.

27. Swaab, D.F., A.M. Bao, and P.J. Lucassen, The stress system in the human brain in depression and neurodegeneration. Ageing Res Rev, 2005. 4(2): p. 141-94.

28. Bouma, E.M., H. Riese, J. Ormel, F.C. Verhulst, and A.J. Oldehinkel, Adolescents' cortisol responses to awakening and social stress; effects of gender, menstrual phase and oral contraceptives. The TRAILS study. Psychoneuroendocrinology, 2009. 34(6): p. 884-93.

29. Meulenberg, P.M. and J.A. Hofman, The effect of oral contraceptive use and pregnancy on the daily rhythm of cortisol and cortisone. Clin Chim Acta, 1990. 190(3): p. 211-21.

30. Deuster, P.A., J.S. Petrides, A. Singh, E.B. Lucci, G.P. Chrousos, and P.W. Gold, High intensity exercise promotes escape of adrenocorticotropin and cortisol from suppression by dexamethasone: sexually dimorphic responses. J Clin Endocrinol Metab, 1998. 83(9): p. 3332-8.

31. Adam, T.C. and E.S. Epel, Stress, eating and the reward system. Physiol Behav, 2007. 91(4): p. $449-58$. 


\section{Chapter 9}

Acute stress-related changes in eating in the absence of hunger

F. Rutters, A.G. Nieuwenhuizen, S.G.T Lemmens, J.M Born, and M.S. WesterterpPlantenga

Obesity 2009 January; 17 (1): 72-7 


\begin{abstract}
Background: obesity results from chronic deregulation of energy balance, which may in part be caused by stress.

Objective: to investigate the effect of acute and psychological stress on food intake, using the eating in the absence of hunger paradigm, in normal- and overweight men and women, while taking dietary restraint and disinhibition into account. In 129 subjects (BMI $=24.5 \pm 3.4 \mathrm{~kg} / \mathrm{m}^{2}$ and age $=27.6 \pm 8.8 \mathrm{y}$ ), scores were determined on the Three Factor Eating Questionnaire (dietary restraint $=7.2 \pm 4.4$; disinhibition $=4.5 \pm 2.6$; feeling of hunger $=3.9 \pm 2.6$ ) and State-Trait Anxiety Inventory (trait score $=31.7 \pm 24.2$ ). In a randomized crossover design, the 'eating in absence of hunger' protocol was measured as a function of acute stress versus a control task and of state anxiety scores.
\end{abstract}

Results: energy intake from sweet foods (708.1 vs. $599.4 \mathrm{~kJ}, \mathrm{p}<0.03)$ and total energy intake ( 965.2 vs. $793.8 \mathrm{~kJ}, \mathrm{p}<0.01$ ) were significantly higher in the stress compared to the control condition. Differences in energy intake between the stress and control condition were a function of increase in state anxiety scores during the stress task $\left(R^{2}=\right.$ $0.05, p<0.01)$. This positive relationship was stronger in subjects with high disinhibition scores $\left(R^{2}=0.12, p<0.05\right)$. Differences in state anxiety scores were a function of trait anxiety scores $\left(R^{2}=0.07, p<0.05\right)$.

Conclusion: acute psychological stress is associated with eating in the absence of hunger, especially in vulnerable individuals characterized by disinhibited eating behavior and sensitivity to chronic stress. 


\section{Introduction}

The prevalence of overweight and obesity has increased worldwide to epidemic proportions [1]. Obesity results from a chronic deregulation of energy balance, with energy intake exceeding energy expenditure, leading to the storage of the excessive energy as fat [2]. This chronic deregulation of energy balance may be caused, in part, by stress, since in Western society high levels of ambient stress are abundantly present [3]. Several human studies in laboratory settings indicate that, in adults, acute stress may influence energy intake [3-7]. Acute stress alters food preference, eating frequency, and amount of energy intake $[3,5]$. During stress, food preference is altered towards intake of sweet foods and foods with saturated fats, next to an increase in the intake frequency and amount of food intake $[4,6,7]$. However, not all studies that investigated the relationship between energy intake and stress have yielded conclusive results [8, 9]. Stress may also result in a decrease in energy intake $[8,9]$. These individual differences in response to stress may relate to eating behavior characteristics [4-7], as are determined using the Three Factor Eating Questionnaire (TFEQ). The TFEQ assesses three factors involved in eating behavior: dietary restraint; disinhibition; and hunger [10]. An increase in energy intake during stress has been found in individuals with high scores on dietary restraint and/or disinhibition [4-7].

A possible technique to study the effect of stress on food intake is the 'Eating in the absence of hunger' paradigm [11]. Eating in the absence of hunger is the behavioral phenotype in which individuals eat when exposed to large portions of palatable foods in the absence of hunger. The paradigm has primarily been used in children [11] and was thought to resemble disinhibited eating patterns observed in adults [11]. Therefore, the objective of our study was to investigate the effect of acute psychological stress on food intake, using the eating in the absence of hunger paradigm, in normaland overweight men and women, while taking dietary restraint and disinhibition into account.

\section{Subjects and methods Subjects}

The study was approved by the Medical Ethical Committee of Maastricht University, and informed, written consent was obtained from all subjects. Healthy, medication-free, non-smoking men $(\mathrm{n}=$ 65 ) and women ( $n=65), 18$ to $45 y$ and with a BMI of 20 to $35 \mathrm{~kg} / \mathrm{m}^{2}$ were recruited to complete all phases of this study. A medical history was obtained from each subject before entry into the study, and exclusion criteria were chronic illness, depression, and a history of eating disorders or current dieting. From 130 subjects recruited, 65 men and 64 women completed the study, and 1 subject dropped out before the actual start of the study. Subjects were not told the real purpose of the study but instead were given a cover story on the effect of activity on leptin concentrations.

\section{Experimental design}

The study was performed in a withinsubjects, randomized, crossover design. Each subject reported to the laboratory on 3 occasions for: 1) measurement of anthropometry and subject characterization; 2) measurement of 'eating in absence of hunger' protocol in combination with a stress task; and 3) measurement of 'eating in absence of hunger' protocol in combination with a control task.

The anthropometry measurements consisted of body weight, height, waist and hip circumference determination. Subjects also completed the State-Trait Anxiety Inventory (STAI trait) and the Three Factor Eating Questionnaire (TFEQ), which assesses restraint, disinhibition, and feeling of hunger.

'Eating in absence of hunger' was measured as a function of acute stress versus control. Analog scales (VAS) that measure hunger and satiety were used to 
determine if subjects ate beyond fullness. A mental arithmetic task with sums that subjects could (control task) or could not solve (stress task) was used as a stress manipulation. To investigate whether the stress condition inflicted psychological or physiological changes, we used the profile of mood states (POMS) and state-anxiety (STAI state) questionnaires, as well as heart rate and blood pressure measurements. Before the eating in absence of hunger measurements, subjects were made familiar with the VAS, POMS, and STAI state questionnaires and were trained to complete them routinously, in order not to disturb the actual activity they were involved in during the measurements.

\section{Measurements}

\section{Anthropometry}

Measurements were obtained in the morning after voiding the bladder and before breakfast. Body weight (Sauter D7470, Ebingen, Germany) and height (Seca, model 220, Hamburg, Germany) were measured to the nearest $0.01 \mathrm{~kg}$ and $0.1 \mathrm{~cm}$, respectively. BMI $\left(\mathrm{kg} / \mathrm{m}^{2}\right)$ was calculated as body weight $(\mathrm{kg})$ divided by height $(\mathrm{m})$ squared. The waist circumference was measured to the nearest $0.1 \mathrm{~cm}$ at the site of the smallest circumference between the rib cage and the iliac crest, whereas the hip circumference was measured to the nearest $0.1 \mathrm{~cm}$ at the level of maximum extension of the buttocks. The waist and hip circumference measurements were obtained with subjects in the standing position [12].

\section{Eating behavior}

Eating behavior was analyzed using a validated Dutch translation of the TFEQ $[10,13]$. The TFEQ measures three components of eating behavior. Dietary restraint reflects the extent to which individuals attempt to cognitively control their food intake. Disinhibition of restraint reflects loss over control over eating in response to the presence of palatable food or other disinhibiting stimuli, such as emotional distress. The third factor measures the subjective feeling of hunger.
Based upon the median for the TFEQ scores in the South of the Netherlands, subjects were characterized as unrestrained when dietary restraint scores were $<9$, and as restrained when scores were $\geq 9$. Subjects were characterized as having low disinhibition when disinhibition scores were $<5$, and as having high disinhibition when scores were $\geq 5$ [13].

\section{Visual Analog Scales (VAS)}

Aspects of appetite were assessed using $100 \mathrm{~mm}$ visual analog scales (VAS) with questions about feelings of hunger, satiety, thirst, and desire to eat. Opposing extremes of each feeling were described at either end of the $100-\mathrm{mm}$ horizontal line, and subjects marked the line to indicate how they felt at that moment [14]. Completion of the VAS questionnaire took our experienced subjects about 0.5 minute. During the 'eating in absence of hunger' protocol, appetite profiles were assessed three times: before lunch, 5 minutes after lunch, and 30 minutes after the stress or control task.

\section{Profile of Mood States (POMS)}

Aspects of mood were assessed using the Dutch translation of the Profile of Mood States (POMS) [15]. This questionnaire contains 70 adjectives that are rated on a five-point scale, anchored by "much like this" to "much unlike this" and is divided into five subscales (depression, tension, confusion, fatigue and anger), each scoring a maximum of 35 points. An increase in POMS scores is associated with a worsening in mood, except in the case of "vigor" [15]. Completion of the POMS questionnaire took our experienced subjects only 3 minutes. During the 'eating in absence of hunger' protocol, mood profiles were assessed five times: 5 minutes after lunch, and at 0, 10, 20 and 30 minutes after the stress or control task.

\section{State-Trait Anxiety Inventory (STAI)} Anxiety was assessed using the Dutch translation of the State-Trait Anxiety Inventory (STAI) [16]. This questionnaire consists of two subscales: the trait scale (anxiety-trait) and the state scale 
(anxiety-state). The trait scale refers to individual differences in the likelihood that a person would experience state anxiety in a stressful situation, and thereby refers to chronic feelings of anxiety. The state scale refers to the transitory emotional response involving unpleasant feelings of tension and apprehensive thoughts. Both scales are composed of 20 questions rated on a four-point scale, ranging from "much like this," to "much unlike this" and require that subjects describe how they feel generally, on the anxiety-trait scale, and how they feel at a specific moment, on the anxiety-state scale [16]. Each subscale of the questionnaire can score a maximum of 80 points and an increase in STAI trait or state scores is associated with an increase in anxiety. Completion of the STAI state questionnaire took our experienced subjects only 2 minutes. At the start of the experiment subjects filled in the trait scale and during the 'eating in absence of hunger' protocol, state anxiety was assessed five times: 5 minutes after lunch, and at $0,10,20$ and 30 minutes after the stress or control task.

\section{Stress/control task}

During the 'eating in the absence of hunger' protocol subjects received a mental arithmetic task with sums that they could or could not solve (control versus stress task). Subjects were told to solve the sums within the time limits specified by the assignment. The control and stress tasks were presented in random order to the subjects. The arithmetic task was a modified and improved version of the computer program previously described and validated by Peters et al. 1998 [17].

'Eating in the absence of hunger' protocol The 'eating in the absence of hunger' protocol consisted of consumption of a standard lunch, followed by completion of a stress or control task, and was concluded with half an hour in which subjects had free-access to snacks. The 'eating in the absence of hunger' protocol was started by completing a VAS, and followed by a standard lunch to minimize the influence of hunger on the subjects' snack intake. The lunch contained $30 \%$ of the subjects' daily energy requirement and consisted of typical Dutch lunch products, namely brown bread (1.0 MJ per $100 \mathrm{~g}$; en $\% \mathrm{C} / \mathrm{P} / \mathrm{F}$ : 74/15/11) with young cheese (1.6 MJ per $100 \mathrm{~g}$; en\% C/P/F: $0 / 26 / 74$ ), as well as ab libitum tea or water consumption. The daily energy requirements were calculated by multiplying the basal metabolic rate (BMR) by an activity index of 1.75 . The BMR (MJ/day) was calculated according to the equations of Harris-Benedict [18]. Subjects were given 15 minutes to consume the lunch and were instructed to eat until they were satiated. Immediately after lunch, subjects completed POMS and state anxiety questionnaires and completed a stress or control task. After completing VAS, POMS and state anxiety questionnaires, which took about 5 minutes, subjects were retained in the research room for half an hour in which they were allowed to relax and read magazines. During this half hour the subjects were presented a tray with containers holding generous pre-weighed portions of sweet snack foods, including $100 \mathrm{~g}$ chocolate (2.2 MJ per $100 \mathrm{~g}$ ) and $200 \mathrm{~g}$ fruit-chew candy (1.5 MJ per 100 $\mathrm{g})$, as well as salty snack foods that included $100 \mathrm{~g}$ potato chips (2.4 MJ per $100 \mathrm{~g}), 50 \mathrm{~g}$ pretzels $(2.1 \mathrm{MJ}$ per $100 \mathrm{~g})$, and $200 \mathrm{~g}$ nuts $(2.7 \mathrm{MJ}$ per $100 \mathrm{~g})$. The subjects were instructed to eat as much as they wished of any of the foods. Every 10 minutes during the half hour, subjects completed POMS and state anxiety questionnaires. At the end of the half hour the subjects completed VAS, POMS and state questionnaires one more time. After the subjects left, each of the containers holding the snack foods were weighed to determine food choice and the amount eaten. Before and after completing the stress or control tasks, heart rate (bpm), and systolic and diastolic blood pressure $(\mathrm{mmHg})$ were measured using an automated device (WelclAllyn OSZ 5 easy, Spreidel and Keller GmBH and Co, KG, Jungingen, Germany). 


\section{Statistical analysis}

Differences between men and women, as well as treatments (control and stress), were determined using unpaired t-tests. Differences over time and between treatments (control and stress) were determined using two-factor ANOVA with repeated measures. To analyze whether the amount of stress experienced during the stress task predicted the difference in energy intake between the stress and control condition, a simple linear regression model was used, depicting the differences in energy intake between the stress and control condition ( $\Delta$ energy intake) as the dependent variable and the differences in state anxiety scores immediately after compared to before the stress task ( $\Delta$ state anxiety scores) as the independent variable. The relation between dependent ( $\Delta$ state anxiety scores) and independent (trait anxiety scores) variable was determined using a linear regression model.

All statistical tests were two-sided.

Differences were considered significant at $p<0.05$, and values were expressed as mean \pm standard deviation.

\section{Results}

\section{Subject characteristics}

The characteristics of the subjects are summarized in table 1. Participants were 18 to 48 years old, and their BMI ranged from 19.8 to $34.8 \mathrm{~kg} / \mathrm{m}^{2}$. Men had a predictably higher height, body weight, and waist circumference than women. Women had higher dietary restraint, disinhibition, and feeling of hunger scores than men. The age, BMI, hip circumference and trait anxiety scores did not differ between the sexes. We did not analyze the results of men and women separately, because no significant differences were found between men and women in VAS, POMS, and state anxiety scores, or in energy intake during the eating in absence of hunger protocol (data not shown).
Table 1: Characteristics of subjects $(n=129)$

\begin{tabular}{llll}
\hline & $\begin{array}{l}\text { Men } \\
(\mathrm{n}=65)\end{array}$ & $\begin{array}{l}\text { Women } \\
(\mathrm{n}=64)\end{array}$ & P value $^{1}$ \\
\hline Age $($ year $)$ & $28.1 \pm 8.9$ & $27.1 \pm 8.6$ & 0.84 \\
Height $(\mathrm{cm})$ & $181.2 \pm 7.5$ & $168.7 \pm 6.2$ & 0.01 \\
Body weight $(\mathrm{kg})$ & $79.8 \pm 10.2$ & $69.9 \pm 10.4$ & 0.01 \\
Body mass index $\left(\mathrm{kg} / \mathrm{m}^{2}\right)$ & $24.4 \pm 3.3$ & $24.6 \pm 3.6$ & 0.74 \\
Waist circumference $(\mathrm{cm})$ & $85.7 \pm 9.5$ & $78.8 \pm 7.9$ & 0.01 \\
Hip circumference $(\mathrm{cm})$ & $102.2 \pm 6.2$ & $104.7 \pm 8.5$ & 0.12 \\
Trait anxiety score & $31.6 \pm 6.7$ & $31.9 \pm 6.7$ & 0.77 \\
Dietary restraint score & $5.8 \pm 3.9$ & $8.8 \pm 4.4$ & 0.01 \\
Disinhibition score & $3.4 \pm 1.7$ & $5.6 \pm 2.8$ & 0.01 \\
Feeling of hunger score & $3.5 \pm 2.5$ & $4.4 \pm 2.6$ & 0.03 \\
\hline
\end{tabular}

Values are means \pm sd.

${ }^{1}$ Differences between men vs. women (t-test)

\section{State anxiety scores}

The changes in state anxiety scores over time in the stress and control condition are depicted in figure $\mathbf{1}$. The state anxiety scores were significantly higher in the stress condition compared to the control condition, immediately (31.3 \pm 8.8 vs. $27.9 \pm 6.4, p<0.001)$ and 10 minutes $(28.4 \pm 7.7$ vs. $27.3 \pm 6.9$, $p<0.05)$ after receiving the stress or control task (figure 1). After receiving the stress task, state anxiety scores increased significantly, while in the control condition no significant changes were observed (4.2 \pm 5.7 vs. $-0.8 \pm 0.3, p<0.001$ ) (figure 1).

Figure 1: Changes in state anxiety scores (means) over time in the stress and control condition in all subjects ( $n$ $=129$ )

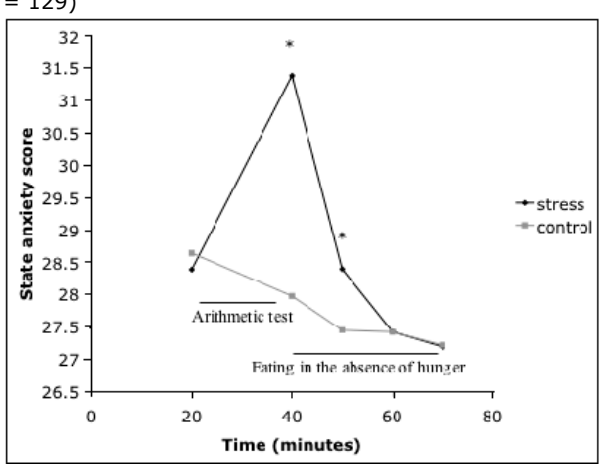

$* p<0.05$ for differences in time in the stress compared to the control condition (ANOVA repeated measures)

\section{POMS scores}

The POMS scores were significantly higher in the stress condition compared to the control condition, namely immediately after receiving the stress task in four out of five POMS categories, which are depression (15.7 \pm 4.1 vs. $14.2 \pm 3.5, p$ 
$<0.05)$, tension $(14.7 \pm 5.1$ vs. $12.7 \pm$ $3.7, \mathrm{p}<0.05)$, confusion (15.9 \pm 4.3 vs. $14.7 \pm 3.1, \mathrm{p}<0.05)$ and anger $(14.6 \pm$ 4.8 vs. $12.6 \pm 3.3, p<0.05)$. After receiving the stress task POMS scores increased significantly, while in the control condition no significant alterations were shown in the categories depression $(0.5 \pm$ 3.2 vs. $-1.0 \pm 2.5, p<0.05)$, tension ( 1.8 \pm 3.9 vs. $-0.7 \pm 2.5, p<0.05)$, confusion $(0.9 \pm 3.2$ vs. $-0.7 \pm 2.4, \mathrm{p}<0.05)$ and anger $(1.7 \pm 3.9$ vs. $-0.4 \pm 1.8, \mathrm{p}<$ $0.05)$.

Heart rate and blood pressure measurements, immediately before and directly after completion of the arithmetic task, showed no changes over time. Additionally, no changes were seen between the stress and control condition in heart rate $(70.3 \pm 13$ vs. $72.3 \pm 12.3$ bpm, $\mathrm{p}<0.86)$ and systolic $(123.7 \pm 14.1$ vs. $125.7 \pm 12.9 \mathrm{mmHg}, \mathrm{p}<0.45)$ and diastolic $(73.5 \pm 10.2$ vs. $72.3 \pm 12.3$ $\mathrm{mmHg}, \mathrm{p}<0.89)$ blood pressure.

\section{VAS hunger and satiety scores}

During the lunch the average energy intake for men was $4.0 \pm 0.5 \mathrm{MJ}$ and for women $3.5 \pm 0.4 \mathrm{MJ}$. The changes in satiety and hunger scores over time in the stress and control condition are depicted in figure 2. No significant differences in satiety scores were seen between the stress and control condition before lunch ( $32.5 \pm 21.1$ vs. $27.6 \pm 15.8)$, directly after lunch ( $65.6 \pm 17.7$ vs. $65.9 \pm 18.3)$ and after the eating in absence of hunger protocol $(70.7 \pm 16.9$ vs. $69.1 \pm 18.5)$. No significant differences in hunger scores were seen between the stress and control conditions before lunch (54.2 \pm 22.9 vs. $58.5 \pm 19.8)$, directly after lunch (18.6 \pm 13.9 vs. $17.5 \pm 13.8)$ and after the eating in absence of hunger protocol (13.5 \pm 19.5 vs. $15.8 \pm 13.7)$. A significant increase in satiety scores and a significant decrease in hunger scores were seen over time in both conditions.
Figure 2: Changes in satiety and hunger scores (means) over time in the stress and control condition in all subjects $(n=129)$

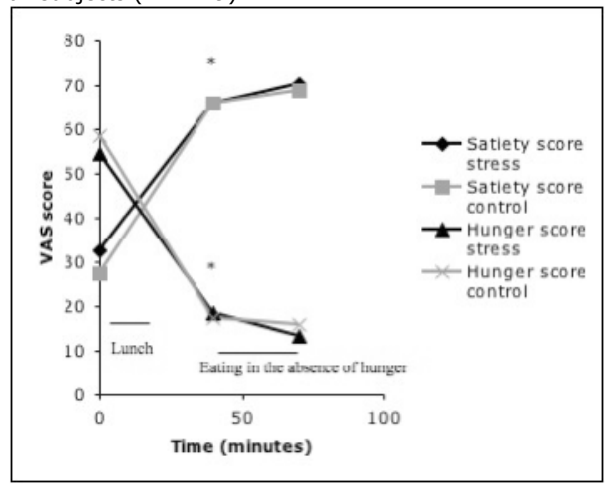

$* p<0.05$ for differences in time in both the stress and control condition (ANOVA repeated measures)

\section{Differences in energy intake in} stress/control condition The differences in energy intake $(\mathrm{kJ})$ during stress and control condition are depicted in figure $\mathbf{3}$. Significant differences were found between the stress and control conditions in energy intake from sweet snack foods (708.1 \pm 798.8 vs. $599.4 \pm 734.4 \mathrm{~kJ}, \mathrm{p}<0.03)$ and total energy intake ( $965.2 \pm 970.6$ vs. $793.8 \pm$ $912.5 \mathrm{~kJ}, \mathrm{p}<0.01)$.

Figure 3: Differences in means ( \pm sd) of energy intake of snack foods $(\mathrm{kJ})$ during stress and control condition in all subjects $(n=129)$

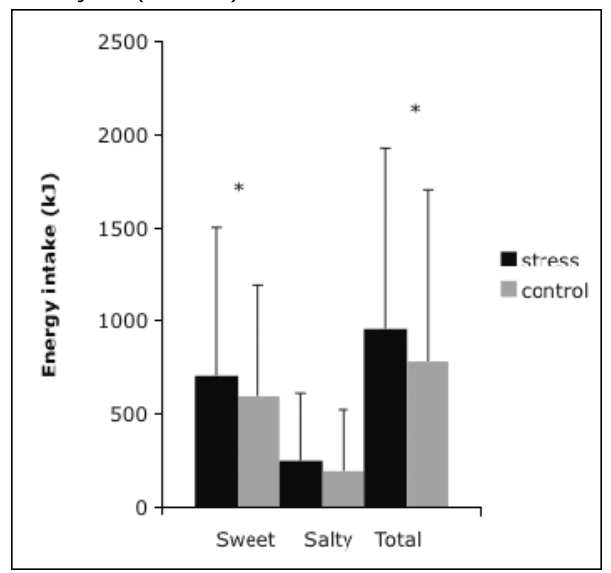

$* \mathrm{P}<0.05$ for stress versus control condition, $\mathrm{t}$-test

Figure 4 depicts the differences in energy intake of snack foods between the stress and control conditions ( $\Delta$ energy intake) as a function of the differences in STAI state scores between immediately after 
compared to before the stress task ( $\Delta$ state anxiety scores). A positive relationship was shown between $\Delta$ energy intake $(\mathrm{kJ})$ and $\Delta$ state anxiety scores $\left(\mathrm{R}^{2}\right.$ $=0.05, \mathrm{p}<0.01)$. Apart from that, no relationship between $\Delta$ energy intake $(\mathrm{kJ})$ and trait anxiety scores was present.

Figure 4: differences in energy intake of snack foods $(\mathrm{kJ})$ between the stress and control condition ( $\Delta$ energy intake) as a function of the differences in state anxiety scores between immediately after compared to before the stress task ( $\Delta$ state anxiety scores) in all subjects ( $n$ =129)

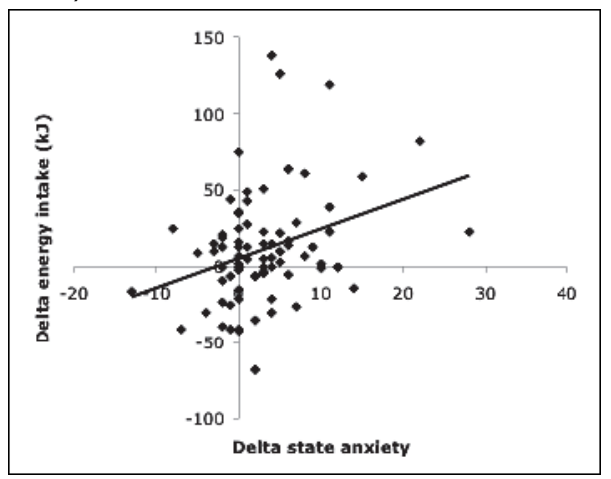

$\mathrm{R}^{2}=0.05, \mathrm{p}<0.01$

Differences in energy intake in stress/control conditions combined with eating behavior

First, linear regression analyses with $\Delta$ energy intake $(\mathrm{kJ})$ as the dependent variable and $\Delta$ state anxiety scores as the independent variable were performed for subjects with low dietary restraint scores $\left(R^{2}=0.05, n s\right)$ and high dietary restraint scores $\left(R^{2}=0.01, n s\right)$.

Second, a multiple linear regression analysis was performed with $\Delta$ energy intake (kJ) as the dependent variable and $\Delta$ state anxiety scores, disinhibition scores and interaction between the $\Delta$ state anxiety scores and the disinhibition scores, as the three independent variables. A significant interaction between $\Delta$ state anxiety scores and disinhibition scores was found, indicating that the explained variance of $\Delta$ of energy intake by $\Delta$ state anxiety scores was different in subjects, namely with low or high disinhibition scores. Therefore,

figure 5 depicts the $\Delta$ energy intake $(\mathrm{kJ})$ as a function of $\Delta$ state anxiety scores plotted for two groups of subjects namely those with a low disinhibition score $\left(R^{2}=\right.$ $0.02, p=0.23$ ) and a high disinhibition score $\left(R^{2}=0.12, p<0.05\right)$.

Figure 5: differences in energy intake $(\mathrm{kJ})$ between the stress and control condition ( $\Delta$ energy intake) as a function of the differences in state anxiety scores between immediately after compared to before the stress task ( $\Delta$ state anxiety scores), plotted for a low disinhibition scores group (in black, $\mathrm{R}^{2}=0.02, \mathrm{p}=0.23$ ) and a high disinhibition scores group (in grey, $\mathrm{R}^{2}=$ $0.12, \mathrm{p}<0.05)$, in all subjects $(\mathrm{n}=129)$

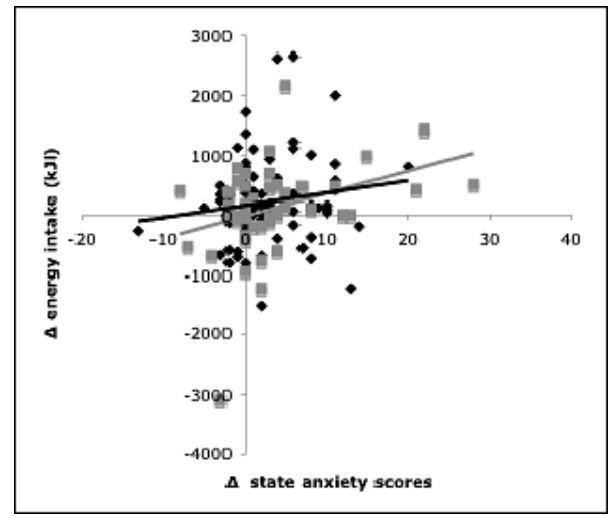

Linear regression model with $\Delta$ state anxiety scores

A linear regression model showed a positive relationship between the $\Delta$ state anxiety scores as the dependent variable and the trait anxiety scores as the independent variable $\left(R^{2}=0.07, p<\right.$ $0.01)$.

\section{Discussion}

The objective of our study was to investigate the effect of acute psychological stress on food intake, using the eating in the absence of hunger paradigm, in normal- and overweight men and women, taking dietary restraint and disinhibition into account. Acute psychological stress, indicated as an increase in state anxiety and POMS scores, was related to an increase in energy intake in the absence of hunger in adults. Moreover, subject specific features including higher trait anxiety scores, were related to a larger increase in state anxiety scores during the stress condition.

With these results, our study adds to the growing literature on the effect of stress on energy intake. To investigate whether 
the stress condition induced stress, we measured anxiety (STAI questionnaire) [16] mood profiles (POMS questionnaire) [15] over time and heart rate and blood pressure. We showed an increase in anxiety and a deterioration of mood during the stress condition, which confirms previous findings $[19,20]$ and thereby confirms stress induction. The changes in anxiety and mood after receiving the stress task compared to the control were observed immediately and after 10 minutes, which indicates acute psychological stress induction that has been shown in previous studies using this particular stress task [17]. Completion of the various questionnaires could be considered a potential stressor.

Nevertheless, the number of questionnaires was identical in both conditions, and the control condition showed a decrease in state anxiety and POMS scores, indicating no stressful experience.

However, contrary to previous studies $[17,21]$, no differences were found in heart rate and blood pressure over time and between the stress and control condition. A possible explanation may be the frequency of the measurements; we measured at two time points (before and after stress/control task), thereby possibly running the risk of missing some changes in heart rate and blood pressure. For future experiments we recommend to focus on heart rate variability [22].

To determine whether subjects were eating beyond fullness, satiety and hunger scores (VAS questionnaire) were measured over time, and in both conditions (stress and control) an increase in satiety scores and a decrease in hunger scores over time were shown. These satiety and hunger scores indicate a state of satiety after the consumption of the lunch, as confirmed by previous research on ab libitum food intake [23], and suggested that possible snack intake was not hunger based. No differences in satiety and hunger scores were seen between the stress and control conditions, suggesting that acute psychological stress did not affect appetite, which is contrary to other studies that did show a decrease in hunger ratings after stress [5]. The contradiction may be due to the fact that in our experiment, the subjects were fed before the exposure to stress, while in the other studies subjects were hungry during stress exposure. The observed food intake, ingested in the absence of hunger after stress exposure, hardly led to further decreases in hunger, underscoring that this may not be a homeostatic mechanism, yet rather a non-homeostatic regulatory mechanisms involved in feeding behavior, such as reward [9, 24].

In accordance with the literature [4-7], we found that (acute psychological) stress altered food preference and amount of energy intake; namely, it increased intake of sweet foods and increased total amount of energy intake. Our study is the first to show that, in adults, eating beyond fullness ('eating in absence of hunger') is affected by acute stress. Before, the paradigm of eating in the absence of hunger only has been used in children [11]. Here it appears to be a sensitive paradigm in adults as well. Since there is no literature on the validity of the paradigm in adults, the paradigm should be used in different studies in order to show reproducibility and sensitivity. A linear regression showed that differences in energy intake between the stress and control conditions was a function of the differences in state anxiety scores between immediately after compared to before the stress task. These results imply that subjects who experienced a greater amount of acute stress had the largest increase in energy intake. Here trait anxiety scores did not play a role, since these did not contribute to the explanation of $\Delta$ energy intake.

Taking subject characteristics into account, it has been suggested that dietary restraint may account for the differences in reaction to stress with respect to energy intake. In contrast to other studies $[5,6]$, our study did not show a relationship between energy intake, stress and dietary restraint. 
Instead, an effect of disinhibition was shown. The relationship between differences in energy intake between the stress and control conditions and differences in state anxiety scores between immediately after compared to before the stress task, was only significant in subjects with a high disinhibition scores, when compared to the subjects with a low disinhibition scores. Thus, disinhibition scores appeared to be a subject specific feature that contributed to increased energy intake during acute stress.

In addition, a linear regression analysis showed that subjects who experienced acute stress had higher trait anxiety scores. These results implicate that a higher likelihood to experience state anxiety in a stressful situation [16], contributes to a higher sensitivity to acute stress from the stress task. Therefore, we conclude that acute psychological stress is associated to eating in absence of hunger, especially in vulnerable individuals characterized by disinhibited eating behavior and sensitivity to chronic stress.

\section{Acknowledgements}

We want to thank our subjects for their participation in this study.

FR (supervised by AN and MW) carried out the study, collected and analyzed the data, and wrote the largest part of the manuscript. SL and JB reviewed the manuscript. Planning, processing the results and writing the manuscript were done under general supervision by $\mathrm{AN}$ and MW. The authors had no conflict of interest. 


\section{Literature}

1. Burton, B.T. and W.R. Foster, Health implications of obesity: an NIH Consensus Development Conference. J Am Diet Assoc, 1985. 85(9): p. 1117-21.

2. Tremblay, A., L. Perusse, and C. Bouchard, Energy balance and body-weight stability: impact of gene-environment interactions. Br ] Nutr, 2004. 92 Suppl 1: p. S63-6.

3. Heatherton, T.F., C.P. Herman, and J. Polivy, Effects of physical threat and ego threat on eating behavior. J Pers Soc Psychol, 1991. 60(1): p. 138-43.

4. Epel, E., R. Lapidus, B. McEwen, and K. Brownell, Stress may add bite to appetite in women: a laboratory study of stress-induced cortisol and eating behavior. Psychoneuroendocrinology, 2001. 26(1): p. 37-49.

5. Mitchell, S.L. and L.H. Epstein, Changes in taste and satiety in dietary-restrained women following stress. Physiol Behav, 1996. 60(2): p. 495-9.

6. Zellner, D.A., S. Loaiza, Z. Gonzalez, J. Pita, J. Morales, D. Pecora, et al., Food selection changes under stress. Physiol Behav, 2006. 87(4): p. 789-93.

7. Oliver, G., J. Wardle, and E.L. Gibson, Stress and food choice: a laboratory study. Psychosom Med, 2000. 62(6): p. 853-65.

8. Pollard, T.M., A. Steptoe, L. Canaan, G.J. Davies, and J. Wardle, Effects of academic examination stress on eating behavior and blood lipid levels. Int J Behav Med, 1995. 2(4): p. 299-320.

9. Adam, T.C. and E.S. Epel, Stress, eating and the reward system. Physiol Behav, 2007. 91(4): p. 449-58.

10. Stunkard, A.J. and S. Messick, The three-factor eating questionnaire to measure dietary restraint, disinhibition and hunger. J Psychosom Res, 1985. 29(1): p. 71-83.

11. Fisher, J.O. and L.L. Birch, Eating in the absence of hunger and overweight in girls from 5 to 7 y of age. Am J Clin Nutr, 2002. 76(1): p. 226-31.

12. Westerterp, K.R., L. Wouters, and W.D. van Marken Lichtenbelt, The Maastricht protocol for the measurement of body composition and energy expenditure with labeled water. Obes Res, 1995. 3 Suppl 1: p. 49-57.

13. Westerterp-Plantenga, M.S., Eating behavior in humans, characterized by cumulative food intake curves--a review. Neurosci Biobehav Rev, 2000. 24(2): p. 239-48.

14. Kovacs, E.M., M.P. Lejeune, and M.S. Westerterp-Plantenga, The effects of enterostatin intake on food intake and energy expenditure. Br J Nutr, 2003. 90(1): p. 207-14.

15. Albrecht, R.R. and S.J. Ewing, Standardizing the administration of the Profile of Mood States (POMS): development of alternative word lists. J Pers Assess, 1989. 53(1): p. 31-9.

16. Tenenbaum, G., D. Furst, and G. Weingarten, A statistical reevaluation of the STAI anxiety questionnaire. J Clin Psychol, 1985. 41(2): p. 239-44.

17. Peters, M.L., G.L. Godaert, R.E. Ballieux, M. van Vliet, J.J. Willemsen, F.C. Sweep, et al., Cardiovascular and endocrine responses to experimental stress: effects of mental effort and controllability. Psychoneuroendocrinology, 1998. 23(1): p. 1-17.

18. Lejeune, M.P., K.R. Westerterp, T.C. Adam, N.D. Luscombe-Marsh, and M.S. Westerterp-Plantenga, Ghrelin and glucagon-like peptide 1 concentrations, 24-h satiety, and energy and substrate metabolism during a high-protein diet and measured in a respiration chamber. Am J Clin Nutr, 2006. 83(1): p. 89-94.

19. Noto, Y., T. Sato, M. Kudo, K. Kurata, and K. Hirota, The relationship between salivary biomarkers and state-trait anxiety inventory score under mental arithmetic stress: a pilot study. Anesth Analg, 2005. 101(6): p. 1873-6.

20. Sarid, O., O. Anson, and Y. Bentov, Students' reactions to three typical examinations in health sciences. Adv Health Sci Educ Theory Pract, 2005. 10(4): p. 291-302.

21. Grossman, P., F.H. Wilhelm, I. Kawachi, and D. Sparrow, Gender differences in psychophysiological responses to speech stress among older social phobics:: congruence and incongruence between self-evaluative and cardiovascular reactions. Psychosom Med, 2001. 63(5): p. 765-77.

22. Bryant, R.A., Longitudinal psychophysiological studies of heart rate: mediating effects and implications for treatment. Ann N Y Acad Sci, 2006. 1071: p. 19-26.

23. Kamphuis, M.M., M.S. Westerterp-Plantenga, and W.H. Saris, Fat-specific satiety in humans for fat high in linoleic acid vs fat high in oleic acid. Eur J Clin Nutr, 2001. 55(6): p. 499-508.

24. Nieuwenhuizen, A.G. and F. Rutters, The hypothalamic-pituitary-adrenal-axis in the regulation of energy balance. Physiol Behav, 2007. 



\section{Chapter 10}

Hyperactivity of the HPA axis is related to dietary restraint in normal weight women

F. Rutters, A.G. Nieuwenhuizen, S.G.T Lemmens, J.M Born, and M.S. WesterterpPlantenga

Physiology and Behavior 2009 February 16; 96 (2): 315-9 


\begin{abstract}
Objective: to investigate the relationship between hypothalamus/pituitary/adrenal (HPA) axis functioning and dietary restraint in normal weight (BMI between 20 and $25 \mathrm{~kg} / \mathrm{m}^{2}$ ) men and women.
\end{abstract}

Methods: we assessed in 38 men and 38 women HPA axis functioning, through measuring 5-hour cortisol exposure and cortisol feedback functioning through a dexamethasone ( $4 \mathrm{mg}$ ) suppression test. Eating behavior was assessed through the Three Factor Eating Questionnaire and body composition through hydro densitometry and deuterium dilution method.

Results: no relationship between HPA axis functioning and dietary restraint was found in men. Normal weight women with a restraint score $\geq 9$ showed increased cortisol concentrations over a 5-hour time period, increased cortisol concentrations after a dexamethasone ( $4 \mathrm{mg}$ ) suppression test, higher BMI, and higher body fat percentage, when compared to women with a restraint score $<9$. Moreover, a positive relationship was found between cortisol concentrations over a 5-hour time period and dietary restraint in combination with the disinhibition score $\left(R^{2}=0.23, p<0.001\right)$.

Conclusion: in normal weight women hyperactivity of the HPA-axis is related to dietary restraint especially in combination with disinhibition. 


\section{Introduction}

In order to either prevent weight gain or induce weight loss, people attempt to restrict food intake through controlled eating behavior [1]. Eating behavior characteristics can be determined using the Three Factor Eating Questionnaire (TFEQ) [2]. The TFEQ assesses 3 factors involved in eating behavior: dietary restraint, disinhibition and feeling of hunger. Dietary restraint reflects the extent to which individuals attempt to cognitively control their food intake. Disinhibition or inhibition of restraint reflects individual differences in the extent to which release from the cognitive suppression of eating occurs in response to the presence of palatable food or other disinhibiting stimuli, such as emotional distress. The third factor refers to the general feeling of hunger [2].

Studies have shown behavioral, metabolic and endocrinological differences between normal weight women with a low score and a high score on dietary restraint. Normal weight dietary restrained women showed behavioral and metabolic differences such as lower self-reported energy consumption, lower energy expenditure, higher body mass index (BMI) and higher body fat percentage when compared to the dietary unrestrained women $[3,4]$. Furthermore, a number of studies showed that normal weight dietary restrained women showed endocrinological differences such as lower post-meal insulin levels [5-7] and increased cortisol levels compared to dietary unrestrained women [8-11]. The increased cortisol levels in dietary restrained women may be secondary to the occurrence of psychological stress, since dietary restraint is experienced as a demanding task [8-11]. However, not all studies investigating the association between cortisol levels and dietary restraint have yielded conclusive results, since some studies found a positive association in the dietary restrained women [8-11], whereas others did not [4$6]$. This inconclusiveness possibly resulted from study limitations such as cortisol measurements at only one (sometimes unspecified) time point during the day or several time points during the night. Moreover, all cortisol measurements were done only under basal conditions. However basal cortisol levels also depend on cortisol conversion, and therefore cortisol measurements under basal condition do not reflect hypothalamic/pituitary/adrenal (HPA) axis functioning. The ability of cortisol to suppress its own secretion, mediated by the glucocorticoid receptor in both the hypothalamus and pituitary (negative feedback) is an important determinant of the HPA axis functioning [12]. However, to our knowledge no studies reported adequately on the possible association between HPA axis functioning, measuring both cortisol exposure and cortisol feedback functioning, and dietary restraint. Consequently, the objective of our study was to investigate the relationship between hypothalamus/pituitary/adrenal (HPA) axis functioning and dietary restraint in normal weight (BMI between 20 and 25 $\mathrm{kg} / \mathrm{m}^{2}$ ) men and women.

\section{Participants and methods Participants and protocol}

The study was approved by theMedical Ethical Committee of the Maastricht University, and a written consent was obtained from all participants. Healthy, medication-free, non-smoking men $(\mathrm{n}=$ $40)$ and women $(n=40)$ aged between 18 to $45 \mathrm{y}$ and with a BMI between 20 and $25 \mathrm{~kg} / \mathrm{m}^{2}$ were recruited to complete all phases of this study. A medical history was obtained from each participant before entry into the study and exclusion criteria were chronic illness, depression, and a history of eating disorders or current dieting. From 80 participants recruited, 38 men and 38 women completed the study, 4 participants dropped out before the actual start of the study.

From each participant we obtained: 5hour cortisol exposure, a progressive maximal cycling test to volitional exhaustion, a dexamethasone $(4 \mathrm{mg})$ 
suppression test, Three Factor Eating

Questionnaire (TFEQ) scores,

anthropometry and body composition.

\section{Measurements}

5-hour cortisol exposure

At 8 a.m. after an overnight fast an intravenous catheter for blood sampling was inserted into the forearm vein. Directly after insertion of the catheter the first blood sample $(9 \mathrm{ml})$ was drawn (0 minutes), and after 15 minutes the participants received their breakfast (20 $\%$ of the participants' daily energy requirement). At 45,90 and 210 minutes the second, third and fourth blood samples were drawn. At 225 minutes the participants received their lunch (30\% of the participants' daily energy requirement) and at 255 and 300 minutes the fifth and sixth blood samples were drawn. During the test, participants were able to drink water ad libitum. Breakfast and lunch consisted of typical Dutch products, namely brown bread (1.0 MJ per $100 \mathrm{~g}$; en\% C/P/F: 74/15/11) with young cheese (1.6 MJ per $100 \mathrm{~g}$; en\% C/P/F: $0 / 26 / 74$ ) as well as ab libitum tea or water consumption. The daily energy requirements were calculated by multiplying the basal metabolic rate (BMR) by an activity index of 1.75 . The BMR (MJ/day) was calculated according to the equations of Harris-Benedict [13]. Participants remained seated during sampling and daytime naps were not allowed. The participants' 5-hour cortisol exposure was measured by calculating the area under the curve (AUC) $(0-300$ minutes).

\section{Progressive maximal cycling test to volitional exhaustion \\ Each subject underwent a progressive maximal cycling test to volitional exhaustion for quantification of $\mathrm{VO}^{2} \max$ [14]. Subjects cycled on an electromagnetically braked bicycle ergometer (Lode, Groningen, The Netherlands) at $80 \mathrm{rpm}$, at a workload of $75 \mathrm{~W}$ for women and $100 \mathrm{~W}$ for men. After 5 minutes, the workload was increased every 2.5 minutes with $50 \mathrm{~W}$, until subjects were no longer able to}

maintain a pedaling frequency above 80 $\mathrm{rpm}$. Open-circuit spirometry was performed with an Oxycon (Mijnhardt Jaeger, Mannheim, Germany), and oxygen consumption $\left(\mathrm{VO}^{2}\right)$ and carbon dioxide production $\left(\mathrm{CO}^{2}\right)$ were measured in the breath-by-breath mode and averaged over 15 seconds. Heart rate was monitored continuously throughout all exercise protocols (Polar s610). Verification that each subject actually achieved $\mathrm{VO}^{2}$ max consisted of meeting the following criteria: 1 ) achieving predicted maximal heart rate and 2) a respiratory exchange ratio of 1.10 or more.

Dexamethasone (4 mg) suppression test Each participant received $4 \mathrm{mg}$ dexamethasone 8 hours before the suppression test, all participants participated in the treatment, and no adverse reactions were reported. Participants abstained from alcohol consumption and strenuous exercise $15 \mathrm{~h}$ before testing. At 8 a.m. after an overnight fast, an intravenous catheter for blood sampling was inserted into the forearm vein and a blood sample was drawn [12].

\section{Blood samples}

Blood samples were collected and mixed in serum tubes (BD Vacutainer, $9.5 \mathrm{ml}$ ). Serum was obtained by centrifugation $\left(4^{\circ} \mathrm{C}, 3000 \mathrm{rpm}, 10\right.$ minutes), frozen in liquid nitrogen and stored at $-80^{\circ} \mathrm{C}$ until analysis of cortisol concentrations. Serum cortisol concentrations were measured using RIA (Buhlmann Laboratories) and detection limits for cortisol concentrations were $2.9 \mathrm{ng} / \mathrm{ml}$. Intra-assay coefficient variation for cortisol concentrations was less than $6 \%$ for all samples.

\section{Attitude towards eating}

Eating behavior was analyzed using a validated Dutch translation of the TFEQ $[2,15]$. The TFEQ consists of 3 factors measuring a person's attitude towards eating. Dietary restraint (Factor 1 ) reflects the extent to which individuals attempt to cognitively control their food intake. Inhibition of restraint (Factor 2 or 
disinhibition) reflects individual differences in the extent to which release from the cognitive suppression of eating occurs in response to the presence of palatable food or other disinhibiting stimuli, such as emotional distress. Factor 3 refers to the subjective feeling of hunger. Based upon the median for the TFEQ scores in the South of the Netherlands, participants were characterized as unrestrained when dietary restraint scores were $<9$, and as restrained when scores $\geq 9$. Participants were characterized as having low disinhibition when disinhibition scores were $<5$, and as having high disinhibition when scores were $\geq 5$ [1].

\section{Anthropometry and body composition} Measurements were carried out in the morning after voiding the bladder and before breakfast. Body weight (BW) (Sauter D7470, Ebingen, Germany) and height (Seca, model 220, Hamburg, Germany) were measured to the nearest $0.01 \mathrm{~kg}$ and $0.1 \mathrm{~cm}$ respectively. BMI $\left(\mathrm{kg} / \mathrm{m}^{2}\right)$ was calculated as body weight divided by height $(\mathrm{m})$ squared. The waist circumference was measured to the nearest $0.1 \mathrm{~cm}$ at the site of the smallest circumference between the rib cage and the ileac crest, whereas the hip circumference was measured to the nearest $0.1 \mathrm{~cm}$ at the level of maximum extension of the buttocks. Both measurements were done with the participants in standing position. Body density was determined by hydro densitometry with simultaneous measurements of residual lung volume with the helium dilution technique. Total body water (TBW) was determined with the deuterium dilution method following the Maastricht protocol [16]. Body composition was calculated from body density and TBW using the threecompartment model of Siri. Fat free mass (FFM) was calculated by dividing TBW by the hydration factor 0.73 . Fat mass (FM) was determined as BW-FFM.

\section{Statistical analysis}

Differences between two groups were determined using unpaired t-tests.
Differences over time and between conditions were determined using twofactor ANOVA with repeated measures. Relationships between dependent and independent variables were determined using simple linear, or multiple regression models. All statistical tests were twotailed, differences were considered significant at $p<0.05$ and values are expressed as mean \pm standard deviation.

\section{Results}

Table 1 shows the characteristics of all participants $(n=76)$. No significant differences were shown between men and women in age, BMI, hip circumference and feeling of hunger score. The male participants showed significantly higher height, body weight, waist circumference, waist-to-hip ratio, and maximal workload during the progressive maximal cycling test when compared to the female participants. The female participants showed significantly higher body fat percentage, area under the curve (AUC) of 5-hour cortisol exposure, cortisol concentrations after a dexamethasone (4 $\mathrm{mg}$ ) suppression test, dietary restraint score, and disinhibition score when compared to male participants. Therefore, the results of the male and female participants were analyzed separately.

Based upon the median for the TFEQ scores in the South of the Netherlands the female participants were characterized as unrestrained when dietary restraint scores were $<9$, and as restrained when score $\geq 9$ [1]. Table 2 shows the characteristics of the dietary unrestrained $(n=26)$ and the dietary restrained $(n=12)$ women. The dietary restrained women showed significantly higher BMI and body fat percentage when compared to the dietary unrestrained women. No significant differences were shown between dietary unrestrained and dietary restrained women in age, height, body weight, waist circumference, hip circumference, waistto-hip ratio, maximal workload during the progressive maximal cycling test, disinhibition score and feeling of hunger score. 
Table 1. Characteristics of participants $(n=76)$

\begin{tabular}{llll}
\hline & $\begin{array}{l}\text { Men } \\
(\mathrm{n}=38)\end{array}$ & $\begin{array}{l}\text { Women } \\
(\mathrm{n}=38)\end{array}$ & P value ${ }^{1}$ \\
\hline Age (year) & $31.2 \pm 5.2$ & $25.9 \pm 7.5$ & 0.17 \\
Height $(\mathrm{cm})$ & $183.5 \pm 7.3$ & $170.4 \pm 6.6$ & 0.01 \\
Body weight $(\mathrm{kg})$ & $75.2 \pm 7.9$ & $65.6 \pm 7.5$ & 0.01 \\
Body mass index $\left(\mathrm{kg} / \mathrm{m}^{2}\right)$ & $22.3 \pm 1.5$ & $22.6 \pm 1.9$ & 0.99 \\
Body fat (\%) & $11.6 \pm 5.2$ & $25.2 \pm 5.5$ & 0.01 \\
Waist circumference $(\mathrm{cm})$ & $80.6 \pm 5.5$ & $74.4 \pm 5.8$ & 0.01 \\
Hip circumference $(\mathrm{cm})$ & $100.8 \pm 5.8$ & $99.6 \pm 5.7$ & 0.12 \\
Waist-to-hip ratio & $0.80 \pm 0.04$ & $0.74 \pm 0.06$ & 0.01 \\
Maximal workload $(\mathrm{V})$ & $323 \pm 55$ & $216 \pm 44$ & 0.01 \\
AUC ${ }^{2}$ of 5-hour cortisol & $1.1\left(10^{5}\right) \pm 0.21 .6\left(10^{5}\right) \pm 0.70 .01$ \\
exposure (nmol/L.min) & & & \\
Cortisol after & $33.9 \pm 12.6$ & $53.7 \pm 28.7$ & 0.01 \\
dexamethasone (4 mg) & & & \\
(nmol/L) & & & \\
Dietary restraint score & $4.7 \pm 3.5$ & $6.5 \pm 3.3$ & 0.08 \\
Disinhibition score & $2.9 \pm 1.2$ & $4.2 \pm 1.9$ & 0.02 \\
Feeling of hunger score & $3.8 \pm 2.5$ & $3.9 \pm 2.4$ & 0.84 \\
\hline
\end{tabular}

${ }_{1}^{1}$ Differences between men vs. women (t-test)

${ }^{2} \mathrm{AUC}$, area under curve

Table 2. Characteristics of dietary unrestrained (score < 9) and dietary restrained (score $\geq 9)$ women $(n=38)$

\begin{tabular}{llll}
\hline & $\begin{array}{l}\text { Dietary } \\
\text { unrestraint } \\
(\mathrm{n}=26)\end{array}$ & $\begin{array}{l}\text { Dietary } \\
\text { Restraint } \\
(\mathrm{n}=12)\end{array}$ & P value $^{1}$ \\
\hline Age (year) & $26.1 \pm 6.2$ & $25.9 \pm 7.5$ & 0.87 \\
Height $(\mathrm{cm})$ & $171.2 \pm 6.2$ & $168.6 \pm 7.2$ & 0.26 \\
Body weight $(\mathrm{kg})$ & $64.8 \pm 7.8$ & $67.2 \pm 6.6$ & 0.35 \\
Body mass index $\left(\mathrm{kg} / \mathrm{m}^{2}\right)$ & $22.1 \pm 1.8$ & $23.7 \pm 1.6$ & 0.01 \\
Body fat $(\%)$ & $24.2 \pm 4.5$ & $28.6 \pm 5.6$ & 0.02 \\
Waist circumference $(\mathrm{cm})$ & $74.9 \pm 6.8$ & $73.4 \pm 3.7$ & 0.57 \\
Hip circumference $(\mathrm{cm})$ & $98.6 \pm 5.9$ & $101.7 \pm 5.2$ & 0.22 \\
Waist-to-hip ratio & $0.75 \pm 0.06$ & $0.72 \pm 0.04$ & 0.22 \\
Maximal workload $(\mathrm{V})$ & $214 \pm 46$ & $218 \pm 41$ & 0.78 \\
Dietary restraint score & $4.7 \pm 2.1$ & $10.5 \pm 1.5$ & 0.01 \\
Disinhibition score & $4.3 \pm 2.1$ & $3.9 \pm 1.8$ & 0.58 \\
Feeling of hunger score & $4.0 \pm 2.5$ & $3.8 \pm 2.2$ & 0.84 \\
\hline
\end{tabular}

${ }^{1}$ Differences between dietary unrestrained vs. dietary restrained women (t-test)

Figure 1 shows the changes in cortisol concentrations (nmol/L.min) over a 5hour time period in the dietary unrestrained and dietary restrained women. The cortisol concentrations were significantly higher at all time points except at 300 minutes in the dietary restrained women when compared to the dietary unrestrained women. Over time there was a significant decrease of cortisol in both groups of women, however, the decrease was significantly stronger in the dietary restrained women. The AUC over a 5 -hour time period of the cortisol concentrations was significantly higher in the dietary restrained women when compared to the dietary unrestrained women $(136429.8 \pm 57665.9$ vs. $193622.5 \pm 89322.2 \mathrm{nmol} /$ L. $\min , \mathrm{p}<$
0.02). Additionally, the cortisol concentrations after a dexamethasone (4 $\mathrm{mg}$ ) suppression test were significantly higher in the dietary restrained women when compared to the dietary unrestrained women $(70.7 \pm 36.6$ vs. $45.8 \pm 20.6 \mathrm{nmol} / \mathrm{L}, \mathrm{p}<0.01)$.

Figure 1. Changes in cortisol concentrations ( $\mathrm{nmol} / \mathrm{L}$ ) over a 5 -hour time period in the dietary unrestrained (grey, $\mathrm{n}=26$ ) and dietary restrained (black, $\mathrm{n}=12$ ) women. Values are means and error bars indicate SD.

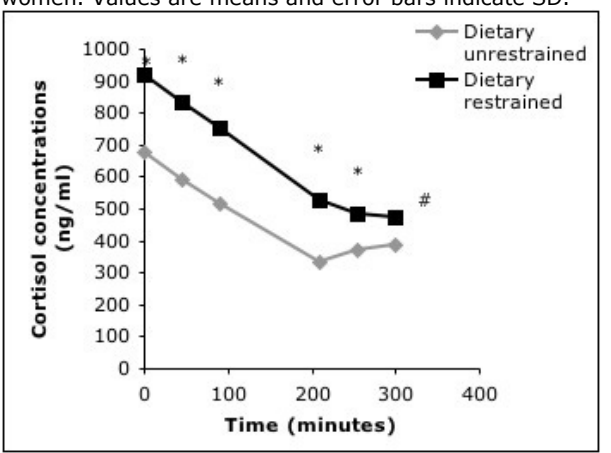

$* \mathrm{P}<0.05$ for differences in dietary unrestrained women compared to dietary restrained women (2- factor ANOVA repeated measures)

\# $\mathrm{P}<0.05$ overall group $\mathrm{x}$ time interaction was significant

Table 3 shows a positive relationship between the cortisol concentrations after a dexamethasone (4 $\mathrm{mg}$ ) suppression test and the AUC over a 5-hour time period of the cortisol concentrations, the dietary restraint score, and the disinhibition scores as the independent variables $\left(R^{2}=\right.$ $0.62, p<0.01$ ) in normal weight women.

Table 4 shows a positive relationship between the AUC over a 5-hour time period of the cortisol concentrations as the dependent variable and the dietary restraint scores and the disinhibition scores as the independent variables $\left(R^{2}=\right.$ $0.23, p<0.01$ ) in normal weight women.

Furthermore, in normal weight men no relationship was seen between HPA axis functioning and eating behavior. Here different relationships appeared that were not primarily related to HPA axis functioning. Dietary restraint scores were $<9$ in the men, except 3 outliers, who were athletes. In these normal weight men a linear regression model showed a 
positive relationship between the dietary restraint score as the dependent variable and the maximal workload during the progressive maximal cycling test as the independent variable $\left(R^{2}=0.12, p<\right.$ $0.03)$. Additionally, a linear regression model showed a negative relationship between the AUC over a 5-hour time period of the cortisol concentrations as the dependent variable and the dietary restraint score as the independent variable $\left(R^{2}=0.13, p<0.03\right)$.

Table 3: Multiple regression model with the cortisol concentrations after a dexamethasone (4 mg) suppression test $(\mathrm{nmol} / \mathrm{L})$ as the dependent variable and the area under the curve of cortisol concentrations over a 5-hour time period ( $\mathrm{nmol} / \mathrm{L})$, dietary restraint score and disinhibition score as the independent variables in normal weight women $(\mathrm{n}=38)$ $\mathrm{R}^{2}=0.53, \mathrm{p}<0.01$

\begin{tabular}{llll}
\hline & Partial $\beta$ & Std. Error & P value \\
\hline Intercept & 9.8 & 11.05 & 0.38 \\
$\begin{array}{l}\text { AUC }{ }^{1} \text { of cortisol concentrations } \\
\text { over a 5-hour time period }\end{array}$ & 0.002 & 0.69 & 0.001 \\
$\begin{array}{l}\text { Dietary restraint score } \\
\text { Disinhibition score }\end{array}$ & 1.1 & 0.1 & 0.32 \\
\hline
\end{tabular}

${ }^{1}$ AUC; area under the curve

Table 4: Multiple regression model with the area under the curve of cortisol concentrations over a 5-hour time period ( $\mathrm{nmol} / \mathrm{L}$ ) as the dependent variable and dietary restraint score and disinhibition score as the

independent variables in normal weight women $(n=38)$ $\mathrm{R}^{2}=0.23, \mathrm{p}<0.01$

\begin{tabular}{llll}
\hline & Partial $\beta$ & Std. Error & $P$ value \\
\hline Intercept & 49329.5 & 34584.1 & 0.16 \\
Dietary restraint score & 8031.7 & 3273.2 & 0.01 \\
Disinhibition score & 12605.3 & 5500.5 & 0.01 \\
\hline
\end{tabular}

${ }^{1}$ AUC; area under the curve

\section{Discussion}

The objective of our study was to investigate the relationship between HPA axis functioning and dietary restraint in normal weight (BMI between 20 and 25 $\mathrm{kg} / \mathrm{m}^{2}$ ) men and women. No such relationship was found in men. Dietary restrained women showed increased cortisol concentrations over a 5-hour time period, increased cortisol concentrations after a dexamethasone (4 mg) suppression test, higher BMI, and higher body fat percentage. Moreover, a positive relationship was found between cortisol concentrations over a 5 -hour time period and dietary restraint alone or in combination with the disinhibition score.
Our study contributes to insight in the relationship between HPA axis functioning and dietary restraint in normal weight women [8-11]. Our study is the first to analyze HPA axis functioning elaborately, since most studies only measured cortisol exposure at only one (sometimes unspecified) time point during the day or the night, and measured no HPA axis feedback functioning. In accordance to the literature $[3,4]$ we found that dietary restrained women have a higher BMI and body fat percentage compared to dietary unrestrained women. To determine cortisol exposure, we measured cortisol concentrations ( $\mathrm{nmol} / \mathrm{L}$. $\mathrm{min}$ ) over a 5hour time period. We showed that the dietary restrained normal weight women had a significant higher AUC over a 5-hour time period of the cortisol concentrations and a stronger decrease in cortisol concentrations compared to the dietary unrestrained women. This suggests that normal weight women, who attempt more to restrict food intake through dietary restraint, have increased cortisol exposure and stronger decline in cortisol levels over time.

Additionally, we measured feedback functioning through a dexamethasone (4 $\mathrm{mg}$ ) suppression test [12], which measures the amount of cortisol that escaped from dexamethasone suppression. When cortisol feedback is strong low amount of cortisol will be present, and when high amounts of cortisol escaped, cortisol feedback is decreased [12]. We showed that the dietary restrained normal weight women had higher cortisol concentrations after dexamethasone suppression test, when compared to the dietary unrestrained women. These results imply that normal weight women, who attempt more to restrict food intake through dietary restraint, have decreased cortisol feedback functioning.

Multiple regression analysis showed a positive relationship between cortisol feedback functioning and cortisol exposure as well as dietary restraint score.

Additionally, we showed a positive 
relationship between cortisol exposure and dietary restraint in combination with disinhibition score. This suggests that especially normal weight women, who attempt to restrict food intake through dietary restraint but who have high inhibition of restraint show increased cortisol exposure, and decreased cortisol feedback. However, the direction of causality cannot be inferred from this research.

The lack of a direct relationship between HPA axis functioning and dietary restraint in normal weight men is consistent with the literature [8-11]. Here different relationships appeared that were not primarily related to HPA axis functioning. A possible explanation may be the gender difference in stress sensation [12]. In men a positive relationship was shown between the dietary restraint score and the maximal workload during the progressive maximal cycling test, which suggests that only men who are sincerely engaged in sports are dietary restraint. Additionally, a negative relationship was shown between the maximal workload during the progressive maximal cycling test and AUC over a 5-hour time period of the cortisol concentrations, which suggests that men who are sincerely engaged in sports have decreased cortisol exposure, as previously shown [12]. In general, only men who are overweight or who are sincerely engaged in sports are dietary restraint. Overweight men were not included in our study and when the normal weight men who are sincerely engaged in sports were omitted from the analysis, no relationship between HPA axis functioning and dietary restraint was found. These results suggest that dietary restraint is not perceived as a stressor in normal weight men.

Increased cortisol exposure, heightened cortisol responsiveness and decreased cortisol feedback functioning are characteristics of hypercortisolism [12]. Hypercortisolism is a state in which the HPA axis responsiveness is preserved, which is also seen in psychological or physiological chronic stressed humans [17-19]. It may therefore be hypothesized that the association between increased cortisol levels and dietary restraint may be mediated through psychological stress [8-11]. Sustained hypercortisolism however may predispose individuals to many illnesses, ranging from inflammatory diseases to major depression, thereby indicating that dietary restraint in combination with disinhibition is a possible health risk [20]. In conclusion, hyperactivity of the HPA-axis is related to dietary restraint especially in combination with disinhibition, in normal weight women.

\section{Acknowledgements}

We want to thank our participants for their participation in this study. We gratefully thank Loek Wouters and Jose Sulon for their assistance. FR (supervised by $A N$ and MW) carried out the study, collected and analyzed the data, and wrote the largest part of the manuscript. $\mathrm{SL}$ and JB reviewed the manuscript. Planning, processing the results and writing the manuscript were done under general supervision by AN and MW. The authors had no conflict of interest. 


\section{Literature}

1. Westerterp-Plantenga, M.S., Eating behavior in humans, characterized by cumulative food intake curves--a review. Neurosci Biobehav Rev, 2000. 24(2): p. 239-48.

2. Stunkard, A.J. and S. Messick, The three-factor eating questionnaire to measure dietary restraint, disinhibition and hunger. J Psychosom Res, 1985. 29(1): p. 71-83.

3. Tuschl, R.J., P. Platte, R.G. Laessle, W. Stichler, and K.M. Pirke, Energy expenditure and everyday eating behavior in healthy young women. Am J Clin Nutr, 1990. 52(1): p. 81-6.

4. Beiseigel, J.M. and S.M. Nickols-Richardson, Cognitive eating restraint scores are associated with body fatness but not with other measures of dieting in women. Appetite, 2004. 43(1): p. 47-53.

5. Pirke, K.M., R.J. Tuschl, B. Spyra, R.G. Laessle, U. Schweiger, A. Broocks, et al., Endocrine findings in restrained eaters. Physiol Behav, 1990. 47(5): p. 903-6.

6. Nickols-Richardson, S.M., J.M. Beiseigel, and F.C. Gwazdauskas, Eating restraint is negatively associated with biomarkers of bone turnover but not measurements of bone mineral density in young women. J Am Diet Assoc, 2006. 106(7): p. 1095-101.

7. Barr, S.I., J.C. Prior, and Y.M. Vigna, Restrained eating and ovulatory disturbances: possible implications for bone health. Am J Clin Nutr, 1994. 59(1): p. 92-7.

8. Anderson, D.A., J.R. Shapiro, J.D. Lundgren, L.E. Spataro, and C.A. Frye, Self-reported dietary restraint is associated with elevated levels of salivary cortisol. Appetite, 2002. 38(1): p. 13-7.

9. McLean, J.A., S.I. Barr, and J.C. Prior, Cognitive dietary restraint is associated with higher urinary cortisol excretion in healthy premenopausal women. Am J Clin Nutr, 2001. 73(1): p. 7-12.

10. Newman, E., D.B. O'Connor, and M. Conner, Daily hassles and eating behaviour: the role of cortisol reactivity status. Psychoneuroendocrinology, 2007. 32(2): p. 125-32.

11. Putterman, E. and W. Linden, Cognitive dietary restraint and cortisol: importance of pervasive concerns with appearance. Appetite, 2006. 47(1): p. 64-76.

12. Duclos, M., B. Gatta, J.B. Corcuff, M. Rashedi, F. Pehourcq, and P. Roger, Fat distribution in obese women is associated with subtle alterations of the hypothalamic-pituitary-adrenal axis activity and sensitivity to glucocorticoids. Clin Endocrinol (Oxf), 2001. 55(4): p. 447-54.

13. Lejeune, M.P., K.R. Westerterp, T.C. Adam, N.D. Luscombe-Marsh, and M.S. Westerterp-Plantenga, Ghrelin and glucagon-like peptide 1 concentrations, 24-h satiety, and energy and substrate metabolism during a high-protein diet and measured in a respiration chamber. Am J Clin Nutr, 2006. 83(1): p. 89-94.

14. Borghouts, C., C.Q. Scheckhuber, A. Werner, and H.D. Osiewacz, Respiration, copper availability and SOD activity in P. anserina strains with different lifespan. Biogerontology, 2002. 3(3): p. 143-53.

15. Westerterp-Plantenga, M.S., V. Rolland, S.A. Wilson, and K.R. Westerterp, Satiety related to $24 \mathrm{~h}$ diet-induced thermogenesis during high protein/carbohydrate vs high fat diets measured in a respiration chamber. Eur J Clin Nutr, 1999. 53(6): p. 495-502.

16. Westerterp, K.R., L. Wouters, and W.D. van Marken Lichtenbelt, The Maastricht protocol for the measurement of body composition and energy expenditure with labeled water. Obes Res, 1995. 3 Suppl 1: p. 49-57.

17. Jacobson, L., Hypothalamic-pituitary-adrenocortical axis regulation. Endocrinol Metab Clin North Am, 2005. 34(2): p. 271-92, vii.

18. Handziski, Z., V. Maleska, S. Petrovska, S. Nikolik, E. Mickoska, M. Dalip, et al., The changes of ACTH, cortisol, testosterone and testosterone/cortisol ratio in professional soccer players during a competition half-season. Bratisl Lek Listy, 2006. 107(6-7): p. 259-63.

19. Tafet, G.E. and R. Bernardini, Psychoneuroendocrinological links between chronic stress and depression. Prog Neuropsychopharmacol Biol Psychiatry, 2003. 27(6): p. 893-903.

20. Sapolsky, R.M., Glucocorticoids, stress, and their adverse neurological effects: relevance to aging. Exp Gerontol, 1999. 34(6): p. 721-32. 

Chapter 11

Discussion 
Body weight appears to be regulated with remarkable precision in healthy adults, and a stable body weight reflects a balance between energy intake and energy expenditure [1]. Chronic deregulation of energy balance with energy intake exceeding energy expenditure, leads to storage of excessive energy as fat, a characteristic of overweight and obesity [2]. The first aim of the studies presented in this thesis was to identify genetic, parental, behavioral, and endocrine factors involved in bodyweight development in children, and the interaction between these factors. The second aim was to assess genetic, behavioral, and endocrine factors and their interaction in body-weight regulation in adults.

\section{Body-weight development during childhood and puberty}

\section{Genetic factors}

With respect to genetic factors involved in body-weight development, we observed that in our Dutch children cohort the $A$ allele of the fat mass and obesityassociated gene (FTO) (rs9939609) was associated with higher BMI, fat mass index (FMI), leptin concentrations, and lower activity scores from childhood to puberty [3]. In the last decades a large number of polymorphisms have been related to variation in body weight [4]. For our studies, we selected polymorphisms with a high allelic frequency distribution and a proposed biological function that could influence body-weight development. The FTO polymorphism is related to altered DNA methylation $[5,6]$, which results in altered biological function. Studies in humans and rodents have suggested a central role for FTO through an effect on regulation of food intake, such as decreased feelings of satiety [7, $8]$, and a peripheral role through an effect on lipolytic activity in adipose tissue [6]. Additionally, we observed in our cohort that at age $13 y$ a larger BMI is associated to the FTO A allele, larger leptin concentrations, and decreased physical activity. These results implicate that at age $13 y$ genetic, endocrine and psychological factors are independent predictors for BMI [3]. At age 12,14, and $15 y$ BMI was associated to larger leptin concentrations, which implicates that during puberty BMI is temporarily predicted by FTO and predominately predicted by endocrine factors [3]. Furthermore, in our cohort polymorphisms of the ciliary neurotrophic factor (CNTF) gene and the peroxisome proliferatedactivated receptor $\mathrm{Y} 2$ (PPARY2) gene did not show similar associations during puberty [9], although this was expected based upon studies in adults [10]. These results suggest that especially polymorphisms with a strong influence on body weight, such as FTO [6], affect body weight during puberty, and that the influence of polymorphisms, such as CNTF and PPARY2, are stronger during early childhood and late adolescence, as observed by previous studies [11, 12]. Our results implicate that the changes in the associations between body-weight development and polymorphisms over time may be explained by the fact that body weight is predominately regulated by physiological and endocrine factors during puberty.

\section{Parental factors}

With respect to parental factors involved in body-weight development, we observed that in our cohort a high BMI of the father and a high disinhibition score of the mother were related to an increased BMI in the child [9]. These observations are in concordance with previous findings, which observed that the childs' BMI is positively related to the parents' BMI $[13,14]$. In contrast to previous findings we did not show a relationship between mothers cognitively restrained eating behavior and the body-weight development of the children [14]. A possible explanation may be that the mothers were successfully restraint, so their high restraint scores helped them to control their weight successfully [15], and only when a high disinhibition score was present this resulted in a relationship with the weight of the child [9]. The parent association is due to genetic and environmental factors, 
such as shared lifestyles (i.e. diets, feeding practices and food choices) and patterns of activity. For future research, it will be of interest to observe whether the role of these genetic and parental factors in body-weight development will become stronger in our cohort as well as in other cohorts during late adolescence.

\section{Behavioral factors}

With respect to the behavioral factors involved in body-weight development, we were the first to show that development of BMI during puberty is inversely related to change in sleep duration [16]. We focused on short sleep duration, as a number of cross-sectional and longitudinal studies have shown a negative relationship between habitual sleep duration and body weight in children $[17,18]$. None of the four longitudinal studies in children however investigated whether changes in sleep duration were associated with changes in body weight [19-22]. Although cause and effect cannot be completely disentangled from the observed inverse relationship between changes in body weight and sleep duration, we carefully suggest that reduction of sleep duration contributes to development of overweight during puberty.

Short sleep has been suggested to result from psychological distress, and the physiological disturbances related to psychological distress, such as hypercortisolemia [23, 24]. Studies investigating the physiological mechanisms on how sleep duration affects body-weight development in humans are however limited. Laboratory based studies have observed that short sleep (4 hours) lead to lower levels of the anorexigenic hormone leptin and higher levels of the orexigenic hormone ghrelin [25, 26]. Short sleep has also been related to reduced insulin sensitivity and increased glucose levels [27]. Other physiological alterations that result from disturbed energy balance are suggested to be involved in body-weight development, but have not been investigated yet. For future research, it will therefore be of interest to identify the physiological mechanisms behind the relationship between short sleep and altered body weight.

\section{Endocrine factors}

With respect to endocrine factors involved in body-weight development, leptin is suggested to be a permissive factor for the start of puberty [28-30], which would be mediated through the stimulatory effect of leptin on the release of gonadotrophic hormones, and consequently gonadal hormones. We observed that in boys the leptin/fat mass ratio decreased from Tanner stage 2 onwards, while in girls this ratio decreased from Tanner stage 2 and increased again at Tanner stage 5 [31]. These results show that factors independent of fat mass become (transiently) more important in the regulation of plasma leptin concentrations in boys and girls [31]. The proposed mechanism behind the temporal relationships between leptin, gonadotrophic hormones, and gonadal hormones during puberty, beholds that leptin independently of fat mass acts on the hypothalamic luteinizing hormonereleasing hormone pulse generator [3234] Consequently, the release of $\mathrm{LH}$ and FSH from the pituitary is stimulated. $\mathrm{LH}$ and $\mathrm{FSH}$ in turn stimulate the gonads to release testosterone and estradiol, which will form a negative feedback loop, which will inhibit the secretion of $\mathrm{LH}$ and FSH. Moreover, testosterone alone will form a negative feedback loop, which will inhibit leptin secretion from the adipocytes, and estradiol will form a positive feedback loop, which stimulates leptin secretion from the adipocytes [34-36]. As a result, the relationship between leptin concentrations and body fat is altered during puberty.

However, in the literature there is also evidence that does not support the role of leptin as a permissive factor for the start of puberty [37]. A sex specific association may explain contradicting findings, as we found that in girls a peak in leptin was present at the start of puberty followed by a peak in the gonadotropic hormone, and temporal relationships were observed between leptin and gonadotropic 
hormones during early puberty. In boys, however there was no peak in leptin, $\mathrm{LH}$, and $\mathrm{FSH}$, and leptin was only related to $\mathrm{LH}$ and $\mathrm{FSH}$ during late puberty [31]. We therefore suggested that in girls leptin acts as a permissive factor for the onset of puberty, while in boys leptin has a different function and different timing [31]. Why it is more important to have a permissive factor for the start of puberty in girls than in boys may be explained from an evolutionary point of view; girls need enough energy reserves in the form of body fat for the start of puberty for reproduction [38]. The sex differences in puberty timing may result from differences in expression of genes involved in puberty timing [39]. For future research, it will therefore be of interest to identify the mechanisms behind sex differences in puberty timing.

To summarize the previous described results, we included a pie chart (figure 1 ) that describes the factors involved in body-weight development in overweight children, and the interactions between the factors in our Dutch children cohort during puberty at age $15 \mathrm{y}$. The results from our studies implicate that body-weight development during puberty is related to the FTO polymorphism, as 80 percent of overweight children had the A allele [3]. Additionally, the behavioral factor sleep duration influenced body-weight development, as 93 percent of the overweight children had short sleep duration [16]. Finally, the parental factors high BMI of the father and high disinhibition score of the mother influenced body-weight development in overweight children. The effects of the genetic, parental and behavioral factors are largely combined, as $28 \%$ of the overweight children have all 4 factors related to body-weight development, and about $43 \%$ of the overweight children have 3 out of 4 factors. Only $28 \%$ of the overweight children have 1 or 2 factors related to body-weight development. Overall, the model (figure 1 ) suggests that the FTO A allele, short sleep duration, and the parental factors interact, and together are involved in development of overweight during puberty. In contrast, most of the normal-weight children still appeared to have one or more of these factors that are associated with overweight. 

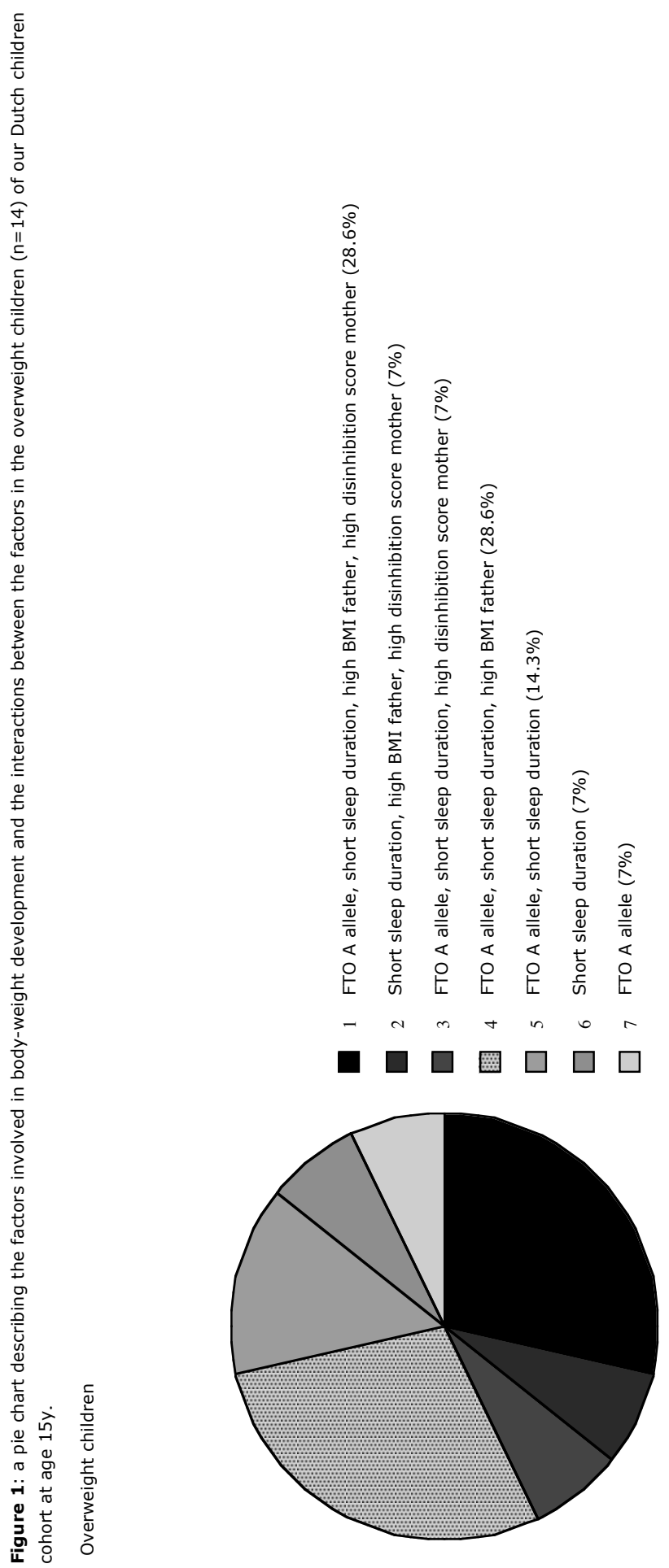


\section{Hypothalamus/pituitary/adrenal (HPA) axis and body-weight regulation}

The HPA axis is involved in body-weight regulation, and alterations in HPA axis functioning are suggested to be involved in the pathogenesis of obesity, in particular obesity characterized by visceral fat distribution [40]. Support for the involvement of the HPA axis in bodyweight regulation is found in two extremes of plasma cortisol levels in humans; Addison's disease (hypocortisolism) that is related to weight loss, and Cushing's syndrome (hypercortisolism) that is related to rapid weight gain, particularly of the trunk and face with sparing of the limbs [41]. It however is not completely clear to what extent the HPA axis is physiologically involved in the regulation of body weight [42]. Evidence for a role of the HPA axis in body-weight regulation is provided via the genetic, behavioral, and endocrine factors described in this thesis.

\section{Genetic factors}

With respect to the genetic factors, several polymorphisms of the glucocorticoid receptor, such as the BclI (rs41423247) polymorphism, have been related to body-weight regulation, body fat distribution and altered HPA axis functioning [43]. We observed that the BclI G/G genotype is associated with increased cortisol exposure as well as decreased cortisol feedback sensitivity under stress in women but not in men [44]. These findings are in concordance with the sex specific associations of the BclI polymorphism observed in other studies, which showed a diminished cortisol response to psychosocial stress in men with the BclI G/G genotype and an increased cortisol response in women [45]. The sex specific associations are presumably caused by the differences in cellular hormonal milieu, which lead to differential expressivity of the underlying genetic networks [46].

The BclI polymorphism is also involved in the efficacy of cortisol signaling and thereby influencing the downstream biology of peripheral and central cortisol responsive systems. Therefore the BcII polymorphism is suggested to be one of the factors that underlie individual susceptibility to stress related disorders, such as depression and the metabolic syndrome. The associations between the BclI G/G genotype and altered body weight and body fat distribution were only found in a few studies in men, while these relationships were always present in women [47-49]. Together with the earlier discussed sex specific associations on altered HPA axis functioning in the BclI G/G genotype [44, 45], this suggests that women with the BclI G/G genotype are more susceptible to disturbed regulation of body weight and HPA axis functioning compared to men with the same genotype. For future research on the role of HPA axis related polymorphism in bodyweight regulation and HPA axis functioning, it is therefore strongly suggested to take possible sex differences into account.

\section{Endocrine factors}

With respect to the endocrine factors, we observed that low cortisol variability, enhanced negative feedback, and impaired HPA axis functioning in a challenged condition under $4 \mathrm{mg}$ dexamethasone were related to visceral fat accumulation in both men and women [50]. These findings add to evidence from previous studies that observed associations between visceral fat distribution and alterations in HPA axis functioning, such as decreased cortisol variability [51-53], and increased cortisol secretion after physical and psychological stressors [51, 52, 54]. Studies on whether body fat distribution is related to feedback functioning, thereby using dexamethasone (a glucocorticoid receptor agonist), have however yielded inconclusive results [52, $53,55]$. Our results are consistent with previous work that suggests a deregulation of the HPA axis in humans with relative more visceral fat [50].

The disturbed state of low cortisol variability related to visceral fat distribution possibly results from a combination of alterations of the HPA axis. 
Firstly, as often stated by the literature, the alterations result from decreased negative feedback mediated through a decrease in glucocorticoid receptors of the pituitary $[52,56]$ and through a decrease in the mineralocorticoid receptor response $[57,58]$, which leads to higher cortisol levels after a stressor [51, 52, 54] and after dexamethasone suppression in unchallenged conditions [50,55].

Secondly, we suggest that lower cortisol levels in a challenged condition under 4 $\mathrm{mg}$ dexamethasone [50] result from decreased sensitivity of the adrenal gland to ACTH as suggested by Mattsson et al 2009 [58]. These suggested alterations have until now not been directly tested, as most studies examine HPA axis functioning under basal conditions or via dexamethasone, an agonist of the GR receptor. For future research it is of interest to study the role of the mineralocorticoid receptor and the decreased sensitivity of the adrenal gland in the disturbance of the HPA axis related to visceral fat distribution.

\section{Behavioral factors}

With respect to the behavioral factors involved in body-weight regulation, we observed that acute psychological stress results in eating in the absence of hunger [60]. In our study, the observed food intake in the absence of hunger after stress exposure, hardly led to further decreases in hunger, underscoring the involvement of a non-homeostatic regulatory mechanism, such as reward. Previous studies on stress-induced eating [61-64] proposed the involvement of reward, and Dallman et al [65] even introduced the term 'comfort foods' to emphasize the idea that the drive behind stress-induced eating is not homeostatic. These studies could however not directly demonstrate the role of reward, as a role for hunger could not be excluded $[65,66]$. This is possible when using the 'eating in the absence of hunger' paradigm [60]. Stress-induced eating is suggested to be caused by disturbance of several neural networks related to reward, such as the opioid and NPY system [67, 68]. Recently, researchers from our lab [69] observed that stress prevented a meal-induced decrease of wanting and energy intake in visceral obese objects and not in normal weight objects. Furthermore, Born et al. [70] from our lab observed in an fMRI study using the 'eating in absence of hunger' paradigm that activity in rewardrelated brain areas were significantly reduced under stress. These findings further support the role of disturbed reward in stress-induced eating.

Large inter-individual differences are present in the effect of stress on food intake; stress can increase, decrease or does not alter food intake. These individual differences in response to stress were also present in our eating in the absence of hunger paradigm [60], and may relate to eating behavior characteristics [71], as an increase in energy intake during stress has been found in individuals with high scores on dietary restraint and/or emotional eating [61-64]. We however observed that stress induced an increase in eating in the absence of hunger especially in vulnerable individuals, which are characterized by disinhibited eating behavior and sensitivity to chronic stress [60]. High dietary cognitive restraint scores did not result in stress induced eating in the absence of hunger, which is contradictory to previous findings [61-64]. The contradicting results may be explained by the fact that previous studies used the Herman-Polivy restraint scale [72], in which high restraint score is related to weight concern, such as disinhibited eating and weight fluctuations, in contrast to the TFEQ [71] that we used in our study, in which high restraint score is related to (successful) control of food intake [15, 73]. It therefore is suggested that stressinduced eating is caused by disinhibition, which reflects individual differences in the extent to which release from the cognitive suppression of eating occurs in response to the presence of palatable food or other disinhibiting stimuli, such as emotional distress [71].

Several studies have suggested that dietary restraint can be experienced as a 
chronic physiological stressor. We observed that in normal weight women hyperactivity of the HPA-axis is related to dietary restraint especially in combination with disinhibition [74]. This is in contrast to previous studies that have shown that only dietary restraint scores were related to alterations in HPA axis functioning, such as increased cortisol levels [75-77]. Our results suggest that dietary restraint in combination with disinhibited eating behavior can be considered as a chronic stressor. Together with the results from our study on the relationship between stress and eating in the absence of hunger [60], our results imply that disinhibition is an important mediator in the relationship between HPA axis functioning and bodyweight regulation. For future research it will be of interest to investigate whether disinhibited eaters have a higher cortisol response to stress, which in turn may lead to larger food intake, and whether these differences are related to altered feelings of reward.

To summarize, we propose a model (figure 2) on how disturbance of the HPA axis is involved in body-weight regulation. Stress (psychological or physical) results via secretion of $\mathrm{CRH}$ and $\mathrm{ACTH}$ in production of cortisol [40]. HPA axis activation is larger in women with the BclI G/G genotype, which results in higher cortisol levels in these women compared to men with the same genotype $[44,45]$. In turn, cortisol interacts with the neuroendocrine pathways that control the homeostatic regulation of food intake, as it potentiates the orexigenic actions of NPY [68], induces leptin resistance resulting in reduced suppression of food intake [78], and interacts with insulin that leads to high-fat food choice [79]. Cortisol also interacts with the neuro-endocrine pathways that control the nonhomeostatic regulation of food intake, which results in a decrease in opioid levels [67].

The interaction of cortisol with the pathways that control the homeostatic and non-homeostatic regulation of food intake results in stress-induced eating in the absence of hunger [60], especially in disinhibited eaters [60]. Stress-induced eating results in a positive energy balance that leads to visceral fat storage, as visceral adipocytes have a four-fold of GR receptors that facilitate fat storage in the presence of high cortisol levels [80, 81]. Visceral fat distribution in turn has been related to the disturbance of HPA axis functioning in basal and challenged conditions [52, 56, 57].

Moreover, increased fat storage may lead to increased weight dissatisfaction, which results in altered eating behavior [71], such as increased dietary restraint to decrease or prevent further weight gain. Dietary restraint in combination with disinhibited eating behavior is considered as a chronic stressor [74], which leads to further activation of the HPA axis. Therefore, we propose that chronic disturbance of the HPA axis initiates a viscous circle (figure 2 ), which puts stress as a major risk factor for excessive visceral weight gain. 
Figure 2: a proposed model on how disturbance of the HPA axis is involved in body-weight regulation (solid lines represent stimulation and dashed lines represent inhibition).

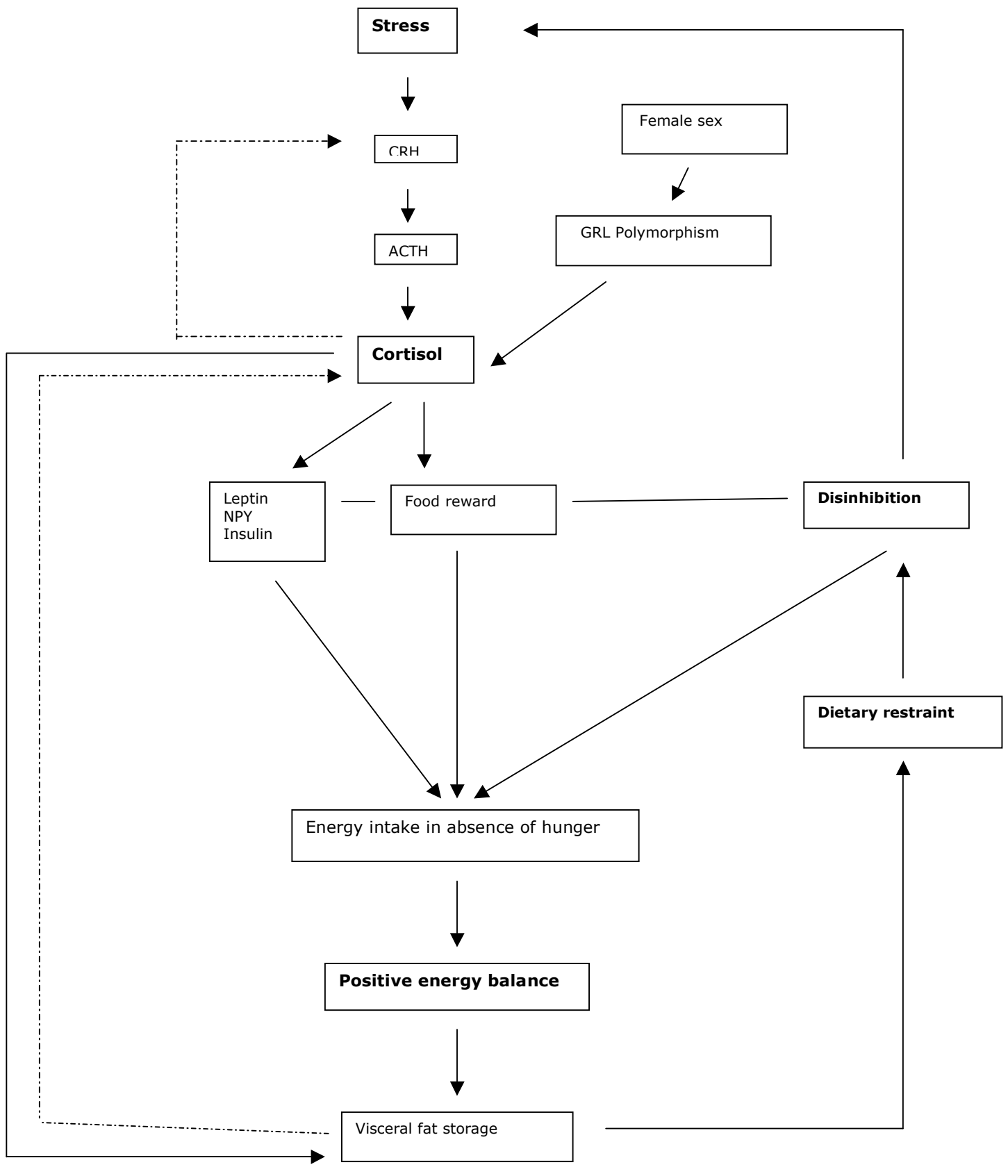




\section{Conclusions}

In children, body-weight development is regulated by various factors and interactions between these factors, such as the A allele of the FTO gene, which was associated with higher BMI, FMI, leptin concentrations, and lower activity scores from childhood to puberty. The influence of the FTO polymorphism however changed over time, as at age $13 y$ the FTO A allele, larger leptin concentrations and decreased physical activity were independent predictors for a larger BMI, while at age 12,14, and 15y BMI was only predicted by larger leptin concentrations. Polymorphisms of the CNTF and PPARY2 genes did not show an association with body-weight development during puberty, which implicates that during puberty BMI is only temporarily predicted by FTO and predominately predicted by endocrine factors. Additionally, the behavioral factor sleep duration was involved in bodyweight development, as changes in BMI during puberty were inversely related to changes in sleep duration. Subsequently, a higher BMI is associated with an earlier leptin peak in girls, and thereby an earlier start of puberty, as in girls leptin acts as a permissive factor for the onset of puberty. In boys leptin however has a different function and different timing. After the start of puberty factors independent of fat mass become (transiently) more important in the regulation of plasma leptin concentrations in boys and girls.

In adults, stress results in eating in the absence of hunger, which demonstrates for the first time that non-homeostatic mechanisms, such as reward, are involved in stress-induced eating. Stress-induced eating was present especially in subjects with disinhibited eating behavior and sensitivity to chronic stress. Disinhibited eating behavior in combination with dietary restraint is related to hyperactivity of the HPA axis. Disturbance of HPA axis functioning under basal and challenged conditions is related to visceral fat accumulation. Therefore, we propose that chronic disturbance of the HPA axis initiates a viscous circle, which puts stress as a major risk factor for excessive visceral weight gain.

\section{Future research}

A further follow-up of our Dutch children cohort is strongly recommended, since this cohort has provided valuable data on body-weight development during childhood and puberty. It is of interest to observe whether the role of endocrine factors will diminish once the children are in late adolescence, and whether the role of genetic factors in body-weight development will become stronger during this period.

Furthermore, for future research, it will be of interest to identify the physiological mechanisms behind the relationship between short sleep and altered body weight, and to investigate whether weight loss or weight stabilization can be achieved via sleep duration modification. Additionally, future experiments on the role of HPA axis functioning in bodyweight regulation should be conducted to further disentangle this relationship. It remains to be elucidated, whether the HPA axis is the primary cause for the obese state in the visceral obese, which can only be investigated via longitudinal studies. Furthermore, the disturbance of several neural homeostatic and nonhomeostatic networks involved in energy intake by HPA axis activation, such as the opioid and NPY system, are thought to be involved in stress-induced eating, however no direct evidence is found in humans yet. For future research it is of interest to identify brain regions involved in stress-induced eating and to evaluate if these regions are involved in homeostatic and non-homeostatic regulated food intake. 


\section{References}

1. Sullivan, P.W., E.H. Morrato, V. Ghushchyan, H.R. Wyatt, and J.O. Hill, Obesity, inactivity, and the prevalence of diabetes and diabetes-related cardiovascular comorbidities in the U.S., 2000-2002. Diabetes Care, 2005. 28(7): p. 1599-603.

2. Tremblay, A., L. Perusse, and C. Bouchard, Energy balance and body-weight stability: impact of gene-environment interactions. Br J Nutr, 2004. 92 Suppl 1: p. S63-6.

3. Rutters, FTO (rs9939609) and development of obesity related characteristics in a Dutch children cohort from childhood to puberty. (in revision), 2009.

4. Dina, C., New insights into the genetics of body weight. Curr Opin Clin Nutr Metab Care, 2008, 11(4): p. 378-84.

5. Stratigopoulos, G., S.L. Padilla, C.A. LeDuc, E. Watson, A.T. Hattersley, M.I. McCarthy, et al., Regulation of Fto/Ftm gene expression in mice and humans. Am J Physiol Regul Integr Comp Physiol, 2008. 294(4): p. R118596.

6. Loos, R.J. and C. Bouchard, FTO: the first gene contributing to common forms of human obesity. Obes Rev, 2008. 9(3): p. 246-50.

7. Wardle, J., S. Carnell, C.M. Haworth, I.S. Farooqi, S. O'Rahilly, and R. Plomin, Obesity associated genetic variation in FTO is associated with diminished satiety. J Clin Endocrinol Metab, 2008. 93(9): p. 3640-3.

8. Wardle, J., C. Llewellyn, S. Sanderson, and R. Plomin, The FTO gene and measured food intake in children. Int J Obes (Lond), 2008.

9. Rutters, F., A.G. Nieuwenhuizen, N. Vogels, F. Bouwman, E. Mariman, and M.S. Westerterp-Plantenga, Leptinadiposity relationship changes, plus behavioral and parental factors, are involved in the development of body weight in a Dutch children cohort. Physiol Behav, 2008. 93(4-5): p. 967-74.

10. Vogels, N., E.C. Mariman, F.G. Bouwman, A.D. Kester, K. Diepvens, and M.S. Westerterp-Plantenga, Relation of weight maintenance and dietary restraint to peroxisome proliferator-activated receptor gamma2, glucocorticoid receptor, and ciliary neurotrophic factor polymorphisms. Am J Clin Nutr, 2005. 82(4): p. 740-6.

11. Salces, I., E. Rebato, C. Susanne, R.C. Hauspie, R. Saha, and P. Dasgupta, Heritability variations of morphometric traits in West Bengal (India) children aged 4-19 years: a mixed-longitudinal growth study. Ann Hum Biol, 2007. 34(2): p. 226-39.

12. Bergen, S.E., C.O. Gardner, and K.S. Kendler, Age-related changes in heritability of behavioral phenotypes over adolescence and young adulthood: a meta-analysis. Twin Res Hum Genet, 2007. 10(3): p. 423-33.

13. Maffeis, C., Aetiology of overweight and obesity in children and adolescents. Eur J Pediatr, 2000. 159 Suppl 1: p. S35-44.

14. Vogels, N., D.L. Posthumus, E.C. Mariman, F. Bouwman, A.D. Kester, P. Rump, et al., Determinants of overweight in a cohort of Dutch children. Am J Clin Nutr, 2006. 84(4): p. 717-24.

15. Westerterp-Plantenga, M.S., L. Wouters, and F. ten Hoor, Restrained eating, obesity, and cumulative food intake curves during four-course meals. Appetite, 1991. 16(2): p. 149-58.

16. Rutters, Sleep duration and body-weight development during puberty in a Dutch children cohort. (in revision), 2009.

17. Marshall, N.S., N. Glozier, and R.R. Grunstein, Is sleep duration related to obesity? A critical review of the epidemiological evidence. Sleep Med Rev, 2008. 12(4): p. 289-98.

18. Patel, S.R. and F.B. Hu, Short sleep duration and weight gain: a systematic review. Obesity (Silver Spring), 2008. 16(3): p. 643-53.

19. Reilly, J.J., J. Armstrong, A.R. Dorosty, P.M. Emmett, A. Ness, I. Rogers, et al., Early life risk factors for obesity in childhood: cohort study. Bmj, 2005. 330(7504): p. 1357.

20. Snell, E.K., E.K. Adam, and G.J. Duncan, Sleep and the body mass index and overweight status of children and adolescents. Child Dev, 2007. 78(1): p. 309-23.

21. Dieu, H.T., M.J. Dibley, D. Sibbritt, and T.T. Hanh, Prevalence of overweight and obesity in preschool children and associated socio-demographic factors in Ho Chi Minh City, Vietnam. Int J Pediatr Obes, 2007. 2(1): p. 40-50.

22. Agras, W.S., L.D. Hammer, F. McNicholas, and H.C. Kraemer, Risk factors for childhood overweight: a prospective study from birth to 9.5 years. J Pediatr, 2004. 145(1): p. 20-5.

23. Vgontzas, A.N. and E.O. Bixler, Short sleep and obesity: are poor sleep, chronic stress, and unhealthy behaviors the link? Sleep, 2008. 31(9): p. 1203.

24. Steptoe, A., K. O'Donnell, M. Marmot, and J. Wardle, Positive affect, psychological well-being, and good sleep. J Psychosom Res, 2008. 64(4): p. 409-15.

25. Spiegel, K., R. Leproult, and E. Van Cauter, Impact of sleep debt on metabolic and endocrine function. Lancet, 1999. 354(9188): p. 1435-9.

26. Spiegel, K., R. Leproult, M. L'Hermite-Baleriaux, G. Copinschi, P.D. Penev, and E. Van Cauter, Leptin levels are dependent on sleep duration: relationships with sympathovagal balance, carbohydrate regulation, cortisol, and thyrotropin. J Clin Endocrinol Metab, 2004. 89(11): p. 5762-71.

27. Copinschi, G., Metabolic and endocrine effects of sleep deprivation. Essent Psychopharmacol, 2005. 6(6): p. 3417.

28. Lewis, K. and P.A. Lee, Endocrinology of male puberty. Curr Opin Endocrinol Diabetes Obes, 2009. 16(1): p. 5-9.

29. DiVall, S.A. and S. Radovick, Endocrinology of female puberty. Curr Opin Endocrinol Diabetes Obes, 2009. 16(1): p. 1-4.

30. Loomba-Albrecht, L.A. and D.M. Styne, Effect of puberty on body composition. Curr Opin Endocrinol Diabetes Obes, 2009. 16(1): p. 10-5.

31. Rutters, The relationship between leptin, gonadotropic hormones, and body composition during puberty in a Dutch children cohort. (EJE, in press), 2009.

32. Dunkel, L., H. Alfthan, U.H. Stenman, G. Selstam, S. Rosberg, and K. Albertsson-Wikland, Developmental changes in 24-hour profiles of luteinizing hormone and follicle-stimulating hormone from prepuberty to midstages of puberty in boys. J Clin Endocrinol Metab, 1992. 74(4): p. 890-7.

33. Grumbach, M.M., The neuroendocrinology of human puberty revisited. Horm Res, 2002. 57 Suppl 2: p. 2-14.

34. Roemmich, J.N. and A.D. Rogol, Hormonal changes during puberty and their relationship to fat distribution. Am J Human Biol, 1999. 11(2): p. 209-224.

35. Kristensen, K., S.B. Pedersen, and B. Richelsen, Regulation of leptin by steroid hormones in rat adipose tissue. Biochem Biophys Res Commun, 1999. 259(3): p. 624-30. 
36. Machinal-Quelin, F., M.N. Dieudonne, R. Pecquery, M.C. Leneveu, and Y. Giudicelli, Direct in vitro effects of androgens and estrogens on ob gene expression and leptin secretion in human adipose tissue. Endocrine, 2002. 18(2): p. $179-84$.

37. Farooqi, S., Insights from the genetics of severe childhood obesity. Horm Res, 2007. 68 Suppl 5: p. 5-7.

38. Bluher, S. and C.S. Mantzoros, Leptin in reproduction. Curr Opin Endocrinol Diabetes Obes, 2007. 14(6): p. 45864.

39. Gajdos, Z.K., J.N. Hirschhorn, and M.R. Palmert, What controls the timing of puberty? An update on progress from genetic investigation. Curr Opin Endocrinol Diabetes Obes, 2009. 16(1): p. 16-24

40. Tsigos, C. and G.P. Chrousos, Hypothalamic-pituitary-adrenal axis, neuroendocrine factors and stress. J Psychosom Res, 2002. 53(4): p. 865-71.

41. Hankin, M.E., H.M. Theile, and A.W. Steinbeck, An evaluation of laboratory tests for the detection and differential diagnosis of Cushing's syndrome. Clin Endocrinol (Oxf), 1977. 6(3): p. 185-96.

42. Nieuwenhuizen, A.G. and F. Rutters, The hypothalamic-pituitary-adrenal-axis in the regulation of energy balance. Physiol Behav, 2007.

43. Derijk, R.H. and E.R. de Kloet, Corticosteroid receptor polymorphisms: determinants of vulnerability and resilience. Eur J Pharmacol, 2008. 583(2-3): p. 303-11.

44. Rutters, Sex specific associations between the BclI polymorphism in the glucocorticoid receptor gene and HPA axis exposure as well as feedback sensitivity under stress. (in revision), 2009.

45. Kumsta, R., S. Entringer, J.W. Koper, E.F. van Rossum, D.H. Hellhammer, and S. Wust, Sex specific associations between common glucocorticoid receptor gene variants and hypothalamus-pituitary-adrenal axis responses to psychosocial stress. Biol Psychiatry, 2007. 62(8): p. 863-9.

46. Weiss, E.P., R.J. Spina, J.O. Holloszy, and A.A. Ehsani, Gender differences in the decline in aerobic capacity and its physiological determinants during the later decades of life. J Appl Physiol, 2006. 101(3): p. 938-44.

47. Tremblay, A., L. Bouchard, C. Bouchard, J.P. Despres, V. Drapeau, and L. Perusse, Long-term adiposity changes are related to a glucocorticoid receptor polymorphism in young females. J Clin Endocrinol Metab, 2003. 88(7): p. 3141-5.

48. Weaver, J.U., G.A. Hitman, and P.G. Kopelman, An association between a Bc1I restriction fragment length polymorphism of the glucocorticoid receptor locus and hyperinsulinaemia in obese women. J Mol Endocrinol, 1992. 9(3): p. 295-300.

49. Panarelli, M., C.D. Holloway, R. Fraser, J.M. Connell, M.C. Ingram, N.H. Anderson, et al., Glucocorticoid receptor polymorphism, skin vasoconstriction, and other metabolic intermediate phenotypes in normal human subjects. J Clin Endocrinol Metab, 1998. 83(6): p. 1846-52

50. Rutters, Hypothalamus/Pituitary/Adrenal (HPA) axis functioning in relation to body fat distribution. (in revision), 2009.

51. Ljung, T., G. Holm, P. Friberg, B. Andersson, B.A. Bengtsson, J. Svensson, et al., The activity of the hypothalamicpituitary-adrenal axis and the sympathetic nervous system in relation to waist/hip circumference ratio in men. Obes Res, 2000. 8(7): p. 487-95.

52. Duclos, M., B. Gatta, J.B. Corcuff, M. Rashedi, F. Pehourcq, and P. Roger, Fat distribution in obese women is associated with subtle alterations of the hypothalamic-pituitary-adrenal axis activity and sensitivity to glucocorticoids. Clin Endocrinol (Oxf), 2001. 55(4): p. 447-54.

53. Garcia-Prieto, M.D., F.J. Tebar, F. Nicolas, E. Larque, S. Zamora, and M. Garaulet, Cortisol secretary pattern and glucocorticoid feedback sensitivity in women from a Mediterranean area: relationship with anthropometric characteristics, dietary intake and plasma fatty acid profile. Clin Endocrinol (Oxf), 2007. 66(2): p. 185-91.

54. Marin, P., N. Darin, T. Amemiya, B. Andersson, S. Jern, and P. Bjorntorp, Cortisol secretion in relation to body fat distribution in obese premenopausal women. Metabolism, 1992. 41(8): p. 882-6.

55. Ljung, T., B. Andersson, B.A. Bengtsson, P. Bjorntorp, and P. Marin, Inhibition of cortisol secretion by dexamethasone in relation to body fat distribution: a dose-response study. Obes Res, 1996. 4(3): p. $277-82$.

56. Pasquali, R., B. Ambrosi, D. Armanini, F. Cavagnini, E.D. Uberti, G. Del Rio, et al., Cortisol and ACTH response to oral dexamethasone in obesity and effects of sex, body fat distribution, and dexamethasone concentrations: a dose-response study. J Clin Endocrinol Metab, 2002. 87(1): p. 166-75.

57. Jessop, D.S., M.F. Dallman, D. Fleming, and S.L. Lightman, Resistance to glucocorticoid feedback in obesity. J Clin Endocrinol Metab, 2001. 86(9): p. 4109-14.

58. Mattsson, C., R.M. Reynolds, K. Simonyte, T. Olsson, and B.R. Walker, Combined Receptor Antagonist Stimulation of the HPA axis test identifies impaired negative feedback sensitivity to cortisol in obese men. J Clin Endocrinol Metab, 2009.

59. De Kloet, E.R., E. Vreugdenhil, M.S. Oitzl, and M. Joels, Brain corticosteroid receptor balance in health and disease. Endocr Rev, 1998. 19(3): p. 269-301.

60. Rutters, F., A.G. Nieuwenhuizen, S.G. Lemmens, J.M. Born, and M.S. Westerterp-Plantenga, Acute stress-related changes in eating in the absence of hunger. Obesity (Silver Spring), 2009. 17(1): p. 72-7.

61. Heatherton, T.F., C.P. Herman, and J. Polivy, Effects of physical threat and ego threat on eating behavior. J Pers Soc Psychol, 1991. 60(1): p. 138-43.

62. Epel, E., R. Lapidus, B. McEwen, and K. Brownell, Stress may add bite to appetite in women: a laboratory study of stress-induced cortisol and eating behavior. Psychoneuroendocrinology, 2001. 26(1): p. 37-49.

63. Mitchell, S.L. and L.H. Epstein, Changes in taste and satiety in dietary-restrained women following stress. Physiol Behav, 1996. 60(2): p. 495-9.

64. Zellner, D.A., S. Loaiza, Z. Gonzalez, J. Pita, J. Morales, D. Pecora, et al., Food selection changes under stress. Physiol Behav, 2006. 87(4): p. 789-93.

65. Dallman, M.F., A.M. Strack, S.F. Akana, M.J. Bradbury, E.S. Hanson, K.A. Scribner, et al., Feast and famine: critical role of glucocorticoids with insulin in daily energy flow. Front Neuroendocrinol, 1993. 14(4): p. 303-47.

66. Adam, T.C. and E.S. Epel, Stress, eating and the reward system. Physiol Behav, 2007. 91(4): p. 449-58.

67. Yoshida, M., S. Koyanagi, A. Matsuo, T. Fujioka, H. To, S. Higuchi, et al., Glucocorticoid hormone regulates the circadian coordination of micro-opioid receptor expression in mouse brainstem. J Pharmacol Exp Ther, 2005. 315(3): p. 1119-24.

68. Corder, R., B. Waeber, D. Evequoz, J. Nussberger, R. Gaillard, and H. Brunner, Effect of ganglion blockade with pentolinium on circulating neuropeptide $Y$ levels in conscious rats. J Cardiovasc Pharmacol, 1988. 12(2): p. 140-3.

69. Lemmens, S., Effects of stress on food choice and intake in the absence of hunger

(in revision), 2009.

70. JM, B., Stress and eating: decreased food related reward activation in the brain during food choice. (in revision), 2009. 
71. Stunkard, A.J. and S. Messick, The three-factor eating questionnaire to measure dietary restraint, disinhibition and hunger. J Psychosom Res, 1985. 29(1): p. 71-83.

72. Herman, C.P. and J. Polivy, Anxiety, restraint, and eating behavior. J Abnorm Psychol, 1975. 84(6): p. 66-72.

73. Laessle, R.G., R.J. Tuschl, B.C. Kotthaus, and K.M. Pirke, Behavioral and biological correlates of dietary restraint in normal life. Appetite, 1989. 12(2): p. 83-94.

74. Rutters, F., A.G. Nieuwenhuizen, S.G. Lemmens, J.M. Born, and M.S. Westerterp-Plantenga, Hyperactivity of the HPA axis is related to dietary restraint in normal weight women. Physiol Behav, 2009. 96(2): p. 315-9.

75. Anderson, D.A., J.R. Shapiro, J.D. Lundgren, L.E. Spataro, and C.A. Frye, Self-reported dietary restraint is associated with elevated levels of salivary cortisol. Appetite, 2002. 38(1): p. 13-7.

76. McLean, J.A., S.I. Barr, and J.C. Prior, Cognitive dietary restraint is associated with higher urinary cortisol excretion in healthy premenopausal women. Am J Clin Nutr, 2001. 73(1): p. 7-12.

77. Newman, E., D.B. O'Connor, and M. Conner, Daily hassles and eating behaviour: the role of cortisol reactivity status. Psychoneuroendocrinology, 2007. 32(2): p. 125-32.

78. Zakrzewska, K.E., I. Cusin, A. Sainsbury, F. Rohner-Jeanrenaud, and B. Jeanrenaud, Glucocorticoids as counterregulatory hormones of leptin: toward an understanding of leptin resistance. Diabetes, 1997. 46(4): p. 717-9.

79. Ia Fleur, S.E., S.F. Akana, S.L. Manalo, and M.F. Dallman, Interaction between corticosterone and insulin in obesity: regulation of lard intake and fat stores. Endocrinology, 2004. 145(5): p. 2174-85.

80. Bjorntorp, P. and R. Rosmond, Obesity and cortisol. Nutrition, 2000. 16(10): p. 924-36.

81. Fried, S.K., C.D. Russell, N.L. Grauso, and R.E. Brolin, Lipoprotein lipase regulation by insulin and glucocorticoid in subcutaneous and omental adipose tissues of obese women and men. J Clin Invest, 1993. 92(5): p. 2191-8. 



\section{Summary}

A stable body weight reflects a balance between energy intake and energy expenditure. Chronic deregulation of energy balance leads to storage of excessive energy as fat, a characteristic of overweight and obesity. The studies described in this thesis encompass genetic, parental, behavioral, and endocrine factors involved in body-weight development and regulation during childhood, puberty and adulthood. The first part elaborates on the factors involved in body-weight development during childhood and puberty, studied in a large cohort of Dutch children, from which valuable anthropometrical data from birth till age $7 y$ were available. To study bodyweight development during puberty, follow-up studies were performed yearly between 2004 and 2008, when the children had a mean age of 12 to $16 \mathrm{y}$. In this cohort the A allele of the FTO gene (rs9939609) was associated with higher BMI, fat mass index, leptin concentrations, and lower activity scores from childhood to puberty. The influence of the FTO polymorphism however changed over time, as at age $13 y$ the FTO $A$ allele, larger leptin concentrations and decreased physical activity were independent predictors for a larger BMI, while at age 12,14 , and $15 y$ BMI was only predicted by larger leptin concentrations

(chapter 2).

In our cohort, polymorphisms of the CNTF and PPARY2 genes did not show an

association with body-weight development during puberty. Our results implicate that BMI is only temporarily predicted by the FTO A allele and predominately predicted by endocrine factors. Next to the genetic factors, parental factors were involved in body-weight development during puberty, as a high BMI of the father and a high disinhibition score of the mother were related to an increased BMI in the child at age $12 y$ (chapter 3 ).

To investigate whether changes in sleep duration were associated with changes in body weight, we measured average sleep duration and body weight from Tanner stage 1 to 5 in our cohort. We were the first to show that development of BMI during puberty is inversely related to change in sleep duration, and although cause and effect cannot be completely disentangled from the observed inverse relationship, we carefully suggest that reduction of sleep duration contributes to development of overweight during puberty (chapter 4).

With respect to endocrine factors, we studied the hormone leptin, as leptin is suggested to be a permissive factor for the start of puberty, which would be mediated through the stimulatory effect of leptin on the release of gonadotrophic hormones, and consequently gonadal hormones. We observed in our cohort that in boys the leptin/fat mass ratio decreased from Tanner stage 2 onwards, while in girls this ratio decreased from Tanner stage 2 and increased again at Tanner stage 5, which shows that factors independent of fat mass become (transiently) more important in the regulation of plasma leptin concentrations in boys and girls. Additionally, we found that in girls a peak in leptin was present at the start of puberty followed by a peak in $\mathrm{LH}$ and $\mathrm{FSH}$, and during early puberty temporal relationships were observed between leptin and gonadotropic hormones. In boys, however there was no peak in leptin, $\mathrm{LH}$, and $\mathrm{FSH}$, and leptin was only related to gonadotropic hormones during late puberty. Leptin is therefore suggested to act as a permissive factor for the onset of puberty in girls, while in boys leptin has a different function and different timing (chapter 5). To conclude, the data from our cohort suggests that the FTO A allele, short sleep duration, and the parental factors interact, and together are involved in development of overweight during puberty.

The second part of this thesis elaborates on the role of the neuro-endocrine system of the HPA axis in body-weight regulation in adults. The HPA axis has been suggested to be involved in body-weight 
regulation, however, to what extent the HPA axis is physiologically involved in the regulation of body weight is not completely clear (chapter $\mathbf{6}$ ). The physiological role of the HPA axis in bodyweight regulation was studied in a cohort of healthy adults, 190 men and women, who had a BMI between 20 and $35 \mathrm{~kg} / \mathrm{m}^{2}$. Evidence for involvement of the HPA axis in body-weight regulation is provided by genetic factors, such as the BclI polymorphism. In our cohort the BclI G/G genotype was associated with increased cortisol exposure as well as decreased cortisol feedback sensitivity under stress in women but not in men. Together with results on associations between the BclI G/G genotype and altered body weight and body fat distribution in women, this suggests that women with the BclI G/G genotype are more susceptible to disturbed regulation of body weight and HPA axis functioning compared to men with the same genotype (chapter 7). Additional evidence for involvement of the HPA axis in body-weight regulation is found in endocrine factors, as we observed that low cortisol exposure, enhanced negative feedback, and impaired HPA axis functioning in a challenged condition under $4 \mathrm{mg}$ dexamethasone were related to visceral fat accumulation in both men and women (chapter 8).

With respect to the behavioral factors involved in body-weight regulation, we observed that acute psychological stress results in eating in the absence of hunger. The observed food intake in the absence of hunger after stress exposure, hardly led to further decreases in hunger, which demonstrates for the first time that nonhomeostatic mechanisms, such as reward, are involved in stress-induced eating.
Previous studies on stress-induced eating propose the involvement of reward, but they could not directly demonstrate the role of reward, as a role for hunger could not be excluded. Large inter-individual differences were present in our eating in the absence of hunger paradigm; stress could increase, decrease or did not alter food intake. These individual differences in response to stress relate to eating behavior characteristics, as we observed a stress-induced increase in eating in the absence of hunger especially in vulnerable individuals, who are characterized by disinhibited eating behavior and sensitivity to chronic stress (chapter 9).

In our cohort disinhibited eating behavior in combination with dietary restraint was related to hyperactivity of the HPA-axis in normal weight women. Our results suggest that disinhibition in combination with dietary restraint can be considered as a chronic stressor. Together with the results from our study on the relationship between stress and eating in the absence of hunger, our results imply that disinhibition is an important mediator in the relationship between HPA axis functioning and body-weight regulation (chapter 10).

To conclude, we propose that in adults chronic disturbance of the HPA axis initiates a vicious circle, which puts stress as a major risk factor for excessive visceral weight gain. Stress results in eating in the absence of hunger, especially in subjects with disinhibited eating behavior and sensitivity to chronic stress. Disinhibited eating behavior in combination with dietary restraint is related to hyperactivity of the HPA axis. In turn, disturbance of HPA axis functioning under basal and challenged conditions is related to visceral fat accumulation. 


\section{Samenvatting}

Een stabiel lichaamsgewicht is een weerspiegeling van de balans tussen energie inname en energiegebruik. Als het evenwicht tussen energie inname en energie gebruik doorslaat naar een positieve balans wordt het teveel aan energie opgeslagen als lichaamsvet. Wanneer deze disbalans lange tijd aanhoudt, ontstaan overgewicht. Dit proefschrift richt zich op erfelijke, ouderlijke, gedragsmatige en endocriene factoren die invloed hebben op de ontwikkeling en regulatie van lichaamsgewicht bij kinderen en volwassenen.

Het eerste deel van dit proefschrift richt zich op de ontwikkeling van lichaamsgewicht zoals dat tijdens de puberteit gemeten is bij een Nederlands kindercohort. Van deze kinderen is vanaf de geboorte tot en met de leeftijd van 7 jaar jaarlijks lengte en gewicht gemeten. Om de ontwikkeling van lichaamsgewicht tijdens de puberteit te bepalen werden tussen 2004 en 2008 vervolgmetingen uitgevoerd, toen deze kinderen gemiddeld een leeftijd van 12 tot 18 jaar hadden. Voor wat betreft genetische invloeden, bleek het voorkomen van het A allel van het fat mass and obesity-associated (FTO) gen (rs9939609) gerelateerd te zijn aan een hogere Body Mass Index (BMI), een hogere vetmassa, hogere leptine concentraties en verlaagde lichamelijke activiteit. De invloed van het FTO A allel bleek echter niet ieder jaar even sterk, want alleen op 13 jarige leeftijd was het FTO A allel een voorspeller voor een hogere BMI. Op 12, 14 en 15 jarige leeftijd waren voornamelijk leptine concentraties voorspellend voor een hogere BMI (hoofdstuk 2).

De verschillende genotypen van de ciliary neurotrophic factor (CNTF) en peroxisome proliferated-activated receptor (PPARY2) genen bleken niet geassocieerd te zijn met de ontwikkeling van lichaamsgewicht in het kindercohort. Voor wat betreft de invloed van de ouders, bleek dat op 12 jarige leeftijd een hogere BMI van de vader en ontremd eetgedrag van de moeder gerelateerd te zijn aan de ontwikkeling van overgewicht bij het kind (hoofdstuk 3).

De ontwikkeling van het lichaamsgewicht tijdens de puberteit werd tevens beïnvloed door gedragsmatige factoren zoals het aantal uren slaap per nacht. Wij hebben met de data van ons cohort als eerste aangetoond dat tijdens de puberteit de daling van het aantal uren slaap per nacht gerelateerd is aan de stijging van het lichaamsgewicht. En hoewel het moeilijk is om in deze relatie oorzaak en gevolg te scheiden, suggereren wij dat een verlaging van het aantal uren slaap tijdens de puberteit zou kunnen bijdragen aan de ontwikkeling van overgewicht (hoofdstuk 4).

Vervolgens werd ingegaan op de rol van de endocriene factor leptine in de ontwikkeling van lichaamsgewicht. Leptine wordt verondersteld een belangrijke rol te spelen in de aanzet tot de puberteit, omdat leptine mogelijk de productie van de gonadotrope hormonen en geslachtshormonen stimuleert. In ons cohort bleek dat de relatie tussen leptine en vetmassa minder sterk werd vanaf Tanner stadium 2 bij jongens; bij meisjes gebeurde dit ook maar werd de relatie weer sterker in Tanner stadium 5. Dat de relatie verandert, laat zien dat tijdens de puberteit de regulatie van de afgifte van leptine (tijdelijk) bepaald wordt door factoren die niet gerelateerd zijn aan de vetmassa. Verder vond er bij meisjes tijdens de start van de puberteit een piek in leptine concentraties plaats, welke werd gevolgd door een piek in de concentraties van de gonadotrope hormonen. Deze pieken waren afwezig bij de jongens en de relatie tussen leptine en de gonadotrope hormonen was alleen aanwezig tijdens de late stadia van de puberteit bij de jongens. Leptine lijkt dus een belangrijke rol te spelen in de aanzet tot de puberteit bij meisjes, maar lijkt een andere rol en andere timing te hebben bij jongens (hoofdstuk 5). 
Uit de resultaten van ons kindercohort beschreven in het eerste deel van het proefschrift, kan worden geconcludeerd dat het FTO A allel, weinig uren slaap per nacht, en ouderlijke factoren samen betrokken zijn bij de ontwikkeling van overgewicht tijdens de puberteit. Het tweede deel van dit proefschrift richt zich op de rol van de hypothalamushypofyse-bijnier as (HPA-as) in de regulatie van lichaamsgewicht bij volwassenen (hoofdstuk 6).

De fysiologische rol van de HPA-as in de regulatie van lichaamsgewicht werd onderzocht in een cohort van gezonde volwassenen: 190 mannen en vrouwen met een BMI tussen de 20 en $35 \mathrm{~kg} / \mathrm{m}^{2}$. Genetische factoren, zoals het BclI polymorfisme, bevestigen de rol van de HPA-as in gewichtsregulatie in ons cohort. Het BclI G/G genotype bleek namelijk gerelateerd te zijn aan verhoogde cortisol concentraties en verminderde remming van de HPA-as tijdens stress bij vrouwen, maar niet bij mannen. Uit de literatuur bleek dat het BclI G/G genotype bij vrouwen is gerelateerd aan een hoger lichaamsgewicht en meer visceraal vet. Het totaalbeeld dat ontstaat is dat vrouwen met het $\mathrm{BclI} \mathrm{G} / \mathrm{G}$ genotype gevoeliger zijn voor verstoorde regulatie van lichaamgewicht en van de HPA-as, dan mannen met het BclI G/G genotype

\section{(hoofdstuk 7).}

Ook endocriene factoren ondersteunen de rol van de HPA-as bij gewichtsregulatie, zoals bleek in ons cohort. Lage exposure van cortisol concentraties, sterkere remming van de HPA-as en verminderd functioneren van de HPA-as bij toediening van $4 \mathrm{mg}$ dexamethasone bleken gerelateerd te zijn aan viscerale vetaccumulatie bij mannen en vrouwen (hoofdstuk 8).

Voorts bevestigen gedragsmatige factoren de rol van de HPA-as bij gewichtsregulatie, zoals bleek uit het verschijnsel dat in ons cohort psychologische stress leidde tot voedselinname zonder dat iemand honger heeft. Bovendien werden de hongergevoelens niet verder verlaagd door de voedselinname, hetgeen voor het eerst aantoont dat niet-homeostatische mechanismen zoals de belonende waarde van voedsel betrokken zijn bij de regulatie van voedselinname tijdens stress. Vorige studies suggereerden een rol voor de belonende waarde van voedsel bij eten als gevolg van stress, maar dit kon niet met zekerheid vastgesteld worden omdat het effect van stress op hongergevoel niet uitgesloten kon worden. Niet iedereen verhoogt zijn voedselinname tijdens stress en grote verschillen bleken dan ook aanwezig te zijn in ons cohort.

Voornamelijk mensen met ontremd eetgedrag en een grote gevoeligheid voor chronische stress eten meer tijdens stress ongeacht hun hongergevoel (hoofdstuk 9). Ontremd eetgedrag afgewisseld met geremd eetgedrag bleek echter weer gerelateerd te zijn aan hyperactiviteit van de HPA-as bij slanke vrouwen. Dit suggereert dat ontremd eetgedrag afgewisseld met geremd eetgedrag chronische stress veroorzaakt. Samen suggereren deze resultaten dat ontremd eetgedrag een belangrijke factor is in de relatie tussen de HPA-as en gewichtsregulatie (hoofdstuk 10). Uit de resultaten beschreven in het tweede deel van het proefschrift kan worden geconcludeerd dat chronische activiteit van de HPA-as als gevolg van stress een groot risico vormt voor de regulatie van lichaamsgewicht. Stress veroorzaakt namelijk voedselinname zonder dat iemand honger heeft, en wel voornamelijk in mensen met ontremd eetgedrag en een grote gevoeligheid voor chronische stress. Ontremd eetgedrag afgewisseld met geremd eetgedrag is gerelateerd aan hyperactiviteit van de HPA-as. Verstoring van HPA-as leidt weer tot opslag van visceraal vet, daarbij een vicieuze cirkel vormend.

Uit de resultaten beschreven in dit proefschrift wordt geconcludeerd dat erfelijke, ouderlijke, gedragsmatige en endocriene factoren invloed hebben op de ontwikkeling en regulatie van lichaamsgewicht bij kinderen en volwassenen. 


\section{Dankwoord}

Een proefschrift schrijf je niet alleen en dit is de plek om de mensen te bedanken die hieraan hebben bijgedragen.

Allereerst wil ik mijn promotor Margriet en copromotor Arie bedanken. Margriet bedankt voor de snel nagekeken manuscripten, interesse in mijn bezigheden, de vaart erin te houden, het vertrouwen in mijn kunnen en zoveel meer. Arie bedankt voor je heldere momenten als ik weer vast zat, gezellige gesprekken en ongeorganiseerdheid (dan valt dat van mij nog wel mee).

De leden van de beoordelingscommissie bestaande uit prof. Dr. K. Westerterp, prof. Dr. N. Schaper, Dr. W.J. Gerver, Dr. S.E. La Fleur en prof. Dr. J. Wardle wil ik graag bedanken voor het lezen van mijn proefschrift.

Mijn paranimfen Sofie en (super stagiaire) Sanne wil ik bedanken voor alle hulp tijdens experimenten, doorlezen van mijn artikelen, super gezelschap tijdens congressen en natuurlijk het feit dat jullie achter me staan tijdens mijn promotie.

Mijn clustergenoten (Jurriaan, Mieke, Ananda, Freeha, Anneke, Margriet, Rick, Marcel, Alberto, Stijn, Astrid, Kristel, Neeltje, Manuela, Annemiek, Mirjam, Carolien, Natalie, Helene) wil ik bedanken voor de fijne samenwerking en gezellige theepauzes. Verder wil ik ook alle stagiaires bedanken voor jullie hulp bij mijn studies.

Paul en Loek wil ik bedanken voor de technische hulp en Jos, Wendy, Loek en Freek voor het uitvoeren van alle analyses. Natuurlijk wil ik ook de HB secretaresses bedanken voor hun administratieve hulp. And although we only met once in person, large part of my thesis would be absent if not for the analyses of cortisol by Jose Sulon, University of Liege.

Mijn 'nieuwe' vrienden en vriendinnen van de keet, Dames 2 van hockeyclub Horst en mijn 'oude' vriendinnen (Laura, Nathalie, Anouk, Yolanda, Barbara en Atsuko) wil ik bedanken voor de nodige ontspanning in de vorm van gezellige stapavonden, hockeywedstrijden en leuke uitjes.

Wim, Petra en Sandra bedankt voor mijn 'derde' huis in Hegelsom.

Pap, mam, Ilke, Yannicke en schoonbroer Ruud bedankt voor mijn 'tweede' huis in Kaatsheuvel en stiekem doe ik dit allemaal voor jullie zodat jullie trots op mij kunnen zijn.

Lieve Danny, jij bent mijn eerste thuis... 


\section{List of publications}

\section{As first author}

1. The relationship between leptin concentrations, gonadotrophic hormones, and body composition during puberty in a Dutch children cohort.

Rutters F, A.G. Nieuwenhuizen, S.P.M. Verhoef, N. Vogels, M.S. Westerterp-Plantenga EJE. 2009 Jun; 160(6): 973-8

2. Acute stress-related changes in eating in the absence of hunger.

Rutters F, A.G. Nieuwenhuizen, S.G.T Lemmens, J.M Born, and M.S. WesterterpPlantenga. Obesity 2009 January; 17 (1): 72-7

3. Hyperactivity of the HPA axis is related to dietary restraint in normal weight women.

Rutters F, A.G. Nieuwenhuizen, S.G.T Lemmens, J.M Born, and M.S. Westerterp-

Plantenga. Physiol Behav 2009 Feb 16; 96(2): 315-9

4. Leptin-adiposity relationship changes, plus behavioral and parental factors, are involved in the development of body weight in a Dutch children cohort.

Rutters F, A.G. Nieuwenhuizen, N. Vogels, F. Bouwman, E. Mariman and M.S. Westerterp-Plantenga.

Physiol Behav. 2008 Mar 18; 93(4-5): 967-74

5. The hypothalamic-pituitary-adrenal-axis in the regulation of energy balance.

Rutters F and A.G. Nieuwenhuizen.

Physiol Behav. 2008 May 23; 94 (2): 169-77

6. Sleep duration and body-weight development during puberty in a Dutch children cohort. Rutters F, A.G. Nieuwenhuizen, S.P.M. Verhoef, M.S. Westerterp-Plantenga Submitted

7. Hypothalamus/Pituitary/Adrenal (HPA) axis functioning in relation to body fat distribution.

Rutters F, A.G. Nieuwenhuizen, S.G.T Lemmens, J.M Born, and M.S. WesterterpPlantenga Submitted

8. Associations between the FTO gene (rs9939609) and development of obesity related characteristics over time in a Dutch children cohort.

Rutters F, A.G. Nieuwenhuizen, F. Bouwman, E. Mariman, and M.S. Westerterp-Plantenga Submitted

9. Sex specific associations between the BclI polymorphism in the glucocorticoid receptor gene and HPA axis exposure as well as feedback sensitivity.

Rutters F, A.G. Nieuwenhuizen, S.G.T Lemmens, J.M Born, F. Bouwman, E. Mariman, and M.S. Westerterp-Plantenga

Submitted

10. Genetic associations with acute stress-related changes in eating in the absence of hunger. Rutters F, A.G. Nieuwenhuizen, S.G.T Lemmens, J.M Born, F. Bouwman, E. Mariman and M.S. Westerterp-Plantenga

Submitted 


\section{As co-author}

1. Changes in cerebral blood volume and amyloid pathology in aged Alzheimer APP/PS1 mice on a docosahexaenoic acid (DHA) diet or cholesterol enriched Typical Western Diet (TWD).

Hooijmans CR, Rutters F, Dederen PJ, Gambarota G, Veltien A, van Groen T, Broersen LM, Lutjohann D, Heerschap A, Tanila H, Kiliaan AJ.

Neurobiol Dis. 2007 Jun 18

2. Daily physical activity counts vs structured activity counts in lean and overweight Dutch children.

Vogels N, Westerterp KR, Posthumus DL, Rutters F, Westerterp-Plantenga MS.

Physiol Behav. 2007 May 22

3. Declarative memory consolidation in humans: a prospective functional magnetic resonance imaging study.

Takashima A, Petersson KM, Rutters F, Tendolkar I, Jensen O, Zwarts MJ, McNaughton $\mathrm{BL}$, Fernandez G.

Proc Natl Acad Sci U S A. 2006 Jan 17; 103(3):756-61

4. Eating what you like induces a stronger decrease of 'wanting' to eat.

Lemmens SGT, Schoffelen PFM, Wouters L, Born JM, Martens MJI, Rutters F, WesterterpPlantenga MS.

Physiol Behav. 2009 In press

5. Is a healthy perceived food a greater risk for restrained subjects than a non-healthy perceived food?

Lemmens SGT, Schoffelen PFM, Wouters L, Born JM, Martens MJI, Rutters F, WesterterpPlantenga MS.

Submitted.

6. Effects of stress on food choice and intake in the absence of hunger.

Lemmens SGT, Born JM, Martens MJI, Rutters F, Westerterp-Plantenga MS

Submitted

7. Acute stress decreases food reward related activation in the brain.

Born JM, Nieuwenhuizen AG, Lemmens SGT, Rutters F, Formisano E, Goebel R, Westerterp-Plantenga MS

Submitted

8. The effect of macronutrient intake on cortisol concentrations in normal weight men. Martens MJI, Nieuwenhuizen AG, Rutters F, Westerterp-Plantenga MS 


\section{Curriculum vitae}

Femke Rutters was born on September 1st 1982 in Waalwijk, the Netherlands. She completed secondary school at the 'Dr. Moller College' in Waalwijk in 2000. In the same year, she started her study Medical Biology at Radboud University Nijmegen, where she graduated with honor in 2005.

She started working as a PhD-student at the department of Human biology of Maastricht University in November 2005 on a project called 'The role of the HPA axis in the regulation of energy balance', guided by Prof. dr. MS Westerterp-Plantenga and dr. AG

Nieuwenhuizen. In July 2007, she was awarded with a New Investigator Award at the Annual Meeting for the Society for the Study of Ingestive Behavior (SSIB) in Steamboat Springs, America. In February 2009, she was awarded a Travel Award of the Van Walree Fonds to visit the Annual Meeting SSIB meeting in Portland, America.

In May 2009 she finished her thesis entitled "Development and regulation of body weight: a genetic, behavioral and neuro-endocrinological approach". In May 2009, she was granted a 'Kootstra Talent Fellowship' scholarship from the Faculty of Health Sciences of Maastricht University to continue her work in the field of body-weight regulation. 